


\section{NETWORK POSITION AND RELATED POWER}

how they affect and are affected by network management and outcomes

Tamara Oukes 


\section{Graduation committee}

prof.dr. T.A.J. Toonen (chair)

prof.dr. A.J. Groen (supervisor)

dr. A.M. von Raesfeld Meijer (co-supervisor)

prof.dr. L-E. Gadde

dr. P.A.T.M. Geurts

prof.dr.ir. J. Henseler

prof.dr. B. Van Looy

prof.dr. J.H. de Vries

prof.dr.ir. P.C. de Weerd-Nederhof
University of Twente

University of Twente

University of Twente

Chalmers University of Technology

University of Twente

University of Twente

KU Leuven

University of Amsterdam

University of Twente

Printed by Ipskamp Printing, Enschede, The Netherlands.

Images created by Dennis de Freytas, Tilburg, The Netherlands

ISBN: 978-94-028-0954-1

(c) 2018 by Tamara Oukes, Apeldoorn, The Netherlands

All rights reserved. No part of this thesis may be reproduced, stored in a database or retrieval system, or published in any form or in any way, electronically, mechanically, by print, photo print, microfilm, or any other means without prior written permission from the author. 


\title{
NETWORK POSITION AND RELATED POWER \\ HOW THEY AFFECT AND ARE AFFECTED BY NETWORK MANAGEMENT AND OUTCOMES
}

\author{
Dissertation \\ to obtain \\ the degree of doctor at the University of Twente, \\ on the authority of the rector magnificus \\ prof.dr. T.T.M. Palstra \\ on account of the decision of the graduation committee, \\ to be publicly defended \\ on Friday, March 16, 2018 at 16.45
}

by

\section{Tamara Oukes}

born February 13, 1991

in Rheden, The Netherlands 
This dissertation has been approved by:

Supervisor prof.dr. A.J. Groen

Co-supervisor dr. A.M. von Raesfeld Meijer 



\section{Contents}

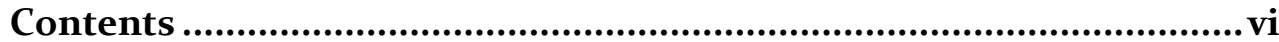

List of figures....................................................................................ii

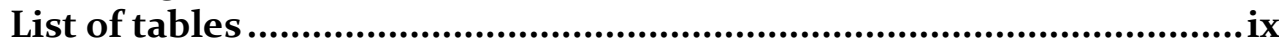

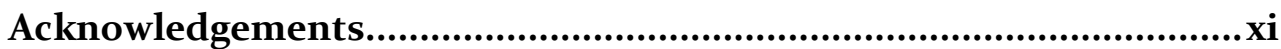

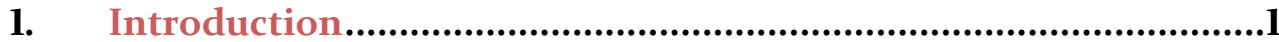

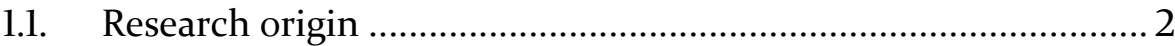

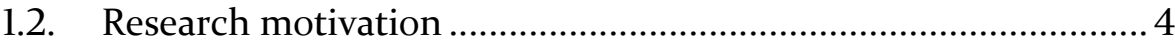

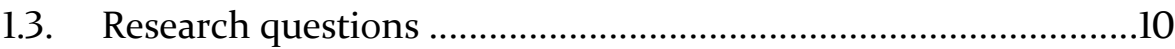

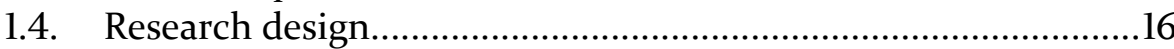

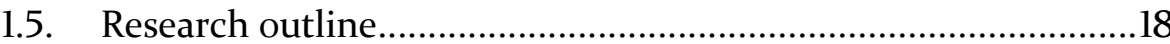

2. Third actors initiating business relationships for a medical device start-up: effect on network embedding and venture creation

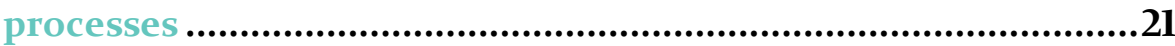

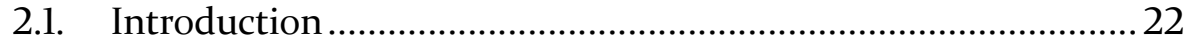

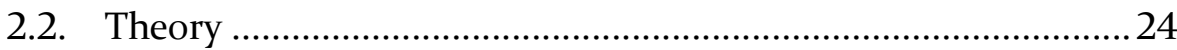

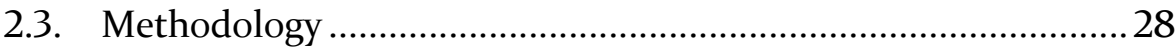

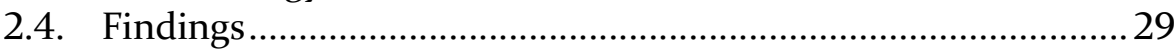

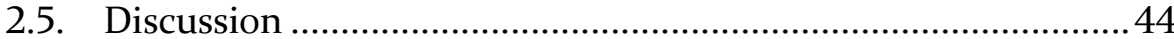

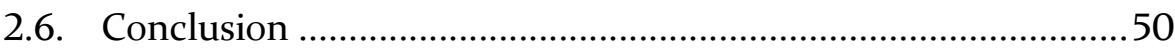

3. A start-up in interaction with its partners ................................. 53

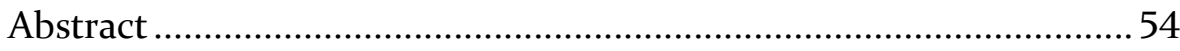

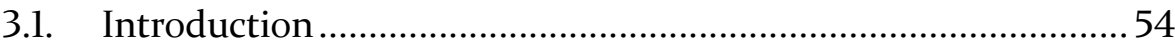

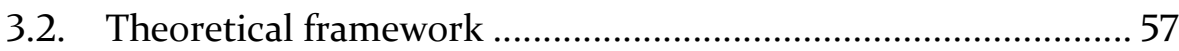

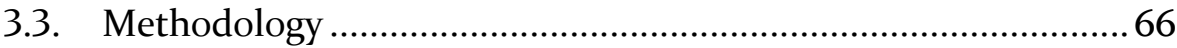

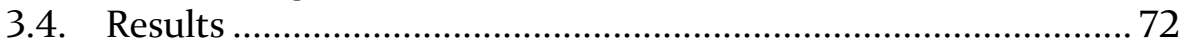

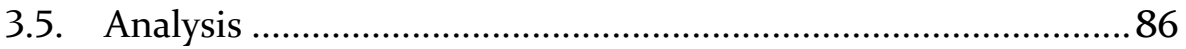

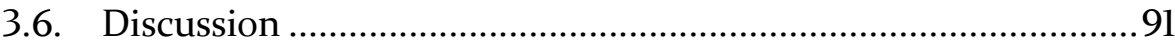

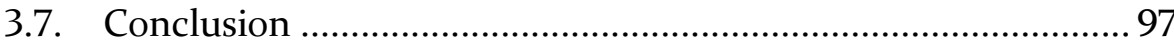

4. Power in a startup's relationships with its established partiners: interactions between structural and behavioural power ..........101

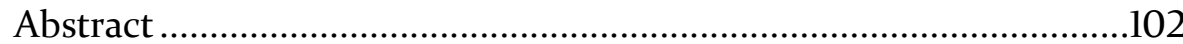

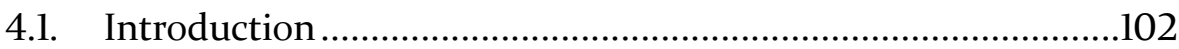

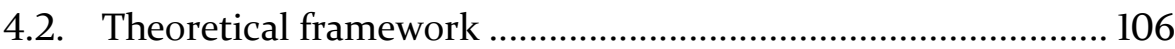

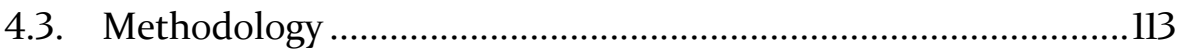

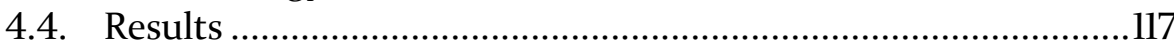

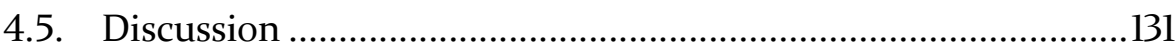

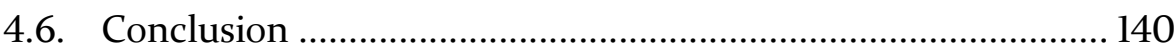


5. Power asymmetry's effects on value creation and appropriation in multipartner alliances ........................................................... 149

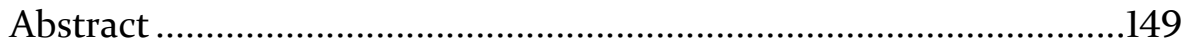

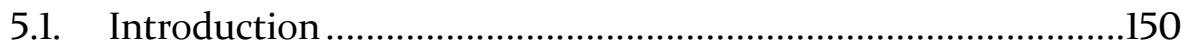

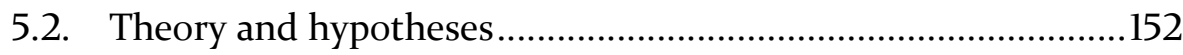

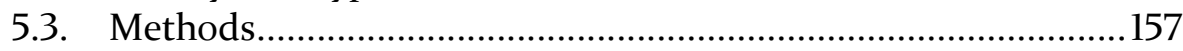

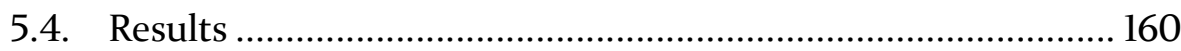

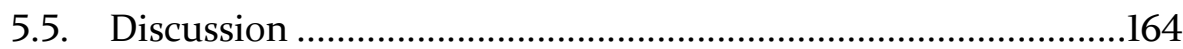

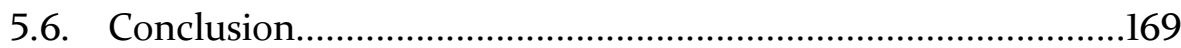

6. The relationship between variety and new product development in multipartmer alliances: the moderating effect of power asymmetry ................................................................................173

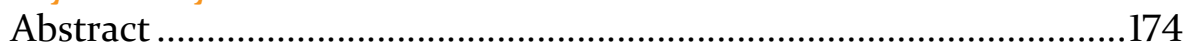

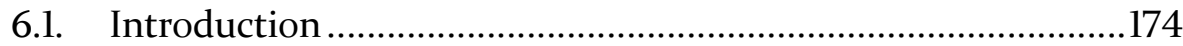

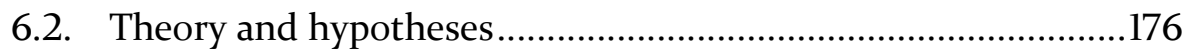

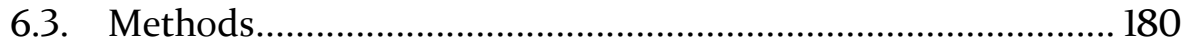

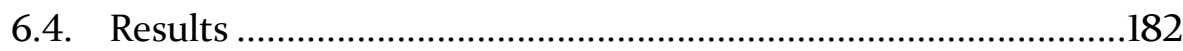

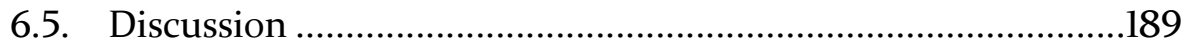

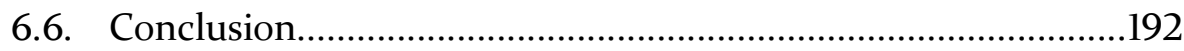

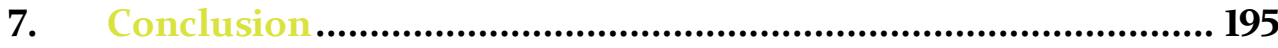

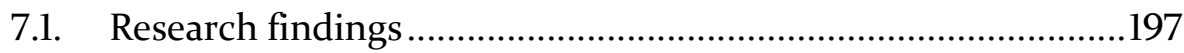

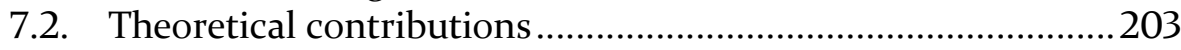

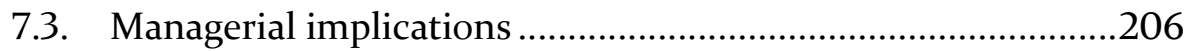

7.4. Limitations and further research ..............................................211

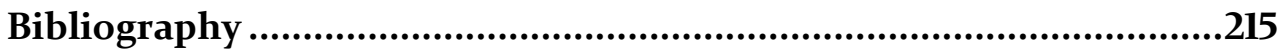

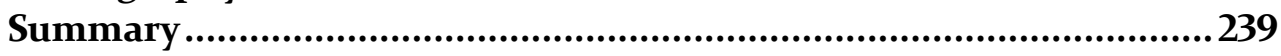

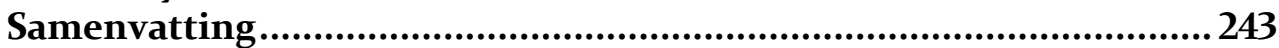

About the author ........................................................................247 


\section{List of figures}

Figure 1.1 The inter-relationships between network position, management and

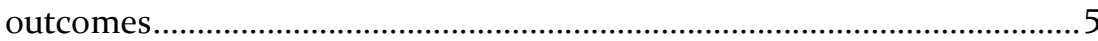

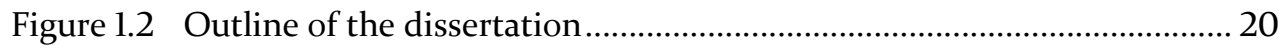

Figure 2.1 Network of start-up between 2007 and 2009 ......................................30

Figure 2.2 Network of start-up between 2010 and 2012 .........................................31

Figure 2.3 Network of start-up between 2013 and 2015........................................32

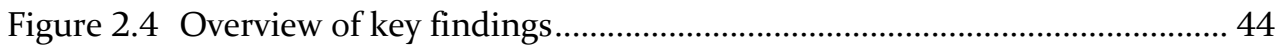

Figure 3.1 A model of the interaction process ...........................................................62

Figure 4.1 A framework of power in relationships between startups and established

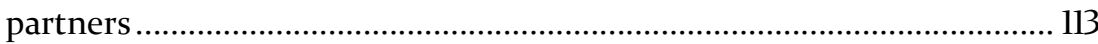

Figure 5.1 Visualisation of the hypothesised relationships ......................................157

Figure 5.2 The interaction effects between centrality, size asymmetry and age asymmetry on value creation and value appropriation in multipartner alliances................................................................................................ 164

Figure 6.1 Hypothesised relationships visualised...................................................... 180

Figure 6.2 The interaction effects between variety and power asymmetry on new product development performance 187 


\section{List of tables}

Table 1.1 Overview of the five studies included in this dissertation .11

Table 2.1 The key findings regarding the third actors' function and role in the relationship initiation process

Table 2.2 The key findings regarding the setting and level of network embedding of the start-up's relationships as well as the effects on its business development ....................................................................................... 34

Table 3.1 Definitions six interaction modes of start-ups and partners...................... 66

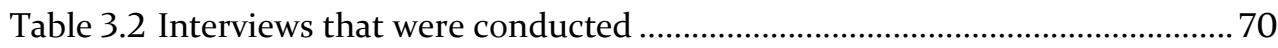

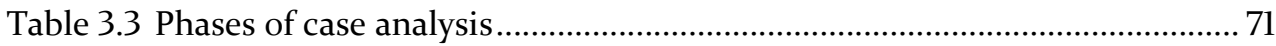

Table 3.4 Trigger, action-interaction and outcome in interaction episodes between

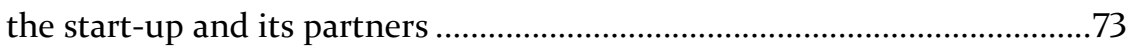

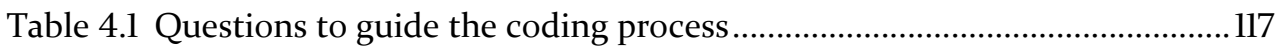

Table 4.2 Summary of the power episodes between the startup and its established partners ....................................................................................................118

Table 5.1 Means, standard deviations and correlations ............................................161

Table 5.2 Determinants of value creation in multipartner alliances...........................162

Table 5.3 Determinants of value appropriation in multipartner alliances ................162

Table 6.1 Means, standard deviations and correlations ...........................................184

Table 6.2 Determinants new product development performance in multipartner alliances 185 



\section{Acknowledgements}

In 2008, I had to choose a Bachelor programme and to decide where I would like to study it. I hesitated between the practice-oriented Business Administration programme at the University of Twente (UT) and the research-oriented one at Radboud University. I chose the former, most importantly because I could not imagine myself working in academia, like, ever. Surprisingly, I experienced much enjoyment doing research during studies at Apollo Vredestein for my Bachelor thesis. So, I decided to do a PhD after my Master's. I discussed the possibilities with Petra de Weerd-Nederhof, the then programme director. She advised me to do the double degree programme Innovation Management and Entrepreneurship of the UT and Technical University Berlin, to increase my chances of getting funding. After some personal doubts, I did.

When I returned from Berlin, Ariane von Raesfeld Meijer - whom I had worked for as student assistant - asked me to do a Master's thesis on managing business relationships under her supervision. After completing my thesis, I got lucky: she asked me to continue the research, as a PhD student. I said yes for many reasons, primarily because I could combine my love of research with practical impact (the connection to practice remains crucial for me!). Four years and a few months later, I can look back at an unforgettable time in which I developed as a person, learned too much to mention, became a better researcher, discovered a new passion, met awesome people, made new friends, visited beautiful places and - above all - actually enjoyed my $\mathrm{PhD}$ journey.

My research is based on the idea that "no business is an island" ${ }^{1}$. Thus, also: no PhD is an island. This dissertation would not have seen the light without all the people who have supported me these past years. I would like to now acknowledge those who have made it possible.

${ }^{1}$ Håkansson, H. \& Snehota, I (1989). No business is an island: The network concept of business strategy. Scandinavian Journal of Management, 5(3), 187-200. 
First, I am very grateful to my promotors, Aard Groen and Ariane von Raesfeld Meijer. Aard, thank you for all your ideas, stories and feedback during my $\mathrm{PhD}$ trajectory. You gave me the freedom and confidence to pursue my own ideas. Also, you recommended me at VentureLab North to give the training 'Valuable network resources' to entrepreneurs, despite my limited teaching experience. I now give this training several times a year, and it is great fun.

Ariane, I could not have done my $\mathrm{PhD}$ without your dedicated supervision: you put me in contact with Inreda Diabetic B.V., gave me the opportunity to become a PhD student, discussed and challenged my research ideas with me, stimulated me to publish in scientific journals from the outset, gave constructive feedback to every single piece I wrote (even at the last moment!), helped me when things didn't go as planned, involved me in teaching, co-authored all my articles, introduced me to new research projects, and much more. My sincere gratitude for your friendship, support and encouragement over the past four years.

I am also thankful to my $\mathrm{PhD}$ committee members for reading and approving my dissertation: Lars-Erik Gadde, Peter Geurts, Jörg Henseler, Bart Van Looy, Petra de Weerd-Nederhof and Hans de Vries. Without compromising the others, I personally acknowledge four. Petra, your unconditional belief in my abilities has encouraged me to develop as student, researcher and teacher. My gratitude to Hans for going through my first three articles with care, although they were outside your field of expertise, and your amazingly swift replies. Peter, your answers to my statistics questions taught me much and greatly improved my last two articles. My thanks to Lars-Erik for guiding me through the review process of the first article I published with your sound, thoughtful feedback.

Further, my gratitude to all my colleagues at NIKOS and other departments of UT for your collegiality. Especially, I am indebted to the students and colleagues with whom I engaged in teaching: Alma, Ariane, Edwin, Ellian, Erik, Isabella, Jeroen, Job, Kasia, Michel, Petra, Rainer, Wesley and many others. Thanks to you, I discovered a new passion during my $\mathrm{PhD}$ 
- teaching. Also, you have inspired, encouraged and supported me to become better at one of things I love to do most. My gratitude to Ariane, Lisa, Raymond and Xander for your collaboration on the Industry 4.0 project we initiated with Biba from the Fraunhofer Project Center. Although we started only recently, I enjoyed delving into a topic that had been unknown to me with you. Further, I am thankful to my fellow (former) PhD colleagues for exchanging knowledge and experiences: André, Andres, Anna, Ari, Arjan, Cherrelle, Dustin, Frederik, Igors, Jacco, Jin, Jorrit, Koen, Letizia, Lisa, Maarten, Matthias, Marlies, Martin, Milana, Milou, Niels, Raja, Shuijing, Sílvia, Tijs, Timo and Yasin. My special thanks to Marlies for welcoming me in your office and becoming my friend. I could always share my PhD-related as well as personal lows and highlights with you. While we unfortunately no longer share an office, I look forward to continuing our daily lunchtime walks.

I would like to acknowledge the organisations and their members for (financially) supporting my $\mathrm{PhD}$ research. Robin Koops, your question about how to manage the business relationships of your startup Inreda became the foundation of my research. I am very grateful for the opportunity to address this question in your company. In those two days a week, I especially learnt how theory works and does not work in practice. Wim, you taught me the ins and outs of being a commercial director, the value of networking, and the importance of reciprocity in negotiation. Further, I enjoyed collaborating with Helga, Mickael and UT students Christopher, Remi and many others, to assess and improve the usability of Inreda's artificial pancreas. Although this sometimes distracted me from my own research, it was inspiring and fun to work in a wholly different area: the differences between business and medicine are truly countless. Over the years, I saw Inreda grow: when I started in 2013, I joined Arianne, Eddy, Erik, Helga, Irene, Pleun, Rob, Robin, Tess and Wim; when I left in 2016, Alex, Bram, Caroline, Christine, Dennis, Gijs, Jan, Kay, Mickael and Robin had joined. I always felt at home with you, and still feel more than welcome when I pass by. Thank you. Also, my gratitude to the PCDIAB consortium - funded through FP7 grant number 305654 from the EC - for its financial contribution to support this study. 
I am also indebted to the many other work-related people who have supported my undertakings, challenged my approaches, and engaged in valuable exchanges in some way. My thanks to the members of the IMP group: my research was greatly inspired by your work, and you made me feel part of a community. Especially Lise Aaboen and Antonella La Rocca have encouraged and supported me to do more with the case I presented at the IMP conference in 2014, which resulted in an additional journal publication and book chapter.

Further, my gratitude to Johan Emerson Grobler for editing most of my dissertation. Your corrections and notes have substantially improved my work and my English. Also, thank you for making laugh several times in the stressful moments before a deadline, and your patience and support in writing these acknowledgements - the very first time I experienced writer's block.

Although written words can barely do justice to my gratitude, I am extremely thankful to the one and only Robin, and my family and friends. Robin, you enjoyed, celebrated and laughed with me in good times, and you were always there when I needed you most. You lent your ears to my frustrations and cheered me up when necessary. You were the first to call when something succeeded, the editor of my English, the support in the stressful last months, and so much more... I love you.

Mam and Pap, thank you for loving me unconditionally, raising me as an independent and curious woman, and giving me all the possibilities to learn; without you, I would not have become who I am today. I am very fortunate that my brother Lennart and my best friend Lisan will be my paranymphs. Lennart, you are always proud of me, no matter what, and your big hugs (when entering, leaving and in between!) make me feel extremely loved. I could not have wished for a better brother. Lisan, I can talk to you about anything during our lunches in Deventer, sauna visits, weekends in Düsseldorf, song festival nights at my home, dinners at your home, and in all the other times and places we meet. Your friendship means the world to me. 
Yvonne, my favourite aunt, and Mireille, my sister-in-law, I am very grateful for your gezelligheid over the years. My thanks to my in-laws - Laura, André, Dyon, Oma Anna, René, Bianca and Arnoud - for your support. Ivar and Marjolein, thank you for our delicious and cosy dinners, especially the one a week before my dissertation deadline: it gave me a very necessary break. Maarten, I discussed our struggles as PhD students at the UT, reminisced about our student days in Berlin, and talked about many other topics with you. Thank you. Although we don't see each other often, Jacobien, I always enjoy catching up. The moment I wrote this, you sent me an appje with an update about your new house - coincidence! Mireille, we've managed some coffee dates, and I look forward to getting to know you better.

Expressing my gratitude to you has made me realise even more how very lucky I am to have had you there during my $\mathrm{PhD}$ journey. Thank you!

Tamara

25 January 2018

Apeldoorn, The Netherlands 



\section{CHAPTER 1}

Introduction

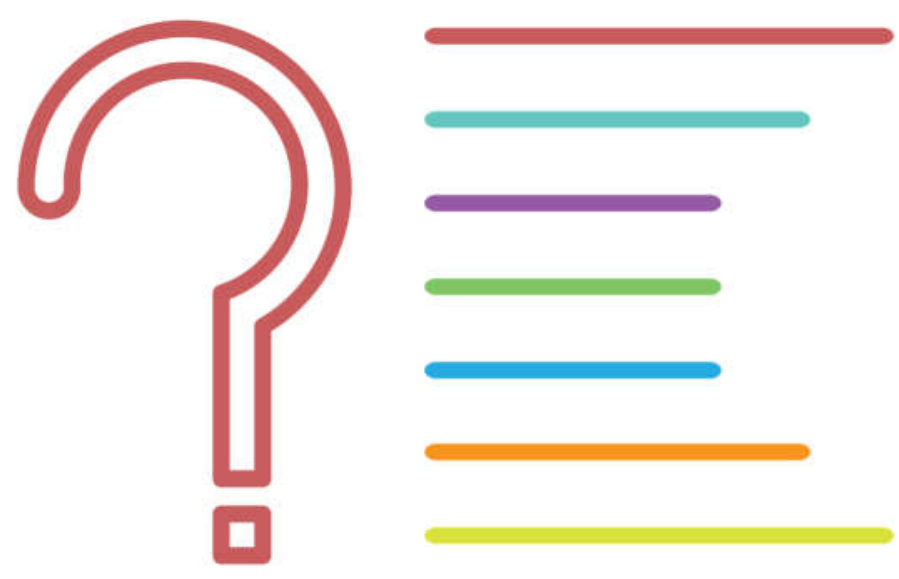




\subsection{Research origin}

In March 2013, I met with Dr. A.M. von Raesfeld Meijer from the University of Twente and Mr. Ronsman² from Biphora concerning the subject for my Master's thesis. The University of Twente and Biphora had just begun to collaborate in a European-funded project. Its main goal was to develop and commercialise Biphora's closed-loop bi-hormonal artificial pancreas. As the University of Twente's project tasks concerned business development, Mr. Ronsman required help, asking: how should I initiate and manage my business relationships? He explained that he had invented a solution to improve the treatment of diabetes: a closed-loop bi-hormonal artificial pancreas. Initially, he combined his mechanical expertise with two friends' software skills and medical competences to develop a prototype; yet the development stagnated in 2006 because they had insufficient resources to run clinical trials. Since Mr. Ronsman had diabetes, and his friend was a diabetes nurse, he thought they had a network to immediately find a suitable partner; however, they were not connected to the network of organisations that develop, test and produce devices for the treatment of diabetes. Thus, it was hard for them to find the right partner.

More than two years later, Mr. Ronsman found that the Medical Center Winstad (MCW) was prepared to run clinical trials. Once he had established a relationship with the $\mathrm{MCW}$, it became slightly easier to initiate new relationships with suitable partners, such as Reseata, Antenyx, and the Insulise Foundation. However, Mr. Ronsman now faced the challenge to successfully manage his relationships and achieve the desired results. Since each relationship had to be created from scratch, he did not know which actions to take in his relationships, how to deal with his partners' expectations, how to negotiate appropriate compromises and the like. Further, he was concerned that his partners would enhance their benefits at the expense of his company's interests because they often possessed more, better and well-connected resources. Mr. Ronsman also felt particularly vulnerable in this European-funded project, because it appeared difficult to identify which partners contribute to the project and which only take of

\footnotetext{
${ }^{2}$ For anonymity reasons, the persons and organisations are given fictive names
} 
several partners at once. Thus, he had no guarantee that the project partners would ever repay his substantial contribution: access to his artificial pancreas.

Research has taught me that Mr. Ronsman's business was not the only person to face such struggles. As new businesses have a fragile position in a pre-existing network, they face unique challenges in successfully initiating and managing business relationships. Further, network position differences and related power imbalances between founders and partners can aggravate these challenges, affecting the extent to which a relationship delivers mutual benefits. This applies to startups' relationships with both one and multiple partners. At the time, scholars had paid little attention to network management dynamics in the context of small and medium-sized enterprises (SMEs). I decided to research the tasks that a SME executed to manage its asymmetrical relationships, how these tasks changed during a relationship and what caused these changes. However, it also turned out that my study did not wholly address Mr. Ronsman' question: there were several opportunities for further research.

My Master's thesis shows that we need to better understand how businesses, in a fragile network position, initiate business relationships and interact with their partners. Additionally, previous work of Dr. Von Raesfeld (see Raesfeld, Geurts \& Jansen, 2012; Raesfeld, Geurts, Jansen, Boshuizen \& Luttge, 2012) showed that it would be fruitful to research the power relationships between multiple partners. Dr. Von Raesfeld asked me to continue investigating these subjects as a $\mathrm{PhD}$ student under her supervision and that of Prof. Dr. A.J. Groen. Since you are now reading the introduction to my dissertation, clearly, I said yes. In this dissertation, I study how network position affects and is affected by network management and network outcomes, both in relationships of businesses in a fragile position in a preexisting network and in relationships in which multiple companies with different network positions collaborate. 


\subsection{Research motivation}

My central thesis is that a business' network position forms the basis of network management, which leads to specific network outcomes. In other words, a business' network position is the location of its power, which affects its possibilities and limitations concerning successfully initiating, developing, and maintaining business relationships (Low, 1997). I define network position as a business' position in a network derived from its relationships with other businesses and these business' relationships with other businesses in the network (Low, 1997). I understand network management as a business' conscious attempts to initiate, develop and maintain a business relationship (Håkansson, Ford, Gadde, Snehota \& Waluszewski, 2009; Low, 1997). I describe network outcomes as the multidimensional effects that appear to relate to a business relationship, concerning either the single business, the business relationship, or the network (Abrahamsen, Henneberg, Huemer \& Naudé, 2016; Håkansson et al., 2009). However, notably, a network position also influences how a business perceives the outcomes of managing its business relationships. Similarly, network outcomes affect a business' network position and management. Finally, a business' relationship management impacts on its outcomes and leads to changes in its network position. These inter-relationships between network position, management and outcomes are shown in Figure 1.1.

In recent years, there has been considerable progress in understanding which network positions are beneficial to company performance and under what conditions (for a meta-analysis, see Wang, Zhao, Li \& Li, 2015), as well as how businesses can change their network position (Low, 1997; Low \& Johnston, 2009). Despite this progress, there is much we do not yet know. In this section, I will not seek to review all we now know about network positions. My focus is on two aspects of network position studies that, in my view, have generally been under-researched: 1) how startups in a fragile network position initiate, maintain and develop business relationships; and 2) how network position and related power influences network outcomes in multipartner relationships. 


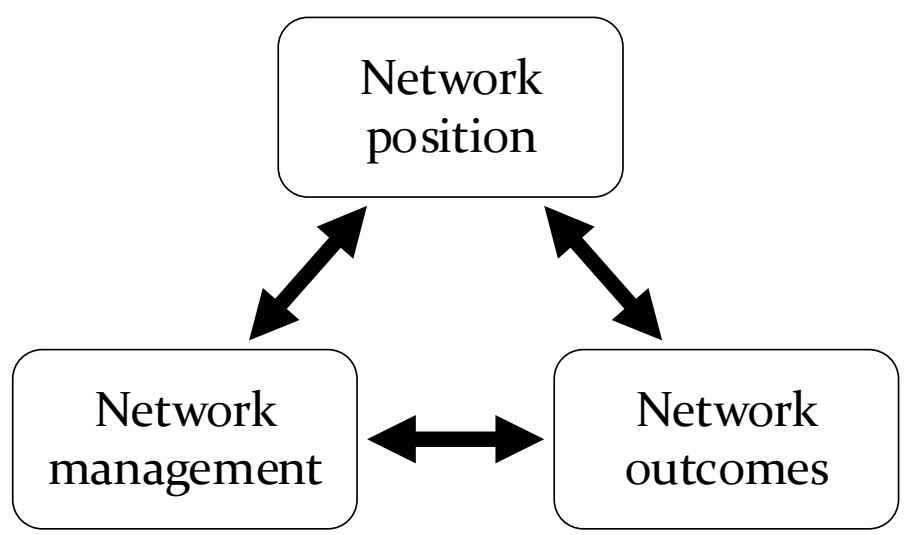

Figure 1.1 The inter-relationships between network position, management and outcomes (adapted from Håkansson et al., 2009)

\subsubsection{Startups managing business relationships: An interactive perspective}

Researchers have investigated network position's implications for small and large businesses' business relationships (Wang et al., 2015). In comparison, we have very little systematic knowledge about network position's consequences for new businesses (hereafter called startups). In the strategic management literature, newness is typically confused with smallness (e.g. Vandaie \& Zaheer, 2014). In this context, this confusion is problematic because, unlike small businesses, startups have not yet positioned themselves in a pre-existing network. This presents startups with three unique challenges in managing business relationships. The first challenge is that startups often have problems in initiating useful business relationships (Prashantham \& Birkinshaw, 2008). Since startups tend to have a narrow network horizon focused on a few key partners, it is difficult to scan the network for new partners with valuable resources (Holmen \& Pedersen, 2003; Kirkels \& Duysters, 2010). Another challenge is that startups usually find it hard to know how and when to act in a business relationship, owing to a lack of stability and predictability in their emerging relationships (Ariño, Ragozzino \& Reuer, 2008; Thorgren, Wincent \& Eriksson, 2011). A further challenge is that startups may find themselves in problematic, expensive and undesirable power struggles with their partners (Cowan, Paswan \& Van Steenburg, 2015). This is because a startup often collaborates with organisations that possess 
more, better and well-connected resources than they do (e.g. Ahuja, Polidoro \& Mitchell, 2009; Kalaignanam, Shankar \& Varadarajan, 2007; Rothaermel \& Boeker, 2008). Thus, it is more challenging for startups to manage business relationships than for well-established businesses, because they usually have a fragile network position and, accordingly, lack the resources needed to effectively manage relationships (Hoffmann \& Schlosser, 2001; Rosenbusch, Brinckmann \& Bausch, 2011; Wynarczyk, Piperopoulos \& McAdam, 2013). Yet, research has shown that successful business relationships are vital to startup survival, growth and success (e.g. Aaboen, Laage-Hellman, Lind, Öberg \& Shih, 2016; Baum, Calabrese \& Silverman, 2000; La Rocca, Ford \& Snehota, 2013; Larson, 1992). Thus, in my view, it is important to get more insight into how startups can successfully manage business relationships within the constraints of their network position.

Although I consider this important, there is a major debate about the possibility to manage business relationships. In the management literature, it has generally been assumed that businesses can independently manage business relationships: they can autonomously choose how to act, and their actions will result in certain outcomes, regardless of their partners' actions (Aaboen, Holmen \& Pedersen, 2017; Slotte-Kock \& Coviello, 2010). However, the Industrial Marketing and Purchasing (IMP) literature suggests that managing business relationships is a process in which (at least) two active parties take part (Aaboen et al., 2017). Potential partners enter a relationship wilfully after a two-sided matching process: both parties must agree to the relationship and any change thereafter. Thus, their actions to manage a relationship form action-reaction loops that result in certain outcomes only through an interactive process (Aaboen, Dubois \& Lind, 2013; Ford \& Mouzas, 2013; Ritter \& Gemunden, 2003; Stuart \& Sorenson, 2007). Owing to this interactive process, IMP researchers argue that relationship management is a matter of handling three paradoxes: 1) the development of relationships provides opportunities to businesses, but also imposes restrictions on their ability to change; 2) businesses' relationships are influenced by their strategy, but the reverse also applies; and 3) the more businesses achieve their ambition of control, the less effective a relationship will be (Håkansson et al., 2009). Thus, I argue that a startup cannot manage its relationships 
independently: its partners affect its actions and vice versa. Nonetheless, startups do behave purposefully: they have the willingness and ability to influence a relationship in accordance with their interests (Aaboen, Dubois \& Lind, 2011; Harrison, Holmen \& Pedersen, 2010; La Rocca et al., 2013; Thorgren, Wincent \& Boter, 2012). To reach their intentions, startups can use the resources, relationships and experiences they possess to make changes to a relationship (Håkansson \& Waluszewski, 2013). Thus, startups' actions are goal-oriented and involve skilful, coordinate and deliberate efforts (Hoang \& Yi, 2015). Thus, I claim that startups can and must manage their business relationships, but that the conventional assumption of independence should be replaced with an interactive perspective. Unfortunately, the literature on startups generally overlooks that there are two partners in a business relationship, neglecting the interactive nature of relationship management (Aaboen et al., 2017; Ariño et al., 2008). An exception is the work of some IMP researchers, collected in the book "Starting up in business networks: Why relationships matter in entrepreneurship". However, they have focused on the initiation of startups' business relationships and have not considered the challenges associated with managing relationships once they are initiated. Thus, I think that there are substantial opportunities to expand our understanding of how startups, which have a fragile network position, can successfully initiate and manage business relationships from an interactive perspective.

\subsubsection{Network position: A source of power in multipartner relationships}

Research that connects networks to power has shown that network position, as a source of power, plays a key role in dyadic business relationships (e.g. Kähkönen \& Lintukangas, 2010; Low, 1997; Yeniyurt \& Carnovale, 2017). However, there has been relatively little empirical research into the implications of network position and related power in multipartner relationships. Albers, Schweiger and Gibb (2015) argue that three effects are key in differentiating multipartner relationships from dyads: timing, complexity and power allocation. The timing effects reflects the sequencing of partner enlistment and partner dynamics. Partners face the question: how does the entrance and exit of heterogeneous partners affect the value creation 
and appropriation possibilities during the relationship? The complexity effect reflects that partner heterogeneity (i.e. the variety of goals, resources, and capabilities) increases owing to the addition of partners to a relationship; thus, the efforts needed to achieve synergies among the partners also increases. The power allocation effect reflects that power's complexity increase when moving from two to multiple partners in a relationship. In a dyadic relationship, either one partner is more powerful than the other, or both are equal. A great number of options exist when there are multiple businesses involved (Albers et al., 2015). Clearly, these three effects make it more complex to understand the implications of network position and power in multipartner relationships than in dyadic relationships. For instance, it is often expected that partners are less likely to exchange resources owing to the potential of free-riding and opportunisms in multipartner relationships with a single powerful partner (Badir, Buchel \& Tucci, 2005; Bunderson \& Reagans, 2011; Hoehn-Weiss \& Karim, 2014). However, a powerful business can also use its power to manage resource exchange between partners by leveraging knowledge mobility, mitigating appropriation concerns, and maintaining relationship stability (Badir et al., 2005; Bunderson \& Reagans, 2011; Dhanaraj \& Parkhe, 2006). Further, a single powerful business usually takes the lead in decision-making in multipartner relationships: weaker ones may legitimate its position and transfer decision rights to allow for effective decision-making, but they may also form coalitions to dominate its power and force their needs into the decision-making process (Albers et al., 2015; Badir et al., 2005; Bunderson \& Reagans, 2011). Thus, power in multipartner business relationships can be characterised as multiplex, as involving different power ratios, and as affecting business relationship management in various ways. Given this multiplexity and power's centrality in business relationships, scholars have suggested that we must better understand network position and related power from a multipartner perspective (Hingley, Angell \& Lindgreen, 2015; Olsen, Prenkert, Hoholm \& Harrison, 2014). I argue that power derived from network position in multipartner relationships urgently requires distinct theoretical development and empirical testing from dyadic relationships. 
Although I argue that network is a key power source, power has been conceptualised and analysed in different fields in the management literature (Belaya, Gagalyuk \& Hanf, 2009; Kähkönen \& Lintukangas, 2010). Thus, there is no single definition of power and no consensus as to which dimensions it contains. Olsen et al. (2014) argue that power can be meaningfully categorised in three dimensions: structural (i.e. power can be held as an attribute of a business), behavioural (i.e. power is used by a business as a source of control) and relational (i.e. power stems from the relationships between businesses in a network). Various other distinctions have been made, such as between potential power and power use (Brass \& Burkhardt, 1993) as well as the macro-level and micro-level perspectives on power (Huxham \& Beech, 2009). Structural, behavioural and relational power are usually treated as alternative explanations in studies of business relationships. Specifically, most studies strongly focus on power base theory based on the taxonomy of French and Raven (1959), who identify power types based on the source of power: coercive, reward, expert, legitimate and referent power. In these studies power is analysed in terms of an organisational attribute; thus, a structural perspective is applied. Even studies that do not adopt a power base theory have investigated power from either a relational, structural or behavioural perspective: few studies have combined the three approaches. Accordingly, the research has tended to overlook the interconnections between power dimensions (Olsen et al., 2014). Yet the actions of businesses are shaped by structure, and structure arises from businesses' actions (Brass $\&$ Burkhardt, 1993). Also, the extent of access to resources in multiple partners in a network will affect a business' ability to create dependencies in dyadic relationships via resource control (Astley \& Sachdeva, 1984). Thus, structural, relational and behavioural power must be understood as simultaneous, complementary processes (Brass \& Burkhardt, 1993; Olsen et al., 2014). Network position may therefore represents a useful starting point when studying power in business relationships (Olsen et al., 2014). However, a single dimension is unable to capture all its aspects simultaneously, providing an incomplete understanding of power (Belaya et al., 2009). Thus, I argue that it is preferable to develop, use and compare measures that account for different power dimensions in business relationships. 


\subsection{Research questions}

In this dissertation, I research how network position, management and outcomes are related. Based on the relevant research gaps identified in the previous section, I first aim to understand how startups in a fragile network position can successfully initiate, develop, and maintain business relationships in interaction. Second, I intend to learn how power, derived from network position but also other power sources, affects outcomes in business relationships, especially those with multiple partners. Thus, my main research question is:

RQ: $\quad$ How do network position and related power affect and are they affected by business relationships management and outcomes in networks?

To address this question, I intend to answer five underlying research questions that correspond to the five studies presented in this dissertation. Before I elaborate on the five studies and related research questions, I summarise each study's research question, contribution in answering the main research question, theoretical foundation, and research method to answer the question in Table 1.1.

Study 1 investigates how startups in a fragile network position successfully initiate relationships become embedded in a network and develop through third actors. Previous research suggests that third actors can connect startups to two or more matching partners in a way that benefits to all parties (e.g. Hite, 2005; Jack, Dodd \& Anderson, 2008; Styhre \& Remneland-Wikhamn, 2015). However, the research into third actors has primarily focused on the perspective of the third actor - the one that connects - rather than the actors that are connected. Thus, we study how third actors affect the startups' relationship initiation process and subsequently its network embedding and its business development. To this end, we build on three theoretical models in the IMP tradition, two that explain the role of third actors in the relationship initiation process (Aarikka-Stenroos \& Halinen, 2007; Holmen \& Pedersen, 2003) and one that conceptualises 


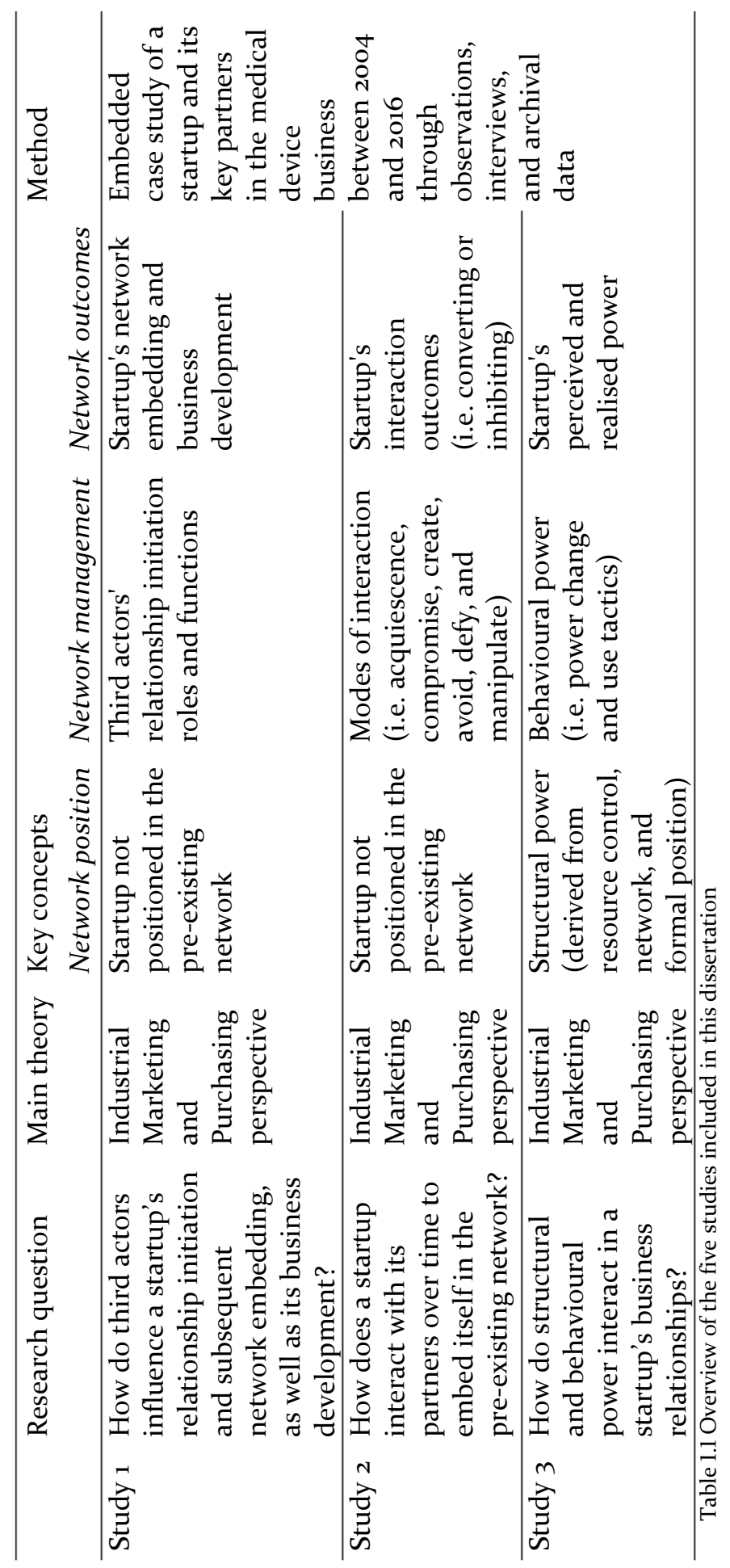




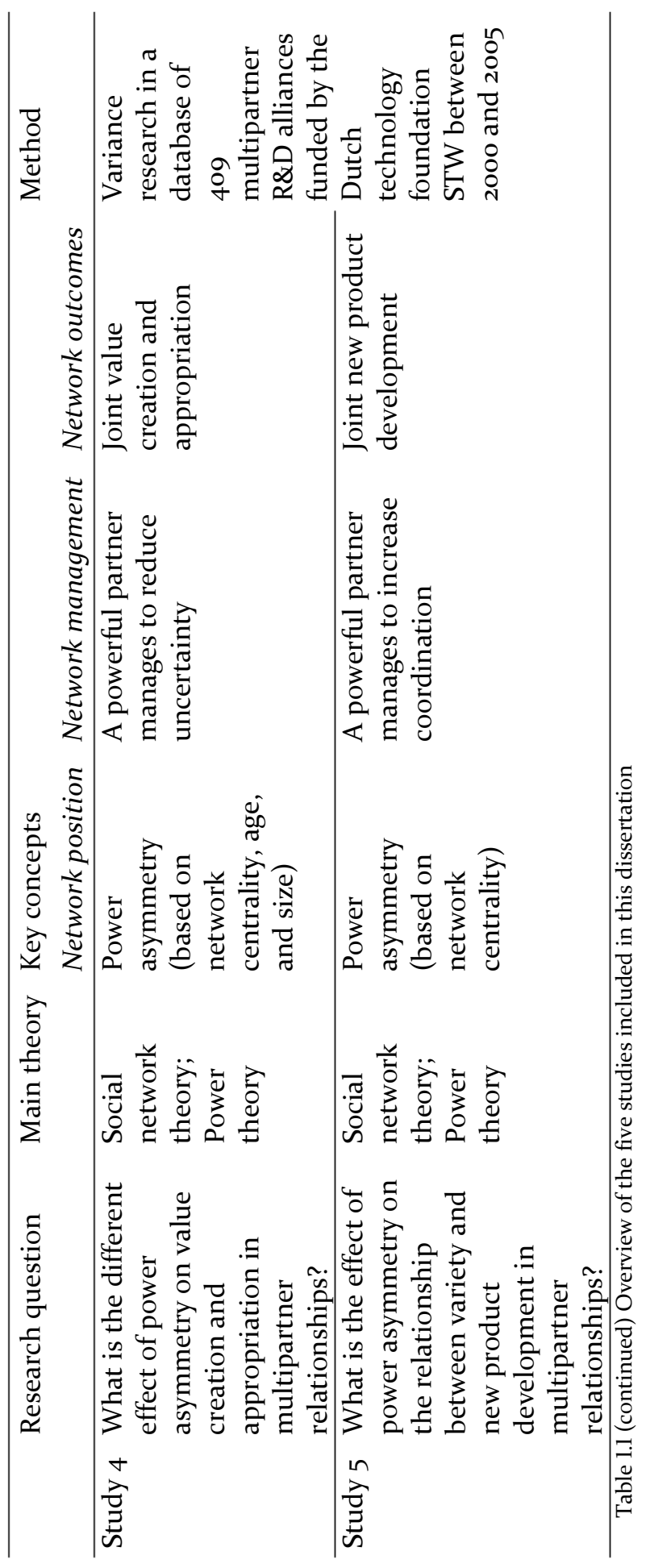


network embedding (Håkansson et al., 2009). Yet the IMP tradition mainly considers what happens between organisations, while it largely ignores what goes on in an organisation. Thus, we complement these models with a theoretical model from the entrepreneurship literature, which represents a startup's business development process (Mainela, Pernu \& Puhakka, 2011). My first research question is:

RQ1: How do third actors influence a startup's relationship initiation and subsequent network embedding, as well as its business development?

Study 2 considers how startups in a fragile network position (un)successfully interact with their partners to develop and maintain business relationships over time. There has been an increase in research interest in the specific actions that startups take in their business relationships (e.g. Ariño et al., 2008; Thorgren et al., 2012). Yet these studies have focused on a single action type at a single point in time, solely from the startups' perspective. Instead, organisational action should be: a) analysed in relation to actions that precede and follow it; and b) characterised by the interaction process of actions and reactions that go back and forth between two partners (Lui \& Ngo, 2005). We seek to learn how startups interact with their partners over time, applying the action typologies of strategic management researchers Lui and Ngo (2005) and Tjemkes and Furrer (2010) to both actors in a relationship rather than only one. We also extend their typologies based on the 'interaction model' (Håkansson et al., 2009, p. 31), which forms the basis of the IMP tradition and explains the intensive interactions that take place between organisations over time. Accordingly, my second research question is:

RQ2: How does a startup interact with its partners over time to embed itself in the pre-existing network? 
Study 3 looks at the role of structural and behavioural power in startups' business relationships management. Although studies have provided valuable insights into startups' business relationships (Aaboen et al., 2011; Baum et al., 2000; Chen, Zou \& Wang, 2009; Das \& He, 2006; Diestre \& Rajagopalan, 2012; Hoehn-Weiss \& Karim, 2014; La Rocca et al., 2013; Rothaermel \& Boeker, 2008; Vandaie \& Zaheer, 2014), few have researched startups' views on and experience with power in business relationships. Also, scholars have typically used either a structural perspective (e.g. Alvarez \& Barney, 2001; Gardet \& Fraiha, 2012) or a behavioural one (e.g. Cowan et al., 2015; Johnsen \& Lacoste, 2016) to create an understanding of power. Yet structural and behavioural power must be understood as simultaneous, complementary processes (Brass \& Burkhardt, 1993). We want to discover how structural and behavioural power interact in startups' business relationships, applying the framework of Kim, Pinkley, and Fragale (2005), which provides an explanation of the relationship between structural and behavioural power in interpersonal negotiations. Since the model is both two-sided and dynamic, it corresponds well with the IMP legacy. Interpersonal power theories have also been shown to be powerful in explaining power at the inter-organisation level. Thus, my third research question is:

RQ3: How do structural and behavioural power interact in a startup's business relationships?

Study 4 investigates power asymmetry's impacts on the effectiveness of multipartner relationships. Effective collaboration in multipartner relationships depends on a partner's ability to create and appropriate value (Dyer, 1997). The research indicates that power asymmetry in multipartner relationships may lead to different value creation and appropriation possibilities (Badir et al., 2005; Kanter, 2000; Provan \& Kenis, 2008). Yet very view studies have examined power asymmetry in combination with both value creation and appropriation. Power is also often associated with an organisation's network position, while it may also derive from control of the resource supply in a relationship. Scholars have suggested that it is important to analyse these two dimensions simultaneously (Astley \& Sachdeva, 1984) owing to the potentially different impacts on different effectiveness types 
(Ibarra, 1993). Nonetheless, the two power sources are rarely combined in studies of business relationships. We seek to determine how power asymmetry, derived from network position and resource control, affects value creation and appropriation in relationships, developing hypotheses based on decision-making literature. Hence, my fourth research question is:

RQ4: What are power asymmetry's effects on value creation and appropriation in multipartner relationships?

Study 5 investigates power asymmetry and partner variety's influences on new product development in multipartner relationships. In multipartner relationships characterised by high power asymmetry, on the one hand, a powerful partner can diminish the innovation-related benefits of partner variety because its resources may be given disproportionate weight, while the powerless partner's contributions may be overlooked (Bunderson, 2003; Bunderson \& Reagans, 2011); on the other hand, a powerful partner reduce the coordination complexities associated with partner variety because it can facilitate the mobilisation of unshared resources and can engage powerless partners in the new product development process (Bunderson \& Reagans, 2011; Pitcher \& Smith, 2001). Yet the dominant approach to conceptualising partner variety in relationships assumes equal power, while power is rarely distributed equally among partners (Albers et al., 2015; Hoehn-Weiss, Karim \& Lee, 2017). We intend to study power asymmetry's impacts on the relationship between variety and multipartner relationship performance, building on two theories from the literature on interpersonal power that explain power asymmetry's effects on the relationship between variety and team performance. Accordingly, my fifth research question is:

RQ5: What is power asymmetry's effect on the relationship between partner variety and new product development in multipartner relationships? 


\subsection{Research design}

The research in this dissertation is positioned in a critical realism philosophy of science. Critical realism's basic principle is that the world exists independently from our thoughts about it. To this end, critical realists distinguish between the real, the actual and the empirical. While the real refers to the structures and power of objects, the actual involves what happens if and when these powers are activated and the empirical includes the domain of experience with the real or actual (Sayer, 2000). Thus, critical realism offers a radical alternative to the well-established philosophies of positivism and interpretivism (McEvoy \& Richards, 2006). In contrast to positivism, critical realists do not understand causation on the model of regularities among sequences of events. Instead, explanation depends "on identifying causal mechanisms and how they work, and discovering if they have been activated and under what conditions" (Sayer, 2000, p. 14). In contrast to interpretivism, they do not deny the possibility of knowing what is real and rule out causal explanations (Sayer, 2000). Thus, in critical realism, "the ultimate goal of research is not to identify generalisable laws (positivism) or to identify the lived experience or beliefs of social actors (interpretivism): it is to develop deeper levels of explanation and understanding" (McEvoy \& Richards, 2006, p. 69).

I position my dissertation in critical realism because it is well suited to investigate heterogeneous structures, such as business relationships. According to critical realists, business relationships are real objects that have the power to cause events, which cannot be explained by analysing individual businesses in isolation (Easton, 2010; Ryan, Tähtinen, Vanharanta \& Mainela, 2012). Businesses' roles and identities are often related, so that what one business is or can do depends on its relationships to others. That is, critical realists see business relationships as social systems that consist of dependencies that causally affect the businesses, and businesses' form and structure causally influence each other and - therefore - the whole (Easton, 2010; Sayer, 2000). Thus, critical realists provide an ontological justification for why business relationships are legitimate and necessary objects of analysis. Further, critical realism allows me to focus not only on what happens in business relationships, but also the mechanisms that contingently cause 
networks positions, management, and outcomes. The critical realist understanding offers a means to explain causality in business relationships. Thus, I can move beyond rich descriptions of business relationships towards analytical generalisation (Ryan et al., 2012).

Critical realists support a relatively wide range of research methods, which they divide into intensive and extensive research designs (Sayer, 2000, 2010). Intensive research is concerned with "how some causal process works out in a particular case or a limited number of cases" (Sayer, 2010, p. 242). Its results can provide very concrete causal explanations and interpretations of meaning in context, but are typically not representative of the whole population (McEvoy \& Richards, 2006; Sayer, 2010). In contrast, extensive research is concerned with "discovering some of the common properties and general patterns of a population as a whole" (Sayer, 2010, p. 242). Its results can identify similarities, correlations, associations and the like that may otherwise be masked, but they are weaker for explanation because they do not clearly identify the causal mechanisms involved (McEvoy \& Richards, 2006; Sayer, 2010). Given their benefits and problems, critical realists argue that intensive and extensive research designs are complementary rather than competing, and that both are needed in research (Sayer, 2010). Thus, I use an intensive and an extensive research design in this dissertation.

In the first three studies (Chapters 2 to 4 ) we conduct a longitudinal embedded case study of a startup and its partners in the medical device industry. Case study research is an intensive research method that is entirely compatible with a critical realism philosophy, because it can explain complex social systems by identifying causes behind an event, i.e. the causal mechanism (Easton, 2010; Ryan et al., 2012). We collected data retrospectively from 2005 to 2013 and then in real-time until May 2016 from three sources: active and passive participant observations at the startup, semistructured interviews with both the startup and its partners, and archival documents. This way of data collection provided me with the intricate details needed to move beyond superficial observations and build the explanatory knowledge that critical realists seek. To analyse the data, we used an 
abductive logic, assuming we could find causal mechanisms from existing theories and from unexplained aspects arising from the data (Ryan et al., 2012). This means that we started the analysis of eight of the startup's business relationship initiations (Chapter 2), 18 interaction episodes between the startup and its partners (Chapter 3), and nine power episodes between the startup and its established partners (Chapter 4) with a priori defined analytical framework. However, the data analysis may also guide us to search for further causal mechanisms.

In part 2 of my dissertation (Chapter 5 to 6 ), we statistically analyse the relationships between power asymmetry and value creation as well as value appropriation based on a database of 409 relationships with multiple partners granted funding from the Netherlands Technology Foundation STW between 2000 and 2004. Although there is a debate among critical realist concerning the usefulness of statistics in social research, the consensus seems to be that they cannot provide causal explanations (Buch-Hansen, 2014). Nonetheless, we can use statistics as an extensive research method to describe the association between power asymmetry and value creation as well as appropriation. This is useful to tease out potentially new causal mechanisms (McEvoy \& Richards, 2006), which then require more concrete explanations in further research with intensive research designs (Sayer, 2010). Further, we applied Social Network Analysis (SNA) to determine the relative network positions and related powers of partners in a multipartner relationship. Although SNA cannot directly explain causal mechanisms, it acknowledges that structural positions impact on businesses' power and liabilities as well as that businesses are not independent objects, but have emerging properties. As these views are consistent with critical realists' principles, it is well suited to gain in-depth knowledge about the nature of relational structures and to disclose structural patterns (Buch-Hansen, 2014).

\subsection{Research outline}

In this dissertation, Chapter 1 explains my dissertation's motivation, questions, and design. In Chapters 2 to 6 , I present the empirical studies that link to research questions 1 to 5 . The empirical research can be divided in two parts based on my dissertation's research motivation (see Section 1.2). In part 
1, we research how startups in a fragile network position initiate (Chapter 2), develop and maintain (Chapter 3) business relationships from an interactive perspective. In part 2, we investigate power's roles in multipartner relationships in relation to value creation and appropriation (Chapter 5) and partner variety (Chapter 6). Study 3 (Chapter 4) sits at the intersection of these two parts because it studies power's complexity in relationships between startups and well-established businesses. Chapters 2 to 6 are based on five individual scientific papers, either published in a peer-reviewed journal, a book or in the proceedings of an international conference, or represents work in progress. I included the papers in their original form, having altered only the layout and numbering. The final chapter answers the overall research question and discusses my dissertation's contributions, limitations and directions for further research. Figure 1.2 represents the seven chapters, the five studies and their relationships. 


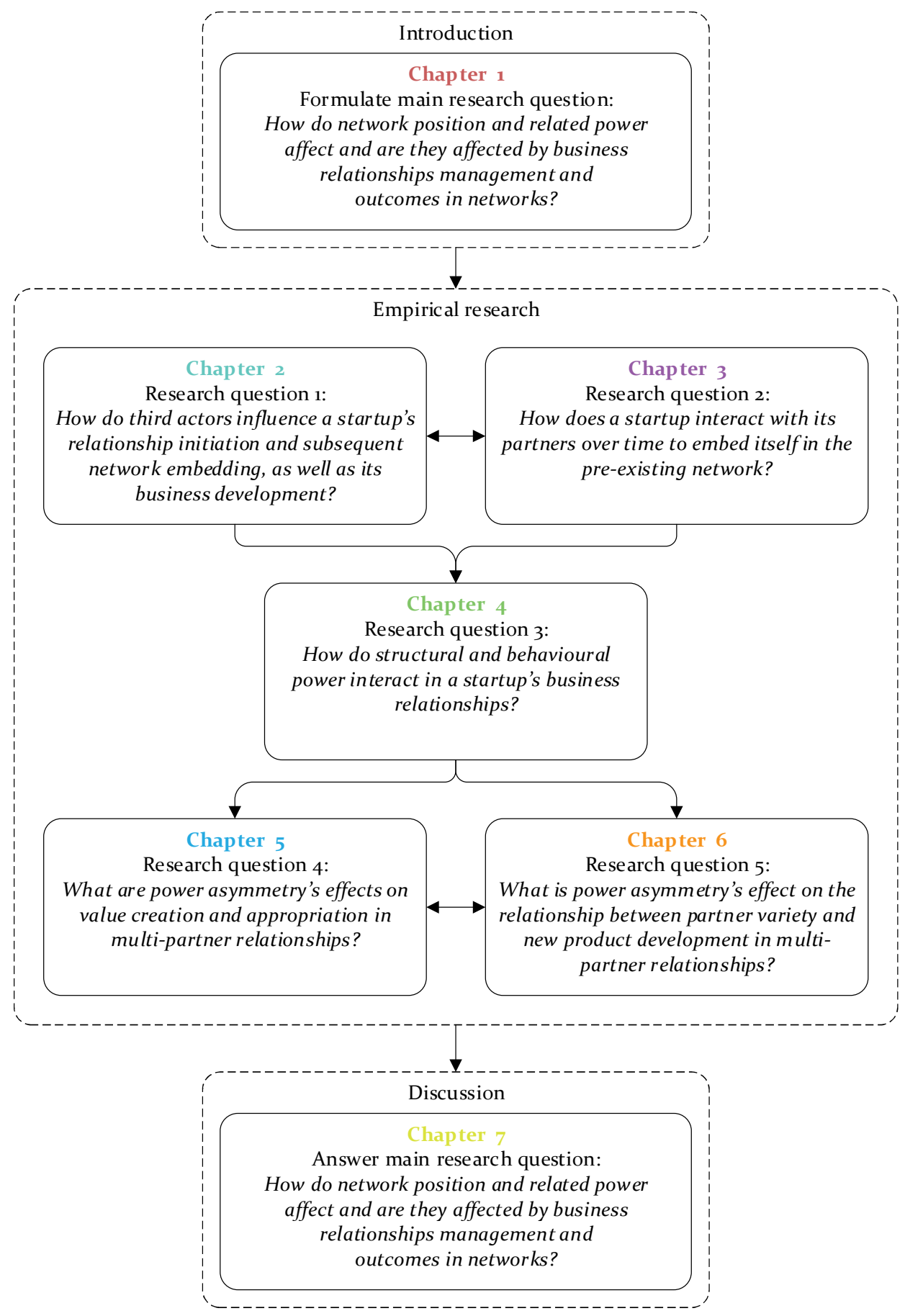

Figure 1.2 Outline of the dissertation 


\section{CHAPTER 2}

Third actors initiating business relationships for a medical device start-up: effect on network embedding and venture creation processes

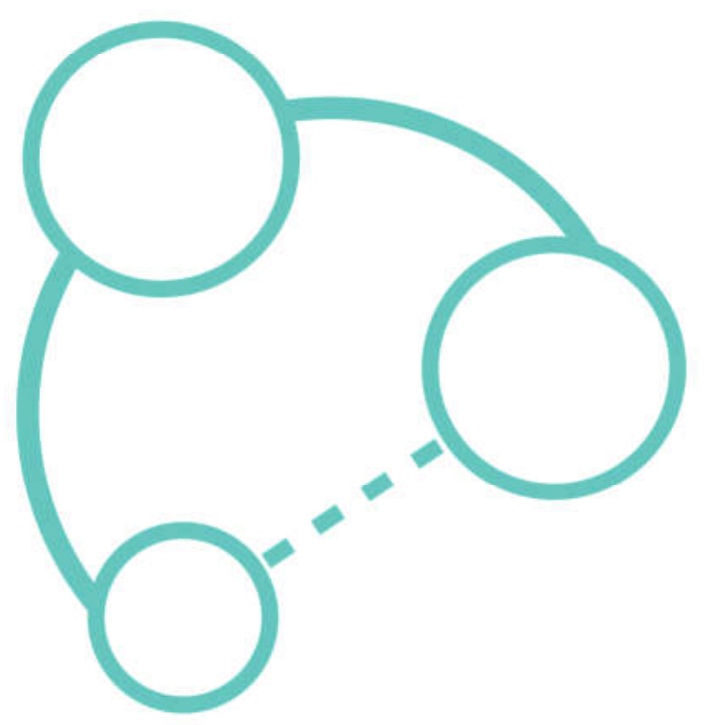

This chapter is published as Oukes, T. \& Raesfeld, A. v. (2017). Third actors initiating business relationships for a medical device start-up: the effect on its network embedding and venture creation process. In: Starting up in business networks: Why Relationships matter in Entrepreneurship. L. Aaboen, Antonella La Rocca, F. Lind, A. Perna and T. Shih (eds.). London: Palgrave Macmillian. 


\subsection{Introduction}

It is widely recognised that it is essential to the survival and growth of start-ups to initiate, develop and maintain business relationships (e.g. Aaboen, Dubois, \& Lind, 2011; La Rocca, Ford, \& Snehota, 2013). Only through establishing business relationships can start-ups embed themselves in the pre-existing developing, producing and using setting (Håkansson, Ford, Gadde, Snehota, \& Waluszewski, 2009). However, start-ups often experience difficulties in initiating the necessary business relationships (Prashantham \& Birkinshaw, 2008). To cope with this challenge, Oukes and Raesfeld (2014) found that a start-up used the mediating function of its partners to initiate new relationships. They showed that after it was made aware of, introduced to or referred to a potential partner by one of its existing partners; the startup could mobilise valuable resources from new partners.

Other researchers (e.g. Aarikka-Stenroos, 2011; Aarikka-Stenroos \& Halinen, 2007; Kirkels \& Duysters, 2010; Yin, Wu, \& Tsai, 2012) have also highlighted the important role of 'third actors' in initiating relationships. Nevertheless, these studies focused on the perspective of the third actor-the one who connects-rather than the actors that are connected. Yet the connection function of a start-up itself is usually limited due to a lack of power, influence, information and control benefits, as well as the constraints on network activities with which it is confronted (Shipilov, Li, \& Greve, 2011; Yin et al., 2012). Nonetheless, the connection function of its partners can support the initiation of a start-up's business relationships in two ways. First, third actors reduce the uncertainty associated with the competencies and resources of a start-up's potential partners by connecting complementary partners in a way that is beneficial to all parties (Howells, 2006). Secondly, a start-up can mitigate the possible detrimental effects of its limited network by relying on its partners to connect some of their existing relationships to the start-up (Holmen \& Pedersen, 2003).

In addition, research has shown that the initiation of business relationships will affect the extent to which the start-up embeds itself in the pre-existing network and develops its business (Lamine, Jack, Fayolle, \& Chabaud, 2015). For example, Mainela, Pernu, and Puhakka (2011) define four 
specific behaviours-internal problem-solving, external solution-creation, opportunity selling, and opportunity organising-as the primary drivers of the development of start-ups and embedding them in networks. Although these studies have given us a valuable understanding of the network embedding process and start-up business development, this type of study usually looks at the initiation of several dyads, that is the relation between two organisations (e.g. Aaboen et al., 2011; La Rocca et al., 2013), or the initiation of a portfolio, that is the relations of a single organisation (e.g. Anderson, Dodd, \& Jack, 2010; Huggins, Izushi, Prokop, \& Thompson, 2015; Mainela et al., 2011). However, relatively little research has investigated the effect of third actors on the network embeddedness and business creation processes.

In summary, only limited research has been undertaken into how third actors influence the process of start-up relationship initiation and how this in turn affects the process by which they embed themselves in the pre-existing network and develop their business. Therefore, our aim is to investigate how third actors influence a start-up's business relationship initiation and subsequent network embedding, as well as its business development. This research aim is addressed in a case study of a start-up. The company involved is developing a medical device for the treatment of persons with diabetes. In the medical device industry, innovation is located within networks in which universities, start-ups, established firms, venture capitalists and professional service firms collaborate. Especially in such a network-based structure, centrally positioned third actors can support the emergence of resource constellations and activity patterns between start-ups and other members of the network (Styhre \& Remneland-Wikhamn, 2015). This chapter starts by sketching a framework of the relevant theory. After that, the method used to address the research aim is briefly discussed. The Results and Discussion sections describe the findings of the case study, analysing the key findings in light of the theory. The chapter ends with our conclusion, discusses the limitations and avenues for future research. 


\subsection{Theory}

\subsubsection{Third actors and a start-up's relationship initiation}

Edvardsson, Holmlund, and Strandvik (2008) showed that the process of relationship initiation consists of three statuses, with increasing likelihood that a business agreement will be achieved: (1) unrecognised, that is the parties do not know each other; (2) recognized, that is there is an awareness of the parties of mutual business opportunities; and (3) considered, that is companies negotiate the objective, scope and terms of the business relationship. The relationship initiation process ends and the relationship begins with the closing of a business agreement. Although the authors developed a conceptualisation of the dynamics in the business relationship initiation process, they did not consider the role and function of third actors in this process. Yet business relationships-especially those of start-upsseldom start from direct approaches, such as cold calls, but often come about with the support of third actors, which introduce two or more matching business partners (Aarikka-Stenroos, 2009).

In particular, third actors are considered to have three functions and four roles in relationship initiation within the IMP tradition. Holmen and Pedersen (2003) discern three mediating functions of three actors: joining, relating and insulating. Joining enables direct coordination on some aspects between the firm of interest and the firm's counterparty. Relating facilitates coordination between the firm and a third party via the counterparty, with both parties having knowledge of each other. Insulating permits coordination between the firm and the third party without the parties having any knowledge of each other. In addition, Aarikka-Stenroos and Halinen (2007) classify twelve roles in four main categories: awareness, access, matching and specifying the deal. Awareness involves identifying potential partners, building awareness among suitable partners and creating a need for a specific partner. Access refers to establishing contact between partners, speeding up the initiation process and delivering marketing information. Matching includes evaluating the fit between partners, offering information about the trustworthiness of a partner and assessing the quality of a partner. Specifying the deal involves providing prospects of the relationship outcome, offering risk-reducing information and making intangible services tangible. 
Both Holmen and Pedersen (2003) and Aarikka-Stenroos and Halinen (2007) emphasise the facilitating role of third actors in fostering relationship initiation. However, outside the IMP tradition, scholars have identified two main types of third actors based on the seminal work of Simmel and Wolff (1950): tertius gaudens and tertius iungens. Tertius gaudens, or 'the third who enjoys', benefits of a position between two disconnected actors by their active separation (Burt, 1992, 2000). Tertius iungens, or 'the third who connects', connects actors in a network by either introducing disconnected actors or facilitating new coordination between connected actors (Obstfeld, 2005). Thus, we argue that third actors may be capable of stimulating advancement and removing blocks that inhibit progress in a start up's relationship initiation. In contrast, they may also be capable of strengthening blocks against moving forward and provoking backwards conversion. However, it remains unsettled how the functions and roles of third actors drive or inhibit relationship initiation from unrecognised, recognised to considered statuses. Therefore, the first research question of this chapter is: How do the roles and functions of third actors drive or inhibit a start-up's relationship initiation?

\subsubsection{Third actors and a start-up's network embedding}

Network embeddedness is "the dependency of a firm on its links with other actors in an industrial network" (Yli-Renko \& Autio, 1998, p. 256). Embeddedness can be divided into three settings (Håkansson et al., 2009), based on the dominant type of activities connecting an organisation to a network (Yli-Renko \& Autio, 1998): the developing, producing and using setting. In the developing setting new ideas are developed; in the producing setting the developed ideas are produced; and in the using setting the ideas produced are used commercially (Håkansson et al., 2009). Start-ups are usually not yet embedded in the pre-existing networks within these settings (Oukes \& Raesfeld, 2016). Yet becoming embedded is crucial to a start-up's survival and growth (Bliemel \& Maine, 2008) because it always builds on the resource constellations, activity patterns and a web of actors in the preexisting network (Snehota, 2011). Moreover, the value of a start-up's resources depends on its connections to the resources of others, and the outcome of its activities is interdependent with its counterparts’ activities (Håkansson et al., 
2009). Although it is widely recognised that becoming embedded in the preexisting network is essential to start-ups (e.g. Bliemel \& Maine, 2008; YliRenko \& Autio, 1998), so far we have no in-depth understanding of how startups establish themselves therein. To shed new light onto how this process unfolds, we aim to explore the role of the third actor.

To embed themselves in the developing, producing and using setting, start-ups have to initiate business relationships (Yli-Renko \& Autio, 1998). Yet the limited resources and scanning abilities of start-ups make it difficult to find competent partners with valuable resources (Kirkels \& Duysters, 2010). Furthermore, a start-up cannot always be directly involved in making new connections among relationships of its partners because of its limited network horizon (Holmen \& Pedersen, 2003). We therefore argue that third actors can stimulate a start-up's network embeddedness by facilitating the initiation of business relationships. The research of Styhre and RemnelandWikhamn (2015) supports this argument. They investigated how a large pharmaceutical company connected small companies with public organisations, venture capital investors, universities and equipment providers to support innovation in life science. In this way, the pharmaceutical company presumably supported the embedding of the smaller companies in the developing, producing and using setting. However, their study adopted the perspective of the large pharmaceutical company, so it remains unclear how third actors stimulate network embedding from the perspective of the start-ups. As a result, the second research question of this chapter is: How do third actors facilitate the embedding of a start-up in the pre-existing developing, producing and using setting?

Business relationships are usually studied as if they were dyadic, even if they are affected by various actors and business in a larger network, (AarikkaStenroos, 2011). However, when a third actor participates in the initiation of a business relationship, a dyadic relationship becomes a triad. A triad exists "when relationships between three directly or indirectly associated actors are connected" (Vedel, Holma, \& Havila, 2016, p. 4). A triad can be open or closed: in an open triad three organisations are indirectly linked to each other through a third actor, while in a closed triad all three actors are linked directly 
(Vedel et al., 2016). It is often assumed that if those connected can communicate directly with each other, the importance of the third actor decreases because it is no longer necessary (Yin et al., 2012). However, Yin et al. (2012) show, inter alia, that if the organisations are dissimilar in size, the role of the third actor remains important. As start-ups often (have to) collaborate with large, established organisations, they may form a triad with the third actor who introduced them, instead of their relationship with it ceasing to exist. Although this may influence a start-up's level of network embeddedness, this has so far remained unexplored. Therefore, the third research question of this chapter is: What is the effect of the type of triadopen versus closed-that is formed with the third actor and its level of importance on the embedding of a start-up in the pre-existing network?

\subsubsection{Third actors and a start-up's venture creation}

A start-up's business development refers to the entrepreneurial process of discovering, creating and exploiting opportunities (Shane \& Venkataraman, 2000). Mainela et al. (2011) combined these phases of business development with research on technological networks and networkbased internationalisation. Based on these bodies of literature, they showed that three venture creation processes can distinguished: (1) the opportunitycentred process is focused on building a start-up's business concept; (2) the technology-centred process involves connecting the initial ideas for new products to innovative technological solutions; and (3) the internationalisation-centred process consists of positioning a start-up in relation to actors in the international, inter-organisational network (Mainela et al., 2011). However, these processes are not independent: a start-up's business and technology develop simultaneously as part of the interaction with the organisations in its business network.

Raesfeld and Roos (2008) linked the three phases of a small firm's business development to the three functions of third actors defined by Holmen and Pedersen (2003). They argued that during opportunity discovery, third actors relate organisations to advance the development of the weak ties necessary for the generation of new business opportunities. During 
the opportunity creation, third actors join organisations to facilitate the formation of strong ties, which are crucial to the sharing of resources and new product creation. During opportunity exploitation, third actors insulate organisations to stimulate the generation of loose ties necessary to deliver products efficiently to customers. However, Holmen and Pedersen (2003) focused on the management of business relationships rather than their initiation. Although third actors may facilitate the management of relationships between connected organisations, they also introduce disconnected organisations (Obstfeld, 2005). In addition, they have only captured part of the venture creation process: the opportunity-centred process. Yet the initiation of relationships by third actors will also influence the other two venture creation processes. As a result, we argue that through initiating business relationships, third actors will affect the venture creation of a start-up. Yet an understanding of how this process unfolds is still unavailable. The fourth research question of this chapter is therefore: How does a third actor affect the venture creation of a start-up through relationship initiation?

\subsection{Methodology}

In order to achieve insights into the role of third actors in the relationship initiation of start-ups, the data collection must include information about at least three actors; the two, three or more relationships which link them; and how these relationship influence each other (Vedel et al., 2016). Therefore, we have used an in-depth case study to analyse the process by which the start-up's key relationships are initiated. The methodology of the case has been reported in detail elsewhere (Oukes \& Raesfeld, 2016). Briefly, a retrospective analysis was done from the foundation of the start-up in 2008 until April 2013. Thereafter, the start-up was followed in real-time until the end of November 2015. The longitudinal data were collected by three methods: interviews, observations and archival data. First, nine individuals from both the start-up and its key partners were interviewed during spring 2012. These interviews were repeated with five of the interviewees one and a half years later. Interviewing the start-up as well as its partners at two different times allowed us to capture the complexities and network characteristics associated with multiplex inter-organisational 
relationships over time. The interviews centred around: (1) how the start-up and its artificial pancreas had developed since its foundation; (2) how its network evolved over time; and (3) how each of its relationships was initiated and coordinated, as well as how resources were exchanged between partners during the relationship. In addition to these aspects, in the second set of interviews questions were asked about how the partners interacted with each other. Despite the semi-structured nature of the interviews, there was sufficient room for the interviewee to give examples and elaborate on important situations. The selection of interviewees was based on: (1) direct interaction with the other partner(s) in the relationship, and (2) direct involvement in the development of the start-up's artificial pancreas. Secondly, the behaviour of the start-up in its relationships was actively and passively observed during the first author's stay at the company from April 2013 until November 2015. Thirdly, archival documents, such as websites, grant proposals, contracts and patents, were collected from the start-up's foundation in 2008 until November 2015. The observations and archival data were primarily used to help the researchers improve their understanding of data collected through the interviews. The data collection involved sensitive, confidential and political issues regarding the start-up and its partners. As a result, the individuals and organisations are given fictional names to maintain confidentiality. The transcribed interviews, field notes and archival documents were analysed in four consecutive steps. First, we described with whom, when, where and why the start-up initiated a relationship. Secondly, we looked at whether a third actor was involved in the relationship's initiation, and if so what the influence of the third actor was on the process. Thirdly, we assessed how the involvement of the third actor in the relationship initiation affected the network embedding of the start-up. Fourthly, we explored how the engagement of the third actor in the relationship initiation affected its venture creation.

\subsection{Findings}

This section describes chronologically how the relationships of the start-up were initiated and the influence of third actors on this process. In addition, we describe how the third actor subsequently affected the network 
embedding and the venture creation processes. Table 2.1 provides the key findings regarding the role and function of the third actors within the relationship initiation process. Table 2.2 presents the main results regarding: 1) the setting in which the start-up can embed itself through the initiation of the relationship with the specific partner, whether or not facilitated by a third actor; 2) three indicators of the level of network embedding: source, type of triad and third actor importance; and 3) the start-up's venture creation process in which the partner is primarily involved, whether or not the relationship was initiated by a third actor. Figures 2.1 to 2.3 show the network development of the start-up over time (2007-2009, 2010-2012, 2013-2015), as well as the influence of third actors on initiating relationships. In addition, the figures show the strength of the ties between the organisations in the start-up's network. Strong ties have a higher level of resource commitment, continue to exist over a longer period of time and have more social content at the inter-personal and inter-organisational level than weak ones.

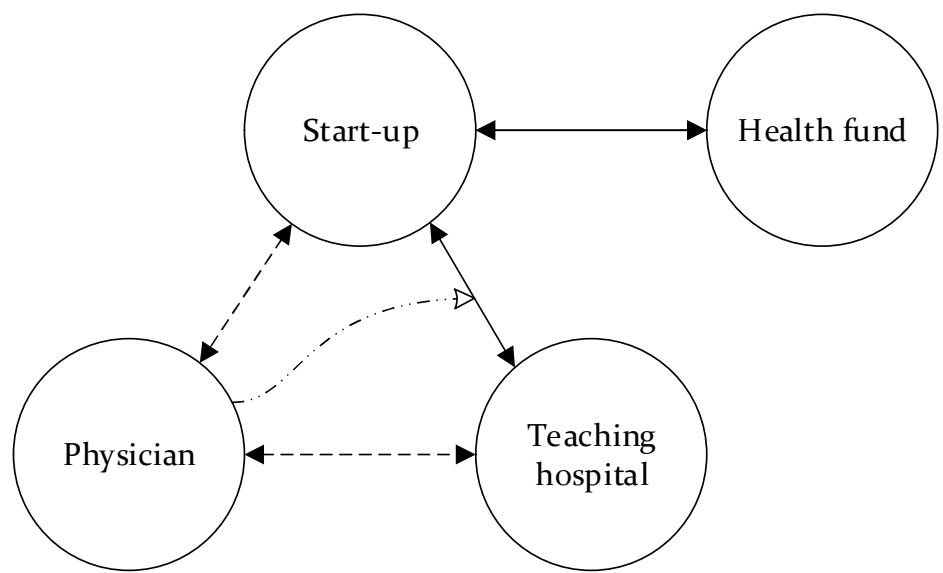

Legenda

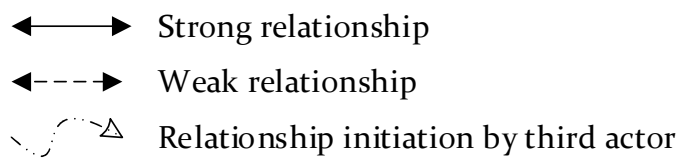

Figure 2.1 Network of start-up between 2007 and 2009 


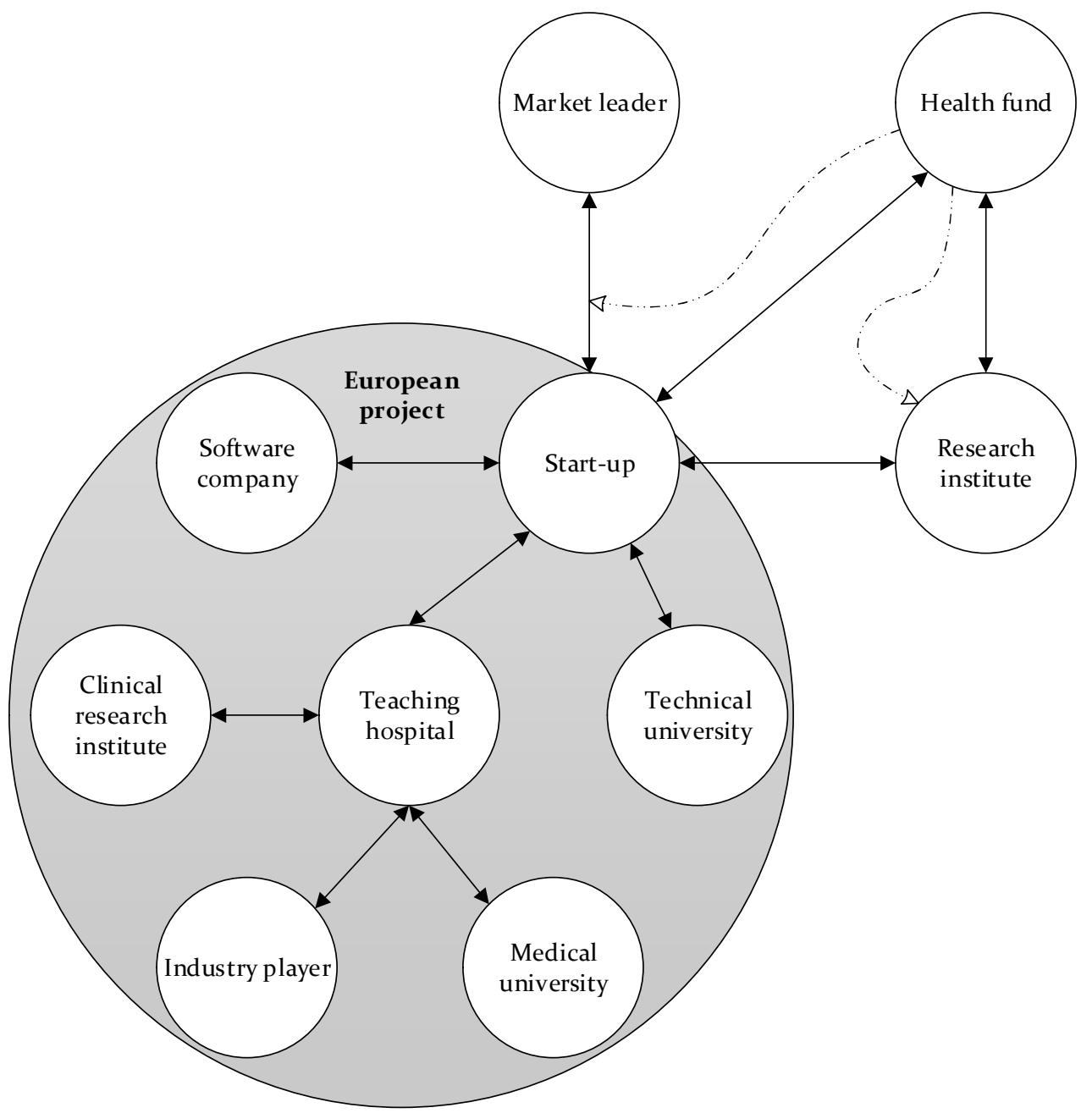

\section{Legenda}

$\longleftrightarrow$ Strong relationship

$\longrightarrow$ Weak relationship

$\checkmark, \triangle \Delta$ Relationship initiation by third actor

Figure 2.2 Network of start-up between 2010 and 2012 


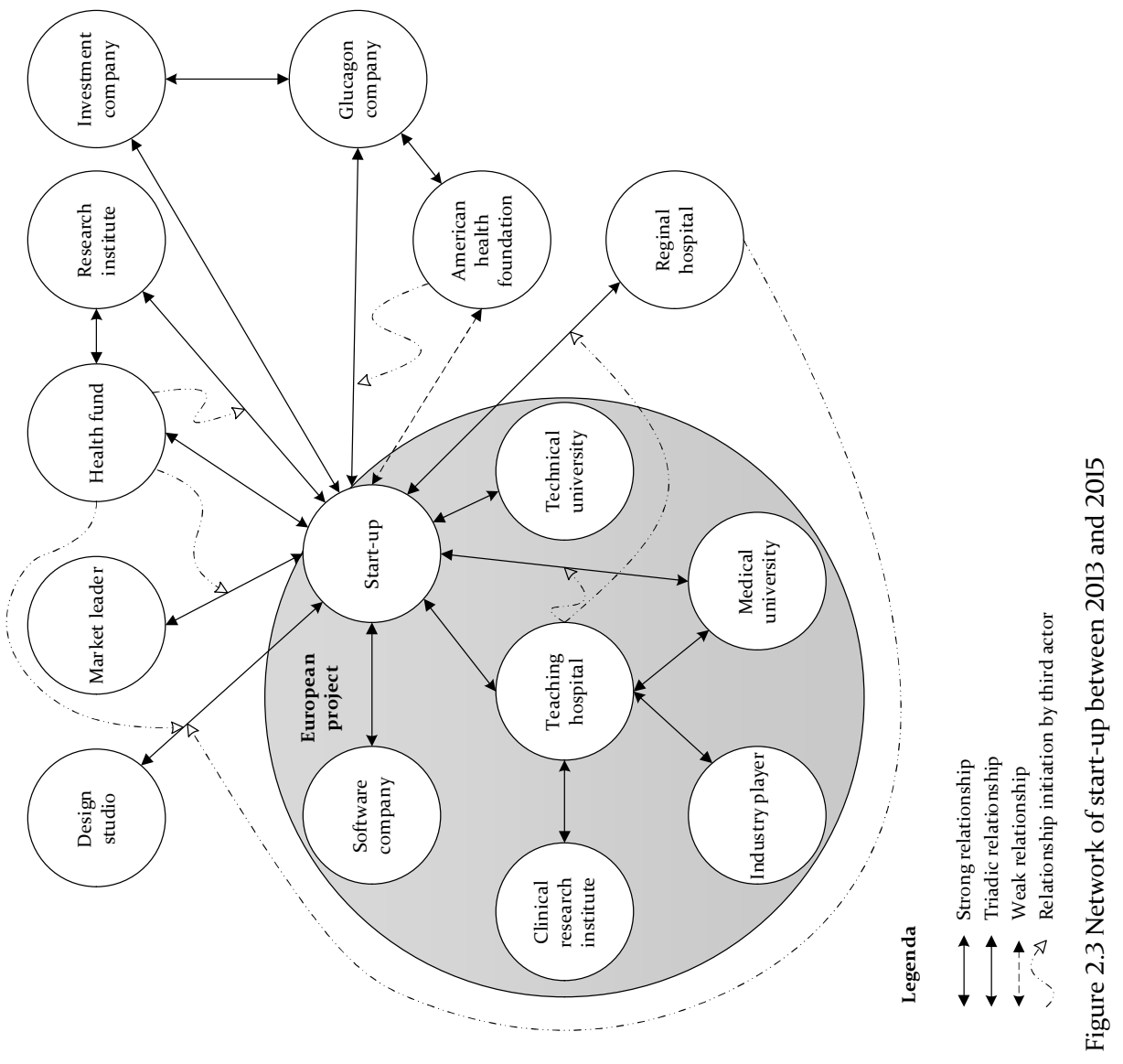




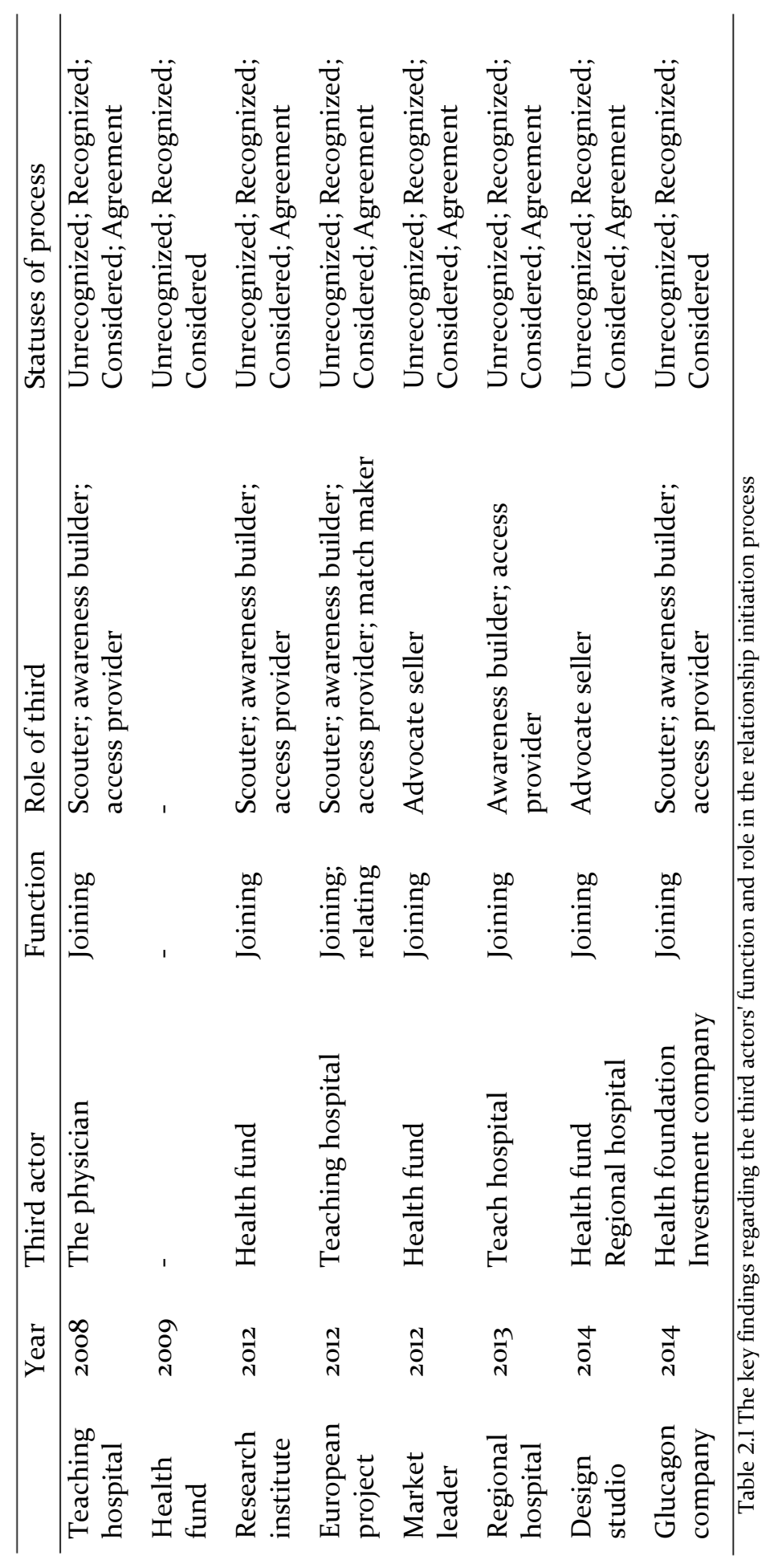




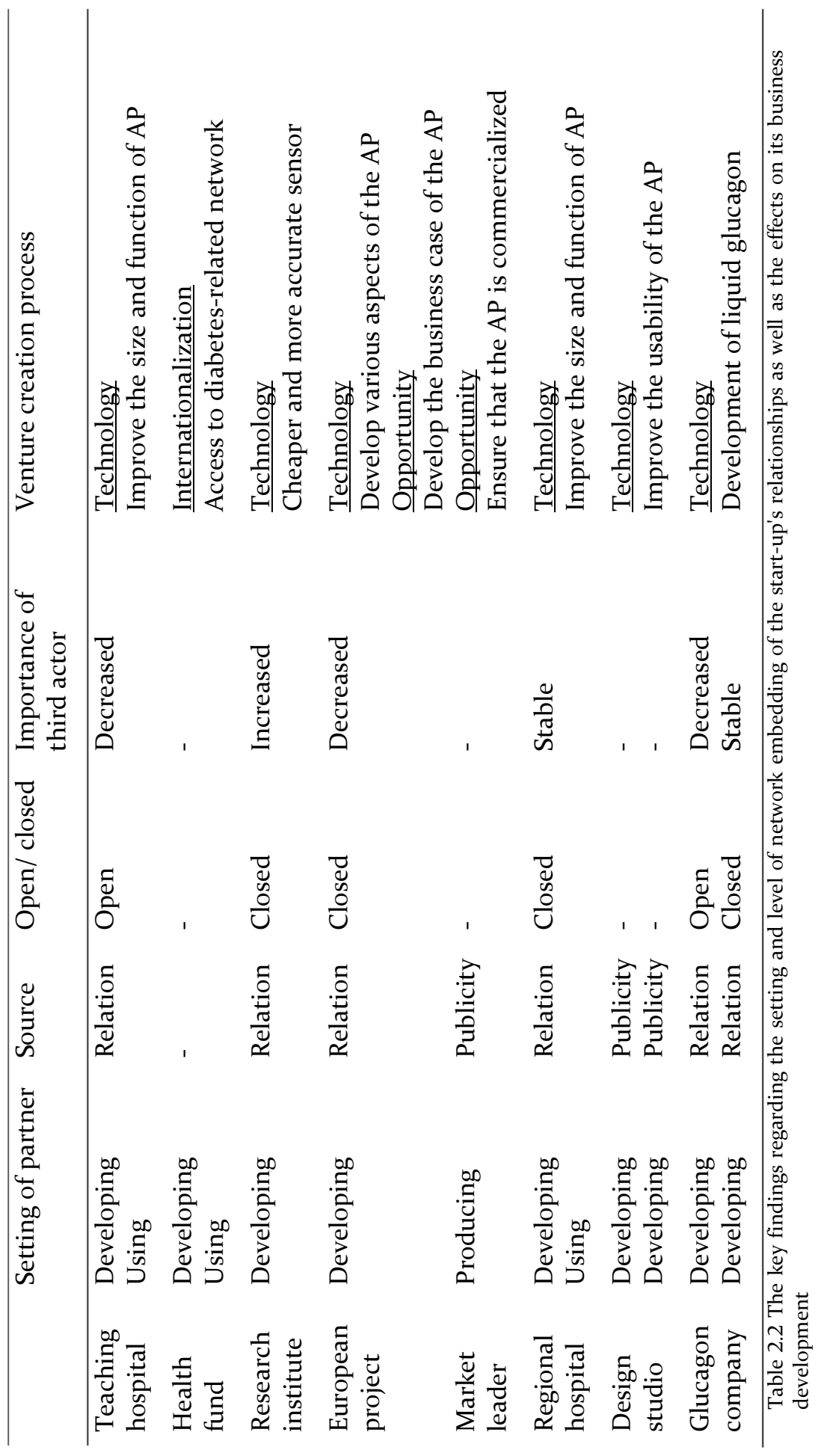




\subsubsection{Brief description of the start-up and its product}

The start-up was established in 2008 by the inventor of the product and an angel investor. The start-up is creating a bi-hormonal artificial pancreas for the treatment of persons with Type 1 Diabetes Mellitus (TIDM). A bihormonal artificial pancreas (artificial pancreas below) connects an insulin/glucagon pump with a continuous glucose monitor by means of an algorithm. The algorithm calculates the correct amount of insulin (decreases blood glucose levels) or glucagon (increases blood glucose levels) to be injected based on the current blood glucose level. In turn, the pump automatically delivers that specific amount of insulin/glucagon to the body. Currently, the treatment of diabetes is a major burden to those who suffer from it. Persons with TIDM must regularly measure their blood glucose level with a finger prick and test strip, calculate their carbohydrate intake, take account of exercise, determine the required amount of insulin and inject themselves. The start-up's artificial pancreas will give them complete freedom of diet and exercise flexibility combined with fewer finger pricks and insulin injections. The expectation is that the device will considerably improve the quality of life of persons with TIDM because their disease becomes less of a burden during the day. Despite the fact that the start-up has been in existence for some time, the artificial system is not yet ready for production, let alone use by persons with TIDM. Consequently, the start-up can still be considered to be in the start-up phase (Oukes \& Raesfeld, 2016). In order to mobilise and leverage the resources necessary to develop the artificial pancreas, such as intellectual property, distribution networks and production facilities, the start-up needed to initiate relationships with other organisations. As we explain in the remainder of this section, the start-up would not have been able to initiate all the necessary relationships without the support of third actors.

\subsubsection{Initiating the relationship with the teaching hospital}

As shown in Table 2.1, the start-up's first relationship was established with the teaching hospital in 2008. It was made aware of the existence of the Diabetology Research Group of this centre by a physician from another hospital. He contacted the start-up after he had read an article about the 
artificial pancreas in a magazine. The start-up anticipated that he would be able run clinical trials. It was necessary to run these trials since the efficiency, effectiveness and safety of the artificial pancreas had to be evaluated. Yet the start-up lacked the required knowledge, financial resources and facilities to run the trials itself. However, the physician was unable to run clinical trials, either, because he lacked the appropriate resources. Nevertheless, the physician referred the start-up to the head of the teaching hospital's Diabetology Research Group. The aim of this group is to conduct medicalscientific research in the field of insulin delivery and continuous glucose monitoring. Therefore, the physician identified the Diabetology Research Group as a suitable partner for the start-up. After he established the first contact between the two potential partners, the start-up was invited to give a presentation to the group's members. During the presentation, the owners of the start-up presented the results of the early tests that were run with a first prototype of the artificial pancreas. According to the head of the teaching hospital's Diabetology Research Group, the results were promising. This convinced him that it would be worth the effort to evaluate the start-up's idea in clinical trials. A series of meetings followed in which the Diabetology Research Group and the start-up negotiated the details of their potential relationship. In the end, they agreed that the teaching hospital would run three clinical trials in exchange for $10 \%$ of the start-up's shares. The outcomes of these trials could be used to create a second, and eventually a third, prototype of their technology: the artificial pancreas. These outcomes would not only be related to technical aspects, such as the performance of the algorithm and the product's reliability, but also involve feedback from users regarding the user-friendliness of the device (see Table 2.2). As presented in Table 2.2, after the agreement between the start-up and the teaching hospital was effected, the physician withdrew from both relationships due to lack of interest in the artificial pancreas as a research topic.

\subsubsection{Initiating the relationship with the health fund}

Shortly after the relationship with the teaching hospital was initiated, the inventor was at a beneficiary meeting of the health fund. The aim of this foundation is to cure diabetes and ensure a healthy life for diabetes patients without the daily concerns about diabetes and its complications by 
facilitating scientific research and providing education. At the meeting, the inventor had a conversation with the health fund's head of research. The two discovered that they had a mutual interest: improving the quality of life of diabetes patients. The mutual interest between the partners marked the start of several meetings to discuss what they might mean for each other. Thus, neither during these negotiations nor during the remainder of the relationship initiation process was a third actor involved (see Table 2.1). As the health fund was known as the largest financer of diabetes-related research, the start-up requested financial support for the development of a second artificial pancreas prototype. However, this request was rejected by the foundation's internal audit committee. According to its policies, every funding proposal had to be approved by this committee to justify the choice for specific projects to their accountants, beneficiaries and the wider public. Therefore, the health fund was not permitted to financially support the development of the start-up's device. In turn, the two partners were unable to reach an agreement about financial support of the artificial pancreas development. However, the health fund also appeared to support diabetesrelated research with its huge network of nurses, physicians, research institutes and pharmaceutical companies. In addition, the foundation promoted new diabetes-related development among its members, such as diabetes patients and their families. As shown in Table 2.2, the health fund could consequently not only support the start-up financially, but also help them to position in the diabetes-related research network. In this way, the health fund could function as a third actor in joining the start-up with valuable partners to advance the development of their artificial pancreas.

\subsubsection{Initiating the relationship with the research institute}

The health fund organised meetings to connect industry and research institutes to advance new product development in the field of diabetes. Before these meetings, the foundation identifies potential partners and during the meeting it establishes contacts between the partners to build awareness among suitable partners (see Table 2.1). In 2012, the health fund organised such a meeting to discuss the latest developments regarding glucose sensors. The start-up was invited to the meeting because the existing glucose sensors 
were not accurate and reliable enough to calculate the correct amount of insulin or glucagon. The meeting was also attended by the research institute-a well-known, independent research institute-since it was developing a glucose sensor based on novel technology. It expected that this sensor would not only be more accurate, but also cheaper than existing ones (see Table 2.2). Yet the research institute needed an industry partner to determine whether there was an actual market application for its sensor and to finance its continued development. The clear complementarities between the start-up and the research institute resulted shortly after the meeting in an agreement to collaborate. They agreed to start a 'co-financing' project. In this type of project the development trajectory is divided into four phases; from scientific research to market authorisation. The start-up had to finance respectively 10, 25, 50 and 100 percent of the sensor development itself, while the remainder was funded by local government. Completing the four phases would result in a patented sensor which the start-up could exclusively licence from the research institute.

As shown in Table 2.2, the importance of the health fund did not decrease when the relationship between the start-up and the research institute was established. In contrast, the health fund became essential in resolving a conflict between the two partners. In the first year, the joint project of the start-up and the research institute made rapid progress. Then the research institute started a multipartner research project with similar objectives. Consequently, the research institute requested the start-up to join and end the co-financing project. This, however, meant that the start-up would have to share the right to licence the patented sensor with several other companies. This was not considered beneficial by the start-up and it consequently turned down the request. This brought the research institute into a difficult position because it required the start-up's patented sensor to make progress in the multipartner research project. As a consequence, the research institute began to obstruct the development of the sensor, so attempting to force the start-up to join the multipartner project. This attempt was unsuccessful and the conflict seemed to end in an impasse. In 2014, the health fund-one of the partners in the multipartner research project of the research institute-proposed a creative solution to resolve these issues. In 
essence, the foundation's proposition involved its providing the necessary financial resources to complete the development of the new sensor. In turn, the start-up would get the exclusive right to licence the patent on this sensor. Thereafter, it would join the multipartner project. This solution appears to have turned out favourably for all three parties.

\subsubsection{Initiating the relationship with the market leader}

Besides the sensor meeting for research institutes and industry, the health fund also organised a contest for innovative research projects. In this way, it aimed to deliver information to the public about the progress of research in the field of diabetes (Table 2.1). In 2012, the start-up participated and won the audience award. Winning this award attracted nationwide attention in the media for the development of its device. In this way, a department of the market leader became aware of the start-up's artificial pancreas. The market leader is a frontrunner in personalised healthcare, a global leader in cancer treatment and the leading provider of in-vitro diagnostics. In the diabetes market the firm is the leader in glucose monitoring. When the business director of the glucose monitoring department heard about the start-up, he invited it to give a presentation. During the presentation the technicians of the market leader discovered that the artificial pancreas was further developed than they had expected. Nevertheless, the development of the artificial pancreas was not yet sufficiently mature to invest in; the risk that it would fail was viewed as too high. However, the market leader wanted to keep abreast of developments at the start-up, to which end they signed a non-disclosure agreement. This agreement enabled the partners to share confidential knowledge and information, but restricts the counterparty from sharing it with third parties. Additionally, they signed a right of first refusal, which gives the market leader the option to enter a business transaction with the start-up before it can enter into such a transaction with a third party.

The agreements between the market leader and the start-up provided the partners the chance to build a trusting relationship and opened up opportunities for future collaboration. As a small, young company the start- 
up had the required flexibility to develop the artificial pancreas, but was expected to lack the resources to produce, market, sell and distribute it. In contrast, the market leader-as a large, established firm-is less well equipped to invent new diabetes devices, but it possesses the production facilities, marketing experience, sales agents and distribution network to commercialise them. Consequently, both partners saw the advantages of long-term collaboration to exploit the device developed by the start-up (see Table 2.2).

\subsubsection{Initiating the European funded project}

In 2012, the start-up not only initiated a relationship with the research institute and the market leader, it also started a European project together with the teaching hospital. When the head of the teaching hospital's Diabetology Research Group came across an interesting call for projects grants under the Seventh Framework Programme for Research and Technological Development (FP7) of the European Commission, he invited the start-up to join the application. The partners could use the grant to build a fourth prototype of the artificial pancreas and evaluate it in additional clinical trials. The teaching hospital introduced the start-up to three organisations with which it had good experience in another ongoing project. As shown in Table 2.1, this project focused on the development of another type of artificial pancreas and they were identified as relevant, suitable and valuable partners. Specifically, the medical university, the established industry player and the clinical research institute joined the project team. Within the European project, the medical university will examine the interactions between insulin \& glucagon administration and continuous glucose monitoring at the same site. In addition, clinical research institute will conduct and coordinate the clinical trials. Furthermore, the established industry player will be responsible for the development of a new glucagon formulation. Also, the start-up's angel investor asked two organisations to join the project: the software firm and the technical university. Within the European project, the software company will be responsible for developing the presentation and reporting software for various stakeholders, such as physicians, researchers and patients. Additionally, the technical university will focus on the business development of the artificial pancreas and support 
the innovation network of the companies involved. Thus, the respective responsibilities of the partners were mainly focused on the technological development of the artificial pancreas. Yet with the inclusion of the technical university, the project partners also aimed to develop the business concept of the start-up to find opportunities to exploit the technology (see Table 2.2). After the project team was formed, the potential partners wrote a project proposal that suited their own interests as well as fulfilled the specifications of the European Commission. The result was a proposal that was granted more than four million Euros in funding. In September 2012, the three-year European project was launched and the partners started working on their respective responsibilities.

In 2015, the European project should have been finalised, but the development of the artificial pancreas progressed more slowly than expected. The partners therefore applied for and were granted a nine-month extension of the project. Nevertheless, the start-up had to find new sources of financing to be able to continue developing its device. To that end, the start-up wrote several new project applications. In almost all of these applications, the medical university was one of the project partners while the teaching hospital was involved only in some of them. As Figures 2.2 and 2.3 show, the teaching hospital first related the start-up and the medical university, while over time it joined the partners: a direct relationship between the partners emerged in which the teaching hospital was only sometimes involved.

\subsubsection{Initiating the relationship with the regional hospital}

At the start of 2013, it appeared that the teaching hospital, responsible for conducting clinical trials within the European project, would have insufficient capacity to do so. Running the additional clinical trials was essential to demonstrate the efficiency, effectiveness and safety of the new technical features of the artificial pancreas the start-up had created, as well as give patients the opportunity to test the usability of the device's interface (see Table 2.2). A former employee of the teaching hospital, who had run the first three clinical trials, heard about this problem. At that time, she worked at the regional hospital, but was still indirectly involved with the start-up project. 
Finally, the teaching hospital's former employee ensured that the regional hospital would provide the capacity to run the clinical trials. As shown in Table 2.2, a close relationship was developed between the regional hospital, which provided the necessary capacity, the teaching hospital, which designed, ran and analysed the clinical trials, and the start-up, which provided technical support. The emergence of this triadic relationship was facilitated by the teaching hospital which, although through a former employee, made the regional hospital and the start-up aware of each other and introduced them to each other. In response to the initiation of this relationship, the regional hospital wrote a press release about the development of the artificial pancreas and its role in this development at the end of 2013. Soon thereafter, the health fund also issued a press release about the start-up's development project. These press releases were picked up by some local newspapers and from there by the national press, magazines, news broadcasts and talk shows. In this way, the regional hospital and health fund spread information about the start-up that was picked up by potential partners (see Table 2.1).

\subsubsection{Initiating the relationship with the design studio}

It was during the intense media attention to the start-up's artificial pancreas in 2013 that the design studio learned about the start-up. The design studio is an institute for art, science and technology in the fields of digital media, biotechnology and cognitive sciences. Recently, the design studio had developed an application that showed the blood glucose level of diabetes patients using colours (indicating a good, neutral or bad blood glucose level) instead of the hard numbers. In this way, blood glucose level measurement was perceived to be more user-friendly. Although designers developed a good-looking design, it was not used in an actual product. So, when one of the employees saw the artificial pancreas on television, she thought that the studio's design could be applied to this device and contacted the start-up. The start-up was previously more focused on getting the artificial pancreas to work properly. However, it was also starting to consider the design of its artificial pancreas market model at that time. As the start-up lacked the required design expertise, it was interested in collaboration. Therefore, the partners started a one-year project to implement the design studio's design in the start-up's artificial pancreas (see Table 2.2). 


\subsubsection{Initiating the relationship with the glucagon company}

In 2014, the established industry player decided to leave the European project because it had shut down its research project to develop stable, soluble glucagon. As a result of the need for stable, soluble glucagon for the bi-hormonal artificial pancreas' commercial success, the start-up had urgently to search for a new partner. The American health foundation is a global organisation that aims to find a cure for diabetes type 1 and its complications. As shown in Table 2.1, the foundation identified the glucagon company as a suitable partner and established the first contact between the potential partners. The glucagon company is a small, American start-up founded in 2005 that is dedicated to the development of stable, soluble glucagon for the treatment of low blood sugar levels. The company was an interesting partner for the start-up as its glucagon was expected to be the first available on the market. The potential partners met a few times and held several transatlantic phone calls. In the end, they agreed it would use the glucagon of the glucagon company in the following clinical trials. In this way, the start-up did not have to use the unstable, powder glucagon currently available, while the glucagon company could test the performance of its glucagon solution in a clinical setting (see Table 2.2). However, a problem occurred: neither the glucagon company nor the start-up had the resources to finance the production of a batch of glucagon for use in the clinical trial. Previously, the start-up had had contact with an American investment company which invests in innovative research in the United States looking for a cure for Type 1 diabetes. Eventually, it appeared that the investment company did not want to invest in the development of the artificial pancreas because it was a European initiative. Yet the start-up supposed that it might be willing to support the glucagon provider, an American start-up. Indeed, the investment company was prepared to invest in the batch of glucagon. In this way, a close relationship emerged between the glucagon company, the investment company and the start-up. In this collaboration, the glucagon company was responsible for supplying the glucagon; the start-up delivered the artificial pancreas; and the investment company provided the necessary financial resources (see Table 2.2). 


\subsection{Discussion}

In this section, we address the research questions raised in the theory section. Figure 2.4 displays the relations between these four questions and the accompanying findings in Table 2.1 and 2.2.

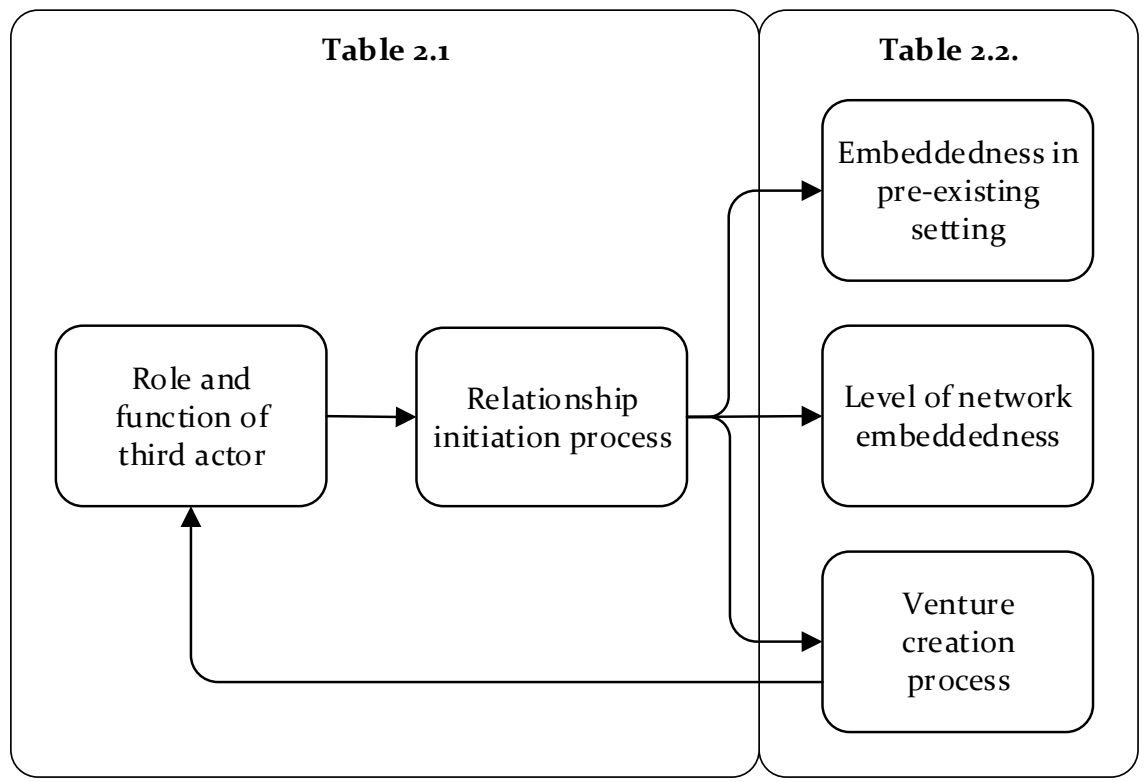

Figure 2.4 Overview of key findings

\subsubsection{How do the roles and functions of third actors drive or inhibit a start-up's} relationship initiation?

The case study shows that third actors were involved in the initiation of seven out of eight of the start-up's business relationships. These third actors drove the initiation of its relationships from the unrecognized to the recognized and the considered statuses. For example, the health fund brought the start-up and the research institute together at a research meeting so that they would recognize their complementarities and consider collaboration. This implies that, as suggested in the literature (Holmen \& Pedersen, 2003; Kirkels \& Duysters, 2010), the start-up experienced difficulties in recognizing partners with the necessary characteristics due to its limited network horizon. In fact, it was almost exclusively dependent on the third actors to develop its portfolio of relationships. However, the third actors did not play an active role 
in the consideration status. For example, the health fund was not involved in the negotiations between the start-up and the research institute.

This lack of involvement of the third actors in the consideration status can be explained by their role in the initiation process. Table 2.1 shows that the role of the third actors in the relationship initiation process was generally either a combination of scout, awareness builder and access provider or advocate seller. The case provided no examples of third actors that specified the deal: three roles which are usually performed in the consideration status (Aarikka-Stenroos \& Halinen, 2007). This may be because Aarikka-Stenroos and Halinen (2007) investigated buyer-supplier relationships while the startup had not yet established any relationships with suppliers or customers. The third actors in the start-up's portfolio were not 'traditional' intermediaries present in 'classical' value chains (Rose, 2012). Moreover, they were not 'traditional' organisations that provide support to young, small firms, such as incubators or venture capitalists. Therefore, the teaching hospital and health fund had neither the expertise nor the motivation to provide concrete evidence, build expectations, reduce risk and function as an evaluation assistant for the start-up and its partners. Thus, the third actors were not involved in the consideration status because they were not skilled and motivated to do so.

In addition, the third actors mainly joined potential partners, as shown in Table 2.1. The other two functions of Holmen and Pedersen (2003) were either not (insulating) or less (relating) evident. This is in line with the findings of Raesfeld and Roos (2008), who argued that in the opportunity discovering, creating and exploiting phases, the third actor would relate, join and insulate, respectively. The start-up was clearly focused on creating the artificial pancreas: it had passed beyond discovering the need for it, while it paid only limited attention to its commercialisation. As this phase requires the start-up to develop strong ties with other organisations to develop its device, it could be expected that 'joining' third actors would facilitate such close collaboration. Indeed, Figures 2.1 to 2.3 show that the majority of the 
relationships being formed, except for the relationship with the physician and the American health foundation, are strong ties.

From the discussions of these functions and roles of the third actors involved in the start-up's relationship initiation, it becomes clear that they acted with a tertius iungens orientation. The third actors acted less as an intermediary that controls inter-organisational relationships and more as a facilitator that fosters them (Styhre \& Remneland-Wikhamn, 2015). This in line with the findings of Obstfeld (2005) who showed that while the tertius gaudens is important for generating new, good ideas, the tertius iungens is crucial in developing these ideas because it requires more explicitly coordinative action. Although it is crucial for the start-up's invention that its third actors act with a tertius iungens orientation, this does not mean they actually have the motivation to do so. For example, the teaching hospital explained that they also participated in a project in which they deliberately linked up two competitors in order to identify the best potential technology.

\subsubsection{How do third actors facilitate the embedding of a start-up in the pre- existing developing, producing and using setting?}

Third actors facilitated the embedding of the start-up in the preexisting developing, producing and using setting through the initiation of its relationships. Indeed Yli-Renko and Autio (1998) showed that in becoming embedded in a setting, the crucial step seems to be establishing initial, intense relationships with other organisations in the network. As shown in Table 2.1, there were two principal third actors - the health fund and the teaching hospital-that facilitated the embedding of the start-up. In total, the health fund connected the start-up three times to potential partners, while the teaching hospital introduced it to four new partners. Figures 2.1 to 2.3 reveal that tie strength affects the number of relationships that were initiated by a third partner. Whereas the teaching hospital and health fund both had a strong relationship, the physician and American health foundation had a weak tie with the start-up. This implies that start-ups can continue to benefit from the third actor role as a partner when they have a strong relationship. 
Furthermore, Table 2.2 shows that both the health fund and teaching hospital were both well-embedded in one or more of the pre-existing settings. This is in line with the findings of Ahuja, Polidoro, and Mitchell (2009), who found that poorly embedded firms are more likely to form relationships with well-embedded firms because, among others, of their access to other potential partners. However, being well-embedded in one or multiple pre-existing settings was a necessary, but insufficient condition for the third actors to connect the start-up to other potential partners: they should also be motivated to do so (Aarikka-Stenroos, 2009). For example, the health fund was motivated to introduce the start-up to other partners since it was unable to provide direct financial support for the development of the artificial pancreas. Yet it believed in the device as a potential solution to diminish the burden of diabetes. This implies that a start-up can benefit from the third actor's functions and roles of well-embedded organisations as long as they are motivated to connect it to partners in its own developing, producing and using setting.

\subsubsection{What is the effect of the type of triad that is formed with the third actor and its level of importance on the embedding a start-up in the pre-existing network?}

When addressing this question, the first thing to notice is that a triad was not necessarily formed when a third actor connected the start-up to a new partner. The case shows that the third actor could take either an active position in the relationship initiation process or a passive one. In the former instance, a triad is (temporarily) formed between the start-up, third actor and a potential partner; that is, the third actor is directly involved in initiating the relationship. For example, the American health foundation connected the start-up and the glucagon company by contacting both organisations. In the latter instance, a triad is not formed between the three actors; that is, the third actor is only facilitating the initiation of new relationships through the generation of media attention for the start-up. For example, the regional hospital and the health fund attracted a lot of media attention to the start-up in 2013. In reaction to this, the start-up was able to initiate a relationship with the design studio. However, neither the regional hospital nor the health fund 
were in direct contact with this new partner. This is in contrast with the arguments of Aarikka-Stenroos (2011), who suggest that when a third actor participates in the initiation of a business relationship, a dyadic relationship becomes a triad. It is more in line with Vedel et al. (2016, p. 3), who argue that "it is not enough that a third actor exists for triad to form. The third actor must be associated to the other two for a triad to form. "Although a third actor is not directly connected to both organisations in the second position, it still facilitates the relationship's initiation: without the media attention that the third actor generated, some of the start-up's relationships would not have been established. Therefore, the 'third actor' can still be considered a third actor, even though no triadic relationship is being formed.

A start-up is embedded in a pre-existing network when it is dependent on the resources of other organisations in that network (Wedin, 2001). These resources are bound together by activities, which form the links between the start-up and the other organisations in the network (Yli-Renko \& Autio, 1998). The case shows that the level of mutual dependency between the partners is the lowest in dyadic relationships (with a passive position of the third actor), moderate in open triads, and highest in closed triads. For example the start-up is greatly dependent on both organisations to successfully develop a new sensor in the closed triad with the research institute and the health fund. Therefore, the degree of network embedding is higher in a closed triadic relationship than in an open triadic and dyadic relationship, respectively. Thus, the third actor can increase the level of a start-up's embeddedness by forming a triadic relationship after initiating the relationship.

Additionally, the case shows that within a triad the importance of the third actor can either increase, decrease, or remain stable. The importance of the third actor is closely related to the dependencies between the partners: when the importance of the third actors increases the dependencies also increase, and vice versa. For example, a triadic relationship was formed between the start-up, the teaching hospital and the medical university. Over time, the start-up and the medical university wrote a joint grant application without the involvement of the teaching hospital. The partners became less 
dependent on the teaching hospital because it was not necessary to run clinical trials in these applications. In addition, the case shows that the strength of a tie plays a role in the importance of the third actor: in two out of three instances in which the importance of the third actor decreases, the start-up had a weak tie with the third actor. The importance of the physician and the American health foundation decreased once the initial contact with the potential partners had been made. Both these actors had a weak relationship with the start-up. Embedding is associated with the level of dependency (Wedin, 2001) as well as tie strength (Moran, 2005). Therefore, the more important a third actor becomes during the relationship with another partner, the higher the level of embeddedness.

\subsubsection{How does a third actor affect the venture creation of a start-up through relationship initiation?}

As shown in Table 2.2, the third actors involved in the relationship initiation of the start-up stimulated its venture creation. If third actors had not established the relationships with the respective partners, the start-up would have been unable to develop its technology, nor its business and network. For example, the relationships with the research institute for the sensor and the glucagon company were initiated by the third actors to ensure that the artificial pancreas could function properly. Thus, this case shows that third actors can play an important role in a start-up's business development through the initiation of relationships. However, the third actor is also influenced by the business development phase of the start-up (see Figure 2.4). As explained in Section 2.5.1, depending on the phase of development, a third actor usually performs a different function. The case reveals that the focus of the start-up's relationships is on the technological development of the artificial pancreas, that is the development of new technological innovations as described by Mainela et al. (2011). In contrast, the development of the business concept and the organisation of the market through its relationships have received far less attention. Only upon initiating of the relationship with the market leader did the start-up take the first steps in bringing the artificial pancreas to market (Oukes \& Raesfeld, 2016). As soon as the focus of the startup's focus comes increasingly to lie on the commercialisation of its artificial 
pancreas, it can expected that the role, function and type of the third actor will change (Raesfeld \& Roos, 2008). For example, the market leader may start to insulate the start-up and the distributors or sale agencies in its network. In this way, it can facilitate the development of the weak ties necessary to deliver products efficiently to customers (Raesfeld \& Roos, 2008).

\subsection{Conclusion}

The first conclusion that can be drawn from this case is that the startup relied heavily on well-embedded partners with which it had a strong relationship and which functioned as a tertius iungens. This type of third actor joined the start-up with potential partners with the resources and activities necessary to advance the its product development. However, the relationships with well-embedded partners do not have to result in new ones because they do not always have the necessary skills or the motivation to perform the roles and functions of a third actor. This implies that start-ups should aim to closely connect not only with well-embedded partners, but partners with the necessary abilities and interests. However, how start-ups may select capable partners and motivate them to become involved in the relationship initiation process has so far remained under-explored. Therefore, two questions for future research are: 1) how can start-ups select wellembedded partners that have the skills to act as a third actor throughout the relationship initiation process? and 2) how can they motivate these partners to perform their role as third actors for a start-up?

Secondly, the case shows that a third actor does not necessarily have to form a triad with the start-up and a potential partner to facilitate the initiation of the relationship. This has important implications for future studies aiming to investigate the role of third actors in the relationship initiation process. To gain a complete understanding of the third actor's role in this process, both the active and passive positions of third actors should be investigated. If research only looks at third actors with a direct relationship to both sides of the new relationship, it may miss important facilitators of the relationship initiation process. Although it is not necessary for an interorganisational triad to form, the embeddedness of the start-up in the pre- 
existing network is higher when a triad is formed, especially when the importance of the third actor increases during the remainder of the relationship. Thus, a start-up can increase its embedding in the developing, producing and using setting by forming a triad with the potential partner and the third actor. The case shows that third actors are willing to form a triad when there is a close dependency between the three actors and a strong tie with the start-up and the third actor. Therefore, a start-up may stimulate the formation of a triad by: 1) attempting to increase the dependency between the three potential partners; and 2) trying to develop an intense, durable and frequent relationship with the third actor.

Thirdly, the case shows that the venture creation process is both affected by and affects the third actor's initiation of relationships. Third actors clearly facilitated the start-up's business development. However, they also performed a joining function just because the start-up was in the opportunity creation phase. This may imply that different third actors may become involved according to the stage of the start-up's development. Accordingly, a start-up does have to select and motivate different types of partners depending on the stage of its venture creation. Therefore, it may be interesting to investigate the two questions raised above for each stage of a start-up's life cycle. This was not possible within the research reported here, because only the opportunity creation phase of the start-up was covered.

In summary, the case presented in this Chapter shows that most of the start-up's relationships are initiated by a third actor. This makes third actors not only crucial to its network embedding in the developing, using and producing setting, but also essential to its venture creation. 



\section{CHAPTER 3}

A start-up in interaction with its partners

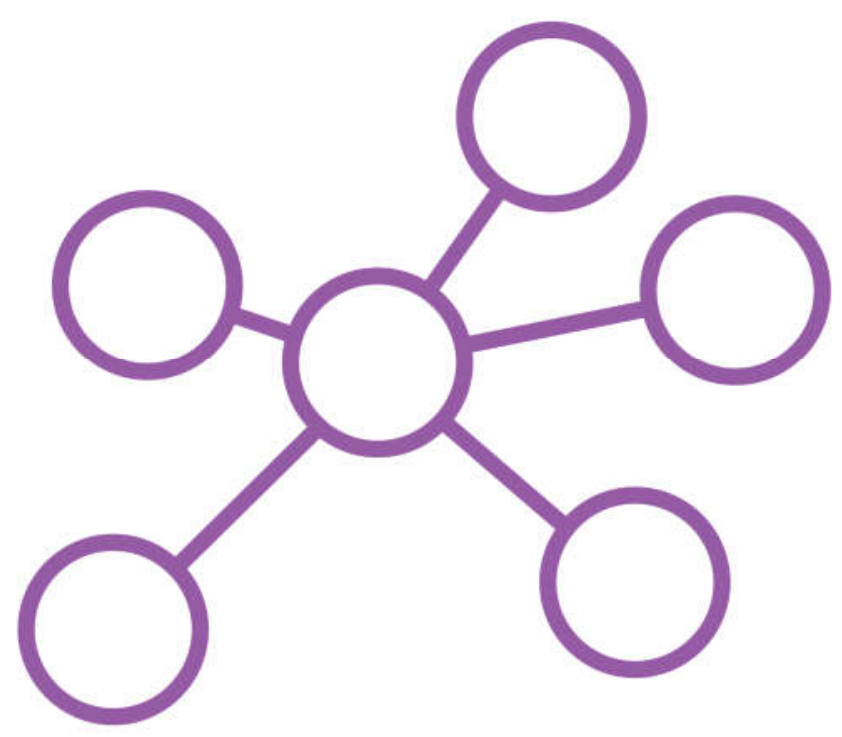

This chapter is published as Oukes, T. \& Raesfeld, A. v. (2016). A start-up in interaction with its partners. The IMP Journal, 10(1), 50-80. A preliminary version of this paper was presented at the HTSF conference in Groningen, The Netherlands, June 2015 and the $31^{\text {th }}$ annual IMP conference in Kolding, Denmark, September 2015. 


\section{Abstract}

Purpose. Start-ups are companies that are not yet embedded in a pre-existing network of relationships. Studies that researched how start-ups act in their relationships focused on just one type of action and assumes that start-ups are autonomous in how they choose to act. However, organisational action in relationships is both interactive and dynamic. Therefore, the researchers aim to investigate how a start-up does interact with its partners over time. Design/methodology/approach. The research aim is addressed through a longitudinal case study of a start-up in the medical device business. It was analysed how this start-up and its six key partners acted and reacted during 18 interactions episodes, what triggered these actions and what the outcomes of their actions were. In addition, the researchers explored if and how the subsequent episodes were related. Findings. Firstly, the case shows that the past and the future affect current episodes. Secondly, it shows that action was triggered by both internal and external events which could expand or constrain opportunities for future interactions. Thirdly, the findings show that there was a pattern in the interaction modes used during the relationship. Fourthly, the findings show that the initial mode of interaction was often imitated by the counterparty. Finally, it is shown that there are clear links between the trigger, interaction process and outcome in an interaction episode. Research implications. The results indicate that besides the focal firm, partners should always be actively and directly involved in any research into organisational action. Moreover, action in relationships should be characterized as a dynamic process that is in a state of continual change. Practical implications. Managers of start-ups: (a) can influence the outcomes of their relationships through their actions; (b) have to react to both opportunities and conflicts in their relationships; (c) can rely on their network to solve conflicts; and (d) should closely consider their own actions and their counterparty's actions.

\subsection{Introduction}

Start-ups do not emerge in a vacuum. They build on the pre-existing resource constellations, activity patterns and a web of actors in the network (Snehota, 2011). To survive in this network, start-ups have to embed 
themselves in the established developing, producing and using setting (Håkansson, Ford, Gadde, Snehota, \& Waluszewski, 2009). It is not sufficient for a start-up to just develop new ideas. These ideas have to be embedded in the producing and using setting to create any desirable economic effect (Håkansson \& Waluszewski, 2007). Consequently, a start-up is defined as $a$ company that is not yet established in the pre-existing developing, producing and using setting. In these settings, the value of a start-up's resources depends on their connections to the resources of others, and the outcome of its activities is interdependent with its counterparties' activities. Therefore, start-ups are dependent on the skills, resources, actions and intentions of other organisations (Håkansson et al., 2009). This interdependence implies that organisations are interactive instead of being independently developed and implemented (Håkansson \& Ford, 2002). The Industrial Marketing and Purchasing (IMP) approach defines interaction as "a constant process of action and reaction involving activities, actors and resources" (Håkansson et al., 2009, p. 197). Interaction may be unplanned and unintentional, but it is also the process through which actors try to achieve their aims. The deliberate actions of a start-up influence the extent to which its partners perceive the outcomes of the relationship as either positive or negative. Subsequently, this affects its partners' willingness to take action to either support or counteract a start-up's action and the potential outcomes (Das \& Teng, 2002; Ring \& Van de Ven, 1994). Therefore, start-ups need to know how to act so as to embed themselves in the pre-existing network and to benefit from the resources, initiatives and activities of others (Håkansson \& Ford, 2002; Lui \& Ngo, 2005).

Yet start-ups face unique challenges in interaction. Their lack of experience, reputation and resources makes it more difficult to know how to act in a relationship (Ariño, Ragozzino, \& Reuer, 2008). Nevertheless, startups contribute their own resources and activities to a relationship, just like any other organisation. Moreover, they are able to control, change and adapt these resources and activities. As a result, start-ups have room for taking action and making changes to reach their aims in interaction (Håkansson, Olsen, \& Bakken, 2013). They need "to act, to try to control, co-ordinate and 
influence, to suggest ideas and initiative, to set limits and to seek opportunities" (Harrison, Holmen, \& Pedersen, 2010, p. 948). Consequently, there is an increasing interest in how start-ups interact with the organisations in their network. Within the IMP approach scholars have researched how start-ups initiate new relationships with customers (La Rocca, Ford, \& Snehota, 2013). Moreover, it was investigated how a small company should interact in its business network (Raesfeld \& Roos, 2008). Furthermore, the patterns of startups' network development have been studied (Aaboen, Dubois, \& Lind, 2011, 2013). However, the greater part of the IMP research deals with firms that are well established in their networks and enjoy long-term, close relationships. In comparison, there are only a few studies on the initiation of relationships, especially by start-ups.

Outside the IMP approach, there is increasing interest in the specific actions that start-ups take in their relationships. For example, Thorgren, Wincent, and Boter (2012) demonstrated that small firms are more likely to comply with group norms than large firms. Also, Ariño et al. (2008) found that entrepreneurial firms are more likely to avoid the problem of governance misalignment than established companies. These previous studies addressed a single type of action in each paper, i.e. compliance and avoidance. Yet neither took other possible types of actions, such as defiance or manipulation, into account. This focus on just one type of action limits our understanding of how a start-up uses different types of actions over time (Tjemkes \& Furrer, 2010). Organisations take a variety of actions over time to achieve their goals. At one point in time, a start-up may support the actions of their partners to retain their goodwill. At another point in time, it needs to confront some aspects of the relationship to improve efficiency in activities and create a development path for resources (Håkansson et al., 2009). Therefore, the actions of start-ups should be analysed by studying the way in which an action occurs in relation to other actions preceding and following it (Lui \& Ngo, 2005). Secondly, a one-sided focus on organisational action restricts our insight into how the actions of start-ups interact with their partners' actions and in turn affect the counterparties involved, the relationship and the network. In a relationship, organisational action always takes place during interaction with the counterparty. Consequently, the freedom of an 
organisation to take action is limited and the outcomes of an action are not unequivocally related to the action of a single organisation (Håkansson et al., 2009). Therefore, the action of start-ups should be characterised by the unique set of interaction patterns created by the actions and reactions that go back and forth between them and their partners (Lui \& Ngo, 2005).

In conclusion, the quest for explaining start-ups' actions has been to focus on how start-ups interact with their partners, and to propose processfocused explanations in their attempt to embed themselves in a pre-existing network (Snehota, 2011). Therefore, the aim of this paper is to study how a start-up interacts with its partners over time in order to embed itself in the established developing, producing and using setting. For this purpose, a case study was conducted on a Dutch start-up. This start-up collaborates with several organisations to develop a new medical device for the treatment of diabetes. Longitudinal data was collected from both the start-up and its partners to capture the interactive and dynamic nature of organisational action. The paper establishes a theoretical framework based on relevant, current literature. In the Methodology section, a brief description is given of the research design. This is followed by a detailed description of the evolution of the start-up's key relationships. Drawing from the case description, the start-up's and its partners' actions over time are identified, analysed and compared. In the Discussion, the findings of this research are compared to the theoretical framework developed in the next section. The paper ends with a short conclusion, and the theoretical and practical implications of this paper.

\subsection{Theoretical framework}

\subsubsection{A series of sequential episodes represent the interaction process}

Interaction in business relationships is a process that is always in a state of ongoing change. All parties will continually make adjustments to the specific relationship as a result of their extensive interaction at the actor, resource and activity levels (Håkansson et al., 2009; Snehota, 2011). Consequently, relationships are intrinsically dynamic (Snehota, 2011). 
Dynamics can be considered as a series of sequential 'episodes' within a continuous interaction process. Episodes are related to each other because interaction is affected by what has taken place previously, and by the perceptions and expectations of future interaction (Ford, Gadde, Håkansson, Snehota, \& Waluszewski, 2008; Håkansson et al., 2009). A single episode can be interpreted as a specific point of interaction in time in which two or more organisations are dealing with particular matters. Each episode follows its own logic for the start-up: it involves specific partners, it deals with certain aspects of the relationship and takes place in a particular context. Most interaction episodes will be perceived as a repetitive sequence of 'normal' interactions as long as the counterparties comply with their formal and informal agreements (Håkansson et al., 2009; Lui \& Ngo, 2005). For a startup and its partners, these interactions are part of everyday life: a normal flow of orders, payments and deliveries. In such a situation, their approach to interaction is often the unconscious result of inertia and simply continues the status quo. As a result, the process of interaction occurs routinely without deliberate effort or planning by any of the organisations involved (Ford et al., 2008; Håkansson et al., 2009).

\subsubsection{External and internal triggers that change the opportunities for future interactions}

Many events occur as a start-up and its partners interact, but these are not all perceived as important. However, events that change the nature of the possible future interaction from either of the counterparties' perspectives may disrupt the otherwise repetitive sequence of 'normal' interactions (Ford et al., 2008; Lui \& Ngo, 2005). Such events may arise from either inside or outside the interaction context (Ariño \& de la Torre, 1998; Medlin, 2004). Internally, a start-up and its partners continuously monitor the specific relationship to judge its value (Ariño \& de la Torre, 1998; Lui \& Ngo, 2005; Ring \& Van de Ven, 1994). These assessments involve considerations of potential, costs, portfolio and network position, time and the view of the relationship held by a counterparty (Ford \& Mouzas, 2008). A similar re-evaluation process takes place when external changes in environmental conditions or the strategic context alter the relationship's expected value to a counterparty. When internal assessments and external events influence the expected value of the 
relationship to a start-up and its partners (Ariño \& de la Torre, 1998), it will have an impact on their judgement of the activity links, resource ties and actor bonds. A trigger can be considered as an element of newness - internally or externally - in interaction that constrains or expands the opportunities for future interaction. Organisations have to continuously adapt to - often unexpected - internal and external elements of newness in their relationships (Ford et al., 2008). Such adaptations involve the two partners taking specific action towards each other (Lui \& Ngo, 2005; Parkhe, 1998). These actions help to restore a new repetitive sequence of 'normal' interactions (Ariño et al., 2008; Ford \& Mouzas, 2008; Medlin, 2004). In this situation, action is often in line with a clear goal or strategy followed by one or both counterparties. It may involve extensive planning, development, negotiation, bargaining or conflict (Ford et al., 2008). As the action taken during this period of change will broaden or narrow the options for future development, a start-up will frequently have to consider its actions (Ford \& Mouzas, 2008; Håkansson \& Waluszewski, 2013).

\subsubsection{Modes of interaction to consciously affect interaction}

As explained previously, strategic management researchers studying organisational action in relationships (e.g. Ariño et al., 2008; Lui \& Ngo, 2005; Thorgren et al., 2012; Tjemkes \& Furrer, 2010) assumed that organisations are autonomous in how they choose to act and how their actions result in certain outcomes for them. Moreover, these researchers presumed that organisations can and do behave purposefully to achieve these outcomes. However, the IMP approach has shown that organisational acting is never one-sided. As a result, outcomes are not unequivocally related to an organisation's behaviour. Instead, the outcomes of an actor's actions arise from the action-reaction loops of both counterparties in the relationship regardless of their intent (Håkansson et al., 2009). Although start-ups cannot determine the outcome of a relationship autonomously through their behaviour, they do seek to behave purposefully. They tend to act in a very self-conscious way, trying to force their counterparties to adapt to their intent (Aaboen et al., 2011, 2013; Håkansson et al., 2009; Harrison et al., 2010; La Rocca et al., 2013). Therefore, it is still relevant to approach start-ups in terms 
of their acting in relationships. Yet in this paper, the organisational actions defined by strategic management researchers are considered 'modes of interaction'. Mode of interaction refers to the way in which an organisation consciously attempts to affect interaction. This definition takes into account that organisations are not autonomous in their actions and that only via a process of interaction between two or more counterparties, actions do result in outcomes. The various modes of interaction are further explained in the next section.

\subsubsection{Interaction: the action-reaction loops between counterparties}

During an interaction episode, a number of 'action-reaction' loops are set in motion (Ariño \& de la Torre, 1998). Therefore, Lui and Ngo (2005) suggest that each relationship is characterised by a unique interaction process created by the actions and reactions that go back and forth between the partners. The interaction process is a process of change that occurs between the counterparties over time. This process and its content may be separated from the two organisations themselves. The interaction process is influenced by how both counterparties act and react as well as the process of interaction itself. As a consequence, the interaction process derives its unique character from the two involved organisations but develops in a way that is not fully controlled by either of them. Thus, what an organisation can do or accomplishes becomes the outcome of the process of interaction, action and reaction, move and countermove (Ford et al., 2008; Håkansson et al., 2009).

\subsubsection{The outcome of interaction on the actors involved, their resources and activities}

The outcome of the interaction process can be defined as the effect on the actors involved in it, the resources they exchange and the activities they perform. Interaction always affects the actors, resources and activities involved in it since it injects some novelty into the relationship. However, a single episode will affect each of those involved in it differently, and therefore will be differently interpreted by each of them (Ford et al., 2008; Håkansson et al., 2009). In general, interactions with a 'converting' character stimulate further development of activity links, resource ties and actor bonds. In contrast, actions with an 'inhibiting' character limit the progress of the 
relationship (Edvardsson, Holmlund, \& Strandvik, 2008; Elo \& Törnroos, 2005). Each interaction will affect subsequent interaction between the counterparties and others in multiple directions. This multidimensionality makes outcomes difficult to interpret (Ford et al., 2008; Håkansson et al., 2009).

In summary, Figure 3.1 shows the process of interaction between a startup and its partners. The arrows from the trigger to both counterparties represent that any event - whether external or internal - that changes the opportunity for further interaction may trigger action from either partner. The arrows from the start-up and its partners to the spiral represent the modes of interaction to further interaction of both counterparties. The arrows from the spiral towards the start-up and its partners represent their interpretation and assessment of what has emerged from the interaction and what have been their counterparty's intentions and modes of interaction. The spiral itself is a representation of the process of interaction. The arrow from the spiral to the outcome is intended to show that the connection from the start-up's or its partners' mode of action to the outcome is beyond their individual control. Together these represent a single episode of interaction in which two or more organisations are dealing with certain issues. In contrast, the arrows from the outcome to both counterparties show that an outcome may result in new modes of interaction by the partners, while the arrow to the trigger expresses that a new event may occur that subsequently brings about action by both partners. This emphasises that episodes are related to each other because they are affected by what has happened previously. Based on the process of interaction shown in Figure 3.1, five research questions were developed that will be addressed in this paper:

1. How are the interaction episodes between a start-up and its partner interlinked?

2. What triggers deliberate action by a start-up and its partner?

3. What modes of interaction do a start-up and its partner use?

4. How do the interaction modes of a start-up and its partner co-occur?

5. What is the usual outcome of the interaction process between a startup and its partner? 


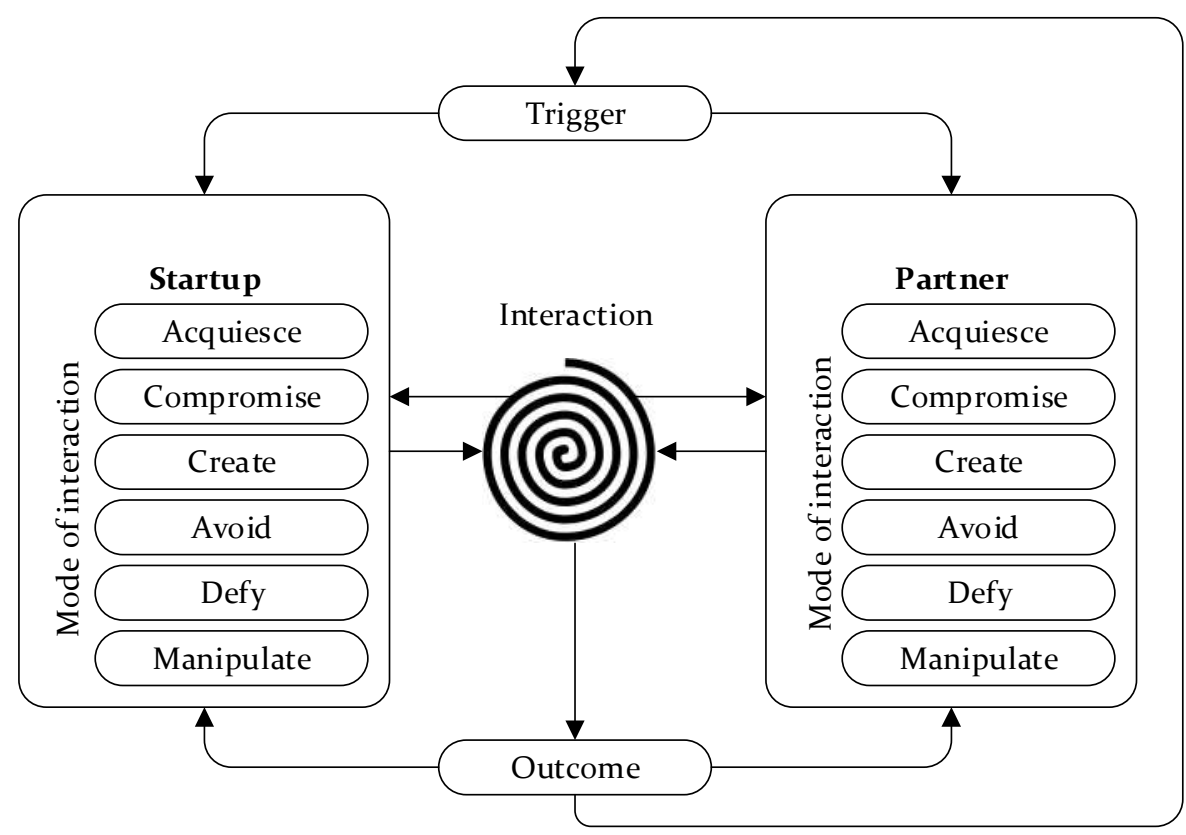

Figure 3.1 A model of the interaction process

\subsubsection{Action in an interactive process: modes of interaction}

The modes of interaction are identified based on the work of Lui and Ngo (2005) and Tjemkes and Furrer (2010). They developed typologies of actions that organisations take in their relationships. These typologies are based on research into the long-term relationships between established organisations. Yet recent studies have found that single actions of these typologies also apply to start-ups (Ariño et al., 2008; Thorgren et al., 2012). Therefore, it is assumed that these action typologies are also useful for studying the emerging relationship between start-ups and their counterparties. Yet in contrast to previous work on a start-up's actions in relationships, this paper aims to identify the variety of interaction modes used by a start-up. As explained previously, a start-up will never use only one type of action. Instead it will use various modes of interaction: at the same time in various relationships and at various times in the same relationship. Therefore, a focus on a single type of action would limit our understanding of the range of alternative interaction modes that are available to and are used by start- 
ups (Tjemkes \& Furrer, 2010). Next, the typologies of Lui and Ngo (2005) and Tjemkes and Furrer (2010) are explained, compared and integrated to identify the possible range of interaction modes that start-ups and their partners may use in their relationships.

A typology including five strategic responses to external institutional processes was developed by Oliver (1991). Lui and Ngo (2005) show that Oliver's typology can be extended to cooperative relationships by conceptualising an organisation's action as exerting external pressure on its counterparty. Specifically, they propose five types of organisational actions in a cooperative context: acquiesce, compromise, avoid, defy and manipulate. Acquiesce refers to the compliance of an organisation with the request or action of the counterparty even against its own short-term interests. Organisations do this either to strategically improve the relationship or simply out of habit. Compromise consists of the partial conformance of an organisation to the demand or action of its counterparty. The organisation negotiates to seek concessions to partially change its counterparty's demand or action. Avoid involves the lack of intention of an organisation to fulfil the counterparty's request or action. Yet the organisation typically conceals this non-compliance by reducing contact so that it can delay its response. Defy refers to an organisation's dismissal of the demand or action of its counterparty by rejecting and denouncing the relationship. In extreme cases, this may lead to termination of the relationship. Manipulate consists of the attempt of an organisation to influence, shape, change or redefine the demand or request of its counterparty with the aim of overpowering it (Lui \& Ngo, 2005).

Similarly, Hirschman (1970) proposed a typology in which exit, voice and loyalty represent three response strategies to decline in firms, organisations and states. Farrell (1983) extended this typology with a fourth strategy - neglect - to form the ELVN (exit-voice-loyalty-neglect) typology. Several studies have used this typology to study response strategies in a cooperative context (e.g. Geyskens \& Steenkamp, 2000; Ping, 1993, 1999). In the relationship context, the four EVLN response strategies are defined as 
follows. Exit indicates the willingness of an organisation to discontinue a current relationship. Relationship termination is the ultimate response to a troublesome situation (Ping, 1999). Voice refers to the attempt of an organisation to overcome an adverse situation by considering the concerns of its counterparty as well as its own. The organisation and its counterparty cooperatively discuss the issue with the intent to develop mutually satisfactory solutions. Loyalty implies an organisation's ignorance of a negative situation in the hope that it will resolve by itself (Ping, 1993). Neglect consists of an organisation allowing its relationship to decline. The organisation expends little effort in maintaining the relationship. Moreover, solutions to solve the undesirable situation are ignored (Ping, 1993, 1999; Pressey \& Qiu, 2007). Tjemkes and Furrer (2010) name the EVLN type of voice 'considerate' because it mostly suggests a positive approach involving the constructive discussion of the adverse situation. In addition, they extend the ELVN typology with three additional responses: creative voice, aggressive voice and opportunism. Creative voice refers to the attempt of an organisation and its counterparty to overcome an adverse situation by the generation of novel and potentially innovative solutions beyond the scope of their original agreement. Aggressive voice consists of the persistent effort of an organisation to solve an undesirable situation without regard for the ideas and preferences of the counterparty. The organisation coerces its counterparty into a one-side solution without trying to avoid conflict. Opportunism occurs when an organisation tries to maximize its own short-term interest at the expense of its partners. The organisation benefits from the relationship in ways that are explicitly or implicitly forbidden within the relationship.

There are clearly similarities between the typologies developed by Lui and Ngo (2005) on the one hand and Tjemkes and Furrer (2010) on the other. Firstly, compromise and considerate voice both refer to the active and constructive negotiation between an organisation and its counterparty in a relationship-preserving manner. Secondly, avoid consists of neglecting to react to an emerging issue with an organisation's counterparty. Tjemkes and Furrer (2010) argue that the issue can resolve by itself (loyalty) or the relationship will start to deteriorate (neglect). Thirdly, defy is similar to opportunistic behaviour depicted in transaction cost theory (Lui \& Ngo, 
2005), and therefore is similar to opportunism as well. As defiance may lead to termination of the relationship in extreme cases, it is also closely linked with exit. Fourthly, manipulate and aggressive voice both involve the forceful effort of an organisation to change its relationship without taking the interests of its counterparty into account. However, the action acquiesce proposed by Lui and Ngo (2005) and the response strategy create described by Tjemkes and Furrer (2010) do not match any of the actions from the other typology.

From this explanation and comparison, it can be concluded that a startup and its partners can choose from six modes of interaction: create, acquiesce, compromise, manipulate, avoid and defy. The first mode of interaction is termed 'create' and relates to the creative voice response strategy described by Tjemkes and Furrer (2010). The five other modes of interaction refer to the actions defined by Lui and Ngo (2005). Compromise and manipulate find their topological equivalent in typology of Tjemkes and Furrer (2010): considerate voice and aggressive voice respectively. Yet the labels of Lui and Ngo (2005) are used because they appear to be more actionoriented. Furthermore, it is acknowledged the latter two modes of interaction - avoid and defy - have a two-dimensional outcome. When the action of the counterparty or the adverse situation is avoided the issue dissolves naturally or the relationship declines. When the action of the counterparty or the troublesome situation is defied, then this may lead to opportunism or exit (Tjemkes \& Furrer, 2010). However, the various outcomes are not regarded as separate actions because the actual behaviour in both cases is similar: avoidance and defiance respectively. Table 3.1 summarises the definitions of the interaction modes applied in this study. 


\begin{tabular}{|c|c|}
\hline $\begin{array}{l}\text { Mode of } \\
\text { interaction }\end{array}$ & Definition \\
\hline Acquiesce & $\begin{array}{l}\text { The compliance of an organisation to the action of its } \\
\text { counterpart or situation even at the expense of its own short- } \\
\text { term interests. }\end{array}$ \\
\hline Compromise & $\begin{array}{l}\text { The partial compliance of an organisation to the action of its } \\
\text { counterpart or situation. The start-up and its counterpart } \\
\text { cooperatively renegotiate the relationship's agreements in a } \\
\text { relationship-preserving manner. }\end{array}$ \\
\hline Create & $\begin{array}{l}\text { The creation of innovative solutions by an organisation and its } \\
\text { counterpart beyond the scope of their initial agreement to align } \\
\text { their interests and preserve the relationship. }\end{array}$ \\
\hline Avoid & $\begin{array}{l}\text { An organisation's lack of intention to react to the action of a } \\
\text { counterpart or situation. To conceal its non-cooperation, the } \\
\text { start-up reduces the contact with the counterpart and delays its } \\
\text { response. }\end{array}$ \\
\hline Defy & $\begin{array}{l}\text { An organisation's dismissal of a counterpart's action or } \\
\text { situation. It may either try to benefit from the relationship at } \\
\text { the expense of its counterpart's interests or the start-up } \\
\text { terminates the relationship. }\end{array}$ \\
\hline Manipulate & $\begin{array}{l}\text { The persistent efforts of an organisation to take action } \\
\text { regardless of the ideas and preferences of its counterpart. It } \\
\text { tries to shape, change or redefine the counterpart's actions or } \\
\text { the situation by overpowering its counterpart. }\end{array}$ \\
\hline
\end{tabular}

Table 3.1 Definitions six interaction modes of start-ups and partners

\subsection{Methodology}

\subsubsection{Methodological approach}

A process research approach is used to address the research questions of this paper. Process studies focus attention on how things and processes emerge, develop, grow or terminate over time. It draws on theorising that explicitly incorporates time as an element of explanation and understanding, and focusses empirically on evolving phenomena. Previous research into organisational action in relationships mainly provided timeless proposition statements, typically generated in variance theorising. The particulars of what makes action actionable -what to do, at what point in time, in what context - were not included. Yet many studies, both within and outside the IMP approach, have revealed that temporality is important and inescapable in organisational life in general and relationships in particular (Bizzi \& Langley, 2012; Halinen, Medlin, \& Törnroos, 2012; Langley, Smallman, Tsoukas, \& Van 
de Ven, 2013). Organisational action takes place in an ongoing process of interaction as exemplified in Figure 3.1. Thus, by taking time as the central element of study, this paper aims to offer an essential contribution to organisational and management knowledge that is not available from most variance-based generalisations.

\subsubsection{Subject of study}

Process research methodologies are often based on qualitative case studies. Case studies enable the researchers to capture the nuances of processes in and around organisations (Bizzi \& Langley, 2012; Langley et al., 2013). Therefore, they correspond well to a research approach that emphasises process questions. Consequently, the empirical data collection involved an in-depth case study of a start-up and its partners in the medical device business. The start-up is currently developing a new solution to improve the treatment of Type 1 diabetes patients: a closed-loop bi-hormonal artificial pancreas. However, its system is not ready to be produced, let alone be used by diabetes patients. Consequently, the company is not yet embedded in the producing and using setting. Therefore, it can still be considered a startup. Developing all the required resources and activities in-house to embed in the pre-existing network is beyond the scope of the start-up. Therefore, it needs to collaborate with a wide range of partners to develop, produce and market the artificial pancreas. Specifically, the start-up has a key relationship with: a teaching hospital to carry out clinical trials on the artificial pancreas; a health foundation to create awareness among patients, diabetes nurses and physicians; a glucagon company to develop a new type of glucagon suitable for the artificial pancreas; a research institute to develop a new type of sensor that more accurately measures blood glucose levels; and a market leader in the diabetes device market to facilitate the marketing, sales and distribution of the artificial pancreas as soon as it is market ready. Moreover, it is involved in a European funded project with six other organisations from five different countries: a teaching hospital (NL), a technical university (NL), a medical university (AT), an established industry player (DK), a clinical research institute (DE) and a software company (TR). The project aims to advance the development of the artificial pancreas to be able to bring it to the homes of 
patients as quickly as possible. It would not have been possible for the startup to develop a new treatment for diabetes without the support of its partners due to a lack of in-house knowledge and resources.

\subsubsection{Data collection}

Longitudinal data is a key feature of process research because it is necessary to observe how processes unfold over time (Langley et al., 2013). Therefore, a retrospective analysis was conducted from the start of the project in 2004 until April 2013. Afterwards, the start-up was followed in real time until the end of December 2014. The combination of the retrospective analysis with real-time longitudinal research allows both the detection of substantial changes in relationships over long time periods and the ongoing development of relationships as they emerge (Bizzi \& Langley, 2012; LeonardBarton, 1990). The analysis is based on empirical data collection from three different sources: semi-structured interviews, observations and archival documents. On the one hand, this is to be able to capture the full complexity of the interaction in the relationship between the start-up and it partners (Bizzi \& Langley, 2012); on the other, to eliminate the risk that a finding is found by chance alone, which is crucial since this study is based on a single case (Doorewaard \& Verschuren, 2010; Gibbert, Ruigrok, \& Wicki, 2008). Firstly, direct passive and active participant observations were carried out during one of the researchers' residence at the start-up for on average of two days a week from April 2013 until December 2014. The prolonged involvement of the researcher in the processes studied enabled her to build interaction expertise and provided close access to events and actions (Langley et al., 2013). Moreover, it allowed the researcher to discover the discrepancies between what participants say they do and what they actually do. To reduce the researcher's hindsight bias, once every week a short evaluation report was written based on the field notes taken during that week. Secondly, archival documents, such as non-disclosure agreements, project descriptions and patents, are used to minimise interviewee hindsight bias and the limitations of memory recall (Langley et al., 2013).

Finally, fifteen semi-structured interviews were held with key individuals from the start-up and its partners at two moments in time as 
shown in Table 3.2. Although collecting data on both sides of the relationship at two moments in time is challenging, it allows the researchers to capture the interactive nature of action: in other words, the pattern of action and reaction between the start-up and its partners over time. Moreover, the various perceptions of triggers, actions, reactions and outcomes can be considered. This complements existing cross-sectional research that collects data from a single organisation per relationship (Ariño et al., 2008; Lui \& Ngo, 2005; Thorgren et al., 2012). The selection of interviewees was based on: (1) direct interaction with the other partner(s) in the relationship; and (2) the direct involvement in the development of the start-up's artificial pancreas. The first set of interviews was held in June and July 2013, while the second set followed in December 2014. Each interview lasted approximately between 30 and 100 minutes. The first set of interviews was structured around: (1) how and why the start-up and its partner initiated the relationship; (2) what the goals of the relationship were and how the start-up and its partner ensured that these goals were achieved; and (3) how resources were exchanged between the start-up and its partner. The second set of interviews focused on: (1) how the relationship between the start-up and its partner had evolved since the first interview; (2) how the goals of the relationship were revised and how the start-up and its partner ensured that these goals were achieved developed; and (3) how the resource exchange between the start-up and its partner had been modified. Then the interviewee was asked to identify: (1) important changes in the relationship; (2) how the start-up and its partners acted during these changes; (3) why they acted the way they did; and (4) how this affected their relationship. However, the interviews were flexible enough to leave room for discussion and allowed interviewees to give examples and expand on important events and situations. The interviews involved sensitive, confidential, and political topics regarding the relationship with the start-up. Consequently, it was important to maintain confidentially. Therefore, the names of organisations and interviewees were made anonymous. All interviews in this research were tape-recorded and then transcribed. 


\begin{tabular}{llrr}
\hline Interviews & & & \\
\hline Organisation & Interviewee & Date & Length \\
Teaching hospital & PhD student & $2-7-2013$ & $29 \mathrm{~min}$. \\
Start-up & PhD student & $21-6-2013$ & $34 \mathrm{~min}$. \\
Start-up & Entrepreneur & $\mathbf{2 0 - 6 - 2 0 1 3}$ & $101 \mathrm{~min}$. \\
& & $\mathbf{1 - 1 2 - 2 0 1 4}$ & $\mathbf{1 0 2} \mathrm{min}$. \\
Start-up & Informal investor & $\mathbf{2 8 - 7 - 2 0 1 3}$ & $54 \mathrm{~min}$. \\
& & $17-12-2014$ & $85 \mathrm{~min}$. \\
Health fund & Head knowledge & $3-7-2013$ & $28 \mathrm{~min}$. \\
& & $3-12-2014$ & $34 \mathrm{~min}$. \\
Teaching hospital & Project leader & $\mathbf{2 - 7 - 2 0 1 3}$ & $32 \mathrm{~min}$. \\
Technical university & & $\mathbf{2 - 1 2 - 2 0 1 4}$ & $50 \mathrm{~min}$. \\
Medical university & Director & $\mathbf{2 4 - 7 - 2 0 1 3}$ & $55 \mathrm{~min}$. \\
Market leader & Researcher & $\mathbf{1 1 - 2 - 2 0 1 3}$ & $55 \mathrm{~min}$. \\
& Head business & $\mathbf{2 8 - 7 - 2 0 1 3}$ & $51 \mathrm{~min}$. \\
Research institute & & $3-12-2014$ & $41 \mathrm{~min}$.
\end{tabular}

\subsubsection{Data analysis}

To analyse the recorded interviews, diary and archival documents, ALTLAS.ti software was employed. This software provided the tools to code the findings in the data; to evaluate the importance of these findings; and visualise the complex relations between these findings. The coding was based on the theoretical framework developed in the previous section that specified important concepts a priori. This helped to improve the research quality as it allowed the researchers to measure concepts more accurately. It is important to note that concepts are necessarily tentative in this type of study. The concepts could either be validated or found to be inadequate in the context of start-ups. If the validity of a concept is confirmed, then the researcher has a firmer empirical grounding for emergent theory. However, if a concept is found to be inadequate, researchers can further refine emergent theory based on the case study findings (Eisenhardt, 1989; Gibbert et al., 2008). 


\begin{tabular}{|c|c|c|c|}
\hline Phase & Analytical goal & $\begin{array}{l}\text { Analytical process used } \\
\text { and outcome }\end{array}$ & $\begin{array}{l}\text { Implications for } \\
\text { conceptual development }\end{array}$ \\
\hline 1 & $\begin{array}{l}\text { Describe the } \\
\text { evolution of the } \\
\text { start-up and its } \\
\text { relationships }\end{array}$ & $\begin{array}{l}\text { Producing a time line } \\
\text { of the evolution of the } \\
\text { start-up }\end{array}$ & $\begin{array}{l}\text { Understanding the } \\
\text { context of interaction } \\
\text { between start-up and its } \\
\text { partners }\end{array}$ \\
\hline 2 & $\begin{array}{l}\text { Uncover triggers } \\
\text { to distinguish } \\
\text { between } \\
\text { interaction } \\
\text { episodes }\end{array}$ & $\begin{array}{l}\text { Temporal bracketing to } \\
\text { identify a chain of } \\
\text { episodes separated by } \\
\text { triggers }\end{array}$ & $\begin{array}{l}\text { Illustration of the } \\
\text { interaction process } \\
\text { according to episodes } \\
\text { divided by triggers. }\end{array}$ \\
\hline 3 & $\begin{array}{l}\text { Identify the } \\
\text { different types of } \\
\text { actions and } \\
\text { reactions in the } \\
\text { episodes }\end{array}$ & $\begin{array}{l}\text { Coding of different } \\
\text { type of actions and } \\
\text { reactions according to } \\
\text { theoretical framework }\end{array}$ & $\begin{array}{l}\text { Operationalization and } \\
\text { illustration of different } \\
\text { type of actions by start-up } \\
\text { in interaction with } \\
\text { partners }\end{array}$ \\
\hline 4 & $\begin{array}{l}\text { Reveal the } \\
\text { outcomes of the } \\
\text { action-reactions } \\
\text { in response to a } \\
\text { trigger }\end{array}$ & $\begin{array}{l}\text { Categorize the } \\
\text { outcome the loop of } \\
\text { action-reaction } \\
\text { (interaction) }\end{array}$ & $\begin{array}{l}\text { The linkage between } \\
\text { rationale and action } \\
\text { results in either } \\
\text { converting or inhibiting } \\
\text { effect on the relationship }\end{array}$ \\
\hline 5 & $\begin{array}{l}\text { Examine the } \\
\text { linkage between } \\
\text { trigger, action and } \\
\text { outcome in } \\
\text { subsequent } \\
\text { episodes }\end{array}$ & $\begin{array}{l}\text { Open coding of how } \\
\text { trigger, action and } \\
\text { outcome are related to } \\
\text { each other in } \\
\text { consecutive episodes }\end{array}$ & $\begin{array}{l}\text { Illustration of how } \\
\text { subsequent episodes are } \\
\text { affected by previous } \\
\text { episodes }\end{array}$ \\
\hline
\end{tabular}

Table 3.3 Phases of case analysis

The data were analysed in five consecutive phases which are summarised in Table 3.3. The analysis started with drawing up a history of the start-up to clarify the context of the phenomena in question. Secondly, the analysis focused on identifying the important interaction episodes between the start-up and its partners. 'Temporal bracketing' (Langley, 1999) was used to identify comparative episodes within the stream of longitudinal data. These temporal brackets were constructed as a chain of episodes separated by identifiable internal or external triggers in the interaction process. Temporal bracketing also enabled the identification of specific actions recurring over time (Van de Ven, 1992). Therefore, the data was coded in order to identify and categorise the actions and reactions of the start-up and its partners in the 
different episodes in the third step. The six actions adopted from Tjemkes and Furrer (2010) and Lui and Ngo (2005) as defined in Table 3.1 were used as the coding template. In the fourth phase the focus was on how the interaction process affected the perceived outcome of relationship as either converting or inhibiting. As explained in the previous section, interactions with a 'converting' character stimulate further development of the relationship, while actions with an 'inhibiting' character reduce activity links, resource ties and actor bonds. However, during the analysis it appeared that the partners did not always agree on the converting or inhibiting nature of the outcome of the interaction episode. In addition, the partners sometimes perceived that the interaction episode had both positive and negative outcomes. In these instances, the outcome of the interaction episode was labelled 'mixed'. Moreover, temporal bracketing permitted us to analyse how the previous episode impacts subsequent actions in the current episode (Langley et al., 2013). Finally, it was analysed how this outcome subsequently resulted in new actions or led to a new trigger: in other words, how each of the episodes was related to each other. The results of this analysis are schematically presented in Table 3.4, and elaborated in the next part of this paper.

\subsection{Results}

\subsubsection{The development of the start-up}

In 2003, an entrepreneur - a diabetic patient - consulted his diabetes nurse for his annual check-up. Over the years, he had become increasingly dissatisfied with the available treatment methods for his disease. That evening, he developed the principle of a new system: a bi-hormonal artificial pancreas. Yet the entrepreneur lacked the necessary knowledge to develop the system on his own. Therefore, he mobilised the support of two friends: a diabetes nurse and a software developer. In 2004, they were able to try out a first prototype of their system, which was the size of a small closet, on the entrepreneur. When it turned out to work as intended, the entrepreneur tested the system on a few more diabetics. The results were promising, and the friends started the development of a prototype of about the size of a microwave oven. Nevertheless, the progress stagnated between 2005 and 2008 for two main reasons. Firstly, the previous prototype was developed at 


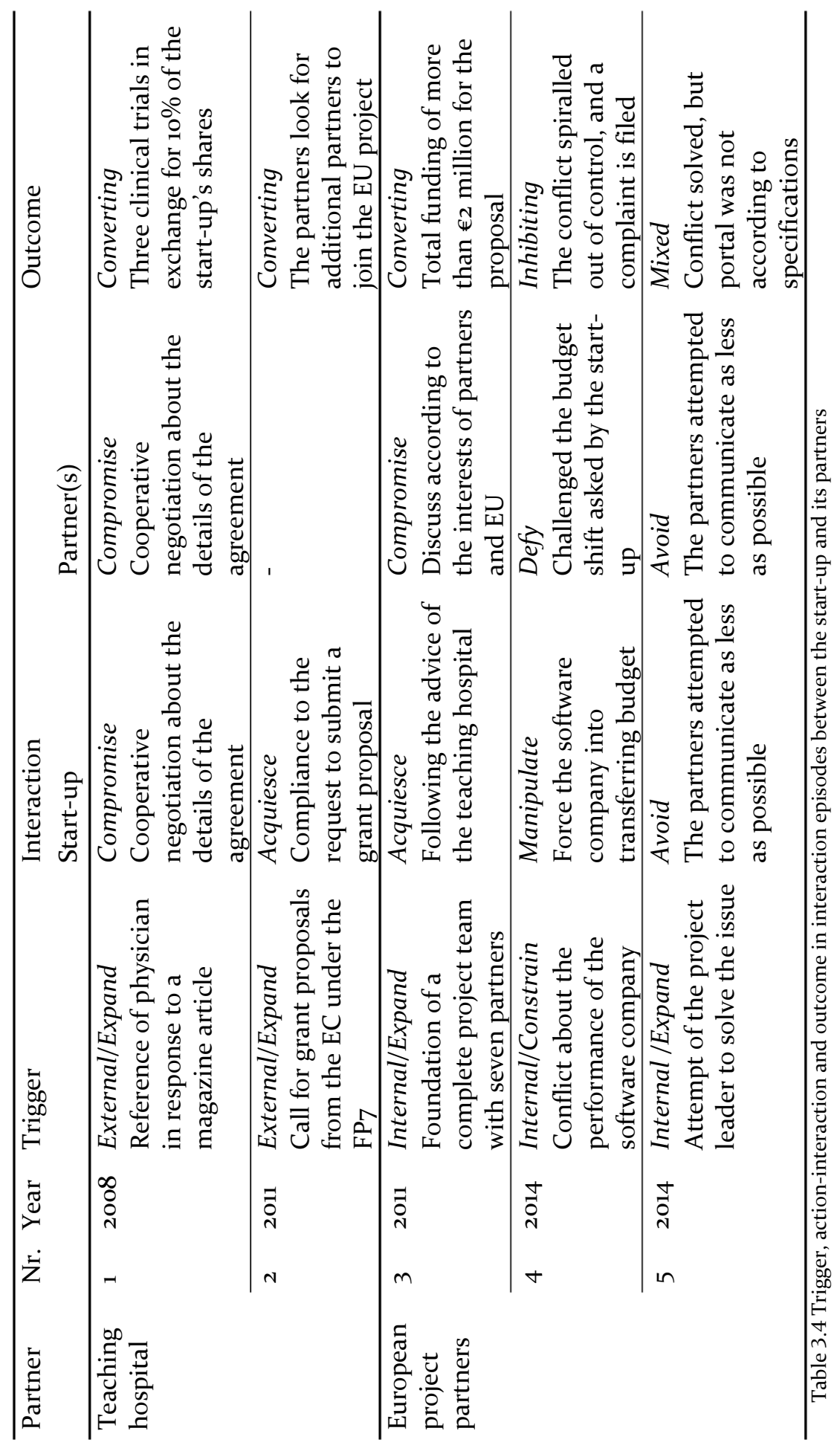




\section{4 | Chapter 3}

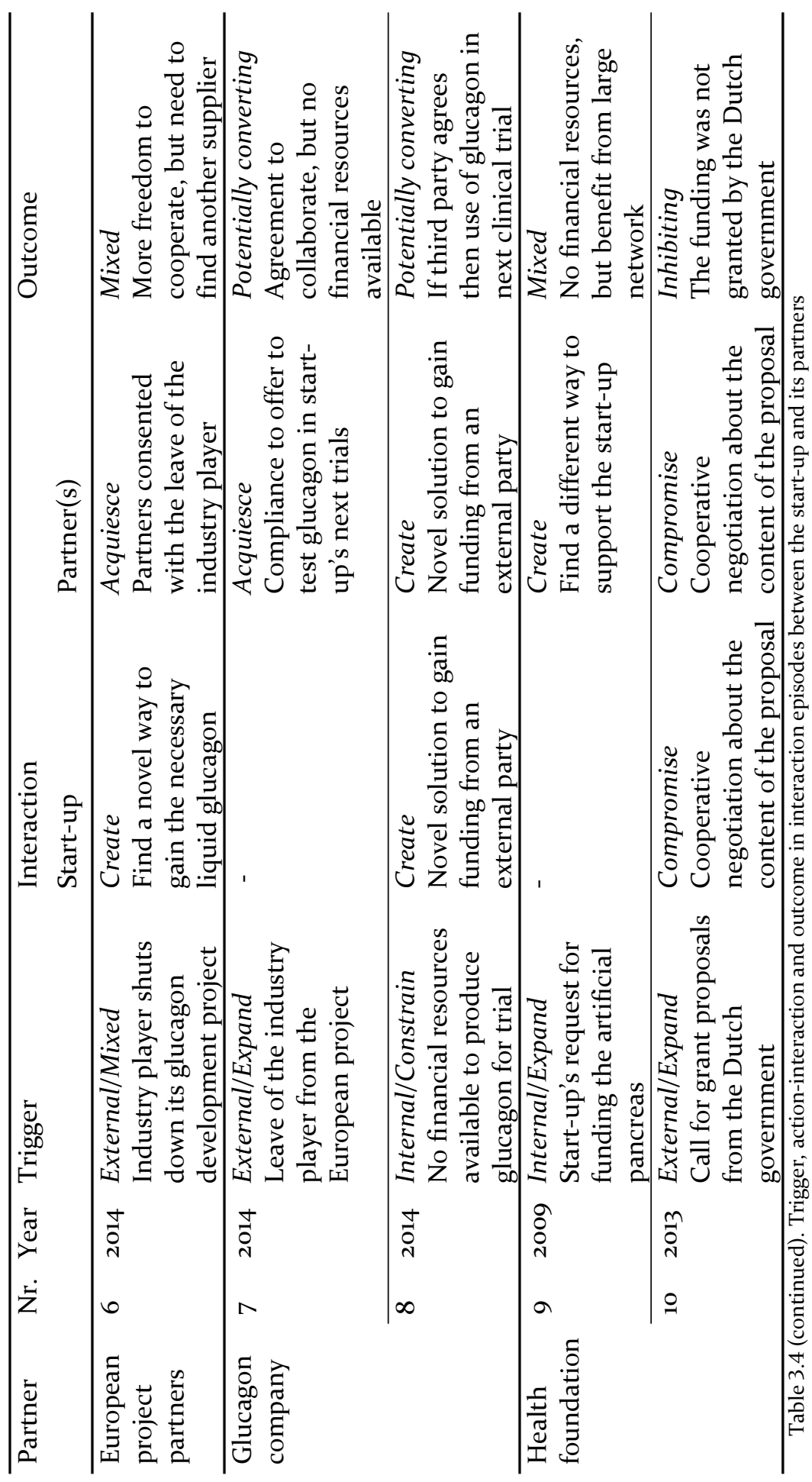




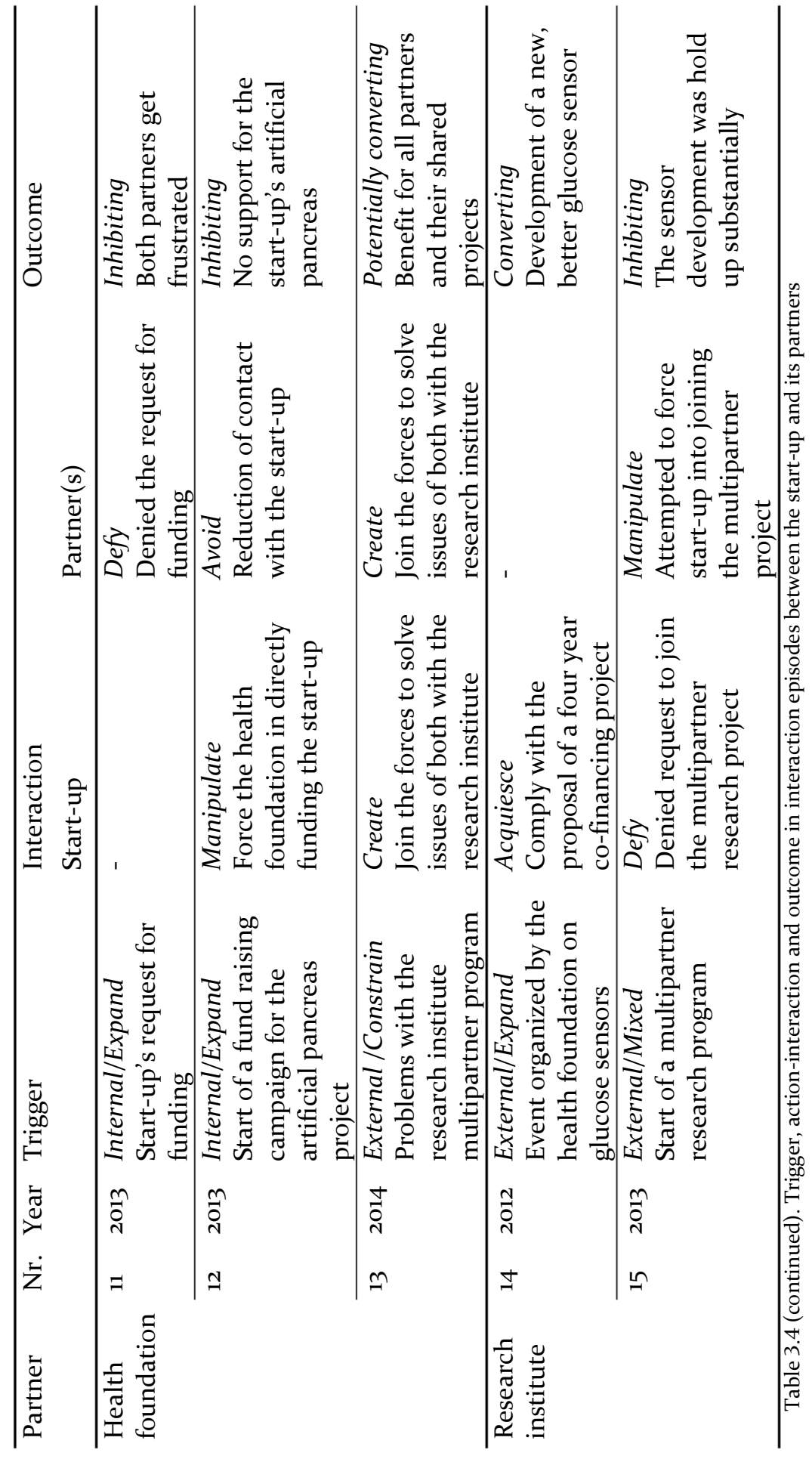




\section{6 | Chapter 3}

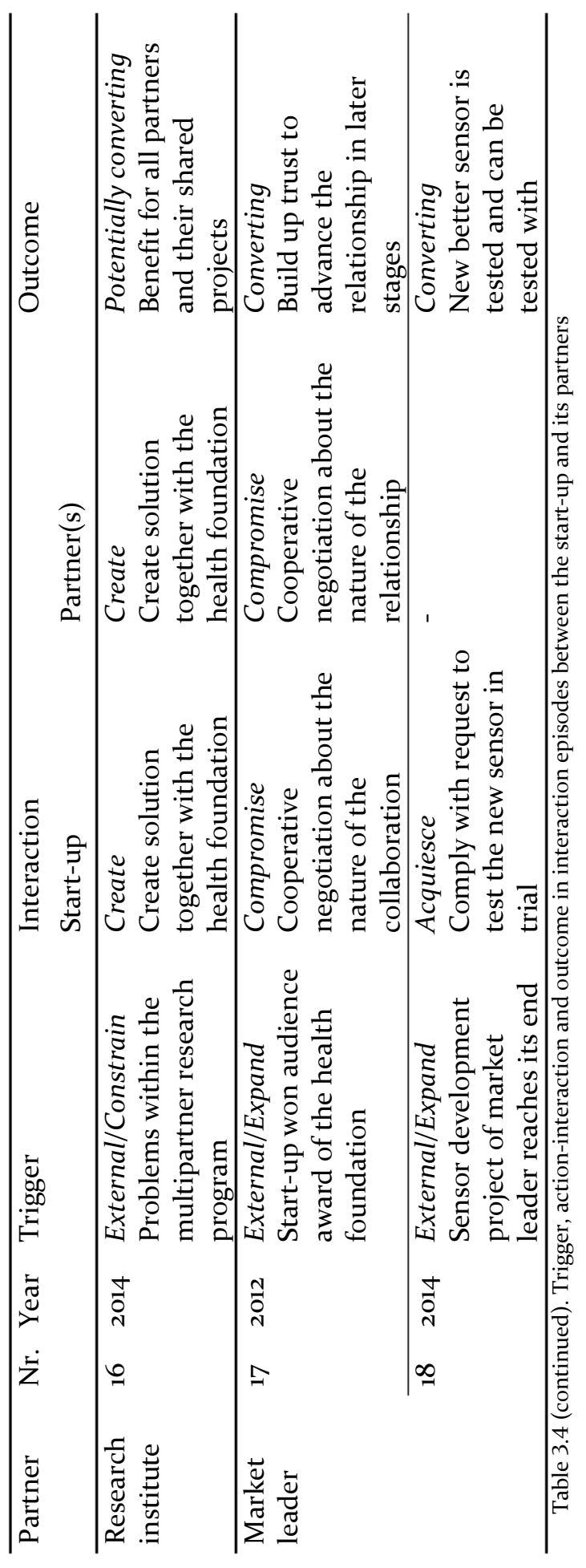


the expense of the three friends. However, these funds were insufficient to finance the development of a second prototype. In 2008, this problem was resolved. The entrepreneur found an angel investor who was prepared to invest the necessary financial resources. To make this investment possible, a new company was founded in 2008: the start-up. Secondly, the start- up lacked a partner to run official clinical trials. Eventually, in 2008, the start-up came into contact with the head of a teaching hospital's diabetology group. By the end of 2011, two clinical trials were run by the teaching hospital. During this period, the start-up also came into contact with the health foundation for diabetes. This foundation appeared to have a large network of research institutes, universities, companies and non-profit organisations that were involved in diabetes-related research. For example, the health foundation brought the start-up into contact with the research institute. The start-up and the research institute had a mutual interest in developing a new glucose sensor together. Moreover, around this time the start-up began to develop a third, smaller prototype with improved functionality. The smaller artificial pancreas was about the size of approximately a laptop computer. As a consequence the start-up and the teaching hospital were able to try out the system in a home-environment. Previously, the artificial pancreas could only be tested in a hospital setting as it was too big to wear. The results of a two day trial - in a home-environment - showed that the device performed as well as the regular diabetes treatment on day one and even better on day two. These promising results gave the start-up the motivation to take the project to the next level. Firstly, in 2012 the start-up and the teaching hospital applied for and were granted funding from the European Commission under the Seventh Framework Programme for Research and Technological Development. This funding allowed the start-up to build a fourth, even smaller, prototype of the artificial pancreas that would be suitable for introduction into the market. In addition, the grant would cover the cost of three additional clinical trials. Secondly, the development of the artificial pancreas was given a boost when the start-up won the health foundation's audience award in 2012. This award generated a lot of media attention. In this way, the project was picked up by a market leader in the diabetes device market. First the market leader was just cooperating to keep track of the start- 
up's invention, but after the promising results of a test with the artificial pancreas they wanted to intensify the relationship. However, the development of the start-up's artificial pancreas did not run as smoothly after 2012. The start-up and the health foundation applied for funding from the Dutch government, but this application was rejected. Additionally, the startup had an issue with the research institute because the institute wished to change the agreements of the relationship but the start-up did not. Moreover, there was a conflict in the European project about the quality of the work that was delivered by one of the involved companies. Also, another partner decided to leave the project after one-and-a-half years. In conclusion, the start-up interacted with an increasing number of partners over the years. Consequently, there were more and more relationships that the start-up had to engage in and manage. In some instances this had a positive effect, but in others it slowed down the development of the artificial pancreas.

\subsubsection{The start-up interacting with its partners}

In this section, the interaction between the start-up and its key partners, the trigger that marked the start of the interaction episode and the outcome are explained in detail. The results are summarised in Table 3.4 for each partner in chronological order and will also be discussed in this way. One important aspect of this table is that there are 'white spots'. These white spots occur when either the start-up or the partner was not actively (re)acting during the interaction episode. In these episodes, one of the partners came with a request, proposal or demand to which the other party reacted, but there was no response from the initiator to its counterparty's reaction.

\subsubsection{Teaching hospital}

In 2006, the start-up started searching for a partner to run official clinical trials. These trials were necessary to advance the development of the artificial pancreas. Moreover, they were essential to gain the legitimacy in the current financial, healthcare and technical network to attract additional resources from other organisations, such as funding from investors or support from diabetes patient foundations. In 2008, the start-up came into contact with a physician who had read an article about the start-up's artificial pancreas. Although he was enthusiastic about the device, he did not have the 
necessary skills and facilities to conduct clinical trials. Therefore, he referred the start-up to the head of the diabetology group of a teaching hospital see Table 3.4, Episode 1 (hereafter there is only referred to the episode number). After some initial meetings to get to know each other, the start-up proposed that the teaching hospital would run clinical trials in exchange for shares in the start-up. The teaching hospital agreed to the type of arrangement, but wanted to cooperatively negotiate about the exact number of shares in exchange for a certain amount of work. They wished to work together because there was a clear dependency between them. As the head of the group explains, "we [the teaching hospital] do not have technical engineers that can develop diabetes technology in-house. However, we [the teaching hospital] have access to patients and clinical expertise." The outcome of the negotiation was that the teaching hospital would run three clinical trials in exchange for ten percent of the shares in the start-up.

In 2011, two clinical trials were run by the teaching hospital, and these showed promising results. As described in Episode 2, the teaching hospital came across a relevant grant for funding under the Seventh Framework Programme for Research and Technological Development (FP7) from the European Commission (EC) at around the same time. Therefore, it asked the start-up if it might be interested in submitting a joint grant proposal. The start-up was very eager to agree to this suggestion because this grant had the potential to provide it with the necessary funds to further develop the artificial pancreas. In addition, being granted funding by the European Union would signal to the current network that the start-up was a capable partner. As the guidelines of the European Commission prescribed more than two partners, they started to search for other partners who might be interested in joining the project.

\subsubsection{European project}

At the end of 2011, the teaching hospital and the start-up found five other organisations prepared to join the project (Episode 3): a medical university (AT), an established industry player (DK), a clinical research institute (DE), a software firm (TR), and a technical university (NL). The first 
three were existing partners of the hospital, while the latter two were introduced by the start-up. Together the partners wrote a grant proposal that both suited their own interests and the requirements of the European Commission. It appeared to be straightforward to compromise over the agreements among them because most partners already had experience in working together. In this process, the start-up mainly agreed with the suggestions of the teaching hospital. As the entrepreneur explained: "for us [the start-up] it was the first time that we had written such a proposal. Then you just follow their [the teaching hospital's ] advice." The result was a proposal that was granted more than two million Euros of funding from the European Commission in August 2012.

As shown in Episode 4, a conflict arose between the start-up and the software company in the European project in 2014. The start-up believed that the software company was working neither effectively nor efficiently. Therefore, it wanted to do the task itself, and requested a budget shift. The software company denied this accusation, and therefore did not agree with the transfer of the budget. In response, the start-up tried to force the software company to comply with its request. This led to the conflict spiralling out of control. As a result, the software company filed a complaint to the project leader. The project leader talked extensively with the partners to explain to them that it is not in the project's interest for the issue to escalate to the point at which either the start-up or the software company leave the project (Episode 5). Eventually, they agreed to stick to their initial agreements. Although the worst part of the conflict was solved, the partners avoided further communication as much as possible. This hindered the development of the portal which the software company was building to monitor the performance of the artificial pancreas during clinical trials. Due to the lack of communication, the portal did not satisfy the requirements of the start-up.

Also in 2014, the established industry player decided to leave the project (Episode 6). The industry player was responsible for development of a stable, liquid glucagon formula. When it shut down its project to develop a stable, liquid glucagon formula, there was no motivation for the industry player to remain in the European project any longer. Most partners of the project were 
content with its leaving because its budget was relatively small and they did not see any opportunity to exchange more knowledge and resources. In contrast, for the start-up it resulted in the considerable challenge to find a new partner. The availability of stable, liquid glucagon was crucial for the success of the artificial pancreas. At that moment, glucagon was only stable for 24 hours and then has to be thrown away. In contrast, the start-up needed glucagon that could be used for longer. If patients had to throw away the unused glucagon every day, the costs for treatment with the artificial pancreas would become unacceptable. However, as a report from the start-up stated "for the development of the glucagon we [the start-up] depend on external partners, which makes it difficult to control... It [the industry player] is a very trusted partner. The company will deliver the glucagon in the near future, but takes its time to develop the best possible solution. Therefore, we need an alternative for when glucagon development is delayed." Thus, the start-up was already looking for alternative companies that were developing glucagon. However, the need to create an alternative partner became suddenly more urgent.

\subsubsection{Glucagon company}

After the established industry player left the European project, the start-up had to find a new partner to develop stable, liquid glucagon for its artificial pancreas; see Episode 7. Through an American health foundation, the start-up came into contact with an American company dedicated to the development of stable, liquid glucagon. In comparison to alterative glucagon providers, the angel investor stated "the others were not far enough [in their development]. It [the US glucagon company] was the most concrete...”. Therefore, the start-up proposed to use its glucagon in one of the next clinical trials with the artificial pancreas. The glucagon company accepted this offer because it was an effective and efficient way to test its glucagon.

Yet there was one problem; neither partner was willing to pay for the production costs of the glucagon to be used in the trial (Episode 8). Nevertheless, they were able to create a solution by using their network to find interconnections between their partners. The start-up knew an American 
investment company which had good relations with the American glucagon company. The start-up had also contact with this company that, although it was interested in the start-up's artificial pancreas, was not willing to invest because it was foreign initiative. Therefore, the start-up thought it might be interested in providing the funds necessary to produce the glucagon for the trial. The investment company is still reviewing if it would invest its financial resources in the glucagon provider. If the investor agrees to fund the joint project, then these funds would be employed to produce the glucagon.

\subsubsection{Health foundation}

As described in Episode 9, the entrepreneur of the start-up and the head of research the Dutch diabetes health foundation met at a donor meeting in 2009. The start-up requested funding for the development of its artificial pancreas as the health foundation is the largest financer of diabetes related research in the Netherlands. The angel investor in the start-up expected "that we [the start-up] would receive funding from it [the health foundation], but that failed". The proposal was denied by the foundation because the members of its internal audit committee did not give their approval. This approval was necessary to legitimise the funding of the start-up's project both to its auditors and to its benefactors. However, the health foundation could do more than only providing financial support. It could "also help by getting them [the start-up] in touch with other parties and researchers... We [the health foundation] can often help people in other ways to find solutions for diabetes." Thus, the health foundation was unable to support the start-up financially, but it provided the start-up with access to its network.

In 2013, the health foundation found a way to go around the foundation's audit committee. They proposed, in collaboration with the teaching hospital and technical university, to apply for funding from the Dutch government (Episode 10). After negotiating the terms of this initiative, the partners agreed to pursue this initiative. For the start-up this was the best chance to obtain (albeit indirectly) funding from the health foundation. Furthermore, the health foundation would be able to legitimise its funding for the project to its accountants and the wider public. The proposal would be reviewed by a committee of experts composed by the government. 
However, the funding was not granted as a result of what the Dutch government regarded as a lack of evidence on the effectiveness of the artificial pancreas.

Before the funding application, the research foundation started a fundraising campaign to obtain sufficient funds to finance the project. Therefore, the start-up again requested direct funding from the health foundation when the application to the Dutch government was rejected (Episode 11). For the same reasons as mentioned previously, the foundation declined. This did not benefit the relationship between the partners. They were frustrated about the fact that both parties were willing to collaborate but not able to so because of internal regulations imposed on the health foundation. Nevertheless, the start-up exerted pressure on the foundation using as leverage the funds that had already been raised to finance the rejected project (Episode 12). As a consequence of what it regarded as manipulative action, the foundation reduced its contact with the start-up. The head of research of the health foundation stated "when it turned out that it [the project application] was not successful, it [the relationship with the start-up] retreated into the background. And I no longer followed the developments closely."

\subsubsection{Research institute}

In 2012, the health foundation organized a meeting for research institutes and industry to discuss the development of new glucose sensors (Episode 14). One research institute had some initial ideas about a new sensor that would not only be more accurate, but also cheaper. However, it lacked an opportunity for practical application in the market. On the other hand, the start-up did not have the required knowledge to develop the sensor it needed. As a consequence of this mutual dependence, they started a four year cofinancing project "in which you have steps from 10, 25, 50, and 100 percent that you [the start-up] have to fund yourself. The steps develop from scientific research to market authorization resulting in the exclusive rights." It was 'take it or leave it' for the start-up since there were no exceptions to these terms possible. The contribution from the research institute is funded from taxes, and the European legislation regarding state aid prohibits any deviations from 
the percentage ratios. The start-up complied with these terms because it appeared that existing sensors, which were used in the previous trials, were not sufficiently accurate.

As shown in Episode 15, an issue between the start-up and the research institute arose in 2013. After starting the relationship with the start-up, the research institute embarked on a multipartner research program with similar goals. As the research institute perceived this project to be more efficient and less uncertain, the research institute requested the start-up to end the cofinancing project, and to join the multipartner research program. However, the terms of the research program were quite different from those of the cofinancing project. The multipartner program would enable the start-up to divide the costs of the project among several project members, but all members would be entitled to use the patent without paying a licence fee. Yet the start-up wanted the exclusive rights to the patent that would have been the result of the co-financing project first. However, the research institute did not agree to this request because the existence of a better alternative substantially reduced their dependence on the start-up. Nevertheless, the research institute was legally obliged to comply with the current contract for as long as the start-up does not agree to suspend it. The re-negotiations took about a one-and-a-half years, and in that time the progress of the joint project slowed down substantially. As the angel investor explained: "it [the research institute] has just been obstructing us [the start-up] to exert pressure to join the multipartner program. We said we will not do that... It used all the tools to obstruct us." Although the delay did not threaten the development of the fourth prototype, the renegotiations cost the start-up precious resources.

By the end of 2014, the health foundation proposed a solution to the issue between the start-up and research institute (Episode 13 and 16). At the same time, this would solve the struggle between the start-up and the health foundation. The multipartner program of the research institute needed knowledge that exclusively belonged to the start-up. Thus, the multipartner program was not able to succeed without its involvement. The health foundation was one of the partners in the multipartner program, and it wanted the multipartner program to succeed. Therefore, it proposed to 
finance part of the start-up's co-financing project with the research institute up to the point to which they could apply for a patent. The condition of this funding was that the start-up would join the multipartner research program after the patent application. This solution appeared to be a potential win-winwin situation for all three partners. The solution would enable improvement first in the 'co-financing project' and later also in the multipartner program. In the words of the entrepreneur: "for everyone it is an opportunity to start over with new courage."

\subsubsection{Market leader}

In 2012, the start-up won the audience award of the health foundation (Episode 17). This award generated a lot of media attention. In this way, the project was picked up by a market leader in the diabetes device market. After negotiating the agreements, the start-up and the market leader signed several contracts, such as a Non-Disclosure Agreement and Right-of-First-Refusal. They agreed that aim of the relationship at this stage was mainly to explore the possibilities for more intensive collaboration. The start-up actually wanted more from the start, such as an investment or joint development program. However, the market leader did not fully agree because the risk that the artificial pancreas would fail was still perceived to be unacceptably high. Yet both partners believed that their mutual dependency could be a good basis for further more intensive collaboration. During such collaboration, the start-up could benefit from the production, sales and distribution facilities of market leader, and the market leader could profit from the innovation capabilities of the start-up. However, to achieve this aim the partners, especially the market leader, needed to build up a certain level of trust before they would agree to a more intensive collaboration.

During the first two years of the collaboration, the market leader's confidence in the start-up's capabilities grew. As the market leader explains: "this is clearly a step; we [the market leader] completed the exploring. We concluded that we wanted to continue with it [the relationship with the startup]." Therefore, the market leader proposed intensifying the collaboration. Its proposal was to use its new sensor in one of the next clinical trials with the 
artificial pancreas (Episode 18). The start-up agreed to this proposal because the market leader's sensor was the most efficient. As a result, the new sensor from the market leader would be used in one of the trials of the start-up; in this way the market leader can inexpensively test its sensor while the start-up can use the best sensor available.

\subsection{Analysis}

The findings described in the previous section show that the start-up and its partners interacted in a way that was predicted by the research framework described in Figure 3.1. Therefore, the findings of the 18 interaction episodes presented previously are summarised, analysed and compared in light of the research framework in this section.

\subsubsection{A series of sequential episodes represent the interaction process}

Table 3.4 shows that after the five episodes with a converting outcome (there are six converting episodes, but only five were followed by a new episode), the start-up and its partners choose acquiescence, defy and manipulate as modes of interaction in the subsequent episode. Although the outcome of the previous episode was converting, they defied and manipulated when a conflict arose between the partners. Yet if the partners saw an opportunity to strengthen the relationship, they acquiesced. In spite of the successful grant for the European project, the relationship between the startup and the software company lead to a conflict. The start-up believed that the software company had worked neither efficiently nor effectively and did not expect it to do so in the future. Therefore, the start-up did manipulate the software company. In addition, Table 3.4 shows that in the five episodes that followed after an episode with an inhibiting outcome, the start-up and its partners choose to create, avoid, defy and manipulate. Although the outcome of the previous episode was inhibiting, they were willing to create a solution if the opportunity arose to advance the relationships in a positive direction again. However, if the partners expected that the conflict would spin out of control or the situation would not improve, they avoided, defied and manipulated. For example, when the start-up and the health foundation applied for funding this was not granted. As a result, the start-up requested direct funding from the health foundation, but this request was rejected. The 
frustration of the start-up caused by this rejection triggered the manipulation of the health foundation by the start-up. In turn, this resulted in the avoidance of the start-up by the foundation. Thus, the case analysis shows that the use of a particular mode of interaction in a current episode is influenced by the outcomes of previous episodes. However, the nature of the trigger also influences, even more strongly, the decision to use a particular mode of interaction.

\subsubsection{External and internal triggers that change the opportunities for future interactions}

Table 3.4 shows that in four out of the six relationships, the first interaction episode starts with an external trigger. In one instance, the startup's partner initiated the first contact after publicity for the start-up in the media. In another relationship, the potential partner came into contact with the start-up at a private meeting. In the other two instances, a third party influenced the relationship between the start-up and a specific partner. In the relationship with the teaching hospital, the start-up was referred to the head of the diabetology group by another physician, and in the relationship with the glucagon company the start-up was prompted to search for a new partner because the industry player left the European project. Thus, in the first interaction episode between the start-up and a specific partner an external trigger often marked the beginning of the relationship. Additionally, Table 3.4 shows that after the first episode of each relationship, interaction was triggered seven times by an external event and five times by an internal event. Internally, the start-up regularly assessed the resource ties and activity links with its partners. For example, the start-up perceived that the software company was not delivering the required quality at the required time. Externally, alterations in the strategic context of the start-up's partners triggered organisational actions; for example when the industry player decided to leave the European project since it had shut down its own glucagon development project. In conclusion, the results show that after the initial episode both internal and external events triggered action by the start-up and its partners. 
Moreover, when the nature of the triggers in Table 3.4 is analysed it appears that in 12 instances the start-up and its partners agreed that the trigger expanded the opportunities for future interaction, while in four episodes they agreed that it constrained those opportunities. In the remaining two instances: (1) they did have different opinions on whether the trigger expanded or constrained the opportunities for future collaboration; or (2) the trigger expanded and constrained the opportunities for future interaction at the same time. For example, the research institute felt that the multipartner program was an opportunity to further develop the relationship with the start-up, while the start-up thought otherwise. Furthermore, the exit of the industry player from the European project reduced the possibility of collaborating with that player, but opened up opportunities to work together with another partner. Therefore, the findings indicate that the actions of the start-up and its partners are triggered by events that both constrain and expand opportunities for future interaction, although there can be varying perspectives on the nature of the trigger. In addition, all the relationships started with opportunities for collaboration, while in four relationships in a later stage events occurred that inhibited further collaboration. Therefore, it can be argued that in the early stages there are always opportunities to collaborate, while in later stages partners are more focused on resolving conflicts as the internal and external conditions of the relationship change.

\subsubsection{Modes of interaction to consciously affect interaction}

Table 3.4 shows that both the start-up and its partners used a variety of interaction modes; they acquiesced, compromised, created, avoided, defied and manipulated. Although the numbers are small, the number of times that the start-up and its partners interact in a particular way can be compared. It appears that the start-up and its partners were almost equally likely to compromise, create, avoid, defy and manipulate. For example, the start-up avoided its partner once, while its partners used this mode of interaction two times. In addition, they both used a creation mode of interaction four times. Table 3.4 indicates that a key aspect of the interaction mode 'create' is the involvement of third parties. In all instances, the start-up and its partners were able to find novel, useful solutions to particular issues by involving a third party into the relationship. If the start-up and its partners would not 
have had these connections, it would have been very hard to overcome their issues. Moreover, the start-up compromised three times and its partners four times. The start-up negotiated with the teaching hospital, the health foundation and the market leader the terms of their collaboration cooperatively. Only the start-up acquiesced twice as often as its partners in the interaction episodes. For instance, the start-up acquiesced when the teaching hospital proposed to submit a grant proposal to gain funding from the European Commission and when the market leader asked if the start-up was interested in using its new sensor in the clinical trials with the artificial pancreas. To sum up, the start-up and its partners both used all modes of interaction and, with the exception of acquiescence, also to roughly the same extent.

\subsubsection{Modes of interaction to consciously affect interaction}

Table 3.4 shows that in seven episodes, the start-up and one of its partners used exactly the same mode of interaction: create-create (three times), compromise-compromise (three times) and avoid-avoid (once). In the remaining 11 episodes, the modes of interaction appeared to have the same nature in the sense that: (1) the partners both followed or at least take the interests of the counterparty into account; or (2) they only acted in accordance with their own interests. For example, the research institute attempted to force the start-up to join the multipartner project while the start-up challenged this coercion without taking each other's interests into account. Furthermore, the partners compromised over the agreements in the proposal for the grant from the European Commission, whereas the start-up just complied with their propositions. Thus, there is a clear co-occurrence of interaction modes of the start-up and its partners within a single episode; either the interaction mode was exactly the same or had the same nature. In addition, Table 3.4 shows that at the beginning in three out of the six relationships the modes of interaction were acquiescing or compromising followed by defiance, avoidance or manipulation in later stages and subsequently creation. For example, the research institute and the start-up initiated the relationship because the institute had the knowledge to develop a new, better sensor while the start-up had the ability to commercialise it. Yet 
when the research institute started the multipartner program a conflict arose about the transfer of the start-up to that program leading to defiance and manipulation. Nevertheless, they are now creating a solution to this problem by involving the health foundation. In conclusion, there appears to be a pattern in the development of the start-up's and its partners' interaction modes during the relationship.

\subsubsection{The outcome of interaction on the actors involved, their resources and activities}

It can be concluded from Table 3.4 that in the 12 episodes perceived to expand the opportunities for future interaction seven times the mode of interaction was acquiescence or compromise and had a (potentially) converting outcome. For example, the use of the market leader's sensors in one of the next clinical trials of the start-up can be beneficial to both. In turn, this motivated the start-up to acquiesce to the request of the market leader. Furthermore, there were three episodes with an inhibiting effect after the start-up and its partners acted by compromising, defying and ignoring in response to an opportunity. In these instances, either one of the partners was unable to take the preferred action or the interaction process was influenced by factors outside the control of both partners. The health foundation was unable to act in conformity because it was restricted by its audit committee from funding the development of the artificial pancreas. Also, the grant proposal of the start-up and the health foundation was declined by the national government. Moreover, in the remainder two episodes, the partners acted by ignorance and creation and the subsequent the outcome was mixed. Additionally, in the four episodes perceived to constrain the opportunities for further collaboration, the interaction outcome was twofold: (a) creative actions did solve the issue and had a (potentially) converting effect; and (b) defying and manipulation caused the issue to escalate and had an inhibiting effect. The same applies when the start-up and its partner did not agree whether the event was positive or negative in nature. Therefore, there appears to be a close interlinkage between trigger, mode of interaction, interaction and outcome. 


\subsection{Discussion}

The aim of this paper was to study how a start-up interacts with its partners over time in order to embed itself in the established developing, producing and using setting. The investigated start-up is clearly embedded in the developing setting. It built several relationships with the partners in the existing diabetes device development network, such as the teaching hospital and the partners of the European project. The start-up's relationships are all research and development oriented. Only following the initiation of the relationship with the market leader could the start-up take its first steps to become embedded in the producing and using settings. However, it still has a long way to go before it can actually produce the artificial pancreas and introduce it successfully into the market. To be able to become embedded in the developing setting and take the first steps into the producing and using settings, the start-up needed to interact with its partners. Without this interaction the start-up would not have been able to initiate, maintain and end its relationships in the pre-existing network.

The Results and Analysis sections show that the evolution of the interaction between the start-up and its partners over time can be characterised as a sequence of interaction episodes. These episodes are interlinked because the outcome of a previous episode affects the interaction in the subsequent episode. Moreover, Table 3.4 demonstrated that within each episode the start-up and a specific partner use a certain type of interaction mode - acquiesce, compromise, create, avoid, defy or manipulate - to respond to an internal or external trigger. In turn, an interaction process is set in motion in which action and reaction go back and forth between the partners. This interaction process results in a converting, inhibiting or mixed outcome for the start-up and its partners as well as for their activities and resources. To discuss each of these aspects in-depth, in this section the research questions raised in the Theoretical Framework section are addressed. 


\subsubsection{A series of sequential episodes represent the interaction process}

The first research question was formulated as: How are the interaction episodes between a start-up and its partner interlinked? The analysis shows that when the previous interaction episode had a converting outcome, the start-up and its partners were more likely to acquiesce and compromise during the next episode. Only when a conflict between them occurred, a positive outcome of the previous interaction episode led to defiance and avoidance in the next episode. When the previous interaction episode had an inhibiting outcome, the start-up and its partners defy, avoid and manipulate in the current one. Only when an opportunity arose that allowed the partners to create a solution, the start-up and its partners acted creatively. Thus, it can be concluded from the analysis that previous episodes affect subsequent episodes. This confirms that the suggestion of Medlin (2004) and others that organisations memorize and interpret previous interaction episodes to decide on how to act in a subsequent episode. In addition, the results showed that the start-up and its partners were influenced by future expectations about the relationships. If the trigger that initiated action from either partner provided an opportunity to advance the collaboration, the future expectations of the outcome of the relationship were positive. In turn, the partners were more likely to acquiesce, compromise and create. However, if the trigger that initiated action inhibited the opportunity to maintain or develop the collaboration, the partners had negative expectations of the outcome of the relationship. As a result, the partners would be more inclined to avoid, defy and manipulate. Indeed the IMP approach argues that not only history impacts on the interaction in a current episode, but also the expectations about future interaction. A particular action can either positively or negatively impact the economic, technical and social outcomes of the interaction episode. If an organisation expects that the potential outcome will be less efficient than it could be, thereby harming innovation and reducing legitimacy, then it will try to counteract the outcome, and vice versa (Håkansson et al., 2009). 


\subsubsection{External and internal triggers that change the opportunities for future interactions}

The second research question was: What triggers deliberate action by a start-up and its partner? The analysis demonstrates that an external trigger often marked the start of the relationship. This finding is similar to the results reported by Holmen et al. (2005) who found in a case study of a small Dutch company that its counterparties initiated the first contact, the contact was initiated by a direct counterparty or the contact was initiated at a public meeting, such as a trade show or trade fair. It may be that the start-up in this case did not directly initiate a relationship with a potential partner as it had only restricted attention from key decision makers in its partner's organisation. Although the importance of establishing the start-up's first relationships is widely recognized (La Rocca et al., 2013), research shows that start-ups often find it very difficult to contact the right individuals in a potential partner's organisation (Das \& He, 2006; Prashantham \& Birkinshaw, 2008). Furthermore, the analysis shows that internal events were equally likely to occur as external events during the relationships. This supports the findings of several authors (e.g. Ariño \& de la Torre, 1998; Medlin, 2004) who found that organisational action is the result of incidents that occur either inside or outside the interaction context.

More importantly, however, the findings reveal that action is triggered by events that expand as well as constrain the opportunities for future interaction. This is in conflict with the findings of Ariño and de la Torre (1998) who found that if the value from the relationship could increase then the initial agreements are executed, but no re-negotiations would follow which may lead to a set of revised agreements beyond the initial one. However, they did a longitudinal case study on the interaction between two partners in a failed joint venture, whereas in this case all the relationships continue to exist. Therefore, the difference may be explained by the fact that in successful relationships partners act on opportunities for further collaboration, while in failing partnerships they do not. Another explanation may be found in the focus of Ariño and de la Torre (1998) on events that triggered action when the relationship was already established, while this paper also included the initial 
interaction episodes in the analysis. The results show that in the early stages there are always opportunities to expand the collaboration. In contrast, in later stages partners have to resolve conflicts as a result of changes in the internal and external conditions of the relationship. Therefore, it may be that Ariño and de la Torre (1998) would have identified events expanding the opportunities for future collaboration that actually triggered action if they would have researched the partners' interaction from the start of the relationship. Taken together, these findings imply that the ultimate success or failure - as well as the stage of a relationship - is important to the nature of the triggers that occur.

\subsubsection{Modes of interaction to consciously affect interaction}

The third research question was formulated as follows: What modes of interaction do a start-up and its partners use? The analysis demonstrates that the start-up and its partners used all six interaction modes. This confirms that the six proposed interaction modes, based on the work of Tjemkes and Furrer (2010) and Lui and Ngo (2005) on established organisations, can also be applied to start-ups. The results of this paper showed that the start-up and its partners used the interaction modes to a similar extend with the exception of acquiesce. This contradicts the findings of Ariño et al. (2008) who found that entrepreneurial firms are less likely to act, and thus avoid their partner, in the presence of governance misalignments than large firms. In this case, the startup and its partners did not experience either excessive or insufficient governance that required action which may explain the contradictory findings. However, it confirms the results of Thorgren et al. (2012) who demonstrated that small firms are more likely to acquiesce than larger firms. It may be that the start-up was more likely to comply with the requests of its partners because it was asymmetrically dependent on that partner. For example, the start-up stated that it complied with all the advice of the teaching hospital regarding the European grant proposal as it did not have the required knowledge of how to write a good proposal. Research into established organisations has already demonstrated that certain characteristics of a relationship, such as dependence and trust, influence organisational interaction (e.g. Lui \& Ngo, 2005; Tjemkes \& Furrer, 2010). However, the underlying rationale for taking a particular action can be 
expected to differ between start-ups and established organisations because of their differences in their efforts to build legitimacy, the type and frequency of external demands, how much they dependent on the relationship and the goals of their organisation (Thorgren et al., 2012).

In addition, the analysis reveals that an important aspect of create is the involvement of third parties. This confirms the findings from Corsaro, Ramos, Henneberg, and Naudé (2011) who demonstrate that network characteristics affect organisational action in a relationship. At the same time, it suggests that the mode of interaction also affects the network in which the relationship is embedded. By involving the third partner into the relationship between the start-up and a particular partner, the balance between the relationships in its network changes. Thus, this confirms the notion of the IMP approach that neither a single organisation nor a single relationship acts in isolation; each relationship will be affected by and affects to a greater or lesser extent the relationships to which it is connected.

\subsubsection{Interaction: the action-reaction loops between counterparties}

The fourth research question was: How do the interaction modes of a start-up and its partners co-occur? The analysis shows that the interaction mode was either exactly the same or at least was of the same nature. Acquiesce, compromise and create co-occurred during the interaction episodes between the start-up and its partners while manipulate, avoid and defy happened together. Acquiescence, compromising and creation have in common that these interaction modes follow or consider the wishes of the partners. Avoidance, defying and manipulation share that a partner tries to force counterparty in a particular direction. This dichotomy overlaps with the two approaches to networking identified by the IMP approach: coerce and concede. Through coercion organisations try to direct specific aspects of interaction in accordance with their own intent, while by conceding they follow the wishes of their partner (Håkansson et al., 2009). Yet the analysis suggests that start-ups and their counterparties have multiple opportunities to choose from in the way they coerce or concede. Also, the analysis reveals a pattern in the development of the start-up's and its partners' interaction 
modes during the relationship from acquiescence and compromise, to manipulation, defiance and avoidance and eventually creation. This pattern may be caused by the development of the trigger over time; in the early stages there are opportunities to expand collaboration which leads to more conceding modes of interaction while in later stages conflicts arise that result in more coercing modes of interaction. However, as soon as the partners realise that they could harm the relationship by acting coercively, they try to develop a solution to the mutual problem. Indeed, the IMP literature argues that as the relationship between partners develops through interaction, they have to agree on more details of their relationship than in the beginning when 'everything' is still possible (Håkansson et al., 2009). This pattern in the evolution of the interaction modes over time emphasises that a focus on a single type of action, as described in the work of Thorgren et al. (2012) and Ariño et al. (2008), limits our understanding of how action evolves over time.

\subsubsection{The outcome of interaction on the actors involved, their resources and activities}

The final research question can be expressed as: What is the outcome of the interaction process between a start-up and its partner? This case shows that interaction episodes had either converting, inhibiting or mixed outcomes. This confirms contemporary literature that outcomes can be either positive and negative (Edvardsson et al., 2008; Elo \& Törnroos, 2005). On the other hand, the mixed outcomes also imply that partners do not always perceive the outcome in the same way and that there may be both positive and negative aspects of the outcome. Previous research, such as that by Tjemkes and Furrer (2010), Lui and Ngo (2005) and Ariño et al. (2008), into organisational action in relationship has mainly focused on its antecedents; what triggers action by a partner and why does a partner chooses a particular action? Although it is important to be able to determine in what situation a particular interaction mode can be used, it does not say anything about whether that is the best action to use. Without considering the outcomes of an action, it is impossible to assess whether that particular mode of interaction will be beneficial or harmful to a specific relationship. It may be that previous studies did not research outcomes because the multidimensional character of relationship outcomes makes them hard to 
interpret (Ford et al., 2008; Håkansson et al., 2009). Conversely, previous research may have implicitly assumed the outcome of certain actions in advance. When acquiescing, compromising and creating, the partner takes the interests of the counterparty into account. Therefore, these modes of interaction are generally expected to result in a converting outcome. On the other hand, avoidance, defiance and manipulation challenge the interests of the other partner. Consequently, these modes of interaction are usually expected to cause an inhibiting outcome. Although the analysis of this case seems to confirm the latter assumption, a conceeding interaction mode did not always result in a converting outcome. In these instances, it appeared that the partners were unable to use the preferred mode of interaction due to internal restrictions or because the interaction process was negatively influenced by external factors. Therefore, the mode of interaction is influenced not only by willingness, but also by the ability to act in a particular way (Oliver, 1991).

Additionally, it can be concluded that there seems to be a close linkage between trigger, mode of interaction, interaction and outcome. If the trigger expands the opportunities for collaboration, the start-up and its partner acted in a conceding way (if they were able to) and this led to a converting outcome. However, if the trigger constrains opportunities for further interaction, the start-up and its partner acted in a coercive way or creative way, and this resulted in an inhibiting or converting outcome respectively. In summary, it is not necessarily the case that conceding and coercive actions lead to converting and inhibiting outcomes respectively.

\subsection{Conclusion}

This paper has contributed to the existing literature on start-ups' actions in relationships by researching how a start-up interacted with its partners, and offers process-focused explanations in this start-up's attempt to embed in a pre-existing network. This was done by developing a conceptual research model in which interaction and dynamics are key aspects. This model was used to analyse the interaction episodes of a start-up in the medical device business with its partners. The results show a high co- 
occurrence of interaction modes which emphasises the interactive nature of the start-up's actions. In addition, they reveal an evolution of interaction modes over the course of the relationship, a clear link between trigger, action, interaction and outcome, and an impact of previous episodes on current ones. All three findings highlight the dynamic nature of the start-up's actions. Moreover, it was found that: (a) triggers can be internal or external in origin and can expand or constrain the opportunities for future interaction; (b) the start-up used a variety of modes of interaction and (with the exception of acquiescence) to a similar extent to its partners; and (c) the start-up and its partners rely on their network to create novel and potentially useful solutions to conflicts. In conclusion, this paper shows that the start-up's actions were not one-sided and stable, but interactive and dynamic.

\subsubsection{Implications for future research}

This paper provides six directions for future research. Firstly, previous literature and this paper provide contradictory results regarding the importance of opportunities for organisational action. As a result, future research may wish to further explore if and how 'beneficial' situations as opposed to 'adverse' situations result in organisational action and in turn affect the outcomes of the relationship. Secondly, the co-occurrence of interaction modes in a single episode and the development pattern of interaction modes during the relationship, stress the importance of analysing the regularities and the recurrence of action in relationships. In other words, interaction modes should be studied in relationship to other actions both preceding and following it. Lui and Ngo (2005) identified three action patterns to characterise cooperative processes: action acquiescence, action simplicity and action reciprocity. As their research was based on established organisations, future research should address the question if these interaction patterns also apply to start-ups. The interaction patterns in single episodes and over multiple episodes that appeared in this research can be used as the starting point to further develop and study the interaction patterns of startups. Thirdly, the conclusions were drawn from 18 episodes of a single startup which limits the ability to say something meaningful about the relationships between trigger, mode of interaction, interaction and outcome in other contexts, i.e. start-ups in other industries or with other types of 
relationships. Nevertheless, the results could form the basis for hypotheses on the relationship between these aspects that can be tested in a larger and more divers sample of start-ups. Fourthly, the discussion reveals that several factors, such as relationship characteristics and perceptions of the past and future interaction, influence the preference for a particular type of action in an episode. Taking into account these factors in future research will help scholars to explain why start-ups and their partners act in the ways in which they do. Fifthly, the research revealed that the start-up and its partner relied on their network to create innovative solutions to their problems. Therefore, it would be interesting to initiate further research on how an interaction mode of a partner in a relationship affects and is affected by the surrounding network. Finally, managers do not only need to know what modes of interaction can be used in a certain situation, but also what the action with the most beneficial outcome is. Therefore, future research into organisational actions in relationships should involve both the antecedents of actions and their outcomes to be of practical value.

\subsubsection{Practical implications}

The findings of this paper also have several implications for the managers, owners and directors of start-ups. Firstly, and most importantly, managers of start-ups have the ability to act in a variety of ways over time and in a variety of relationships. Although they do not have complete control the outcome of the interaction process, they do influence it with their actions. The case shows that if the start-up acquiesced, compromised or created it was more likely to result in converting outcomes, whereas when it avoided, defied or manipulated it was more likely to result in inhibiting outcomes. Secondly, managers of start-ups do not only have to act in response to internal or external events that constrain the opportunities for future interaction, but also to opportunities that expand the scope for future collaboration. Thirdly, they have to closely consider the ways in which they are going to act or react because partners are likely to act in a similar way. If a manager wants a partner to concede it should not act coercively because that would probably trigger a coercive reaction. Fourthly, managers of start-ups have to be aware that they can and need to rely on their network to resolve conflicts with their partners. 
Fifthly, they need to create an understanding of their own and their partners' interaction patterns. In this way, they will be better able to anticipate the actions and reactions of their partners. Finally, they can stimulate the initiation of relationships by seeking media attention, attending both public and private meetings and using existing partners to connect to potentially new partners. 


\section{CHAPTER 4}

Power in a start-up's relationships with its established partners: interactions between structural and behavioural power

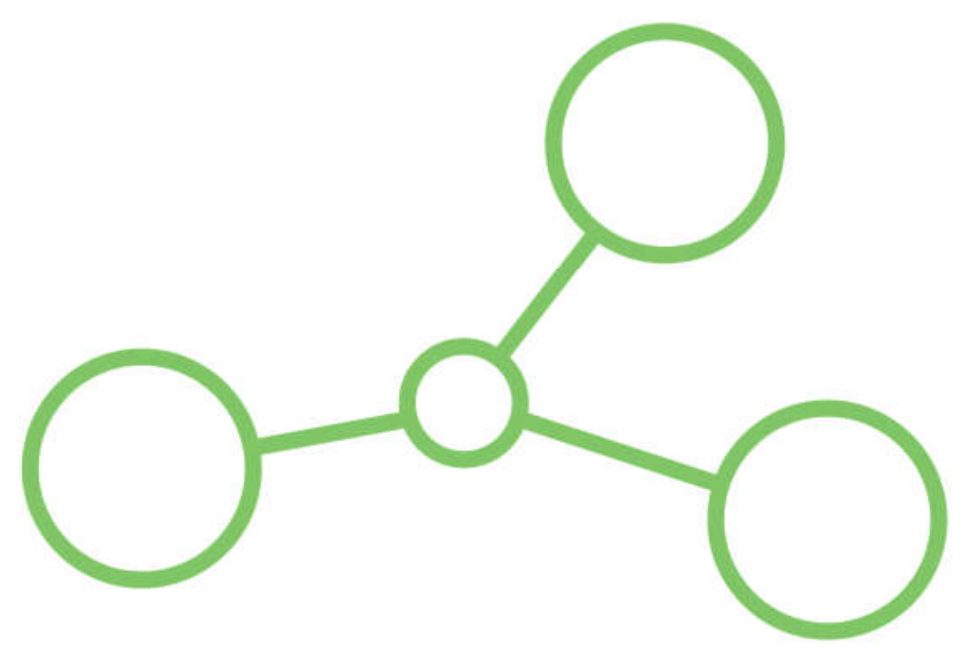

This chapter is published as Oukes, T., Groen, A. \& Raesfeld, A. v. (2017). Power in a start-up's relationships with its established partners: interactions between structural and behavioural power. Industrial Marketing Management. https://doi.org/10.1016/j.indmarman.2017.12.007 (in press). A preliminary version of this paper was presented at the HTSF conference in Enschede, The Netherlands, June 2014 and the $30^{\text {th }}$ annual IMP conference in Bordeaux, France, September 2014. 


\section{Abstract}

Power plays a key role in the relationships between startups and established organisations. Yet researchers have devoted little attention to the startup's perspective on power in such relationships. To study startups' view on power, a useful starting point is their structural power, but this also requires an investigation of their power behaviour. We explore how structural and behavioural power interrelate in a startup's relationships with its established partners in the medical device business. Our longitudinal, embedded case study reveals nine interaction episodes in which power plays a decisive role. The power episodes show that the case startup often uses hostile power use tactics because it overestimates its structural power. Since its established partners recognise its lack of power, they usually do not accept such behaviour. Thus, the case startup could not extract the intended benefits. Nonetheless, we find that the case startup could benefit from its relationships if it employs conciliatory power use tactics or power change tactics. With these insights, we contribute to the startup business relationship literature by providing a better understanding of startups' experience with power. We also extend the power literature by showing that it is the perception of power that determines power behaviour rather than the de facto structural potential.

\subsection{Introduction}

When startups are founded, they are usually exposed to liabilities of smallness and newness: they lack the resources (e.g. financial, human, social and/or marketing capital) and have not yet established the business relationships (e.g. with suppliers and customers) necessary to successfully exploit opportunities for new products and services (Aaboen, Holmen \& Pedersen, 2017; Bruderl \& Schussler, 1990; Laage-Hellman, Landqvist \& Lind, 2017). These liabilities can be compensated for by interacting with other organisations (Das \& He, 2006; Håkansson, Ford, Gadde, Snehota \& Waluszewski, 2009). Research has shown that especially relationships with established organisations are a major source of financial and non-financial resources (Baum, Calabrese \& Silverman, 2000; Deeds \& Hill, 1996). They can also provide startups with the legitimacy and endorsement they need to survive (Bengtsson \& Johansson, 2012; Stuart, 2000). However, startups and 
established organisations do usually not have compatible goals, shared benefits and mutual interdependence (Chicksand, 2015). Thus, their interactions are usually characterised by disagreements about what to do and how to do it. To coordinate their relationship, they need to negotiate and use their power, because there is a lack of formal hierarchy (Achrol, 1997; Pfeffer, 2009; Whetten, 1981). Thus, power is an important characteristic of interactions between startups and established organisations, and an unavoidable mechanism to decide on an appropriate course of action (Achrol, 1997).

However, few studies have investigated startups' views on and experience with power in relationships with established organisations. Researchers have directed considerable attention to power's roles in buyersupplier relationships. For instance, they have researched how poweradvantaged partners use their power to influence less powerful partners (for an overview, see Habib, Bastl \& Pilbeam, 2015; Johnsen \& Lacoste, 2016). However, in its early stages, a startup will not always have customers or suppliers yet (Aaboen, Dubois \& Lind, 2011; La Rocca, Ford \& Snehota, 2013). Accordingly, they will also develop their initial business idea by interacting with universities, research institutes, governmental institutes, non-profit organisations and the like (Zeng, Xie \& Tam, 2010). Previous research, such as work by Herlin and Pazirandeh (2012) and Tang, Tang and Katz (2014), indicates that power also shapes the interactions with these types of established organisations. However, these studies have focused on established non-profit organisations and small and medium-sized enterprises (SMEs) which, unlike startups, are not (as strongly) confronted by liabilities of newness (Bruderl \& Schussler, 1990). Also, research into startups' business relationships has either ignored power altogether or has treated it in less depth. It has primarily focused on other topics, such as resource complementarity (Rothaermel \& Boeker, 2008), initial customer relationships (Aaboen et al., 2011; La Rocca et al., 2013), partner selection (Das \& He, 2006; Diestre \& Rajagopalan, 2012), capabilities (Chen, Zou \& Wang, 2009; Vandaie \& Zaheer, 2014) and network composition (Baum et al., 2000; Hoehn-Weiss \& Karim, 2014). 
To create an understanding of power, researchers have typically used either a structural or a behavioural perspective (Meehan \& Wright, 2012; Olsen, Prenkert, Hoholm \& Harrison, 2014). The structural perspective understands power as the underlying potential to influence future outcomes (Provan, 1980), while the behavioural perspective interprets power as the exercise of this structural potential (Molm, 2009). On the one hand, studies from a structural perspective have shown that startups are usually in a powerdisadvantaged position vis-à-vis their established partners owing to their liabilities of newness and smallness (Gardet \& Fraiha, 2012). Thus, the relationship's benefits are often skewed towards the established organisation (Alvarez \& Barney, 2001). On the other hand, studies from a behavioural perspective have shown that power-disadvantaged organisations are not locked into a power position (Cowan et al., 2015). They can undertake power change tactics (Kim, Pinkley \& Fragale, 2005) to impose their will on a powerful partner and can mediate against a powerful partner's power (Johnsen \& Lacoste, 2016). For instance, Tang, Tang and Katz (2014) have taken a behavioural perspective to show that proactiveness can decrease a SME's power differences with the media and government. Structural and behavioural power must be understood as simultaneous, complementary processes because "structure arises from the actions of people and these actions are shaped by structure" (Brass \& Burkhardt, 1993, p. 443). Nonetheless, Olsen et al. (2014) have shown that few studies have combined the two approaches (see also Huxham \& Beech, 2009; Meehan \& Wright, 2012). A few exceptions - such as Lai (2009) as well as Plouffe, Bolander, Cote and Hochstein (2016) - have simultaneously applied the two approaches to study power in buyer-supplier relationships, but did not investigate the unique context of startups' interactions with established organisations.

There is a need to create a better understanding of power in the interactions between startups and established organisations from a startup's perspective. Moreover, research must go beyond studies with a single power approach towards investigations of both structural and behavioural power in such interactions. We address these needs by investigating the following research question: How do structural and behavioural power interact in a startup's relationships with its established partners? To answer this question, 
we conduct a longitudinal case study on a startup with R\&D relationships with seven powerful established organisations - a teaching hospital, a health foundation, a market leader, a research institute, a software company, an industry player and a glucagon provider - to develop a new medical device for the treatment of diabetes. The primary focus is on power's roles in the case startup's interactions with its established partners from the startup's perspective. Yet power is a relational concept (Huxham \& Beech, 2009), i.e. a startup's structural and behavioural power cannot be fully explained without considering those of its partners (Meehan \& Wright, 2012; Oukes \& Raesfeld, 2016; Rutherford \& Holmes, 2008). For this reason, we take an interactive approach to study power's roles in this startup's interactions with its established partners.

We seek to contribute to the startup business relationship and power literatures. First, we extend the startup business relationship literature by studying power's under-examined roles in the interactions between a startup and its established partners. Second, we contribute to the power literature by investigating power in these interactions from a structural and a behavioural perspective simultaneously rather than by applying a single approach. We also seek to provide support to startup managers. Through a better understanding of power's roles in their interactions with established partners, startup managers will be better able to understand a partner's perspective (Barbuto \& Gifford, 2009). Further, they will have a more transparent vision of their own and their partner's current and future power (Lacoste \& Johnsen, 2015; Lee \& Johnsen, 2012). In turn, they are better equipped to enact desired changes, set development properties, manage problems and make decisions that will impact on how they are perceived and valued (Barbuto \& Gifford, 2009; Lee \& Johnsen, 2012).

This paper proceeds with the state-of-the-art literature regarding the structural and behavioural approaches to power and the relationships between them. In the methodology, we briefly describe our research design. This is followed by a detailed description of nine power episodes between the case startup and its established partners. Drawing on this description, we 
summarise the interactions between the case startup's structural and behavioural power and its established partners. We conclude with an analysis of our findings, theoretical contributions, managerial implications, our study's limitations and suggestions for further research.

\subsection{Theoretical framework}

There are two approaches to understanding power (Brass \& Burkhardt, 1993; Huxham \& Beech, 2009; Olsen et al., 2014; Pfeffer, 2009). The first approach focuses on structural capacity (Pfeffer, 2009) and reflects the properties of a social system (Brass \& Burkhardt, 1993). It provides a structural perspective on power, since it refers to the larger organisational context in which the day-to-day operations of an inter-organisational relationship take place (Brass \& Burkhardt, 1993; Huxham \& Beech, 2009). The second approach to power derives from an organisation's particular actions within a structural context (Brass \& Burkhardt, 1993; Pfeffer, 2009). It offers a behavioural perspective on power, because it focuses on the day-to-day enactment of power between organisations (Huxham \& Beech, 2009). The structure-behaviour split also exemplifies the distinction between potential power and power use (Brass \& Burkhardt, 1993) and the macro-level and microlevel perspectives on power (Huxham \& Beech, 2009). We will now explain the structural and behavioural perspectives on power and will then relate the two perspectives based on Kim et al.'s (2005) framework.

\subsubsection{Structural power: Resource control, network position and formal position}

Although various structural sources of power at different levels have been identified (Huxham \& Beech, 2009), they can be categorised into three types. The first type includes work that argues that power derives from control over resources (Pfeffer, 2009) needed by another (Pfeffer \& Salancik, 1978). These organisations that control the supply of critical resources that are not controlled or mediated by others acquire power, since they increase others' dependence on them (Astley \& Sachdeva, 1984; Brass \& Burkhardt, 1993). For instance, Forshey (2014) shows that the initial bargaining position of a startup and an established organisation are based on the control over resources desired by the other. Startups with more valuable resources receive a greater financial contribution from their established partner. Yet when 
established organisations control more valuable complementary resources, such as manufacturing capabilities and commercialisation experience, they decrease their financial contribution to the partnership beyond a fair market exchange. In turn, this limits startups' ability to profit from the innovations they create (Forshey, 2014).

A second form of structural power derives from an organisation's position in its network (Astley \& Sachdeva, 1984; Huxham \& Beech, 2009; Pfeffer, 2009). To survive, grow and prosper, startups need to initiate business relationships (Bliemel \& Maine, 2008). Startups are more likely to form relationships with well-positioned organisations owing to their access to potential partners (Ahuja, Polidoro \& Mitchell, 2009) and relevant resources (Brass \& Burkhardt, 1993). For instance, Oukes and Raesfeld (2017) show that a medical startup was almost exclusively reliant on two wellpositioned established organisations to develop its relationship portfolio. Thus, established organisations that are central to a network (i.e. with many direct relationships with other organisations) are in a strong position to influence startups (Huxham \& Beech, 2009; Pfeffer, 2009). Especially organisations that occupy a bridging position between two or more unconnected or weakly connected organisations acquire power, since they provide value or benefits by accessing information or social ties that other organisations cannot (Burt, 1992; Pfeffer, 2009). Indeed, Olsen et al. (2014) have found that retailers with a gatekeeper function are able to encourage, direct and force suppliers to restructure their activities for their own benefit.

A third structural source of power is the influence that derives from occupying a formal position. An official position come with hierarchical authority rights: the right to make decisions and to allocate tasks and resources (Astley \& Sachdeva, 1984; Pfeffer, 2009). Inter-organisational relationships are usually considered to lack traditional hierarchy. Yet there may be situations in which an organisation is given formal authority over other organisations in a collaboration via legislative mandate or prior agreement (Provan, 1980). This may especially be the case in governmentsponsored multipartner partnerships in which an official lead organisation 
must be specified (Kassler \& Goldsberry, 2005). Conversely, partners may voluntarily appoint decision rights and authority to a lead organisation to allow for effective decision-making in a multipartner setting (Albers, Schweiger \& Gibb, 2015). The organisation with formal authority can dominate decisions about which organisations to involve and how joint objectives are formed and carried out (Huxham \& Beech, 2009). Thorgren, Wincent and Boter (2012) have shown that especially startups are more likely to comply with group norms determined by a lead organisation in a multipartner partnership than large organisations. They typically have less power vis-à-vis other participants, since they are highly dependent on participation in a multipartner partnership. Thus, a startup risks losing its access to a partner's resources if it violates group norms. Further, breaking such norms may signal a lack of social competence, allowing distrust to develop (Thorgren et al., 2012).

\subsubsection{Behavioural power: Power change and power use tactics}

Behavioural power studies investigate the power tactics an organisation employs to influence its partner (Brass \& Burkhardt, 1993; Kim et al., 2005). In specific, power use tactics concern the ways in which organisations may attempt to leverage structural power sources, while power change tactics concern the ways in which they attempt to alter a power relationship (Kim et al., 2005).

Power change tactics. Organisations sometimes perceive that they possess insufficient structural power to obtain desired outcomes. As can be concluded from the discussion above, startups often have less structural power than their established partner. When one organisation primarily holds the power, its partner may attempt to improve its own power to acquire a greater share of the total exchange value (Bazyar, Teimoury, Fesharaki, Moini \& Mohammadi, 2013; Ford, Wang \& Vestal, 2012; Kim et al., 2005; Lacoste \& Johnsen, 2015). Kim et al. (2005) argue that there are four basic power change tactics - also known as power-balancing process (Hallen, Katila \& Rosenberger, 2014; Molm, 2009) and countervailing power (Lacoste \& Johnsen, 2015). Organisations can alter a power relationship by 1) improving the quality of their alternatives, 2) decreasing the quality of a partner's 
alternatives, 3) decreasing the valuation of a partner's contribution, and 4) increasing a partner's valuation of their own contribution. The weaker organisation therefore seeks to reduce the power asymmetry by either increasing the importance of its own contribution to the stronger actor, or decreasing the importance of the stronger organisation's contribution for itself (Habib et al., 2015).

Power use tactics. Once an organisation perceives that it has sufficient structural power, it is inclined to exercise power use tactics - also known as influence strategies (Lai, 2009) - to obtain desired benefits (Kim et al., 2005). However, an organisation can also act as if it has power since its partners usually do not operate with complete information (Brass \& Burkhardt, 1993). Therefore, startups may also create the impression that they have power by applying power use tactics. There are two major research traditions in the study of power use tactics: the business-to-business (B2B) marketing and channels literature and the management and industrial/organisational psychology literature. A review of both literatures identifies 11 unique power use tactics: consultation, collaboration, personal appeal, inspirational appeal, apprising, integration, exchange, coalition, legitimation and pressure (Plouffe et al., 2016). However, Kim et al. (2005) conclude that an overwhelming number of tactics is not helpful as an organising framework for a theoretical analysis. Instead, they propose using the broad distinction between conciliatory and hostile power use tactics (Lawler, 1992). Conciliatory tactics involve positive acts, such as coordination or collaboration, to extract benefits in ways that reduce a partner's damage. Hostile tactics refer to negative acts, such as competition, intimidation and resistance, to extract benefits in ways that increase the harm to a partner (Kim et al., 2005).

\subsubsection{The interaction between structural and behavioural power}

The structural and behavioural perspectives on power can be viewed and are usually treated as alternative explanations (Brass \& Burkhardt, 1993). However, power is not only potential in that it derives from structures, but also actual in that it only exists when used. All the structural power available to an organisation is seldom exercised in all circumstances (Provan, 1980). Its 
exercise depends on an organisation's structural power and the structural power and power behaviour of those with which it interacts (Oukes \& Raesfeld, 2016; Rutherford \& Holmes, 2008). For instance, an organisation can have structural power owing to its possession of and access to resources, but whether it enacts that power depends on its partner's power and behaviour. Thus, structural power can be possessed, but its exercise is spatially and temporally contingent (Rutherford \& Holmes, 2008). Owing to this two-sided interaction between structural and behavioural power over time, power is inherently dynamic.

Kim et al. (2005) offer a two-sided dynamic framework to explain how structural power relates to behavioural power. The framework was designed to explain interpersonal power in negotiations within organisations. Interpersonal power within organisations is different from power in interorganisational relationships. The main difference is the form of power that can be used to coordinate activities: inter-organizational coordination builds on subtle forms of power (i.e. resource control and networks centrality), while it also occurs through an overarching formal authority structure within organisations (Achrol, 1997; Whetten, 1981). However, inter-organisational relationships are embedded in networks of personal relationships (Granovetter, 1985): individuals represent the organisation and negotiate on its behalf (Wilkinson, 1996). For this reason, they are also subject to elements of interpersonal relationships (Whetten, 1981), such as social, friendship and reputation influences (Achrol, 1997; Meehan \& Wright, 2012). Especially, Larson (1992) shows that personal relationships play an important role in the initiation, coordination and control of startups' business relationships. Thus, interpersonal power frameworks are shown to be powerful in explaining power at the inter-organisational level (e.g. Davenport \& Leitch, 2005; Ford et al., 2012). In addition, Herbst, Schwartz and Voeth (2008) have shown that the differences in negotiation characteristics (e.g. the parties, interests, processes and outcomes) between intra-organisational and interorganisational negotiations are limited. Thus, we propose that Kim et al.'s (2005) framework is also applicable to study power in interaction between startups and established organisations. Accordingly, we describe it here from an inter-organisational perspective. The framework relates structural to 
behavioural power through linking it to perceived power and realised power. Since we explained structural and behavioural power in Sections 4.2.1 and 4.2.2, we will now focus on perceived power, realised power and the underlying relationships.

Perceived power. Perceived power is defined as an organisation's assessments of its own structural power and its partner's structural power (Kim et al., 2005; Wolfe \& McGinn, 2005). Perceived power is an important concept if one is to understand the relationship between structural and behavioural power (Huxham \& Beech, 2009). Nonetheless, the concept has received limited attention in the inter-organisational power literature, because it generally does not question the objectivity of respondent-reported power (Huxham \& Beech, 2009; Meehan \& Wright, 2012). Yet these responded-reported interpretations of power are more consistent with perceived power than with structural power (Meehan \& Wright, 2012). Previous research has shown that organisations' perceptions of their power do not correspond well to their structural power, i.e. their perceived power may diverge from their actual potential (Kim et al., 2005; Wilkinson, 1996; Wolfe \& McGinn, 2005). Since there is an absence of perfect information and there is bounded rationality (Kim et al., 2005), organisations cannot be aware of everything that goes on their own and their partners' organisations. They fill in these blanks based on witnessed power behaviour and other information sources. In turn, it is likely that their power perceptions are distorted (Pinkley, 1995; Provan, 1980; Wolfe \& McGinn, 2005). Further, the power perceptions of two or more partners in a relationship are likely misaligned (Huxham \& Beech, 2009). Thus, an organisation tends to form an imperfect perception of its own and the other's structural power. In turn, this imperfect power perception determines the way organisations change and use their power. In other words, it is the perception of power, rather than the actual structural potential, that drives power behaviour (Huxham \& Beech, 2009; Molm, 2009; Wilkinson, 1996; Wolfe \& McGinn, 2005).

Realised power. Realised power refers to the extent to which organisations extract benefits from a relationship through their power 
behaviour. The implementation of power tactics directly influences the extent to which an organisation can realise power (Kim et al., 2005; Wilkinson, 1996). The extent to which it uses power will also affect the accumulation and loss of (perceived) structural power (Huxham \& Beech, 2009; Kim et al., 2005; Wilkinson, 1996). The consequences of power use tactics for the relative power of two organisations depend on the type of tactic employed. Kim et al. (2005) suggest that an organisation will gain power if it uses conciliatory tactics, while it will lose power if it uses hostile tactics. Further, an organisation can build a reputation for being powerful through its power change tactics. If an organisation changes others' power perception, this perception may become a reality and it will gain power by being seen as being powerful (Ford et al., 2012). Thus, power behaviour can determine realised power and may modify the structural and perceived power of two organisations (Brass \& Burkhardt, 1993; Kim et al., 2005; Molm, 2009; Wilkinson, 1996).

Our theoretical discussion makes it possible to explain how a startup and its partner's structural and behaviour power interact by linking this to perceived and realised power. A startup and its established partner have a de facto power potential (i.e. structural power) derived from their resource control, network centrality and formal position. Based on this potential, they form an - often inaccurate - perception of their own and their partner's structural power. This perception, rather than their structural power, determines their power behaviour, reflected in the power tactics they employ: power change tactics (i.e. increasing one's own or decreasing one's partner's contribution) or power use tactics (i.e. using conciliatory or hostile tactics). In turn, the behaviour of a startup and its partner affects the extent to which they can derive the intended benefits from their relationship (i.e. realised power). Also, their power behaviour may change their structural and perceived power. These relationships are summarised in Figure 4.1. 


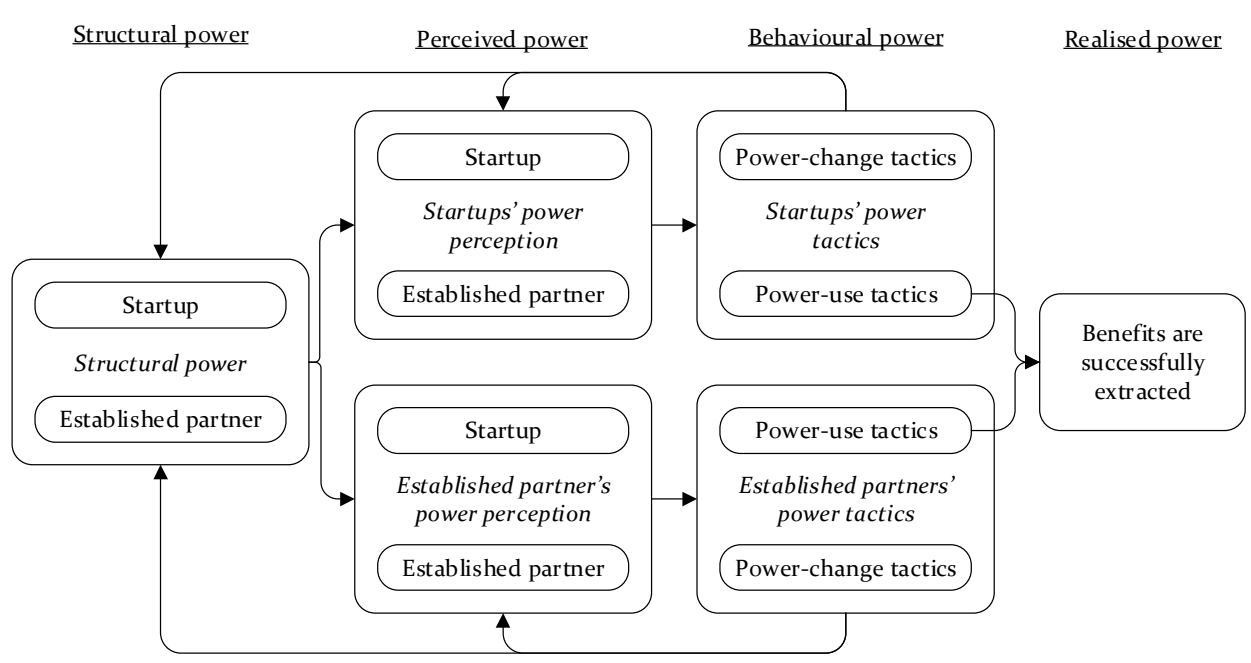

Figure 4.1 A framework of power in relationships between startups and established partners (adapted from Kim et al., 2005)

\subsection{Methodology}

We used a case study approach to investigate how structural and behavioural power interact in a startup's relationships with its established partners. We chose a case study approach for three reasons: 1) the choice for a case study was apparent because our study involves a social process (Swanborn, 2013); 2) a case study's inherent flexibility suits the study of complex, evolving relationships and interactions (Beverland \& Lindgreen, 2010); and 3) a case study allowed us to understand not just that something happened, but also how and why it happened (Huberman \& Miles, 1994).

\subsubsection{Subject of study}

The empirical data collection involved an in-depth case study of a startup in the medical device business. The case startup was developing a closed-loop bi-hormonal artificial pancreas, a new medical device for the treatment of diabetes type 1 patients. This breakthrough in diabetes management included the automated administration of insulin and glucagon while the patient's glucose level was continuously monitored. The case startup had a partially developed product and highly specific expertise with new technologies. However, startups in the medical device industry usually 
lack the following: sufficient cash to continue product development, technical expertise with the clinical trials process, manufacturing capabilities and commercialisation experience (Forshey, 2014). Consequently, the case startup collaborated with established organisations to overcome such weaknesses. We included all established partners that were crucial to the development of the case startup's artificial pancreas, whether or not they are (potential) customers/suppliers. Specifically, the case startup's five established partners were: 1) a teaching hospital that ran crucial clinical trials on the artificial pancreas, 2) a health foundation that connected the startup with key partners through its large network, 3) a research institute that developed a new sensor type that very accurately measures blood glucose levels, 4) a market leader in the diabetes market that could facilitate the marketing, sale and distribution of the artificial pancreas, and 5) a glucagon supplier that developed stable liquid glucagon, which is essential for the successful commercialisation of the artificial pancreas. Further, the case startup was involved in a Europe-funded project with six other organisations: the teaching hospital, a technical university, a medical university, an established industry player, a clinical research institute and a software company. The project sought to boost the development of the artificial pancreas and to bring it to the market as soon as possible.

\subsubsection{Data collection}

We collected the empirical data from the establishment of the case startup in 2008 until May 2016: from 2008 until April 2013, we conducted a retrospective analysis; from April 2013 until May 2016, we followed the case startup in real time. To improve the study's validity (Beverland \& Lindgreen, 2010), we combined three data collection methods to investigate the case startup during this period. First, we interviewed nine representatives from the case startup and its more powerful partners. The interviews were semistructured, yet flexible enough to enable interviewees to give examples, go into detail about important situations, and leave room for discussion. We held the interviews with the case startup in June and July 2013 and structured them as follows: 1) how the startup and its artificial pancreas had developed since its establishment; 2) how the startup's network had evolved over time; 3) which of the startup's relationships were perceived as power-asymmetrical 
and why; 4) how each power asymmetric relationship was initiated and managed. Around the same time, we interviewed seven representatives from the startup's established partners. These interviews centred on how the partner initiated and managed relationships with startups in general and with this startup. In December 2014, we conducted a second set of interviews. The two interviews with the case startup were structured around how, since the previous interview: 1) the startup and its artificial pancreas had developed;2) the network had evolved; 3 ) the power asymmetry between the startup and its partners had changed; and 4) each power asymmetrical relationship was initiated (only in the case of a new partner) and managed. Consecutively, we did five interviews with representatives from the startup's established partners, which were structured as follows: 1) how the partner experienced the power asymmetry with the startup and 2) how the way the relationship managed had changed since the previous interview. The representatives from the case startup and its partners were also asked to identify important events in the relationship, how they had behaved during these events, and whether (and, if so, how) power asymmetries played a role in their organisation's decision to act in a certain way.

Second, our lead author carried out observations during her stay at the case startup. Her role in the case startup can be described as a participant observer; she made it clear that she was undertaking research, but she also participated fully in the startup. Between April 2013 and May 2016, she was present for about two days a week at the company's site, while during the other three, she worked at the university. She focused her observations primarily on a limited aspect of the social setting: the case startup's business relationships. In this way, she sought to minimise the risks associated with fully participating in the case startup, but still developed a full appreciation of the case through detailed and long-lived observations. Third, archival documents, such as patents, non-disclosure agreements (NDAs) and project descriptions, were collected from the period between the case startup's establishment in 2008 and May 2016. We primarily used the observations and archival data to improve our understanding of the data collected through the interviews, as well as to design questions for the interviews, which were 
important for a thorough understanding of the case but were not known when the study was designed (Mack, Woodsong, MacQueen, Guest \& Namey, 2005). The data collection involved confidential issues regarding the case startup and its relationships with its established partners. Thus, it was essential to maintain confidentially. Accordingly, we anonymised the names of the case startup and its partners.

\subsubsection{Data analysis}

We analysed the tape-recorded and transcribed interviews, textual notes of the observations and archival documents with ATLAS.ti. Since this software views a theory as a connected network of links between concepts (Huberman \& Miles, 1994), it was suitable for exploring the structural and behavioural power interactions in the relationships between the case startup and its established partners. We analysed the empirical data in three consecutive steps. In step 1 , the analysis focused on drawing up a history of the case startup and its evolving network to create an understanding of the context of the phenomena in question. In step 2 , we coded the data to identify and categorise: 1) the structural power of the case startup and its partners, 2) their perceptions of their own and the other's structural power, 3) the power change tactics they applied, 4) the power use tactics they employed, and 5) the outcomes associated with the power tactics. We based the coding on the theoretical framework presented in Figure 4.1. To guide the coding process, we developed 11 questions, as shown in Table 4.1. The concepts were necessarily tentative in this study. For instance, we found that the case startup and its partners used hostile power tactics not yet identified in the literature, namely the rejection of a partner's request, demand or wish. In the final step, we linked the codes to reveal the relationship between structural power and behavioural power. This analysis step revealed nine episodes in which the relationships between these concepts became particularly visible. An episode "can be interpreted as a specific point of interaction in time in which two or more organisations are dealing with particular matters" (Oukes \& Raesfeld, 2016, p. 52). Since the case startup and its established partners were specifically dealing with power issues, we called them power episodes. Thus, power episodes are the points in time were either the case startup, its 
established partner or both attempt to use or to change their power. We will now describe each of these power episodes in turn.

\begin{tabular}{|c|c|}
\hline & Question \\
\hline \multirow[t]{3}{*}{ Structural power } & $\begin{array}{l}\text { What resource does the partner have that is needed by the } \\
\text { other(s)? }\end{array}$ \\
\hline & How central is the partner's position in the network? \\
\hline & What is the partner's formal position? \\
\hline \multirow{2}{*}{ Perceived power } & How does the partner perceive its own power? \\
\hline & How does the partner perceive the other's power? \\
\hline \multirow[t]{4}{*}{ Behavioural power } & $\begin{array}{l}\text { How does the partner try to influence the other in a } \\
\text { conciliatory way? }\end{array}$ \\
\hline & $\begin{array}{l}\text { How does the partner try to influence the other in a hostile } \\
\text { way? }\end{array}$ \\
\hline & $\begin{array}{l}\text { How does the partner try to increase the importance of its } \\
\text { own resources? }\end{array}$ \\
\hline & $\begin{array}{l}\text { How does the partner try to decrease the importance of the } \\
\text { other's resources? }\end{array}$ \\
\hline \multirow[t]{2}{*}{ Realised power } & $\begin{array}{l}\text { Has the other's (perception of) the structural power } \\
\text { changed? If so, how? }\end{array}$ \\
\hline & $\begin{array}{l}\text { Has the partner benefitted from its influence attempt? If so, } \\
\text { how? }\end{array}$ \\
\hline
\end{tabular}

Table 4.1 Questions to guide the coding process

\subsection{Results}

In this section, we describe the nine power episodes between the case startup and its partners. The characteristics of the power plays - structural power, perceived power, power behaviour and power outcomes - have been summarised in Table 4.2. Sections 4.4.1 to 4.4.9 provide in-depth explanations about the structural power of the case startup and its partner, the way they perceived their own and each other's power, and the ways in which they changed or used their power. We also describe whether (and, if so, how) their power behaviour influenced their (perceptions of) structural power. Importantly, we focused solely on the interaction episodes between the case startup and its partners in which power played a decisive role. 


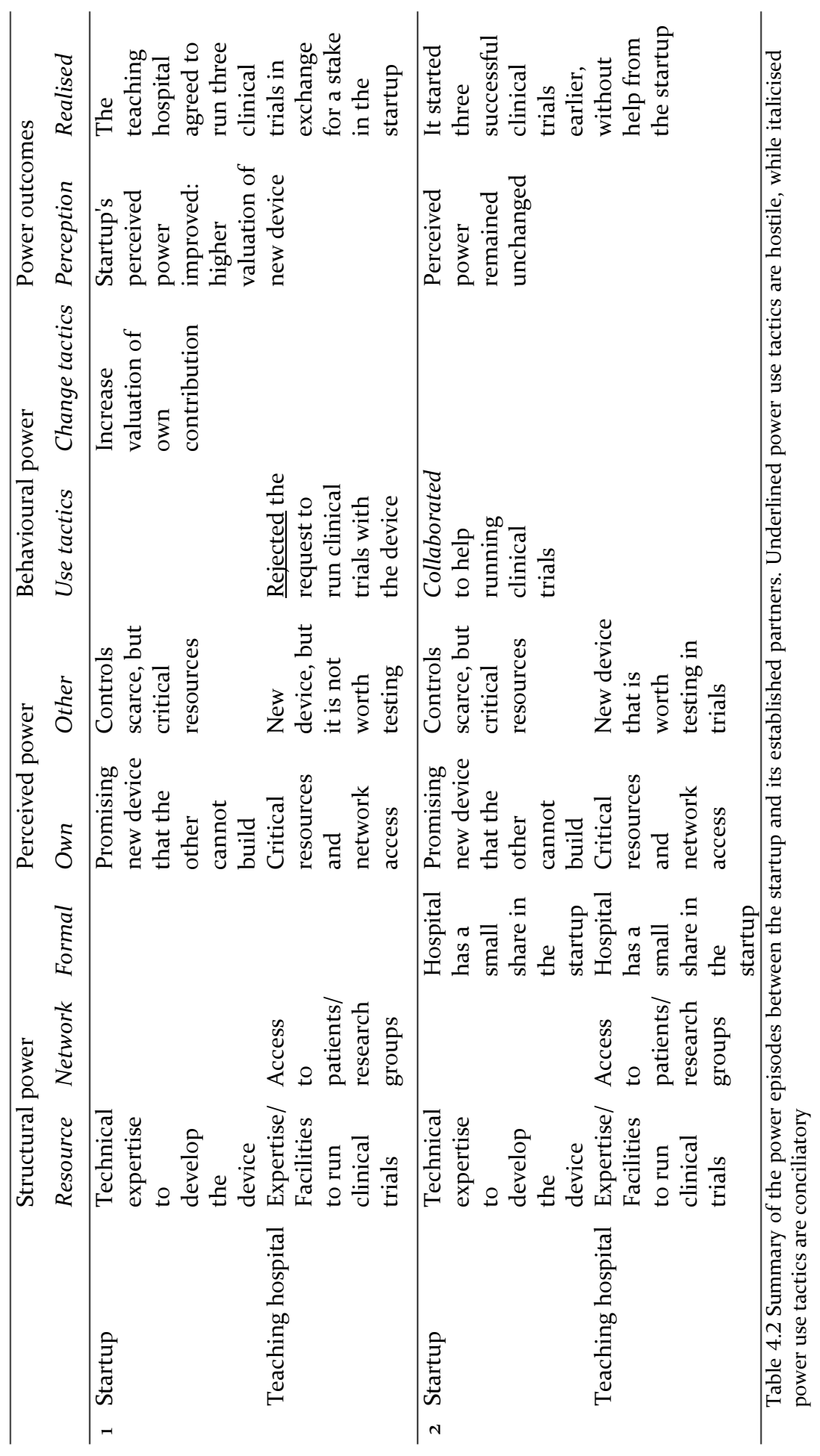




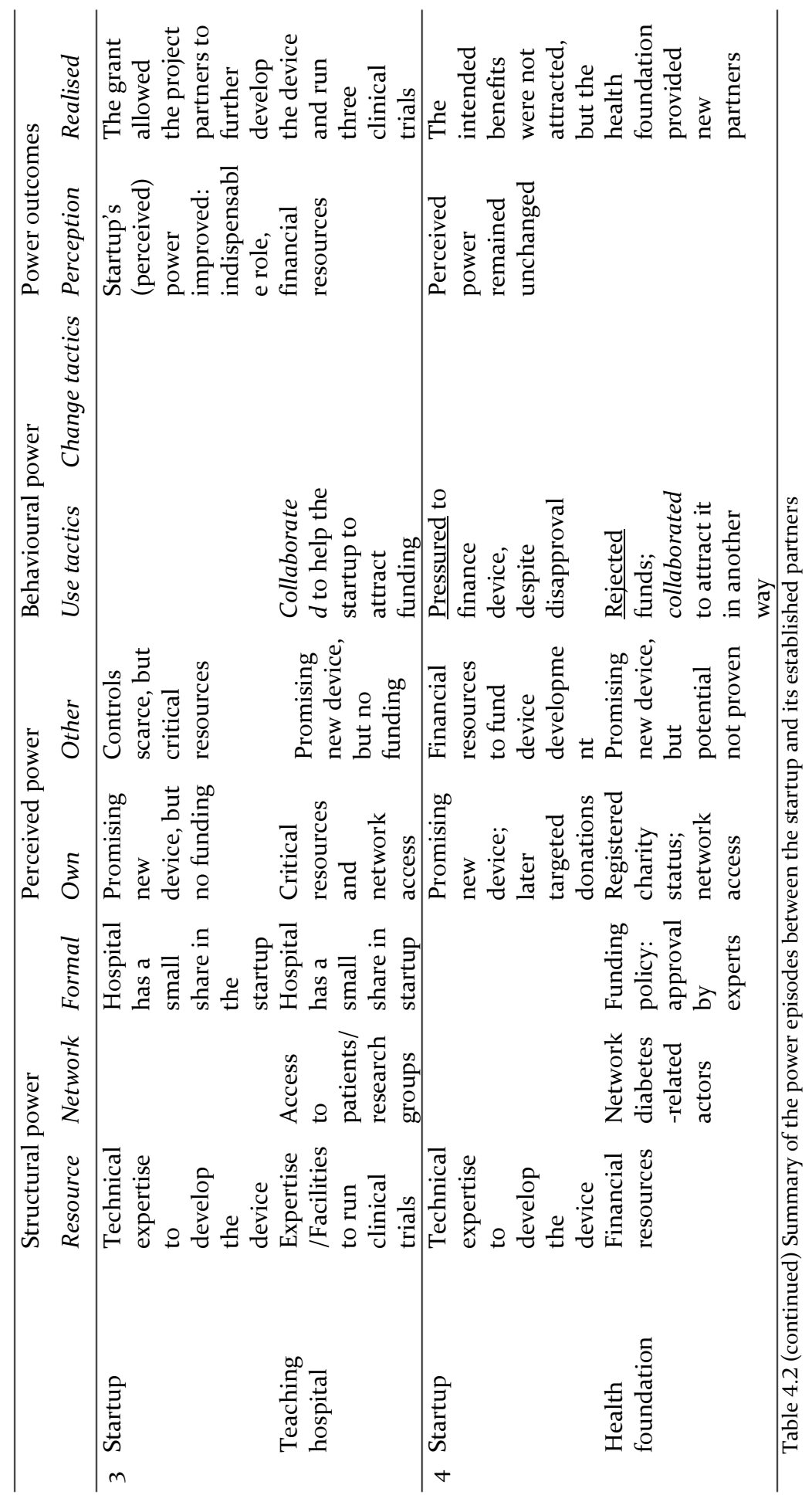




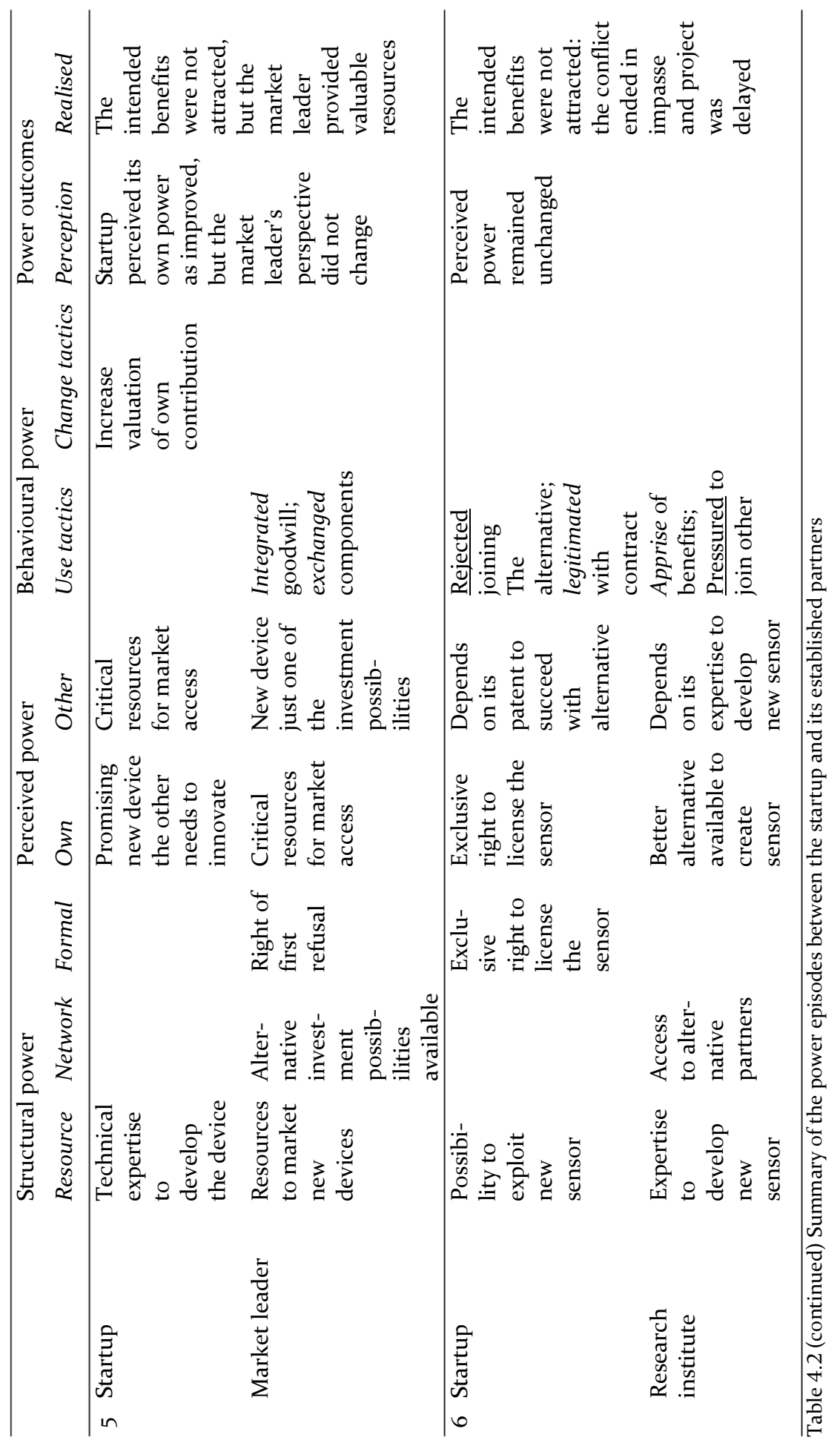




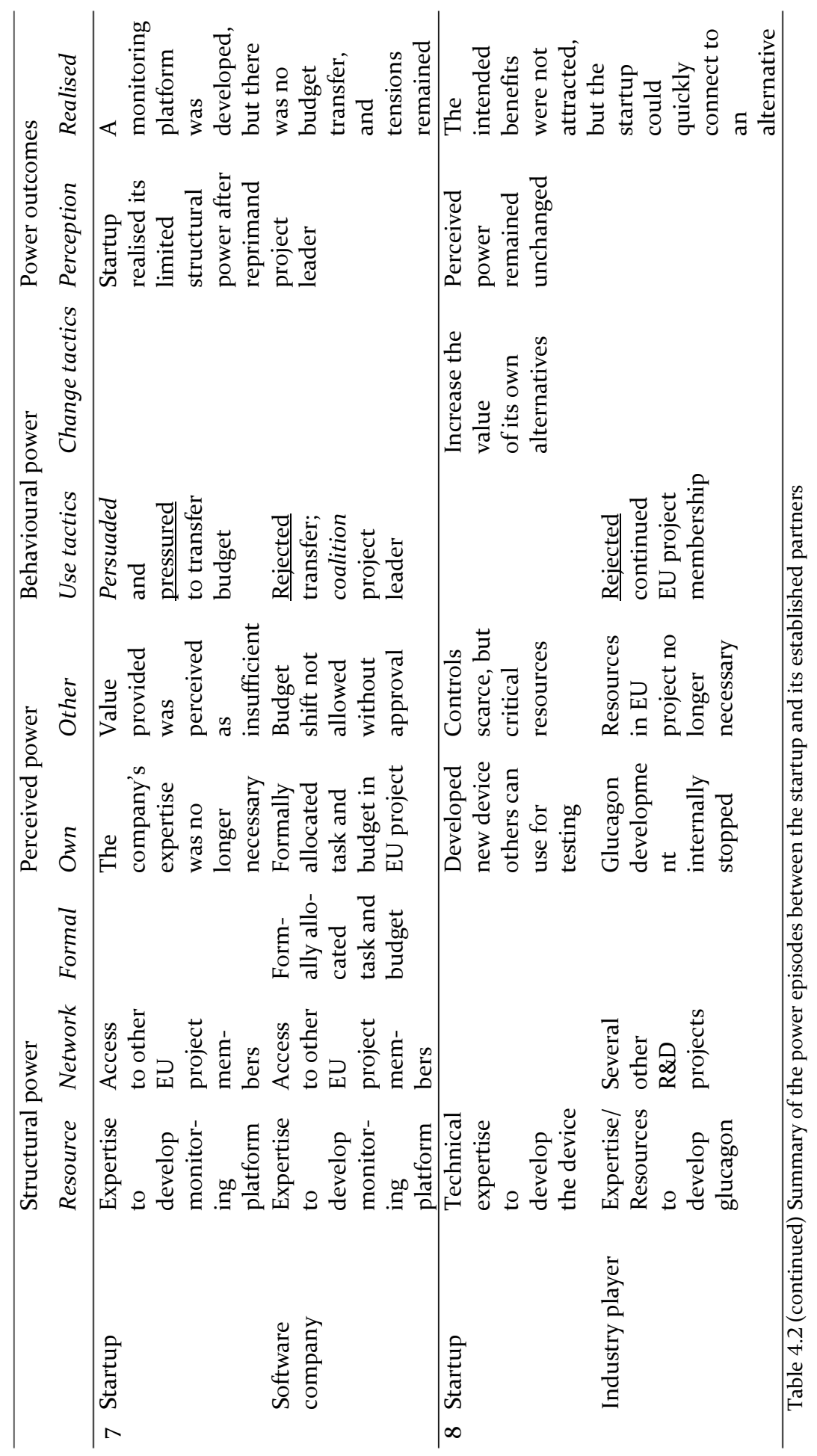




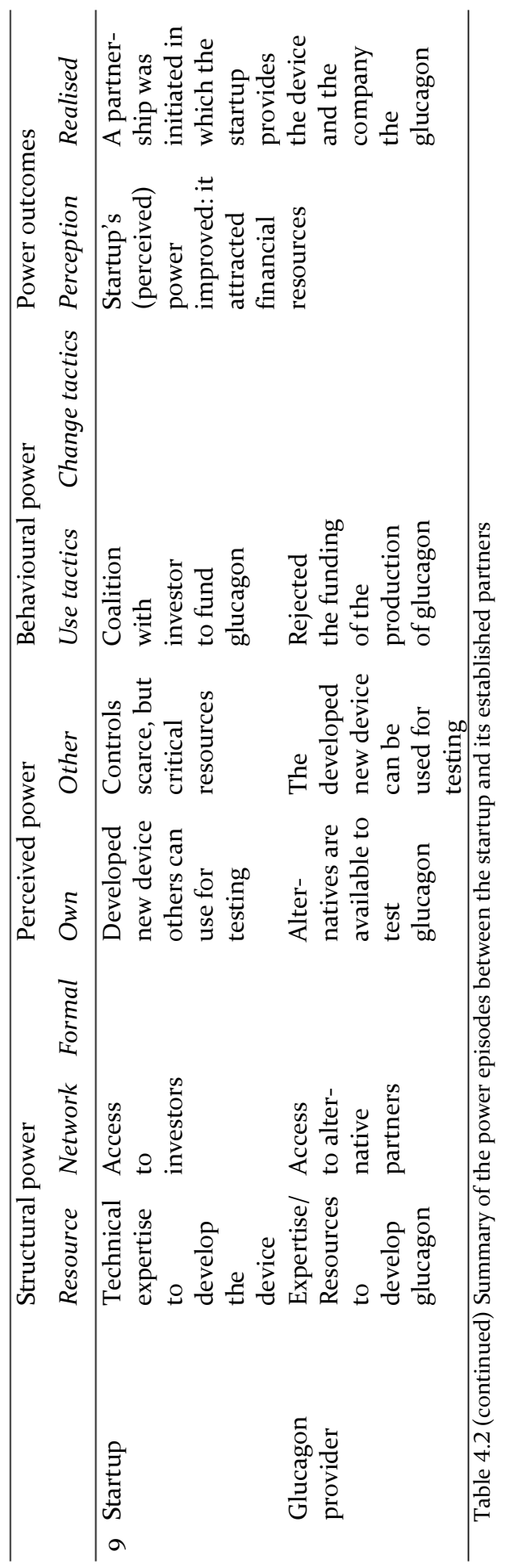




\subsubsection{Power episode 1: The teaching hospital almost said no to the relationship with the startup}

The first power episode the startup encountered was during the initiation of the relationship with the teaching hospital's diabetology group in 2008. The startup's structural power derived from its technical expertise to develop new diabetes technologies. The teaching hospital's structural power originated from its control over the facilities and the expertise necessary to run clinical trials. Further, the hospital had an extensive network of diabetes patients and several collaborations with other diabetes-related research groups. The startup recognised that it would not be able to run clinical trials by itself and that it needed to collaborate to test the artificial pancreas' performance. The initiation of a relationship with the diabetology group was perceived as particularly critical, since it appeared to be difficult to find a suitable partner. In the previous three years, it had been in contact with various hospitals, but they were either unwilling or unable to collaborate. Nonetheless, the startup anticipated that the diabetology group would be willing to collaborate, because the group did not have people qualified to develop new diabetes technologies. However, the group initially wanted to reject the startup's request to collaborate. As the group head explained: "there have been more people who believed that they had developed an artificial pancreas. I thought that the results in the slides were very bad". The group also knew that it could refuse a new cooperation as it had sufficient research projects running. Nonetheless, the startup was invited to explain its results in a meeting. The startup took this opportunity to convince the group of its artificial pancreas' usefulness, efficiency and safety. During the meeting, the startup changed the group's perception of the value of its contribution. The group thought that the startup's artificial pancreas was still an idea, but one that was worth testing in clinical trials. In the end, both parties successfully derived benefits from this power episode: they reached an agreement that the diabetology group would run three clinical trials in exchange for $10 \%$ of the shares in the startup. 


\subsubsection{Power episode 2: How to convince the teaching hospital to do what it had promised?}

The startup successfully changed the diabetology group's perception of the artificial pancreas' value and thereby convinced it to collaborate. Although the group agreed to run clinical trials, the startup considered the execution to be too slow. It realised that the diabetology group had the power to limit its effort in the trials, because the group was also involved in another research project with a similar objective but a much larger budget. Thus, the startup felt it was just "a drop in the ocean". In turn, it offered the group help to fulfil its agreement by contributing human resources to design, implement and analyse the trials. One of the startup's owners noted that the PhD student assigned to the project by the diabetology group was "the driving force, but she could not have done it on her own without our support. You should monitor patients continuously for sixty hours; you cannot do that on your own... We did it, the four of us [the startup's employees at the time] and the PhD student". By the end of 2011, the startup had successfully derived benefits from power episode 2 : three clinical trials were run, and they showed promising results.

\subsubsection{Power episode 3: The importance to the startup increases with the European grant}

After the three clinical trials, the challenge to attract funding emerged: the startup did not have the financial resources to fund the artificial pancreas' further development. As the diabetology group perceived that the three clinical trials proved the artificial pancreas' potential value, it offered the startup help to acquire funding. Specifically, it used its structural power - i.e. its connections to diabetes-related research groups and its experience with government-funded projects - to successfully apply for funding from the European Commission together with the startup and five other partners. The grant substantially improved the perceived power of the startup. As the group head explained: "with the grant, the [startup's] project gained viability... Before, we could have endlessly invested our own resources into the project. In the long term, that would not have been feasible for us or for the startup". As the project's success depended largely on the startup's technology, it gained a central position within the project. It also became a more important partner of the diabetology group owing to the financial resources that became 
available through the grant. The funding also allowed the startup and the teaching hospital to miniaturise the artificial pancreas and to cover the costs of three additional clinical trials.

\subsubsection{Power episode 4: Formal authority prevents an investment by the health foundation}

The startup was not only involved in power struggles with the teaching hospital, but also with the diabetes health foundation. The startup's structural power stemmed from its expertise to develop a new technology - an artificial pancreas - with the potential to reduce the burden of diabetes. The health foundation's structural power derived from its control of financial resources to fund diabetes-related research and development. It also had access to a wide network of diabetes-related actors, from research institutes to industry. Yet its most decisive power source was it status as a registered charity with the national fundraising institute. To remain a registered charity, it had to adhere to the institute's standards. This included that any funding application had to be approved by an independent, international panel of field experts. If it would become known that it did not follow the institute's standards, it would withdraw the foundation's status and the number of donations it receives would drop. The expert panel's power inhibited the foundation from investing in the startup up to three times. In 2009, the startup formally applied for funding for the first time. It anticipated that the health foundation would be willing to invest in its promising new diabetes technology: an artificial pancreas. Yet the expert panel rejected the funding application, because it was not convinced that this project would be more successful than others. The foundation then offered the startup help to fulfil its request, despite this negative decision. It recognised that they needed each other to reach their shared goal: to develop an artificial pancreas. Thus, in 2013, they applied for a local government funding program. The foundation's head of research explained, "it would be nonsense to seek review from our expert panel when it is also assessed by the government. So, if they accept our proposal, we would have sufficient proof to invest our money". However, the panel compiled by the government rejected the application, since there was a lack of scientific proof on the startup's artificial pancreas' performance. When the startup and 
the foundation were applying for government funding, the foundation started to raise donations specifically for the development of the startup's artificial pancreas. The startup used these donations as leverage to persuade the foundation to provide direct financing. Still, it could not understand why the foundation would not want to invest in such a promising new diabetes technology. However, the foundation's head of research mentioned that "it was difficult, because we did not have the financial resources to give a big push, and we had no independent assessment... We wanted to do something with it, but we did not yet know how and what". Despite the three failed attempts to attract financial resources, the foundation used its structural power to support the startup by connecting it to diabetes-related industry partners (e.g. market leader) and knowledge institutions (e.g. the research institute) in its network. In addition, the foundation's head of research said: "If there is, at any given time, the possibility to amplify each other, we can always explore $i t$ ". Thus, some benefits were derived from this power episode, even though it was not what the startup had intended.

\subsubsection{Power episode 5: The startup's tries to convince the market leader to invest}

In 2012, the startup met with a market leader in the diabetes device market. The startup's structural power originated from its the capabilities to quickly develop a patented artificial pancreas. In contrast, the market leader's structural power derived from its marketing and sales functions, production facilities, distribution network and brand. It also had several alternative attractive investment opportunities, i.e. partnerships with other research groups working to develop artificial pancreas systems. Although there were clear complementarities between these two potential partners, the relationship remained largely non-committal. They only effected a right of first refusal, which gave the market leader the option to buy the startup's artificial pancreas before the latter is entitled to sell it to a third party. In the years that followed, the startup tried to improve the market leader's valuation of its own contribution. It recognised that it was much more dependent on the market leader to commercialise its artificial pancreas than the other way around. Specifically, the startup a) shared clinical trial data and outcomes to show the value of its artificial pancreas, b) explained how it managed the 
uncertainties of the development process to reduce the market leader's risk perceptions, and c) developed its own knowledge base to gain a better negotiating position. As one of the startup's owners explained: "you must invest in the relationship, otherwise it would not work out. You need to provide proof to that kind of partners to convince them to invest in the relationship". During these years, the market leader also showed its goodwill by providing the startup with components of and accessories for the artificial pancreas. In 2015, the startup perceived that its power was substantially improved owing to its own efforts and the market leader's generosity. Therefore, the startup anticipated that it could sell a minority stake to the market leader for $€ 10$ million to fund the commercialisation of the artificial pancreas. However, the market leader's power perception had not changed: it still had the power to reject the opportunity to invest. To persuade the startup to keep it up-to-date with the artificial pancreas's progress, it provided the startup additional components and accessories that, although valuable, were not what the startup had asked for.

\subsubsection{Power episode 6: The impasse between the startup and the research institute}

Initially, the relationship between the startup and the research institute was characterised by a relatively symmetrical power structure. The research institute's structural power stemmed from its technical skills to develop a new glucose sensor, while the startup structural power derived from its opportunity to commercialise a new glucose sensor. When the relationship was established in 2012, the startup needed another glucose sensor to improve the artificial pancreas' accuracy. However, it realised that it lacked the necessary technical skills to develop it. As one of the startup's owners stated, "it is very difficult for us [the startup] to develop a sensor ourselves. This can only be done by large organisations". In contrast, the institute recognised that it had the technological expertise to develop the sensor, but not the possibility to commercialise its ideas. Based on these complementarities, the research institute and the startup decided to start a four-year sensor development project. However, the perception of the institute's own power improved in 2013. By that time, the institute started a multipartner project 
with the same intentions. It believed this project to be a better alternative than the project with the startup; thus, the relationship lost its value. The institute tried to convince the startup to end their bilateral relationship and join the multipartner project by explaining the benefits of the multipartner project. Yet, the perception of the startup's own power was also improved after closing the deal: it gained the exclusive right to licence the patent once the new glucose sensor was developed. Thus, the startup was only prepared to join if it would keep the exclusive right to license the patent. Yet the institute was unwilling to complete the project so far that it could apply for a patent. It then put pressure on the startup to join the multipartner project by delaying the glucose sensor's development. The startup tried to counteract this attempt by suggesting that this behaviour counters their formal agreement. Both partners expected that they would give in to each other's requests eventually. On the one hand, the startup anticipated that the institute needed the patent to make the multipartner program successful. On the other hand, the institute recognised that it had the power to delay the glucose sensor's development as long as necessary. The conflict between the organisations finally resulted in an impasse. The project should have been finished in 2016, but even year one's project objectives were not completed. Neither party could derive any benefits from this power episode.

\subsubsection{Power episode 7: The conflict between the software company and the startup in the EU project}

In the European project, the startup had a relationship with a software company. The software company initially had more structural power than the startup. The company had the expertise to develop a software platform to monitor patients during a clinical trial. It was also formally allocated the task and associated budget in the EU project to develop such a platform. During the project, however, the startup attracted personnel with the capabilities to develop such a platform. Also, the results provided by the company did not live up to its expectations. Therefore, the startup felt more powerful than at the outset and requested a budget shift so that it could develop the platform itself. The European Commission allowed these transfers, but there was a ground rule: all partners should agree with the transfer. For obvious reasons, the company rejected the startup's demand by suggesting it was inconsistent 
with the rules. Despite that the startup lacked the formal authority to do so, it used all possible means to force the company into a budget transfer. In turn, the company sought the aid of the teaching hospital and the project leader in influencing the startup to stop its intimidation. It sent a message to the project leader in which it argued that the startup used blackmail to exert pressure. The project leader recognised that the conflict was spiralling out of control and that it should intervene. He explained that, "in situations in which one party wants to go left and the other wants to go right, it may beneficial when the project leader says let's go left this time. Then it helps that both parties have the feeling that the project leader is good at his job and has proven this in the past". The project leader made it clear that no budget can or will be shifted if the software company does not approve. Although some tensions remained between the arguing parties, this largely solved the conflict, and the intended software platform was developed.

\subsubsection{Power episode 8: The startup tried to enlarge its power in relation to the established industry player}

In the European project, an established industry player was responsible for developing stable liquid glucagon. A strong power asymmetry characterised the relationship between this industry player and the startup. The development of glucagon was crucial to the survival of the startup because, without it: a) the clinical trials' costs would be become unacceptably high and b) it would become almost impossible to successfully commercialise the artificial pancreas. Conversely, the development of the new glucagon was just one of the industry player's many activities. In addition, its allocated budget in the European project was relatively small, and not nearly enough to fund the entire glucagon development. Even though the artificial pancreas could be used to test the glucagon, the startup recognised that it was substantially more dependent on the industry player than vice versa. It also anticipated that the industry player's glucagon development would be delayed. Accordingly, the startup attempted to improve the quality of its own alternatives by getting "a good overview of all the potential suppliers of glucagon. It put much effort into identifying, selecting and talking to potential partners". However, it did not have the power to prevent the industry player 
from prematurely withdrawing from the European project. The project was already strategically unimportant to the industry player, but it perceived it as truly needless after it shut down its glucagon development. Nonetheless, the startup's efforts led to some benefits: it could find a suitable new partner to develop stable liquid glucagon soon after the industry player had left.

\subsubsection{Power episode 9: How did the startup enhance its offer's value for the glucagon company?}

In 2015, the startup was negotiating an agreement with another glucagon company. The startup's structural power derived from its possession of the artificial pancreas, while the glucagon company's power derived from its possession of stable liquid glucagon and to access to alternative collaboration partners. During the negotiations, the two parties agreed that they wanted to run a clinical trial together in which the company would provide the glucagon and the startup would provide the artificial pancreas. Then, both parties could use the trial's results to further develop their products. Although the company was prepared to provide the glucagon, it did not want to finance the associated production costs. In addition, the startup was unable to free up budget to fund the required glucagon production. The company had the power to let the negotiations fail for this reason. It realised that it did not require the relationship with the startup to succeed, since it was also collaborating with several other researchers who were developing artificial pancreas systems. In contrast, the startup recognised that it was heavily dependent on the availability of stable liquid glucagon, as explained in paragraph 4.8 in some detail. It also noticed that the number of businesses with which it could collaborate for this purpose was limited. There were two other options, but these companies had a substantial longer expected time to market. Thus, the startup realised that the partnership must not fail and it that it had to acquire the necessary financial resources itself. Eventually, it succeeded when it found an investment company that was ready to fund the glucagon production costs. Thus, the startup successfully extracted benefits from this power episode: it could convince the company to initiate a partnership. 


\subsection{Discussion}

\subsubsection{Resource control, network position and formal position shape structural power}

In line with our theoretical framework, our results show that the case startup's structural power derived from its resource control, network position and formal position. Previous research has argued that startups are usually in the power-disadvantaged position vis-à-vis established partners (Gardet \& Fraiha, 2012). However, our findings indicate that this research provides an incomplete understanding of startups' power because it typically focuses on a single power source rather than all three. We reveal that the case startup often had a power-disadvantage vis-à-vis its established partner, because it lacked a favourable network and formal position, even though it did control valued resources. We will now briefly discuss the case startup's relative power position concerning each power source.

Resource control. The relative value of the case startup's resources and its established partners' resources were comparable in each relationship: they both had control over resources needed or desired by the other (Table 4.2, episodes 1 to 9). This contrasts with previous research that suggests that resource control does explain the differences in structural power between startups and established organisations (Astley \& Sachdeva, 1984; Brass \& Burkhardt, 1993; Forshey, 2014). one reason may be that resource complementarity is a necessary condition for the formation of a relationship between them. The research has consistently shown that startups and established organisations are more likely to initiate a relationship if they can benefit from each other's resources (e.g. Forshey, 2014; Rothaermel \& Boeker, 2008). In other words, it is unlikely for a relationship to form if they do not control resources valuable for the other. Thus, a relatively equal power relationship is likely in terms of resource control once the relationship starts. Our findings provide some evidence in this direction: it was only when the teaching hospital perceived the case startup's resources as valuable that it agreed to initiate a relationship. After the relationship started, the case startup's ability to develop new diabetes technologies and the teaching hospital's expertise in clinical trials were equally valued by the partners. 
Network position. The case startup often had no access or restricted access to alternative partners from which it could acquire necessary resources, while its established partners had more options to pursue a similar objective (Table 4.2, episodes 1 to 6,8 ). For instance, our findings show that the industry player could withdraw from the European project without any consequences, prompting a quick search for a new partner. This is in line with research that indicates that network position is a key determinant of a startup's and its established partner's relative power position (Huxham \& Beech, 2009; Olsen et al., 2014; Pfeffer, 2009). A relationship with an established organisation leaves a startup vulnerable to its partner's power, because the latter can withdraw from the relationship without difficulties (Hughes-Morgan \& Yao, 2016). Further, a greater availability of choices often results in a lower cooperation level (He, Ghobadian \& Gallear, 2013). The importance of network position to an organisation's structural power highlights that the power relationship between startups and established organisations does not exist in isolation, but is affected by their portfolio of relationships, i.e. the alternatives in which they are involved (Brennan, Canning \& McDowell, 2014; Håkansson et al., 2009).

Formal position. The case startup's structural power position was also determined by formal position (Table 4.2, episodes 2 to 7). In the European project, for instance, the teaching hospital was appointed as lead organisation and used this power to resolve the conflict between the case startup and the software company. Thus, we confirm previous literature (Albers et al., 2015; Kassler \& Goldsberry, 2005; Provan, 1980; Thorgren et al., 2012) that argues that organisations may acquire power because they are given the formal authority and decision rights. We also found that contractual agreements determined the structural power position of the case startup and its established partners, although usually in favour of the established organisation (Table 4.2, episodes 4, 5 and 7), occasionally also to the case startup's benefit (Table 4.2, episode 6). Mouzas and Ford (2007, p. 44) argue that "contracts may provide more benefits and fewer restrictions on one of the parties within a relationship when compared to the other", resulting in a power imbalance. Contracts may generally favour the established partner, because it is often able to insert clauses that allow it to shape a relationship's structure 
and to institutionalise the power imbalance (Mouzas \& Ford, 2007; Rindt \& Mouzas, 2015). An example of such a contract is the right of first refusal that the market leader closed with the case startup. However, it is widely known that prior contractual agreements can limit an organisation's ability to change its arrangements in the future (Mouzas \& Ford, 2007). Thus, an established organisation could influence the conclusion of a contract such that it meets its own interests. However, the same contract may become an obstacle when it wants to change its arrangements in response to unforeseen circumstances, shifting power to a startup. In our case, the startup's exclusive right to license the technology only became a problem for the research institute once the institute encountered more valuable alternatives.

\subsubsection{The case startup had a less accurate power perception than its established partners}

In our theoretical framework, we argued that structural power affects perceived power, even though the two generally do not fully correspond. Indeed, our results show that structural power influences the case startup's and its established partners' power perceptions. However, we also reveal that there is a substantial difference in the extent to which their perceived power accurately reflects their structural power. The case startup's perception of its own and its partners' power often did not reflect their de facto structural potential: it tended to overestimate its own power (Table 4.2, episodes 1, 2, 8 and 9), while it was likely to underestimate its partners' power (Table 4.2, episodes 3, 4 and 7). For instance, the case startup did not realise that the teaching hospital had alternative new diabetes technologies that it could test. In comparison, the case startup's partners had a reasonably accurate perception of their structural power (Table 4.2, episodes 1 to 5, 7 to 9). One reason may be that, compared to startups, established organisations have had considerably more time to learn about their ability to influence others. Thus, they are more likely to form a fairly accurate perception of their power over one another than startups (Wilkinson, 1996). Further, startups may lack the experience to properly assess the value of their partners' contribution and alternatives. In such a situation, they tend to project their own situation - i.e. with valuable resources but limited alternatives - onto those of their partners. 
Thus, startups may think that they are in an equal power relationship, regardless of differences in structural power (Pinkley, 1995; Wolfe \& McGinn, 2005). Thus, our findings suggest that there is a conceptual and an empirical difference between structural and perceived power in inter-organisational relationships. This difference is meaningful because it is the power perception rather than structural power that determines the ways in which power tactics are applied, (as discussed in Section 4.5.3). Yet the distinction between the two concepts has not yet clearly emerged from research into interorganisational power (Huxham \& Beech, 2009; Meehan \& Wright, 2012).

\subsubsection{Perceived power and relationship atmosphere determine power behaviour}

Confirming our theoretical framework, our results show that the case startup's power perception influenced its power behaviour, i.e. its decision to employ power change or power use tactics. It is to be expected that a startup would use more power use tactics than change tactics, if it behaved based on its perceived power. This is because an organisation will generally "use more of its power the more it perceives it to have"(Wilkinson, 1996, p. 36), regardless of its de facto structural potential. Indeed, we find that the case startup applied power use tactics when it perceived that it had sufficient power vis-àvis its established partners (Table 4.2, episodes 2, 4, 6, 7 and 9), while it only applied power change tactics when it realised it lacked the necessary structural power to influence its partners (Table 4.2, episodes 1, 5 and 8). Thus, it used more power use tactics than power change tactics than one may expect from its power-disadvantaged position. Therefore, our findings imply that organisations - just like individuals (e.g. Kim et al., 2005; Wolfe \& McGinn, 2005) - choose whether to apply power change or power use tactics based on their perceived power, not their structural power.

In contrast to our theoretical framework, however, we reveal that the choice for a specific power change tactic (i.e. whether to increase the valuation of own contribution or decrease the valuation of a partner's contribution) and power use tactic (i.e. whether to act in a hostile way or in a conciliatory way) cannot be explained by the case startup's perceived power. Rather, this decision seems to be affected by other aspects of the relationship 
atmosphere in which organisations act. Besides the power relationship between organisations, this atmosphere consists of their 1) overall closeness,2) conflict level and 3) expectations (Brennan et al., 2014; Håkansson, 1982). Like Kiyak et al. (2001) as well as Maglaras, Bourlakis and Fotopoulos (2015), our findings indicate that situational factors strongly influence the exercise of power. This stresses that a model of power behaviour is not complete when other aspects that influence organisations' decisionmaking process are not considered. We will now briefly discuss the impact of each relationship atmosphere's aspect on the case startup's behaviour.

Overall closeness. The case startup sought to increase the value of its own contribution at the start of the relationship (Table 4.2, episodes 1 and 5), yet tried to improve the quality of its own alternatives once the relationship was initiated (Table 4.2, episode 8). For instance, the case startup sought to convince the teaching hospital of the performance of its artificial pancreas when it almost declined the prospect of collaborating. It may be that the increasing closeness between organisations over the course over a relationship explains this finding. In the early stages of a relationship, perceptions of power are likely to be unclear (Håkansson, 1982). Thus, it may require relatively little effort for startups to influence their partners' understanding of each other's power Although structural and perceived power can change over time, the power perceptions become more stable during a relationship (Håkansson, 1982). In turn, it may be more difficult for startups to change their partners' valuation of their contribution than to increase the quality of their own alternatives.

Conflict level. The case startup was more likely to apply hostile than conciliatory power use tactics when its partners also apply hostile tactics (Table 4.2, episodes 4, 6 and 7). For instance, the case startup declined to join the research institute's multipartner project when pressured to join. A reason for this reciprocity may be that startups' reactions are likely to be affected by the conflict level generated by their partners' use of power. Johnsen and Lacoste (2016) argue that many studies have shown that the hostile use of power increases conflict to a point where it can damage a relationship. If an 
organisation uses hostile power tactics, its partner may feel forced into doing something against its will. In turn, this may lead to dysfunctional conflict, where its partner is more likely to reciprocate its hostile tactics (Brennan et al., 2014; Kiyak, Roath \& Schatzel, 2001; Pfajfar et al., 2017; Wilkinson, 1996).

Expectations. The case startup was more likely to apply conciliatory power use tactics when it expected to benefit from the relationship in the future (Table 4.2, episodes 2 and 9). For instance, the case startup involved an investor into the relationship with the glucagon provider, since it hoped to get access to its glucagon, even though it wanted to reject the relationship. Startups' expectations of a relationship's future opportunities may influence the ways they exercise their perceived power, because the way they use power is likely to trigger their partners to react (un)favourably. If startups force their established partners to do something they had not planned to do, this may negatively affect their partners' willingness to collaborate in the future (Gadde, 2010; Wilkinson, 1996). For instance, Rokkan and Haugland (2002) found that hostile power behaviour may inhibit the realisation of long-term benefits offered by an inter-organisational relationship. Thus, it is not problematic for a startup to aggressively apply power when it does not expect to benefit from a relationship in the future. Yet conciliatory power use tactics may offer an advantage over hostile tactics if a startup expects a relationship to lead to enhanced performance in the future (Gadde, 2010; Van Bockhaven, Matthyssens \& Vandenbempt, 2015).

\subsubsection{Power change tactics result in realised power, if perceived power is successfully changed}

In our theoretical framework, we argue that the implementation of power tactics directly influences realised power, i.e. the extent to which an organisation can extract benefits. Although our results show that the implementation of power change tactics does affect realised power, we also reveal that this does not occur directly. First, our results show that the application of power change tactics always resulted in a benefit for the case startup, but that it could either be the intended benefit or an unintended one (Table 4.2, episodes 1, 5 and 8). For instance, the case startup sought to change the market leader's perception of its power, but failed. Nonetheless, it 
received valuable components that it could use in the development of its artificial pancreas. Although the case startup extracted benefits from the relationship in both instances, we argue that it realised power only if the desired results were achieved. If a startup's intention is to affect its partner's power perception or its behaviour, and it succeeds in doing so in the desired direction, Wrong (1979) argues that it clearly has realised some power over its partner. However, if this intention to change its partner's perception or behaviour fails, he suggests that it has not realised power over its partner but has caused to an unintended influence. In line with Kim et al. (2005), who use influence tactics synonymously with power tactics, we did not regard influence as distinct from power. In fact, most studies (e.g. Cowan, Paswan \& Van Steenburg, 2015; Kipnis, Schmidt \& Wilkinson, 1980; Lai, 2009; McFarland, Challagalla \& Shervani, 2006; Yukl \& Falbe, 1990) use influence tactics without establishing clearly distinguishing between power and influence. An exception is the work of Gnizy (2016), who explicitly studies power rather than influence in an industrial marketing context. In ordinary usage of the terms, however, power and influence are not understood as completely substitutable (Zimmerling, 2005). Considering unintended benefits in response to the case startup's usage of power tactics, our findings also imply that it may not be justifiable to assume that power and influence are synonymous in inter-organisational relationships.

Second, we reveal that it depended on whether the case startup could successfully change its partner's power perception: if the case startup could successfully change its partner's perception of its power, power change tactics had the intended effects (Table 4.2, episode 1); if the case startup failed to adjust its partners' perception of its power, they had unintended benefits (Table 4.2, episodes 5 and 8). For instance, the case startup did not get the glucagon it sought from the industry player when it increased its alternatives, but could quickly find a new glucagon partner. Startups may be unsuccessful in changing partners' power perception because they tend to demonstrate their value from their own perspective rather from the perspective that of their partners (Lee \& Johnsen, 2012). The fact that the case startup did not seek to decrease its valuation of a partner's contribution or to decrease the 
quality of a partner's alternatives further supports this argument. To change a partner's perception of power, startups should also demonstrate their value in areas that are key to their partner (Lee \& Johnsen, 2012). Yet, startups often lack the resources and time (Colombo, Laursen, Magnusson \& RossiLamastra, 2012) to gain a good understanding of its partner's resources and alternatives.

\subsubsection{Conciliatory use tactics result in realised power, but only coalition-building changes power}

In line with our theoretical framework, our results show that power use tactics - unlike power change tactics - directly influence realised power. When the case startup applied conciliatory tactics (collaborate, persuade, build a coalition, integrate, exchange or apprise), it achieved its intended benefits (Table 4.2, episodes 2 and 9). For instance, the case startup ran the first three clinical trials sooner by collaborating with the teaching hospital. When the case startup applied hostile tactics (reject, pressure or legitimate), it was unable to realise its perceived power (Table 4.2, episodes 4, 6 and 7). For instance, the health foundation did not fund the artificial pancreas' development when put under pressure. Our findings seem unsurprising, because conciliatory tactics are used to inflect less harm on a partner than hostile tactics, and thus prompt less resistance. Consequently, conciliatory tactics are usually more successful for extracting benefits than hostile tactics (Kim et al., 2005). Yet previous research has shown that hostile power behaviour can be successful: power-disadvantaged organisations may accept hostile power behaviour as long as they also benefit (Hingley, 2005; Muthusamy \& White, 2006) or simply because they have no alternatives (Homburg, Wilczek \& Hahn, 2014; Sutton-Brady, Kamvounias \& Taylor, 2015). A reason the case startup failed to achieve the desired benefits when using hostile power tactics may be that it often employed them when it felt more powerful, even though it did not have the de facto power. As its partners usually recognised that the case startup did not have the de facto power, they considered the use of hostile tactics as unjustified and were likely to resist such behaviour. Our findings provide some evidence in this direction: the software company did not transfer budget to the case startup after it was pressured, because it did not believe that the case startup had the right to 
demand this. This finding implies that hostile power tactics can result in realised power if an organisation that applies hostile tactics is also perceived as more powerful by its partner. If an organisation feels more powerful than its partner perceives it to be and it exercises hostile tactics, this behaviour is more likely to cause resistance, and it is less likely to extract the intended benefits. As Meehan and Wright (2012) note, it is not only important how an organisation perceives its own power, how its partners perceive its power is perhaps more important.

In addition to realised power, our theoretical framework suggests that the ways in which an organisation uses its power will also affect the accumulation and loss of both perceived and structural power. Specifically, previous research suggests that conciliatory tactics will shift relative power in favour of the power holder, while hostile tactics will shift relative power in favour of the power target (Bunderson \& Reagans, 2011; Kim et al., 2005). However, we reveal that the case startup's power use tactics generally did not result in a change in structural or perceived power (Table 4.2, episodes 2,4 and 6). One reason may be that partners are likely to reciprocate each other's behaviour (Oukes \& Raesfeld, 2016). As discussed, both the case startup and its partners in our study are likely to use either conciliatory or hostile tactics. If both partners act in the same way, it is to be expected there is no de facto or perceived change in their power relationship: although both organisations' absolute power may change, the relative power difference between them does not. It may be that previous research has reached a different conclusion, because it has often conceptualised power as a simple one-way relationship (Hingley, Angell \& Lindgreen, 2015; Meehan \& Wright, 2012). Researchers who take a one-sided view of (perceived) power may assume that the target's power stays the same when there is a change in the power holder's (perceived) power. Yet our findings suggest that a shift in an organisation's (perceived) power is also likely to cause a shift in its partner's (perceived) power. This supports the notion that a one-sided perspective leads to a distorted or incomplete picture when analysing issues as sensitive as power in interorganisational relationships (Hingley et al., 2015; Meehan \& Wright, 2012; Meqdadi, Johnsen \& Johnsen, 2017). 
Although power use tactics usually did not result in a change in structural or perceived power, there was one exception: coalition-building (Table 4.2, episodes 7 and 9). Coalition-building refers to "seeking the aid of others in influencing the target" (Plouffe et al., 2016, p. 10). For instance, the software company built a coalition to counteract pressure from the case startup, and the case startup built a coalition with an investor in order to get the glucagon provider to collaborate. In these situations, the power perceptions were no longer solely based on the structural potentials of the case startup and its partners, but also on their perceptions of the third party's structural power. As the third party could reinforce the power of either, this influenced the perception of the power relationships between the other two partners. In a relationship between two organisations, either one partner is more powerful than the other, or both are equal. However, many more options arise when multiple partners are involved (Albers et al., 2015). Thus, in line with Heuven and Groen (2012) as well as Sheu (2015), we argue that power in inter-organisational relationships can also have a multidirectional dynamic rather than just a two-way one.

\subsection{Conclusion}

Researchers have paid little attention to the interrelationships between structural and behavioural power in the interactions between startups and established organisations from a startup's perspective. We sought to explore how structural and behavioural power interact in a startup's relationships with its established partners, conducting a longitudinal embedded case study on nine power episodes between a startup and its established partners in the medical device business. Our study's main finding is that structural and behavioural power interact through perceived power, i.e. a startup's and its partners' assessment of their relative power. On the one hand, we reveal that the case startup based its decision to apply power use or change tactics on its perception of its own and its partners' power rather than their de facto structural potentials. Its decision to use a specific type of tactic was affected by three other aspects of the relationship atmosphere: 1) closeness, 2) conflict level, and 3) expectations. On the other hand, we showed that the case startup's own and its partners' (perceived) structural power usually did not change with the startup's power behaviour. Only if one of the partners 
decided to build a coalition with a third actor did the structural power relationships change to an extent that they modified their power perceptions. In addition, we found that the case startup's power-disadvantaged position vis-à-vis its established partners was usually not a result of its lack of needed resources, but its limited access to alternative partners and its unfavourable formal position. However, the case startup often did not recognise its powerdisadvantaged position: it tended to feel more powerful than it was, based on its structural power. As a result, the case startup used more power use tactics than power change tactics than expected. When the case startup applied power change tactics, it always turned out favourably, yet not always in the way it intended. When the case startup applied power use tactics, it could succeed or fail in extracting the desired benefits, depending on whether it exercised conciliatory or hostile tactics.

\subsubsection{Theoretical contributions}

We contribute to the startup business relationship literature by studying power's roles in the interactions between startups and established partners. Researchers have studied different aspects of startups' business relationships (Aaboen et al., 2011; Chen et al., 2009; Das \& He, 2006; Diestre \& Rajagopalan, 2012; Rothaermel \& Boeker, 2008; Vandaie \& Zaheer, 2014), but they have paid limited attention to their views of and experiences with power. Owing to startups' liabilities of smallness and newness, Gardet and Fraiha (2012) argued that they are often considered to be in a powerdisadvantaged position compared to their established partners. Our findings provide more insights into what liabilities cause startups' subordinate power position, namely its small network of alternatives and disadvantageous formal power position, rather than its lack of valuable resources. Previous research (e.g. Cowan et al., 2015; Rehme, Nordigården, Ellström \& Chicksand, 2016) also suggests that startups are not necessarily stuck in this powerdisadvantaged position; thus, it is worth considering their actions intended to change a power balance. However, to this end, startups must recognise their subordinate position, and our findings suggest that this is often not the case. Thus, startups may not try to change the power relationship at all, but may seek to exercise power that does not exist. As long as startups uses its 
non-existent power "to motivate a development towards a more collaborative relationship" (Rehme et al., 2016, p. 185), this has no negative impact on the relationship. However, hostile power behaviour from startups is likely to evoke resistance from their partner and to give rise to conflict in the relationship, especially if their partner does not share their power perception. Since power perceptions and behaviour can affect the extent of collaboration (Rehme et al., 2016), our study reveals that power plays a decisive role in startups' interactions with established partners, whether they are universities, companies, research institutes or non-governmental organisations.

We also contribute to the power literature by deriving the structural power position not only from a resource dependency perspective (i.e. resource control), but also considering an organisation's network and formal position. Most importantly, we study the under-examined interaction between structural and behavioural power based on Kim et al.'s (2005) framework. Our study shows that their framework, which was designed to explain power in interpersonal negations, largely applies to the study of power in interactions between startups and established organisations. As Kim et al. (2005) propose, we found that structural power partly influences a startup's perception of its own and others' power. In turn, the perceived power determines whether a startup applies power change or use tactics. Then, the ways in which it behaves (in)directly affects the extent to which it realises power. Yet, our findings suggest that the model should be expanded with a new element: the relationship atmosphere. Besides its perception of the power relationships, a startup's power behaviour also depends on its closeness with its partner, their conflict level and their mutual expectations. Thus, studies that only consider structural and behavioural power will not capture the full complexity of power dynamics between startups and established organisations.

Another contribution to the power literature is our interactive approach to analysing power, which includes the perspectives of a startup and an established organisation. Although previous research (Oukes \& Raesfeld, 2016; Rutherford \& Holmes, 2008) has suggested that an organisation's exercise of power depends the power perceptions and behaviour of those with 
which it interacts, few studies have taken a two-sided approach to this (Hingley et al., 2015). Yet several of our findings emphasise that the two-way consideration of power in inter-organisational power literature is crucial. For instance, the case startup's decision to use a specific power use tactic was shown to be influenced by its partners' power behaviour. Also, the case startup's successful implementation of hostile power use tactics was shown to depend on how its partners perceived its power position. However, our findings suggest that power is not necessarily dyadic: network position was found to partly determine the structural power of the case startup and its partners, and coalition-building was shown to substantially influence their power perceptions. Thus, the structural, perceived and behaviour power of the two organisations that are directly involved are key, but also that of their indirect counterparts. Nonetheless, very few studies have provided a multisided perspective of power; notable exceptions in the research into buyer-supplier relationships are studies by Kähkönen $(2014,2015)$ and Touboulic, Chicksand and Walker (2014). Perhaps there is a lack of such studies, since they are less accessible and replicable than studies with a single or two-sided view (Hingley et al., 2015). Either way, research with a multisided perspective on power is essential to create a more complete understanding of inter-organisational power in the context of startups.

\subsubsection{Practical implications}

Our conclusions have implications for the managers, owners and directors of startups. Startups must continually assess their structural power position relative to their established partners and any other involved third actors if they can reasonably predict and are ready to respond to how these partners and actors will to behave. Such assessment must be based not only on the value of the resources they control, but also on their network centrality and hierarchical authority, two aspects that are generally neglected or ignored by startups. A realistic assessment of all three aspects can also keep startups from over-estimating their importance to an established business partner. If startups perceive that they have insufficient power compared to their established partners, they can try to minimise the power imbalance. In the early stages of a relationship, they can increase their partners' perceptions of 
the value of their own resources. In the later stages of a relationship, they can decrease their reliance on a specific partner by increasing the value of their alternatives. Both efforts may change their partners' power perceptions and may convince them to comply with startups' request. However, an effort to alter a power imbalance does not always have the intended outcomes: startups' established partner may reject their request. Nonetheless, an established partner may be prepared to support startups' in other ways. If startups are open to this, they can still benefit from their efforts to change a power imbalance, although not in the way they may at first desire.

If startups perceive that they have sufficient power compared to their established partners, they can use either conciliatory or hostile power tactics. Startups should be extremely wary to use hostile power tactics because they often harm an established business partner. For this reason, a partner is unlikely to respond well to rejection, pressure or legitimation, especially if they perceive that a startup has insufficient power to use such tactics. In turn, startups are then unable to extract the intended benefits from the relationship. Startups must be aware of this interplay, since they tend to overestimate their own power, applying more hostile power tactics than is suitable, given their lack of structural power, and not achieving the desired results. Here, they are better off using conciliatory power tactics. If startups use conciliatory power tactics, they either reduce the harm to their established partners or use their power to support it in a certain way. Accordingly, a partner is more likely to respond well to collaboration, persuasion, coalition, integration and exchange, regardless of whether they share a similar perspective of their power. In turn, startups have a higher likelihood of getting their intended benefits from the relationship.

\subsubsection{Limitations and future research}

Our study provides several meaningful theoretical contributions and managerial implications. However, it has limitations, which open avenues for further research. Three limitations arise from the boundaries of our theoretical framework. We apply the framework of Kim et al. (2005) to our case. This framework is suitable because it allowed us to study how structural and behavioural power interact through a startup's and its partners' power 
perceptions. However, there are a multitude of definitions and taxonomies of power. Although they are interconnected and overlap, a single model cannot capture all power dimensions simultaneously (Belaya, Gagalyuk \& Hanf, 2009). Thus, we make no claims regarding the roles of other power dimensions in the interactions between startups and established organisations. Accordingly, it would be interesting to investigate power in such interactions from different definitions and/or taxonomies of power (Johnsen \& Lacoste, 2016), such as French and Raven's (1959) power base theory or Hardy and Phillips's (1998) conceptualisation of power as powers of resource, process, meaning and system.

As usual in inter-organisational power research, we have treated power and influence as synonyms in our theoretical framework. However, our findings and the work of Gnizy (2016) suggest that we need to explicitly distinguish between the two concepts. An analysis of Zimmerling (2005) on the merits and shortcomings of interpersonal influence's definitions, as distinguished from power, may provide some guidance. Although the distinction is unclear and controversial, he argues that research should define them as two categories, because this is "best compatible with ordinary usage and most useful for theoretical purposes" (Zimmerling, 2005, p. 141). Specifically, he defines power as the "ability to get desired outcomes by making others do what one wants" and influence as "the ability to affect others' beliefs" (Zimmerling, 2005, p. 141). Using these definitions in further research, researchers will better reflect the de facto use of power (rather than merely influence).

Another limitation is that we take a power lens to investigate the relationships between a startup and its established partners. This focus makes sense, since researchers have to date neglected power's roles in such relationships. In contrast, other factors such as partner selection (Das \& He, 2006; Diestre \& Rajagopalan, 2012) and resource complementarity (Rothaermel \& Boeker, 2008) have been studied more extensively. Nonetheless, our study shows that the case startup's power behaviour does not solely depend on its perception of its own power, not even only on the 
structural power and power behaviour of its partners. Also, the relationship stage and future benefits influence its decision to employ a certain power tactic. To get an in-depth understanding of why startups and their established partners choose a specific power tactic, further research should take a broader perspective that includes factors such as resource complementarity, future benefits and the like.

Two further limitations result from our methodological approach. Our longitudinal embedded case study is appropriate for exploring the interactions between structural and behavioural power in a startup's relationships with its established partners. However, an in-depth analysis of nine power episodes limits our ability to thoroughly investigate the dynamics of power over time. The case startup's relationship with the teaching hospital was the only one with multiple power episodes: for the rest, there was just one power episode per partner. However, we did show that the power perceptions and behaviour of the case startup and the teaching hospital changed over time. Also, previous research suggests that power relationships are seldom static (Chicksand, 2015), but are inherently dynamic and likely to change over time (Rehme et al., 2016; Wang, 2011). Power-advantaged organisations may seek to shift their power towards its maximum, while power-disadvantaged organisations may try to minimise their power imbalance (Molm, 2009). Yet Olsen et al. (2014) have suggested that we lack empirical research into the dynamics of power. Thus, an in-depth understanding of power dynamics in business relationships is a fruitful further research area. For instance, researchers can investigate whether the perceived power and power behaviour of each partner follows a pattern over time.

We cannot make generalisable inferences about the power tactics' effectiveness owing to the limited number of power episodes. We conclude that if a startup applies conciliatory power use tactics, it results in the intended outcomes, while hostile power use tactics don't lead to intended outcomes. Further, power change tactics are usually beneficial to a startup, even though not always in the way it expected. Although these conclusions seem straightforward, we must be cautious when generalising them to other 
types of startups, relationships, contexts and the like. To draw more generalisable inferences, studies that systematically examine the effectiveness of different power tactics in a larger, more diverse sample are a useful further research avenue, because startup managers are, above all, interested in the outcomes of such tactics. Otherwise, they cannot assess whether they will be beneficial or harmful in extracting value from a relationship (Plouffe et al., 2016). Further, the literature provides an inconsistent view of power tactics' effectiveness (e.g. McFarland et al., 2006; Plouffe et al., 2016). 



\section{CHAPTER 5}

Power asymmetry's effects on value creation and appropriation in multipartner alliances

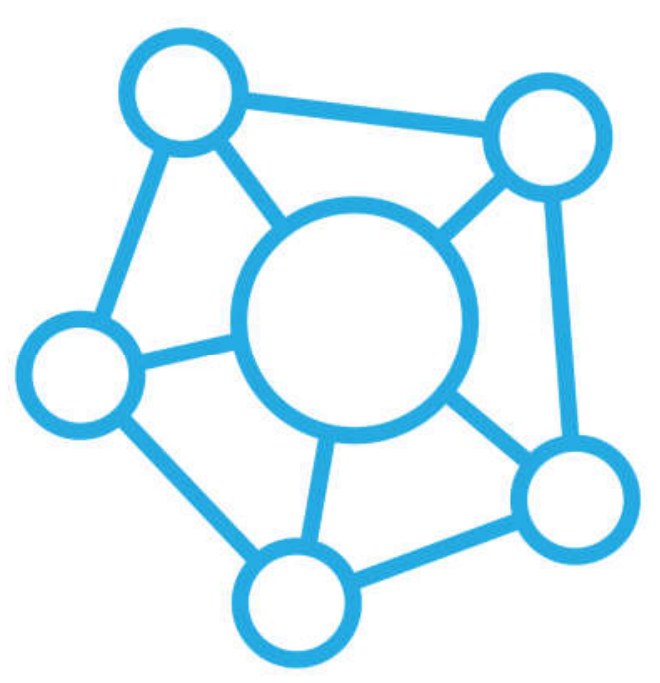

Authors are T. Oukes, A.J. Groen, P. Geurts \& A. von Raesfeld. This paper was submitted to the Annual Conference of the Strategic Management Society in Paris, France, September 2018. 


\section{Abstract}

Power asymmetry potentially affects multipartner alliances' effectiveness, because it determines which partners have the right to make decisions. Extant research has shown that power and effectiveness are multidimensional concepts. However, very few studies have examined the effects of power asymmetry derived from different power sources on different effectiveness types. We investigate the impacts of power asymmetry, based on partners' size, age and network centrality, on value creation and value appropriation in 409 alliances with multiple partners. These alliances received funding from Netherlands Technology Foundation STW between 2000 and 2004. We showed that network centrality asymmetry positively affects value creation, but negatively effects value appropriation. Another finding is that the positive relationship between centrality asymmetry and value creation is weakened by size asymmetry. We also find that the negative relationship between centrality asymmetry and value appropriation is weakened by age asymmetry. The findings clearly indicate that the structural (i.e. size and age) and relational (i.e. centrality) power dimensions are interconnected. Thus, scholars should conceptualise and measure them jointly instead of separately. The findings also suggest that partner composition should change along with a multipartner alliance's goal, i.e. to create or to appropriate value.

\subsection{Introduction}

Multipartner alliances are "a group of three or more organisations connected in ways that facilitate achievement of a common goal" (Provan, Fish $\&$ Sydow, 2007, p. 482). Multipartner alliances' value creation possibilities are likely to outweigh the results of dyadic alliances, because a large multilayered resources pool can be created, exchanged and combined (Albers, Schweiger $\&$ Gibb, 2015). Also, they have the potential to reduce market, capabilities and interaction failures, hindering the innovation process (e.g. Bach, Matt \& Wolff, 2014; Hagedoorn, Link \& Vonortas, 2000; Lavie, Lechner \& Singh, 2007; Sakakibara, 1997a, 2002). Yet alliances with multiple partners also have a higher likelihood of failure and poorer outcomes than dyadic alliances, because they are accompanied by numerous management challenges that are not present in the agreements between two companies (Castiglioni, Castro \& 
Galán, 2015; Human \& Provan, 2000). Thus, it is less likely that multipartner alliances are formed without governmental support, even considering their private and social benefits. Thus, since the 1970s, the funding of alliances between multiple partners has been an oft-used government policy to stimulate social welfare (Sakakibara, 1997a, 2002).

Considering the long history of government-funded multipartner alliances, there is surprisingly little empirical research into such alliances' effectiveness. Effective collaboration in alliances with multiple partners depends on the partners' ability to collectively create and appropriate value (Dyer, 1997). As organisations often engage in alliances between multiple partners to create value, mutual value creation has received the most scholarly attention in this area (Ellegaard, Medlin \& Geersbro, 2014). There has been substantially less research into joint value appropriation, yet it is essential to multipartner alliance effectiveness, because multilateral collaboration offers partners an opportunity to capture mutual benefits from created value (Sridharan \& Simatupang, 2013). The few studies show that multipartner alliances do not always successfully collectively create and deliver value (Yan \& Wagner, 2017). Thus, it is important to examine the factors that contribute to their success. Previous research in this area has mainly focussed on the impacts of project characteristics (e.g. project duration, budget and scale) and partner characteristics (e.g. experience, amount and variety) (Arroyabe, Arranz \& Fdez. de Arroyabe, 2015; Nepelski \& Piroli, 2016; Raesfeld, Geurts \& Jansen, 2012; Raesfeld, Geurts, Jansen, Boshuizen \& Luttge, 2012; Schwartz, Peglow, Fritsch \& Günther, 2012).

Recently, scholars have called for more research into power asymmetry in multipartner alliances (Albers et al., 2015; Hingley, Angell \& Lindgreen, 2015; Yan \& Wagner, 2017). Alliances with multiple partners are governed based on the interplay of the involved partners' power, because it determines which partner has the right to make decisions (Badir, Buchel \& Tucci, 2005; Provan \& Kenis, 2008; Sridharan \& Simatupang, 2013). Thus, the distribution of power is expected to strongly affect multipartner alliances' success (Provan \& Kenis, 2008). However, power asymmetry has been under-examined in 
alliances with multiple partners owing to the complexity of conceptualising power in multilateral organisational forms (Albers et al., 2015; Hingley et al., 2015). There is no single definition of power and no consensus on what its dimensions are (Olsen, Prenkert, Hoholm \& Harrison, 2014). Power is often associated with an organisation's network position (i.e. relational power), while it may also derive from control of the resource supply in a specific relationship (i.e. structural power). Scholars have suggested that every dimension of power is necessary but not sufficient on its own for a business to gain power (Astley \& Sachdeva, 1984). Further, it can be expected that the power asymmetry derived from different power dimensions lead to different value creation and value appropriation possibilities (Ibarra, 1993). This implies that it is crucial to analyse the two power dimensions simultaneously. However, the two power sources are rarely combined in a single study into inter-organisational relationships in general (Huxham \& Beech, 2009; Meehan \& Wright, 2012; Olsen et al., 2014), and specifically multipartner alliances.

We seek to provide an integrative understanding of power asymmetry's impacts on value creation and value appropriation in multipartner alliances by investigating the potentially different impacts of relational and structural power dimensions. Accordingly, our research question is: What are power asymmetry's effects on value creation and value appropriation in multipartner alliances? To address this question, we analysed 409 multipartner alliances initiated between 2000 and 2004 funded by The Netherlands Technology Foundation STW. In the following sections, we will develop our hypotheses based on relevant theory. We will then explain our methodology and present our empirical results. We conclude with a discussion of our findings, implications and suggestions for further research based our study's limitations.

\subsection{Theory and hypotheses}

\subsubsection{Value creation and value appropriation in multipartner alliances}

The main premise of collaboration in multipartner alliances is the partners' potential to integrate their resources and capabilities with the aim to collectively create and appropriate value (Dyer, 1997; Yan \& Wagner, 2017). 
To create value, alliance partners must identify, control and combine their complementary resources and capabilities to complete an idea, turning it into a concrete product or service that can be transferred to others: an idea becomes a reality. To appropriate value, they must capture a share of the economic profits by commercialising a product or service, connecting to the actors and activities that will allow it to be used in the real world (Ellegaard et al., 2014; Kanter, 2000). The ability to appropriate value is contingent on the alliance partners' abilities to create value: the more successful an alliance in terms of value creation, the more value the alliance can appropriate. Further, a high level of created value usually indicates a commercially successful product, which could bring long-term economic benefits (Yan \& Wagner, 2017). Despite the recent insights into the antecedents of value creation and value appropriation in multipartner alliances, one question remains unanswered: how are they influenced by power asymmetry? To start addressing this question, we develop five hypotheses grounded in the decision-making and the governance literatures.

\subsubsection{How does power asymmetry affect value creation and value appropriation?}

Power has been dimensionalised in many ways (Belaya, Gagalyuk \& Hanf, 2009; Brass \& Burkhardt, 1993; Huxham \& Beech, 2009; Olsen et al., 2014). We focus on both structural power (i.e. power held as an attribute of an organisation) and relational power (i.e. power that stems from the relationships between a business in a network) dimensions. We consider power as derived from the properties of an organisational system rather than from the actions of organisations in this system, because "power asymmetry serves as potential which is different to exercise of power" (Sridharan \& Simatupang, 2013, p. 84). The most commonly applied source of structural power is organisational size. Larger organisations obtain power because they are usually less dependent on a single relationship than smaller organisations: what is a small proportion of one's business is a large proportion of the other's (Gardet \& Fraiha, 2012; Pfeffer \& Salancik, 1978). Although under-examined in extant research, a second source of structural power arises from an organisation's age. Older organisations gain power because they can often 
acquire new capabilities and resources faster than younger organisations (Hamel, 1991) owing to their accumulated experience and knowledge (Nishimura \& Okamuro, 2016). Further, the research evidence strongly suggests that network centrality is a signifcant source of relational power (Astley \& Sachdeva, 1984; Ibarra, 1993). Central organisations in a network gain power because their involvement in multiple relaitonships makes them structurally indispensible (Astley \& Sachdeva, 1984; Tichy \& Fombrun, 1979). Also, they enjoy access to alternative partners outside a specific relationship from which it can acquire resources (Koka \& Prescott, 2002; Lavie, 2007). We will now briefly discuss the effects of size, age and network centrality asymmetry on value creation and value appropriation in multipartner alliances.

Size asymmetry. Size asymmetry refers to organisational size differences among partners in an alliance. In a size-asymmetrical alliance, alliances governance occurs via a large lead organisation that coordinates all alliance-related activities and decisions. This highly centralised governance restricts an alliance's value creation potential, because it diminishes the quantity and quality of knowledge-sharing among partners, prevents swift responses to changing circumstances, and limits partners' commitment to the alliance. While value creation requires resource-sharing, flexibility and invovlement, value appropriation is different. Shared governance will likely be unsuccesful, because it cannot effectively coordinate the interdependent interactions necessary to stimulate product adoption beyond an alliance's boundaries. Further, an old lead organisation will usually have much-needed resources it can allocate to stimulate collective value apporpriation (Badir et al., 2005; Belso-Martínez, 2015; Ibarra, 1993; Kanter, 2000; Provan \& Kenis, 2008). Thus, we hypothesise:

Hypothesis 1: $\quad$ Size asymmetry negatively affects value creation (a) and positively affects value appropriation (b) in MPAs.

Age asymmetry. Age asymmetry refers to organisational age differences among partners in an alliance. In age-symmetrical alliances, alliance governance is shared: the partner collective manages its activities and 
makes its decisions. This highly decentralised governance enhances an alliance's value creation potential, because it stimulates knowledge-sharing among partners, generates the flexibility as well as adaptability, and increases partners' involvement in the alliance. Yet the opposite form of governance is likely necessary to facilitate value appropriation. Lead organisation governance is more likely to be effective, because it is better suited to coordinate the cross-boundary interactions required to commercialise a new product. Further, an older lead organisation will typically have legitmacy as an organisation, which it can leverage on behalf of the alliance's value appropriation as a whole (Badir et al., 2005; Belso-Martínez, 2015; Ibarra, 1993; Kanter, 2000; Provan \& Kenis, 2008). Thus, we hypothesise:

Hypothesis 2: Age asymmetry negatively affects value creation (a) and positively affects value appropriation (b) in MPAs.

Centrality asymmetry. Centrality asymmetry refers to organisations' network centrality differences among partners in an alliance. In centralityasymmetrical alliances, governance occurs via a lead organisation; in centrality-symmetrical alliances, governance is shared. As discussed, shared governance is considered to be more condusive to value creation, while lead organisation governance is more conducive to value appropriation. However, we argue that governance by a lead organisation that is central in the network (i.e. high centrality asymmetry) is beneficial to both value creation and value appropriation (Badir et al., 2005; Ibarra, 1993; Kanter, 2000; Provan \& Kenis, 2008). Centrally positioned lead organisations stimulate value creation because they promote trust, act as conflict resolvers, play a strategic role in coordinating collective action, and monitor partner behaviours in multipartner aliances (Chesbrough, Vanhaverbeke \& West, 2006; Gulati, 1998; Heidl, Steensma \& Phelps, 2014; O’Sullivan, 2005; Vanhaverbeke, Duysters \& Noorderhaven, 2002). Also, they enhance value appropriation, because they generally have the network capabilities needed to address the network-level demands of succesful product commercialisation (Badir et al., 2005; Ibarra, 1993; Kanter, 2000; Provan \& Kenis, 2008). Thus, we hypothesise: 
Hypothesis 3: Centrality asymmetry positively affects value creation (a) and value appropriation (b) in MPAs.

Interaction effects. Previous research suggests that relational power does not exist independently from structural power, because they "share two characteristics: (1) they imply different degrees of access to or control over specific information, support, and material resources; and (2) they are associated with different degrees of status" (Ibarra, 1993, p. 495). Thus, we need an examination of how structural and relational dimensions interact to yield value creation and value appropriation (Astley \& Sachdeva, 1984; Borgatti \& Halgin, 2011; Ibarra, 1993). Particularly, the two dimensions are expected to interrelate in governing multipartner alliances. Based on the formulated hypotheses, it can be expected that the advantages of a central lead organisation in stimulating value creation will become a disadvantage if an alliance is characterised by high size asymmetry and high age asymmetry. Further, it is possible that older and/or larger organisations that are not central in a network are unlikely to leverage their experience and resources to play a significant role in collective value appropriation. Given the previous hypotheses, we hypothesise that:

Hypothesis 4: Size asymmetry weakens centrality asymmetry's positive effect on value creation (a) and strengthens its positive effect on value appropriation (b).

Hypothesis 5: Age asymmetry weakens centrality asymmetry's positive effect on value creation (a) and strengthens its positive effect on value appropriation (b).

Figure 5.1 visualises the hypothesised relationships. 


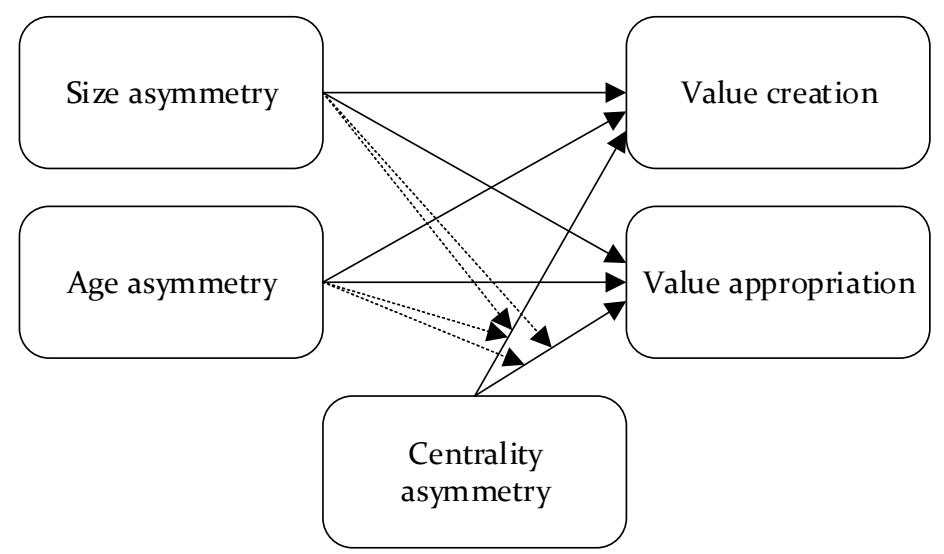

Figure 5.1 Visualisation of the hypothesised relationships

\subsection{Methods}

\subsubsection{Sample and data sources}

We tested the hypotheses in a set of multipartner alliances funded by the Dutch Technology Foundation STW, which funds application-oriented research projects in which research institutes and users collaborate. From the start, each project should include (potential) users, such as large, mediumsized and small businesses, non-profit organisations and healthcare institutes, of its results. As the partner composition and the goal of the multipartner alliances funded by STW are consistent with our definition, we argued that they are an appropriate research setting to study power asymmetry's effects on product application and value creation performance. We analysed the publicly available data of the 409 alliances with multiple partners initiated between 2000 and 2004. Besides basic information, such as project title, project budget and start date, the data include relevant information about the project results - product development and revenues both five and 10 years after project completion. To enrich the data set, we extracted the year of establishment and the number of employees between 2000 and 2009 of each user from REACH (Bureau van Dijk, Amsterdam, The Netherlands). If this information was unavailable, especially in the case of non-Dutch users, we retrieved the required data from ORBIS (Bureau van Dijk, Amsterdam, The Netherlands). The information in the two databases is standardised and can therefore be used in parallel. Also, we enriched the data 
set with the centrality of every user in the STW network. We calculated centrality with the support of UCINET version 6.623 (Analytic Technologies, Harvard, MA, U.S.).

\subsubsection{Measures}

Dependent variables. We used STW's evaluation of the extent to which a concrete product was developed five years after project completion as a measure of value creation. Based on a survey among researchers, project managers and users involved in a multipartner alliance, STW classifies projects into three categories: (A) there was no concrete product: more research was necessary to obtain a product that is for users; (B) a partial product was developed: verification and refinement were still required, and users could not independently use it; or (C) a full product was developed: it was a finalised concept that users could autonomously use. We used STW's evaluation of the extent to which revenues were generated 10 years after project completion as a measure of value appropriation. Based on the same survey, STW classifies projects into three categories: (A) no revenues were generated from the project; (B) parts of the knowledge generated in the project were occasionally sold; and (C) there was a substantial and/or continuous revenue stream.

Independent variables. We measured the three power asymmetries size, age and centrality asymmetry - at the multipartner alliance level with the coefficient of variation. We calculated the coefficient of variation as follows: $\frac{\sqrt{ }\left[\sum\left(D_{i}-D_{\text {mean }}\right)^{2} / n\right]}{D_{\text {mean }}}$ where $\mathrm{D}_{\mathrm{i}}$ is the amount of attribute $\mathrm{D}$ of user $i$, $\mathrm{D}_{\text {mean }}$ is the average amount of attribute $\mathrm{D}$ in a project, and $\mathrm{n}$ is the number of users. We used this formula, because it captures the dominance that is fundamental to our definition of power asymmetry. It reflects the distances between alliance members and the resource concentration of those with more power; when the minority holds more power than the majority, there is greater asymmetry than when the situation is reversed (Harrison \& Klein, 2007). To measure size asymmetry, we used the average number of employees over the period from 2000 - the year of the first projects started - until 2009 - the last projects' completion year. To measure age asymmetry, we subtracted the year 
of establishment from 2016, to obtain a member's age (in number of years). To measure centrality asymmetry, we used Bonacich's (1987) measure of power centrality, which reflects the total amount of potential influence a node can have on all others in a network. In our case, this network consists of the user relationships between partners involved in all the projects initiated between 2000 and 2004. We calculated the Bonacich (1987) power centrality of a user $i$ in UCINET 6.623 as $c_{i}=\sum A_{i j}\left(\alpha+\beta_{c j}\right)$ where $\mathrm{A}$ is a given adjacency matrix, $\alpha$ is used to normalise the measure, and $\beta$ is an attenuation factor that provides the amount of dependence of each user's centrality on the centralities of the users it is connected to.

Control variables. We included the following control variables in our analysis. First, we controlled for project budget, which we measured as the amount of funding (in euro) the project received from STW. Second, we controlled for number of partners, calculated as the absolute number of partners involved in the project. Third, we controlled for the possible influence of technology by creating a dummy variable for whether the project is directed at nanotechnology (1) or not (0). Further, we added a dummy variable for the project's technological area: (A) engineering, (B) life sciences or $(\mathrm{C})$ chemistry. Finally, we controlled for the value creation (measured as explained) in our model with value appropriation as dependent variable.

\subsubsection{Data analysis}

We performed the statistical analysis using SPSS version 22 (IBM Corp., Armonk, NY, U.S.). We ran mean, standard deviation (S.D.) and correlations for the dependent, independent and control variables. We performed an ordinal logistic regression to test the effects of size, age and centrality asymmetry on product application and value creation performance after controlling for project budget, number of project partners, and technology field. This analysis was appropriate, because the dependent variables are ordinal and have more than two categories. We assessed the suitability of ordinal logistic regression prior to analysis. Most importantly, the estimated models have proportional odds, as assessed by a full likelihood ratio test comparing the fitted model to a mode with varying location parameters. To 
meaningfully interpret the interaction effects, we centred the variables prior to analysis. We considered one-tailed values of $\mathrm{p}<0.05$ to be statistically significant.

\subsection{Results}

In Table 5.1, we present the means, standard deviations and correlations for all variables. In Tables 5.2 and 5.3, we present the results of the ordinal logistic regression we used to test our hypotheses. We tested our hypotheses after controlling for the project budget, number of partners, and technology field. Three effects of the control variables on the dependent variables are notable. First, Table 5.2 shows that a value creation increase caused an in increase in the odds of value appropriation, with an odds ratio of 7.49, 95\% CI [2.77 to 20.22] and 26.71, 95\% CI [9.76 to 74.22]. Further, Table 5.2 - a life sciences project - has higher value creation odds than one in engineering, with an odds ratio of $1.703,95 \%$ CI [1.05 to 2.76]. Also, projects in life sciences and chemistry have higher value appropriation odds than those in engineering, with an odds ratio of $2.95,95 \%$ CI [1.66 to 5.26 ] and $2.09,95 \%$ CI [1.09 to 4.02] respectively. Further, Table 5.3 shows that an increase in the number of partners resulted in an increase in the value appropriation odds, with an odds ratio of $1.13,95 \%$ CI [1.02 to 1.15$]$.

In $\mathrm{Hl}$, we proposed that size asymmetry negatively affects value creation and positively affects value appropriation. Table 5.2 shows that size asymmetry's effect on the value creation odds is negative yet insignificant. Thus, we reject Hla. Further, Table 5.3 shows a positive yet insignificant effect of size asymmetry on the value appropriation odds. Thus, Hlb is not supported.

Second, H2 predicted that age asymmetry negatively affects value creation and positively affects value appropriation. Table 5.2 shows that size asymmetry's effect on the value creation odds is negative yet insignificant. Thus, H2a is rejected. Further, Table 5.3 shows a positive yet insignificant effect of age asymmetry on the value appropriation odds. Thus, H2b is not supported. 


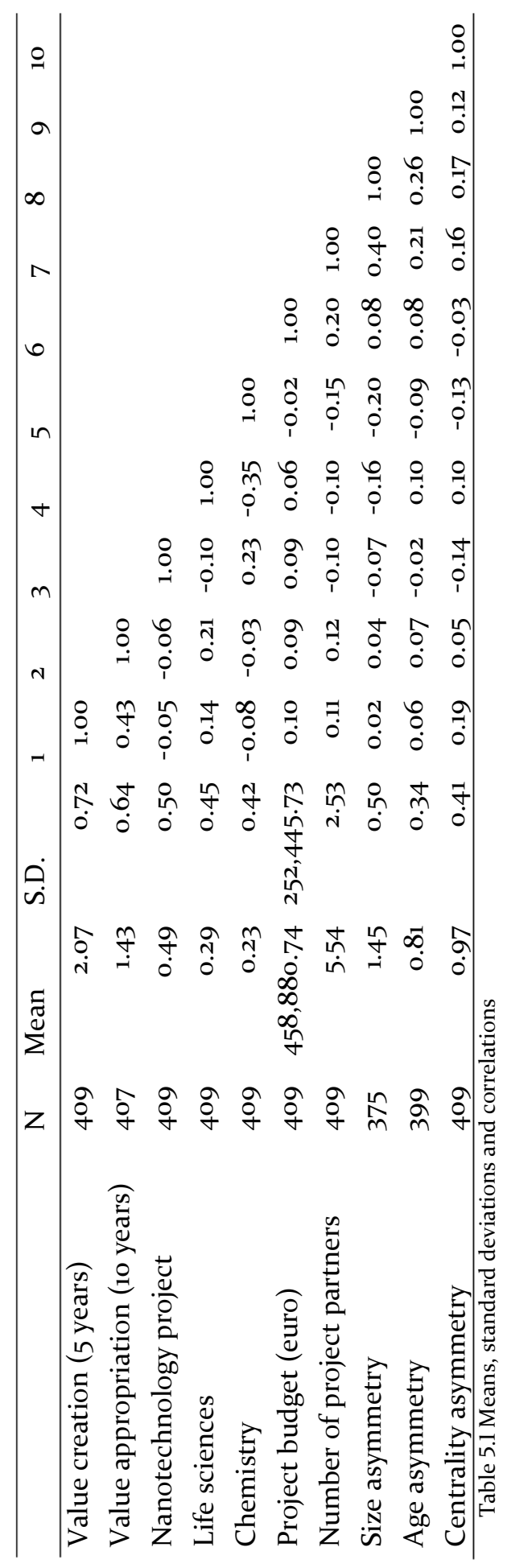




\begin{tabular}{|c|c|c|c|c|c|c|c|c|c|}
\hline & \multicolumn{3}{|c|}{ Model 1} & \multicolumn{2}{|c|}{ Model 2} & \multicolumn{3}{|c|}{ Model 3} & \multirow[b]{2}{*}{ Sig. } \\
\hline & $\mathrm{B}$ & s.e. & Sig. & $\mathrm{B}$ & s.e. & Sig. & $\mathrm{B}$ & s.e. & \\
\hline$[$ Value creation $=1]$ & -1.15 & 0.18 & 0.00 & -1.08 & 0.19 & 0.00 & -1.08 & 0.19 & 0.00 \\
\hline [Value creation $=2$ ] & 0.99 & 0.17 & 0.00 & 1.12 & 0.19 & 0.00 & 1.13 & 0.19 & 0.00 \\
\hline Nanotechnology project & -0.14 & 0.19 & 0.24 & 0.05 & 0.20 & 0.40 & 0.08 & 0.21 & 0.35 \\
\hline Technology area (chemistry) & -0.03 & 0.24 & 0.46 & 0.07 & 0.26 & 0.40 & 0.09 & 0.27 & 0.37 \\
\hline Technology area (life sciences) & 0.65 & 0.23 & 0.00 & 0.51 & 0.24 & 0.02 & 0.53 & 0.25 & 0.02 \\
\hline Project budget (euro) & 0.00 & 0.00 & 0.10 & 0.00 & 0.00 & 0.11 & 0.00 & 0.00 & 0.10 \\
\hline Number of project partners & 0.08 & 0.04 & 0.02 & 0.08 & 0.04 & 0.05 & 0.07 & 0.04 & 0.06 \\
\hline Size asymmetry & & & & -0.09 & 0.23 & 0.34 & -0.06 & 0.23 & 0.39 \\
\hline Age asymmetry & & & & -0.05 & 0.32 & 0.44 & -0.11 & 0.32 & 0.37 \\
\hline Centrality asymmetry & & & & 0.69 & 0.26 & 0.00 & 0.69 & 0.26 & 0.00 \\
\hline Size $\mathrm{x}$ centrality asymmetry & & & & & & & -0.95 & 0.55 & 0.04 \\
\hline Age $\mathrm{x}$ centrality asymmetry & & & & & & & 0.37 & 0.69 & 0.29 \\
\hline
\end{tabular}

Table 5.2 Determinants of value creation in multipartner alliances. Notes: Model 1, Nagelkerke Pseudo $R^{2}=0.05, \chi(5)=17.25, \mathrm{p}<0.01, \mathrm{~N}=409$; Model 2, Nagelkerke Pseudo $\mathrm{R}^{2}=0.06, \chi(8)=$ 19.92, p = 0.01, N = 375; Model 3, Nagelkerke Pseudo $R^{2}=0.06, \chi(10)=23.05, p=0.01, N=375$.

\begin{tabular}{|c|c|c|c|c|c|c|c|c|c|}
\hline & \multicolumn{3}{|c|}{ Model 1} & \multicolumn{2}{|c|}{ Model 2} & \multicolumn{4}{|c|}{ Model 3} \\
\hline & B & s.e. & Sig. & B & s.e. & Sig. & B & s.e. & Sig. \\
\hline [Value appropriation $=1$ ] & 3.15 & 0.50 & 0.00 & 3.20 & 0.51 & 0.00 & 3.26 & 0.52 & 0.00 \\
\hline [Value appropriation $=2$ ] & 5.21 & 0.54 & 0.00 & 5.28 & 0.56 & 0.00 & $5 \cdot 36$ & 0.56 & 0.00 \\
\hline Nanotechnology project & -0.25 & 0.23 & 0.14 & -0.36 & 0.25 & 0.07 & -0.33 & 0.25 & 0.10 \\
\hline Technology area (chemistry) & 0.54 & 0.31 & 0.04 & 0.74 & 0.33 & 0.01 & 0.74 & 0.33 & 0.01 \\
\hline Technology area (life sciences) & 0.94 & 0.27 & 0.00 & 1.08 & 0.29 & 0.00 & 1.08 & 0.30 & 0.00 \\
\hline Value creation (full product) & 3.29 & 0.50 & 0.00 & 3.27 & 0.51 & 0.00 & 3.29 & 0.52 & 0.00 \\
\hline Value creation (partial product) & 2.07 & 0.49 & 0.00 & 2.00 & 0.50 & 0.00 & 2.01 & 0.51 & 0.00 \\
\hline Project budget (euro) & 0.00 & 0.00 & 0.26 & 0.00 & 0.00 & 0.21 & 0.00 & 0.00 & 0.18 \\
\hline Number of project partners & 0.10 & 0.04 & 0.02 & 0.12 & 0.05 & 0.01 & 0.12 & 0.05 & 0.01 \\
\hline Size asymmetry & & & & 0.17 & 0.27 & 0.26 & 0.20 & 0.27 & 0.23 \\
\hline Age asymmetry & & & & 0.25 & 0.37 & 0.26 & 0.15 & 0.38 & 0.35 \\
\hline Centrality asymmetry & & & & -0.61 & 0.32 & 0.03 & -0.61 & 0.33 & 0.03 \\
\hline Size $\mathrm{x}$ centrality asymmetry & & & & & & & -0.05 & 0.68 & 0.47 \\
\hline Age $\mathrm{x}$ centrality asymmetry & & & & & & & 1.42 & 0.81 & 0.04 \\
\hline
\end{tabular}


Third, in $\mathrm{H} 3$, we predicted that centrality positively affects value creation and value appropriation. Table 5.2 shows that an increase in centrality asymmetry resulted in value creation odds, with an odds ratio of $1.99,95 \%$ CI [1.19 to 3.33]. Thus, H3a is supported. Further, Table 5.3 shows that centrality has a significant yet negative effect on the value appropriation odds. Thus, we reject $\mathrm{H} 3 \mathrm{~b}$.

Fourth, H4 proposed that size asymmetry moderates the relationships between centrality asymmetry and value creation as well as value appropriation. Table 5.2 shows a negative and significant interaction effect between size and centrality asymmetry on the value creation odds. To this end, Figure 5.2a shows that centrality asymmetry's positive effect on the value creation odds was weakened when size asymmetry was high. Thus, H4a is supported. Further, Table 5.3 shows that the interaction effect between size and centrality asymmetry on the value appropriation odds is negative yet insignificant. Thus, H4b is rejected.

Fifth, we proposed that age asymmetry moderates the relationships between centrality asymmetry and value creation as well as value appropriation. Table 5.2 shows a positive yet insignificant interaction effect between age and centrality asymmetry on the value creation odds. Thus, H5a is not supported. Further, Table 5.3 shows that the interaction effect between age and centrality asymmetry on the value appropriation odds is positive and significant. To this purpose, Figure 5.2b shows that centrality asymmetry's negative effect on the value creation odds was weakened when age asymmetry was high. Thus, $\mathrm{H} 5 \mathrm{~b}$ is rejected. 
a. Size asymmetry

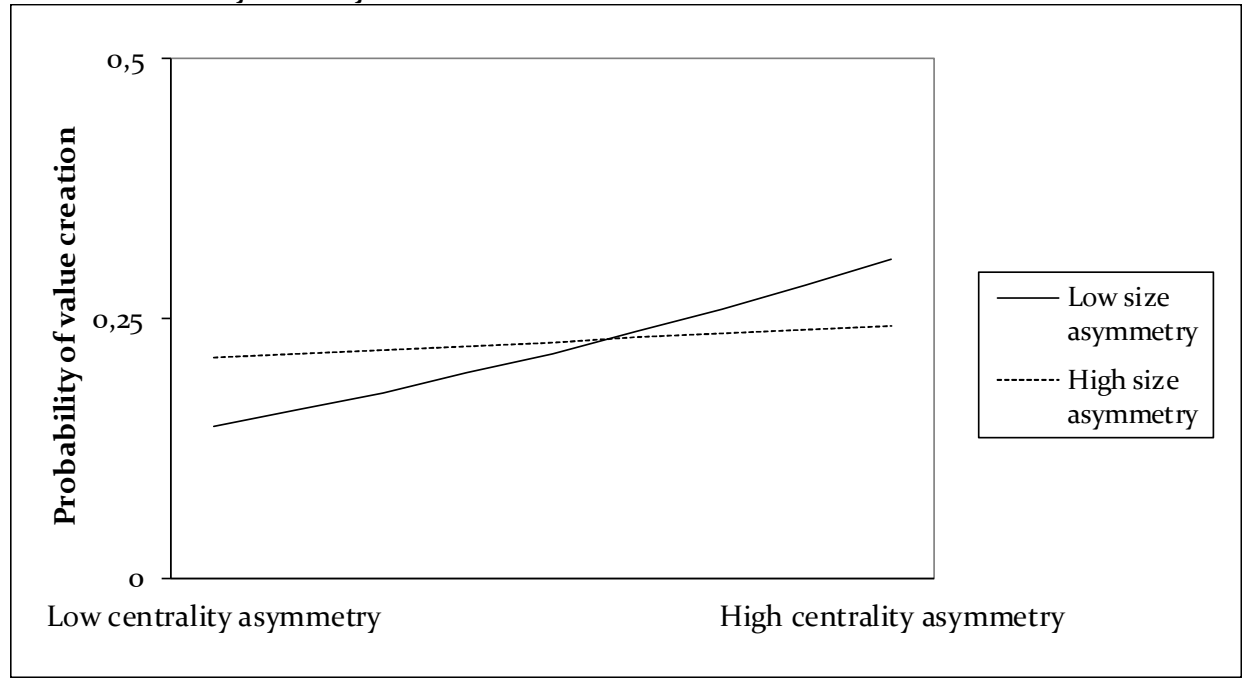

b. Age asymmetry

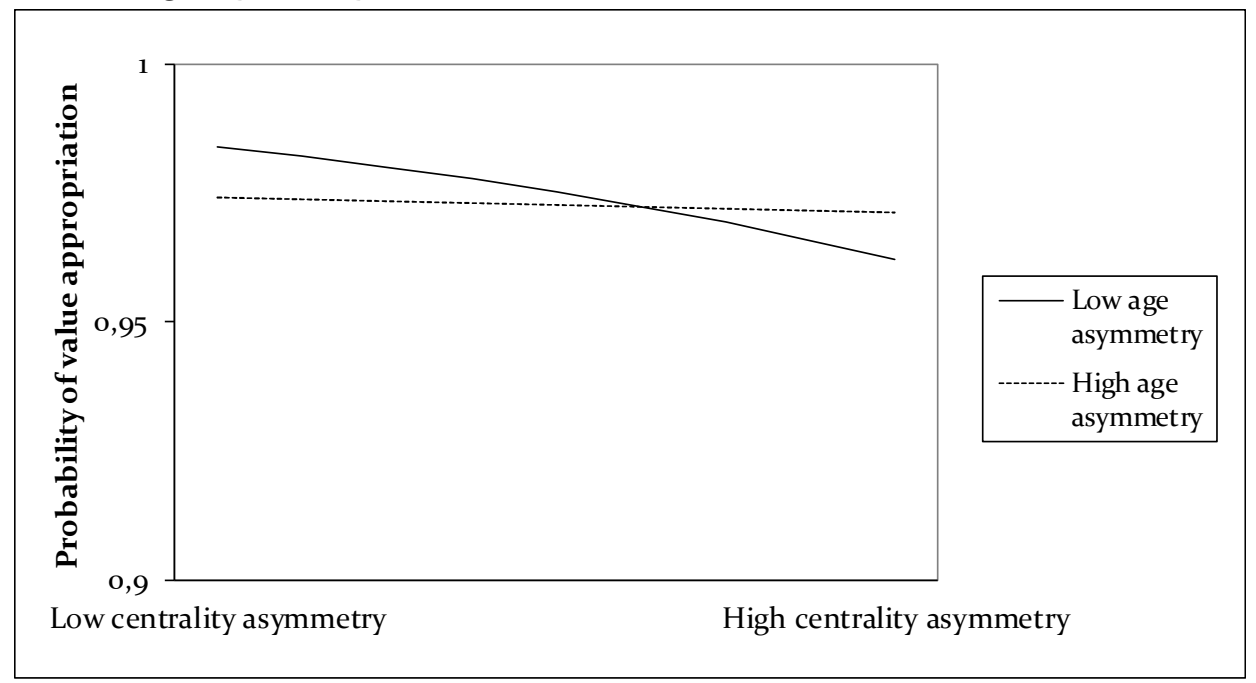

Figure 5.2 The interaction effects between centrality, size asymmetry and age asymmetry on value creation and value appropriation in multipartner alliances

\subsection{Discussion}

Our study reveals four key findings regarding the relationships between size, age and centrality asymmetry and value creation as well as value appropriation in multipartner alliances. Our first finding is that governance 
in a multipartner alliance by a single central lead organisation seems to be beneficial to value creation, while shared governance by partners with equal network positions is suggested to be necessary to facilitate value appropriation. Specifically, our results show that centrality asymmetry has a direct positive effect on value creation in multipartner alliances. Thus, we confirm previous studies that show that centrally positioned partners play a key role in initiating, maintain and coordinating multilateral relationships so as to create value (e.g. Chesbrough et al., 2006; Gulati, 1998; Heidl et al., 2014; O'Sullivan, 2005; Vanhaverbeke et al., 2002). In contrast, our results show that centrality asymmetry has a direct negative effect on value appropriation in multipartner alliances. This sharply contradicts our expectations based on extant research suggesting that alliances with shared governance will be unsuccessful in capturing value (e.g. Badir et al., 2005; Ibarra, 1993; Kanter, 2000; Provan \& Kenis, 2008). We speculate that these opposite effects are caused by the fact that a central lead organisation is more motivated to govern the multilateral relationships between alliance partners to develop new products and/or services than to commercialise them. Mutual value creation is shown to be positively related to a lead organisation's value appropriation (Yan \& Wagner, 2017). In other words, it can expect benefits from governing a large, diverse pool of partners with resources high in combinatorial potential (Hoehn-Weiss, Karim \& Lee, 2017). Thus, it is in the lead organisation's interest to support the alliance in reaching its collective new product/service development goal. This incentive may disappear as soon as the new value is created, i.e. a new product and/or service is completely developed. At that moment, the central lead organisation is the only partner with the necessary network capabilities to commercialise the newly created value. Since the other partners lack a central network position, they have little to contribute to the commercialisation process. Thus, it is not worth it for the lead organisation to invest in effortful forms of governance. Instead, it will seek to maximise its own benefits at the expense of the collective value appropriation potential (Hoehn-Weiss et al., 2017; Raesfeld, Geurts \& Jansen, 2012; Wincent, Thorgren \& Anokhin, 2013). 
Further, our findings suggest that the relationship between centrality asymmetry and multipartner effectiveness is influenced by two factors: size asymmetry and age asymmetry. First, our results show that size asymmetry weakens the positive relationship between centrality asymmetry and value creation. This indicates that a central lead organisation that is large is less likely to stimulate collective value creation in a multipartner alliance than one that is small. Larger organisations have more complex and diversified resources than smaller ones (Camison-Zornoza, Lapiedra-Alcami, SegarraCipres \& Boronat-Navarro, 2004). Thus, a small organisation must identify, assess and legitimise resources from different partners to be able to create value. In contrast, a large organisation tends to impose its own resources even if not the most beneficial to developing new resources combinations on the value creation process. This undermines the joint value creation efforts, because partners' resources that are unique or even superior are not included in the value creation process (Bunderson, 2003; Bunderson \& Reagans, 2011; Corsaro, Cantù \& Tunisini, 2012). Second, our results show that age asymmetry weakens the negative relationship between centrality asymmetry and value creation. Thus, lead organisation governance by a central and old organisation is less likely to damage a multipartner alliance's value appropriation potential than governance by a central and young organisation. The opportunity cost of enhancing its self-interests tend to be higher for older than for younger organisations, because opportunistic behaviours could severely harm its carefully arroyab reputation and legitimacy as a trustworthy partner. It may also find it difficult to form new partnerships (Bae \& Gargiulo, 2004; Bunderson \& Reagans, 2011; Heidl et al., 2014; Sakakibara, 1997a). These two findings are also relevant, because they show that small cannot be equated with young organisations and large with established organisations when measuring asymmetry in multipartner alliances. Theoretically, it is often assumed that smallness/bigness implies newness/oldness (Vandaie \& Zaheer, 2014). However, this assumption is empirically invalid: there are organisations that remain small for years, while others are born big. Further, our results show that size asymmetry and age asymmetry are only weakly correlated; besides this, they impact differently on the relationship between centrality asymmetry and multipartner alliance effectiveness. Thus, we argue that it is crucial to theoretically distinguish 
between size and age in conceptualising power and to measure them separately so as to compare their potentially different impacts.

From our previous discussion, we can conclude that the same power source does not necessarily have the same influence on different indicators of multipartner alliance effectiveness. This is in in line with previous studies that found different impacts of various partner characteristics, such as size and variety, on the different effectiveness types (e.g. Arroyabe et al., 2015; Nepelski \& Piroli, 2016; Raesfeld, Geurts \& Jansen, 2012; Raesfeld, Geurts, Jansen et al., 2012; Schwartz et al., 2012). Taken together with these studies' results, our findings imply that partner composition in multipartner alliances should be different, depending on the partners' intended outcome. The intended outcomes often roughly correspond to the innovation process as it unfolds over time: initially, the alliance's goal will be to develop new products and/or services (i.e. value creation); later, it will be to commercialise the newly developed products and/or services (i.e. value appropriation) (Kanter, 2000). In contrast to dyadic relationships, partners can enter and exit a multipartner alliance without causing its termination. Thus, it is possible to change the partner composition during an alliance's existence without endangering its survival. Yet, this confronts partners with the question whom to invite into or allow to join the alliance at certain points in time (Albers et al., 2015). Our results indicate that a partner configuration consisting of partners with unequal network positions and equal sizes initially stimulates value creation, while a configuration of partners with equal network positions and unequal ages enhances value creation at the end. The need for new partners to enter and old ones to leave when the goal of value creation shifts to value appropriation also present questions we cannot answer based on our study, but which are fruitful avenues for further research (Albers et al., 2015), such as how can a new partner be integrated into the alliances to utilise its full potential as early as possible.

Finally, we examined the effects of two power dimensions on multipartner alliance effectiveness: structural and relational. This enables us to compare the strength of structural power sources (based on a resource 
control perspective) and relational power ones (grounded in social network theory) as an explanatory variable. Our results show that centrality asymmetry has a significant positive effect on value creation and a significant negative effect on value appropriation, while size asymmetry and age asymmetry did not have direct effects. This suggests that relational power sources are a stronger predictor of multipartner effectiveness than structural power sources. This is in line with previous findings in the interpersonal power literature. For instance, Ibarra (1993) found that network centrality was a stronger determinant of individual involvement in administrative innovation efforts than personal attributes. He argues that power derived from centrality is particularly conducive to administrative innovation, because it increases individuals' potential to mobilise a much broader support base and the accuracy of their assessment of a group's power distribution (Ibarra, 1993). Thus, it may be concluded that social network theory provides a better explanation of power in multipartner alliances than a resource control perspective. However, social network theory tends to explore how individual relational aspects, such as power centrality, affect organisational choices and success. In response to criticism relating to the theory's "antiattribute ideology" (Kilduff \& Brass, 2010, p. 322), several scholars have called for the examination of the consequences of network relationships in interaction with the characteristics of all network members (Borgatti \& Halgin, 2011; Kilduff \& Brass, 2010). Our results show that size asymmetry and age asymmetry moderate the relationships between centrality asymmetry and value creation and value appropriation. This implies that relational and structural power sources are linked and mutually influence each other: a central position holds certain potentialities, but the de facto outcomes depend on several additional factors, including size and age (Kilduff \& Brass, 2010). Thus, our findings emphasise the importance of this call: the properties of all organisations in a network should be studied, besides the relationships between them. Social network theory alone cannot fully capture how network relationships benefit or constrain multipartner alliance effectiveness. Only by integrating it with a resource control perspective can it be determined how they affect their mutual value creation and value appropriation. 


\subsection{Conclusion}

\subsubsection{Implications}

Two primary theoretical implications can be derived from our study, which contributes to the multipartner alliance and the power literatures. First, it extends the multipartner alliance literature by showing that asymmetry derived from the same power source impacts different effectiveness types differently. Extant research has investigated the impacts of several project and partner characteristics on both value creation and value appropriation in multipartner alliances (Arroyabe et al., 2015; Nepelski \& Piroli, 2016; Raesfeld, Geurts \& Jansen, 2012; Raesfeld, Geurts, Jansen et al., 2012; Schwartz et al., 2012). However, to date, power asymmetry has received little attention in multipartner alliances (Albers et al., 2015; Hingley et al., 2015; Yan \& Wagner, 2017), even though it strongly affects how a multipartner alliance will be governed (Badir et al., 2005; Provan \& Kenis, 2008; Sridharan \& Simatupang, 2013). Although it is hard to fully capture power in multilateral relationships, our results clearly show the importance of examining how power asymmetry and effectiveness interrelate in multipartner alliances. Specifically, we found that asymmetry derived from network centrality has a direct positive effect on value creation, but a negative effect on value appropriation in multipartner alliances. Second, our study complements the power literature by showing that asymmetry derived from different power sources impact the same effectiveness type differently. Previous research has typically focused on either a structural dimension or a relational dimension of power (Belaya et al., 2009; Olsen et al., 2014), despite the fact that it has been suggested that they are connected (Ibarra, 1993). We applied a more integrative approach, combining structural and relational power sources in a single study. This allowed us to compare each source's effect on multipartner alliance effectiveness. We found that power asymmetry derived from a relational source (i.e. network position) has a direct significant effect on multipartner effectiveness. In contrast, power asymmetry derived from structural sources (i.e. size and age) only indirectly affects multipartner alliances: it moderates the relationships between centrality asymmetry and value creation as well as value appropriation. These findings emphasise that it is not only preferable, but necessary to develop, use and compare 
conceptualisations and measures that account for different power dimensions (Belaya et al., 2009).

For policy-makers, our study has identified key relationships that should be considered when designing eligibility criteria for governmentfunded multipartner alliances. Currently, these criteria have primarily focussed on organisational size. However, our findings show that organisational size asymmetry only affects value creation in multipartner alliances in combination with network position asymmetry. Specifically, an alliance governed by a single central lead organisation is more likely to develop new products and/or services than by equally positioned organisations collectively; yet, organisations should be of similar size, otherwise this positive effect will be weakened. Thus, policy-makers should require that organisations initiate a multipartner alliance with partners of unequal network positions but similar size. However, over time, the most effective partner composition changes because the alliance's purpose shifts from value creation to value appropriation. Presently, policy-makers often do not allow partners to enter or exit an existing multipartner alliance; certainly, it is not encouraged. Instead, they seek to enhance alliance flexibility by requiring that as many partners as possible are involved. Yet, our findings clearly suggest that lead organisational governance by a single central organisation is not suitable for capturing benefits from commercialising new products, regardless of the number of partners. Thus, policy-makers should require multipartner alliances to adapt the partner composition as soon as its goal shifts: from a composition with a single central organisation to one with organisations with equal network positions. If this is not possible, for whatever reason, policy-makers can reduce the harm caused by a single central lead organisation by requiring that organisations with different ages join a multipartner alliance. Our findings show that centrality asymmetry's negative effect on value appropriation is mitigated by age symmetry. Overall, the best partner composition shifts along with a multipartner alliance's goals: while value creation benefits from partners with unequal network positions and similar sizes, value appropriation benefits from partners with equal network positions. If more partner stability is desired, a multipartner alliance 
benefits most from position and age asymmetries between partners in network together with size symmetry.

\subsubsection{Limitations and further research}

Although in our view, this study has important implications, it also has limitations, which open directions for further research. One limitation is that this study cannot provide direct evidence of the causal mechanisms we hypothesised. We supported our hypotheses by arguing that either shared governance or lead organisation governance is more effective, depending on the effectiveness type and the considered power source. However, our data did not allow us to directly observe how a multipartner alliance was governed. Although our findings are partly consistent with our theoretical expectations, they also indicate that a lead organisation can abuse its power instead of governing multilateral relationships. Thus, more research is needed into the causal mechanisms that underlie power asymmetry's effects on value creation and value appropriation.

A further limitation arises from the selection of government-funded multipartner alliances as a sample. Governmental institutes often not only provide final support to alliances, but also promote social relationships and mutual trust between partners (Okamuro \& Nishimura, 2015; Ring, Doz \& Olk, 2005; Sakakibara, 1997a). Previous research has shown that this increases the effectiveness of multipartner alliances, because it results in less destructive conflicts and more effective governance (Matt, Robin \& Wolff, 2012; Okamuro \& Nishimura, 2015; Tripsas, Schrader \& Sobrero, 1995). Thus, our findings cannot readily be generalised to explain power asymmetry's effects on effectiveness of multipartner alliances not funded by a government. Accordingly, further research may compare power asymmetry's effects in subsidised multipartner alliances to the effects in such alliances that did not receive public funding.

Another limitation arises from our conceptualisation of power asymmetry. We chose to focus on two dimensions of power: relational and structural. Thus, we focused on the underlying potential of organisations to 
influence and control others' behaviours (Huxham \& Vangen, 2013; Olsen et al., 2014). Yet, an organisation seldom exercises all its potential power in all situations (Provan, 1980). Also, it can use its power to benefit the collective interest, or at its expense (Bunderson \& Reagans, 2011). Our findings provide some evidence in this direction: a central lead organisation is likely to use its power to enhance joint value creation, but not mutual value appropriation. Thus, a better understanding of how and when organisations use their potential power in multipartner alliances may be fruitful.

Also, we relied on size, age and centrality as approximate measures of an organisation's power in a multipartner alliance. Although each measure has previously been used as a proxy of power, they do not fully capture power's multidimensionality, not even if you integrate them as we did. Thus, researchers should use more direct power measures in further research (e.g. see Nyaga, Lynch, Marshall \& Ambrose, 2013; Wang, 2011). We could not apply such measures because the necessary information cannot be extracted from existing database. To address this shortcoming, scholars may investigate power asymmetry in multipartner alliances more directly via survey, case study or ethnographic research.

Our study's final limitation relates to our measurement of centrality. We measured a single centrality type: Bonacich's (1987) power centrality measure. However, there are several ways to measure centrality, each reflecting another aspect of power. We could not include multiple centrality measures in our analysis, because the symmetric nature of our network caused strong multicollinearity between them. Nonetheless, previous research in other contexts (see Valente, Coronges, Lakon \& Costenbader, 2008) has shown that these measures are conceptually related yet distinct. Thus, we encourage researchers to collect asymmetrical network data from densely connected networks with many nodes, so that multiple measures of centrality can be included. 


\section{CHAPTER 6}

The relationship between variety and new product development in multipartner alliances: power asymmetry's moderation effect

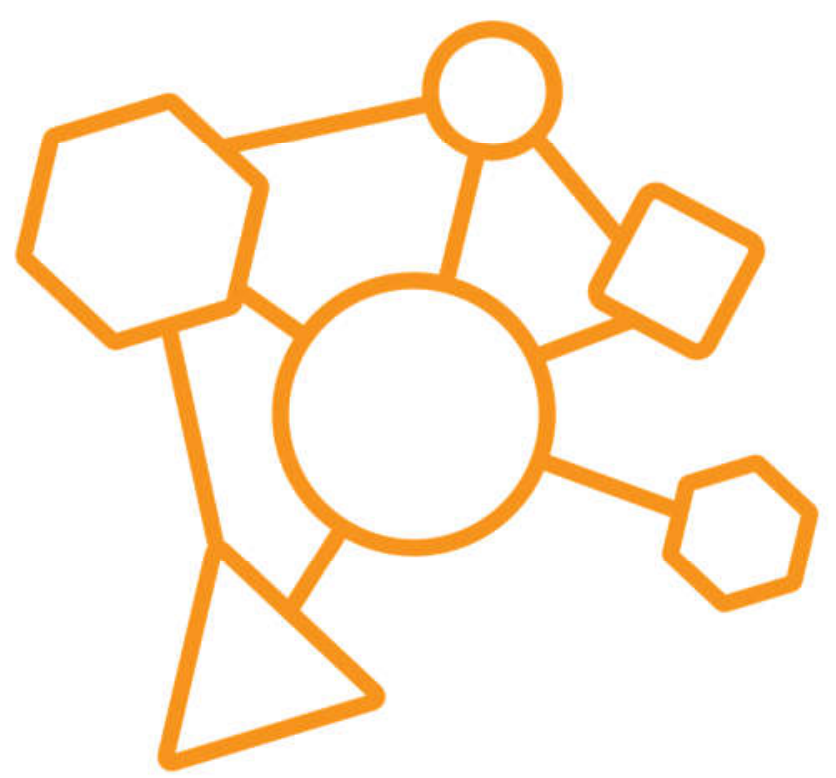

Authors are T. Oukes, A.J. Groen, P. Geurts \& A. von Raesfeld. This paper was submitted to the Annual Meeting of the Academy of Management in Chicago, IL, United States, August 2018. A previous version of this paper was presented at the HTSF conference in Amsterdam, The Netherlands, June 2017 and the annual PDMA research forum in Chicago, IL, United States, November 2017. 


\section{Abstract}

Power asymmetry exists in almost all multipartner alliances. The literature on interpersonal teams suggests that these power differences influence the extent to which variety in partners' functional purpose and characteristics results in successful new product development. However, little is known about power asymmetry in multipartner alliances generally, specifically its effect on the relationship between variety and new product development. We investigate power asymmetry's moderation effects on the relationship between functional, organisational and industry variety and new product development in multipartner alliances using a database of 409 alliances with multiple partners that had received funding from the Netherlands Technology Foundation STW between 2000 and 2004. We find that functional and organisational variety's negative and positive effects on new product development success in multipartner alliances are amplified if power asymmetry is high rather than low. Furthermore, we show that high industry variety increases the likelihood that a multipartner alliance will result in new product development success as well as failure if power asymmetry is low. We also find that the odds of new product development success are usually higher regardless of the industry variety level if power asymmetry is high. These results suggest that to get a clear understanding of variety's benefits and costs in multipartner alliances, researchers should always consider power asymmetry. Also, they highlight that business managers should carefully design their multipartner alliances, both in terms of variety and power relations.

\subsection{Introduction}

The alliance literature has a rich tradition of examining "comparative interorganizational differences on certain attributes or dimensions" (Parkhe, 1991, p. 582) and new product development in alliances. Most of this literature has focused on dyadic alliances and alliance portfolios (Cobeña et al., 2017), but there exists a growing interest in the effects of inter-organisational differences (here after, variety) on new product development in multipartner alliances (e.g. Arranz \& de Arroyabe, 2012; Branstetter \& Sakakibara, 2002; Raesfeld, Geurts \& Jansen, 2012; Raesfeld, Geurts, Jansen, Boshuizen \& Luttge, 
2012; Sakakibara, 1997b; Schwartz et al., 2012; Spanos \& Vonortas, 2012). These studies show that multipartner alliances with different partners create access to complementary resources that can be combined to develop new products (Cui \& O'Connor, 2012; Nieto \& Santamaria, 2007). However, at the same time, the coordination efforts necessary to manage resource flows between multiple partners greatly increases when variety increases, increasing the costs of new product development (Goerzen \& Beamish, 2005; Phelps, 2010).

Despite this invaluable understanding, the dominant approach to conceptualising variety in alliances is based on an implicit assumption of equal power. However, power is rarely distributed equally among multipartner alliance partners (Albers et al., 2015; Bunderson, 2003; HoehnWeiss et al., 2017). The literature on interpersonal variety suggests that this power asymmetry may affect the likelihood that variety in multipartner alliances will result in successful new product development in two opposing ways (Bunderson, 2003). The 'personalised' perspective on power argues that when power relations are asymmetrical, a powerful partner's resources may be given disproportionate weight, while the powerless partner's contributions may be overlooked (Bunderson, 2003; Bunderson \& Reagans, 2011), diminishing variety's new product development-related benefits. On the other hand, the 'socialised' perspective on power argues that a powerful partner can facilitate the mobilisation of unshared resources and can engage powerless partners in the new product development process (Bunderson \& Reagans, 2011; Pitcher \& Smith, 2001), reducing the coordination complexities associated with variety.

These insights suggest that to get a clear picture of variety's effectss on new product development in multipartner alliances, research should consider power asymmetries. Unfortunately, we have limited insight into power asymmetries within multipartner alliances, compared to our depth of understanding about dyadic alliances (Albers, Schweiger \& Gibb, 2015; Hingley et al., 2015). The previous research has also overlooked power asymmetries' implications on the relationship between variety and alliance 
performance. One exception is the work of Hoehn-Weiss, Karim and Lee (2017), which shows that redundancies in the alliance portfolio exacerbate non-uniformity of power imbalance's negative influence on company performance. Yet, substantial opportunities exist to expand our understanding of power asymmetry's effect on new product development in diverse multipartner alliances. Accordingly, we address the following research question: What is power asymmetry's effect on the relationship between partner variety and new product development in multipartner alliances? In the following sections, we develop our hypotheses, explain our methods, present our empirical results, discuss our findings, describe our study's implications, and provide suggestions for future research.

\subsection{Theory and hypotheses}

\subsubsection{Variety and new product development in multipartner alliances}

Following previous literature, we consider variety in functional purpose and partner characteristics as two key domains that affect new product development success (Jiang et al., 2010). Earlier studies (e.g. Cui \& O'Connor, 2012; Goerzen \& Beamish, 2005; Marhold et al., 2017; Nieto \& Santamaria, 2007; Phelps, 2010) have shown that different variety domains affect new product development in another way (Lee et al., 2014). Thus, we briefly explain variety's effects in functional purpose and two partner characteristics - industry and organisational type - on new product development in alliances with multiple partners.

Functional variety. Functional variety refers to partners' different functional activities, such as research and development (R\&D), manufacturing and marketing (Jiang, Tao \& Santoro, 2010). Cui and O'Connor (2012) found that functional portfolio diversity negatively influences innovative company performance. Cross-functional resource mobilisation is difficult owing to a lack of overlap in prior knowledge and common ground between partners (Cui \& O'Connor, 2012), which, increases the likelihood of coordination failures, such as project delays and suboptimal product development (Gulati et al., 2012). Thus, we hypothesise: 
Hypothesis 1: Functional variety negatively affects multipartner alliances' new product development success.

Organisational variety. Organisational variety refers to the partners' different organisational types, such as companies, governmental parties, research institutes and hospitals (Jiang, Tao \& Santoro, 2010). It is shown that organisational variety positively influences multipartner alliances innovation performance (Raesfeld, Geurts \& Jansen, 2012; Raesfeld, Geurts, Jansen, Boshuizen \& Luttge, 2012; Schwartz, Peglow, Fritsch \& Günther, 2012). Organisations that collaborate with others of "different sizes, structures and purposes increase their breadth of search, learning capabilities, and resource access" (Jiang, Tao \& Santoro, 2010, p. 1139). Further, the risk of coordination failures is limited, because the present non-commercial partners are usually able to manage the partners' contradicting goals, interests and perspectives (Wu \& Pangarkar, 2015). Thus, we hypothesise:

Hypothesis 2: Organisational variety positively affects multipartner alliances' new product development success.

Industry variety. Industry variety refers to the different industries partners that are involved in, such as wholesale \& retail trade, information \& communication \& education (Jiang, Tao \& Santoro, 2010). Goerzen and Beamish (2005) as well as Jiang, Tao and Santoro (2010) show that there is a U-shaped relationship between industry portfolio diversity and economic company performance. At low industry variety levels, the common background of partners facilitates the integration of supplementary resources (Das \& Teng, 2000; Jiang, Tao \& Santoro, 2010). At moderate industry variety levels, the potential of coalitions with like others increases partners' concerns about knowledge leakage, which leads to problems of unshared resources (Harrison \& Klein, 2007; Li et al., 2012). At high industry variety levels, partners are open and receptive to coordinating others' resources (Harrison \& Klein, 2007), increasing the possibility of developing new resource combinations (Jiang, Tao \& Santoro, 2010). Thus, we hypothesise: 
Hypothesis 3: Industry variety has a U-shaped effect on multipartner alliances' new product development success.

\subsubsection{Power asymmetry and the relationship between variety and new product development}

Power asymmetry refers to the composition of differences in proportion of power among partners in an alliance, i.e. inequality or relative concentration (Harrison \& Klein, 2007). Scholars have dedicated considerable effort to understanding power asymmetry's effects on new product development in dyadic alliances (e.g. Colurcio et al., 2012; Gil \& Beckman, 2007; Kim \& Park, 2015; Rutherford \& Holmes, 2008; Stuart, 2000; Tang et al., 2014; Wang, 2011, Yang et al., 2014). However, the theories (e.g. resource dependency theory and transaction cost theory) used in this literature are not well suited to explain power effects in multipartner alliances, because power's dynamics change drastically when moving from two to multiple partners. In a dyadic alliance, either one partner is more powerful than the other or both are equal, but a greater number of options arises when multiple partners are involved. Thus, power in multipartner alliances requires distinct theoretical development from dyadic alliances (Albers, Schweiger \& Gibb, 2015). Here, we build on theories from the literature on power in interpersonal teams, because it provides two perspectives that can explain power asymmetry's effects on the relationship between variety and new product development success in multipartner alliances: a 'socialised' and 'personalised' perspective (McClelland, 1975).

A 'socialised' perspective of power - grounded in functionalism theory - suggest that a powerful partner can coordinate the complexities associated with diverse multipartner alliances. A powerful partner can identify, assess and legitimise resource contributions from different partners and then arrange resource transfers to others (Bunderson \& Reagans, 2011; Dhanaraj \& Parkhe, 2006). Thus, it enables partners to realise their combined potential for innovation (Gibb et al., 2016; Heidl et al., 2014; O'Sullivan, 2005). Further, a powerful partner can ensure an "equitable distribution of value and mitigate appropriability concerns" (Dhanaraj \& Parkhe, 2006, p. 663). This will help powerless partners to feel safe when and encouraged in contributing to the 
new product development process (Bunderson \& Reagans, 2011; Dhanaraj \& Parkhe, 2006). Also, a powerful partner can decrease an alliance's instability: the higher the stability, the higher the alliance's potential for value creation (Dhanaraj \& Parkhe, 2006).

A 'personalised' perspective on power - grounded in conflict theory suggests that a powerful partner will diminish the new product developmentrelated benefits of variety in multipartner alliances. A powerful partner may share only certain parts of its resources at strategic times. Also, powerless partners are less likely to share their resources owing to problems of freeriding and opportunism. This reluctance to share resources can undermine joint innovation efforts (Bunderson \& Reagans, 2011; HoehnWeiss, Karim \& Lee, 2017). Further, the partners' different resources are often not equally represented in an alliance's new product development process. Powerful partners can impose their resources - even if not the most valuable to developing new resource combinations - while the partners with unique or even superior resources are not involved (Bunderson, 2003; Bunderson \& Reagans, 2011; Corsaro et al., 2012; Harrison \& Klein, 2007).

From the 'personalised' perspective on power, it can be concluded that higher power asymmetry levels would reduce the new product developmentrelated benefits from variety in multipartner alliances. Yet, we expect a powerful actor to use its power to achieve joint new product development goals because it may: a) undermine its own power position if it uses its power to enhance self-interests (Bunderson \& Reagans, 2011; Kim et al., 2005); b) damage its reputation as a trustworthy partner if it acts opportunistically (Bae \& Gargiulo, 2004; Bunderson \& Reagans, 2011); c) find it difficult to form new partnerships if it develops a reputation as a bad team player (Bunderson \& Reagans, 2011); and d) risk other partners withdrawing their support if they perceive they are being exploited (Dhanaraj \& Parkhe, 2006). Thus, we argue - in line with the 'socialised' perspective on power - that higher power asymmetry levels will decrease the coordination challenges of variety in multipartner alliances. Accordingly, we hypothesise that: 
Hypothesis 4a: Power asymmetry weakens the negative relationship between functional variety and new product development success of multipartner alliances.

Hypothesis 4b: Power asymmetry strengthens the positive relationship between organisational variety and new product development success of multipartner alliances.

Hypothesis 4c: Power asymmetry flattens the U-shaped relationship between industry variety and new product development success of multipartner alliances.

Figure 6.1 visualises the hypothesised relationships.

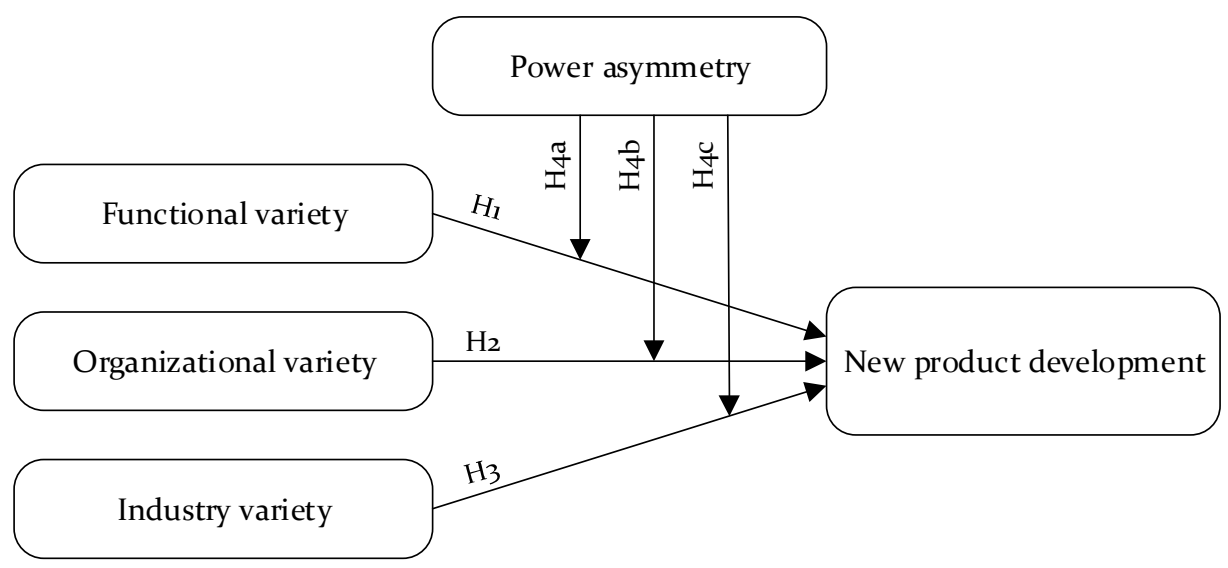

Figure 6.1 Hypothesised relationships visualised

\subsection{Methods}

\subsubsection{Sample}

We tested the hypotheses in a set of multipartner R\&D alliances funded by the Dutch Technology Foundation STW which funds application-oriented research projects in which research institutes and potential users of the generated knowledge such as large, medium-sized and small businesses, nonprofit organisations and healthcare institutes, collaborate. Sience the partner composition of multipartner alliances funded by STW were consistent with our definition of variety, it was an appropriate research setting to test our hypotheses. We used the publicly available data of 409 multipartner alliances 
initiated between 2000 and 2004. Besides basic information, such as project title, project budget and start date, the data includes information about: a) the users involved in the project; and $b$ ) the project results five years after the project completion.

\subsubsection{Measures}

Dependent variable. We used STW's evaluation of the extent to which a concrete product was developed five years after project completion as a measure of new product development success. Based on a survey among researchers, project managers and users involved with the project, STW classified projects into three categories: (A) there was no concrete product: more research was necessary to obtain a useful product for users; (B) a partial product was developed: verification and refinement were still required and users could not independently use it; or $(\mathrm{C})$ a full product was developed: it was a finalised concept that users could autonomously use.

Independent variables. To measure multipartner alliance variety, we classified each partner into different categories. For functional variety, we coded the partners' functions into three categories: (A) researcher and/or developer, (B) producer, or (C) user. For organisational variety, we coded the partners' organisational types into six categories: (A) companies, (B) governmental parties, (C) research institutes, (D) hospitals and medical institutes, (E) universities and schools, and (F) special interest groups. For industry variety, we coded the partners' industry, using the Dutch version of the SIC coding, into nine categories: (A) mining of minerals, (B) industry, (C) wholesale and retail trade, (D) information and communication, (E) consultancy, research and other business services, (F) public administration, public services and compulsory social insurance, $(\mathrm{G})$ education, $(\mathrm{H})$ health and welfare and (I) other. As suggested by Harrison and Klein (2007), we calculated variety at the multipartner alliance level with the Blau index, normalized for the number of categories. The normalised index was computed as follows: $B^{*}=\frac{1-\sum p_{k}^{2}}{1-1 / k}$, where $\mathrm{p}$ is the proportion of unit members in $k$ th category. 
We operationalized power asymmetry as the extent of concentration in the partners' centrality in the alliance, because organisations that are central nodes in a network are generally assumed to gain power (Astley \& Sachdeva, 1984, Bonacich, 1987, Freeman, 1978, Koka \& Prescott, 2002, Lavie et al., 2007, Tichy \& Fombrun, 1979). Specifically, we used Bonacich's (1987) measure of power centrality, considering that it measures the total amount of potential influence a node can have on all others via both direct and indirect channels (Hughes-Morgan \& Yao, 2016). We calculated every user's Bonacich (1987) power centrality within the STW's network between 2000 and 2004 using the standard formula in UCINET (version 6.623; Analytic Technologies, Harvard, MA, USA). Since the coefficient of variation captures the dominance of those with higher extents of a certain attribute (Harrison \& Klein, 2007), we used it as a measure of asymmetry at the multipartner alliance-level. We computed the coefficient of variation as follows: $\frac{\sqrt{ }\left[\sum\left(D_{i}-D_{\text {mean }}\right)^{2} / n\right]}{D_{\text {mean }}}$, where $\mathrm{D}_{\mathrm{i}}$ is the amount of attribute $\mathrm{D}$ of user $i, \mathrm{D}_{\text {mean }}$ is the average amount of attribute $\mathrm{D}$ in a project and $\mathrm{n}$ is the number of users.

Control variables. We included three control variables. We measured project budget as the amount of funding (in thousand euros) the project had received from STW. We calculated the number of partners as the absolute number of partners involved in the project. In our sample, $49 \%$ of the projects focused on nanotechnology. This technology's immaturity could influence the extent to which a concrete product is developed. Thus, we controlled for a focus on nanotechnology by creating a dummy variable for whether the project is directed at nanotechnology (1) or not (0).

\subsection{Results}

Table 6.1 presents the mean and standard deviations as well as the correlations for all variables. Table 6.2 presents the results of the multinominal regression used to test our hypotheses. To meaningfully interpret the U-shaped effect and interaction effects, the variables were centred before analysis. First, Table 6.2 shows that an increase in functional variety caused an increase in the odds of developing no product, compared to a partial product, with an odds ratio of $1.29,95 \%$ CI [1.08 to 1.55]. However, Table 6.2 
shows that functional variety did not significantly predicted whether a partial or a full product was developed. Thus, $\mathrm{Hl}$ was partially supported.

Second, Table 6.2 shows that an increase in organisational variety lowered the odds of developing no product, compared to a partial product, with an odds ratio of $0.37,95 \%$ CI $[0,18$ to 0,76$]$. Yet Table 6.2 shows that organisational variety did not significantly predicted whether a partial or a full product was developed. Thus, $\mathrm{H} 2$ was partially supported.

Third, Table 6.2 shows that industry variety's direct and squared effects had a positive and negative significant effect respectively on the odds of whether a partial or no product was developed, indicating a U-shaped relationship. The uncentred turning point was 1.25 , which was located well within the data range [0.97 to 2.79]. Furthermore, Table 6.2 shows that industry variety's direct and squared effects had a positive significant and negative insignificant effect respectively on the odds of whether a partial or a full product was developed. This indicates that industry variety had a positive linear effect on the odds of developing a full product, compared to a partial product. Thus, H3 was partially supported.

Fourth, Table 6.2 shows a significant positive interaction effect between functional variety and power asymmetry on the odds of whether no product or a partial product was developed. Figure 6.2a shows that functional variety's negative effect on the odds of developing a partial product, compared to no product, was subtaintially strengthened when power asymmetry was high. Table 6.2 also shows a positive, yet insignificant interaction effect between functional variety and power asymmetry on the odds of whether a partial or a full product was developed. Thus, H4a is rejected.

Fifth, Table 6.2 shows a significant negative interaction effect between organisational variety and power asymmetry on the odds of whether no product or a partial product was developed. Figure $6.2 \mathrm{~b}$ shows that organisational variety's effect on the odds of developing a partial product, 


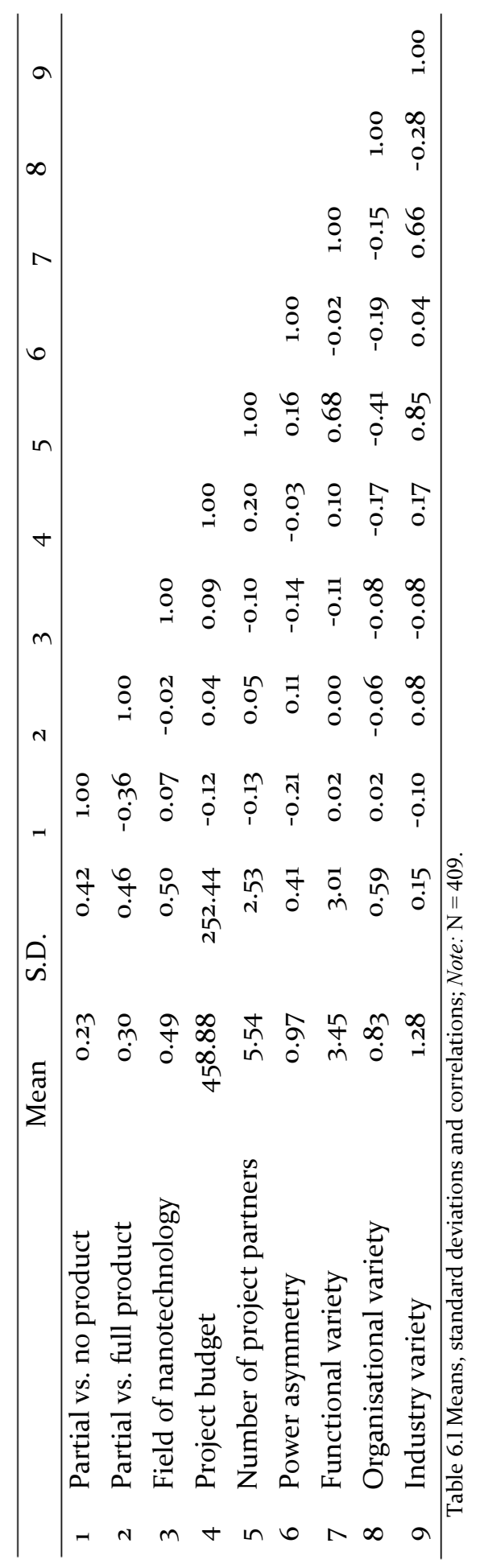




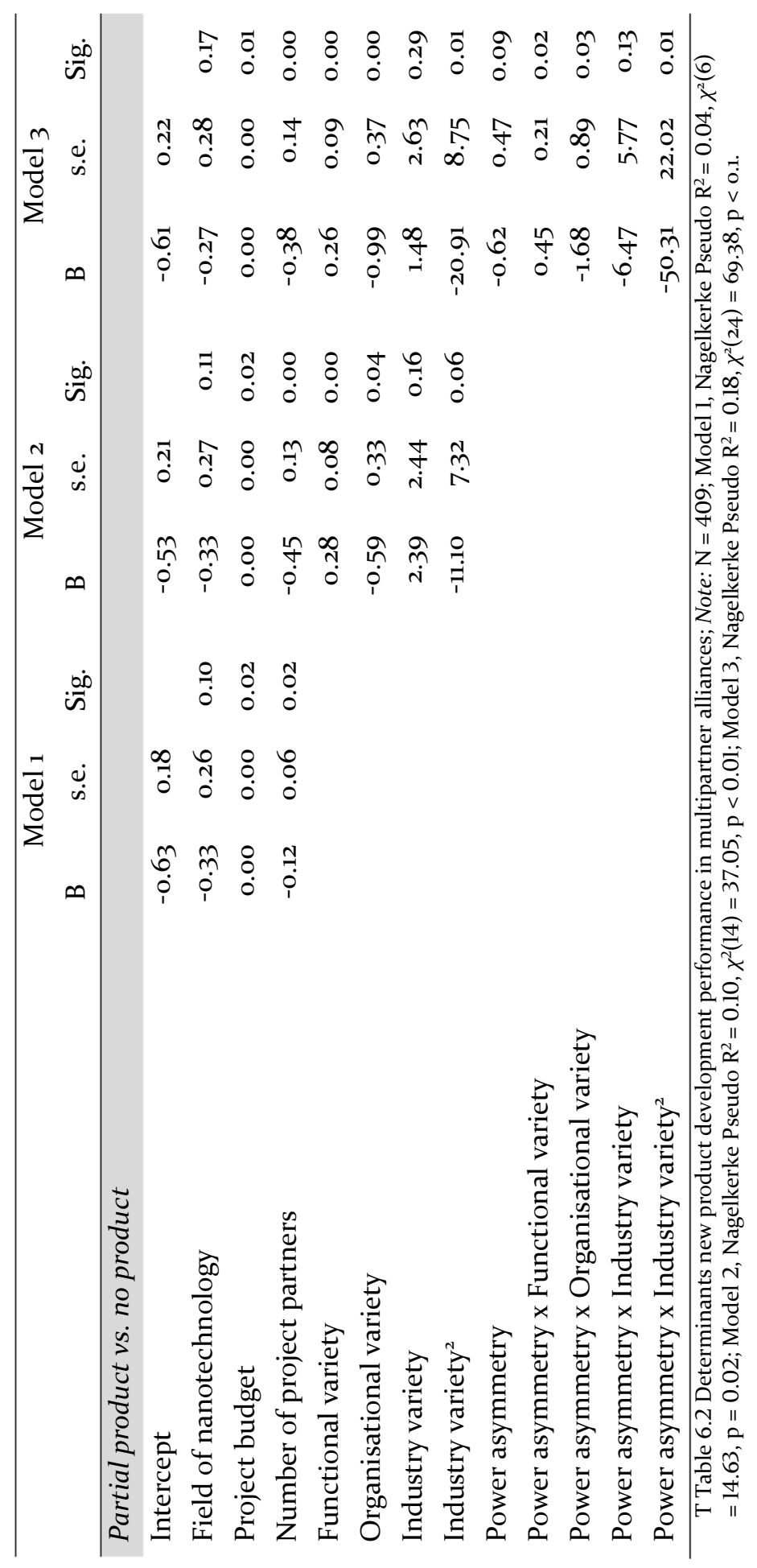




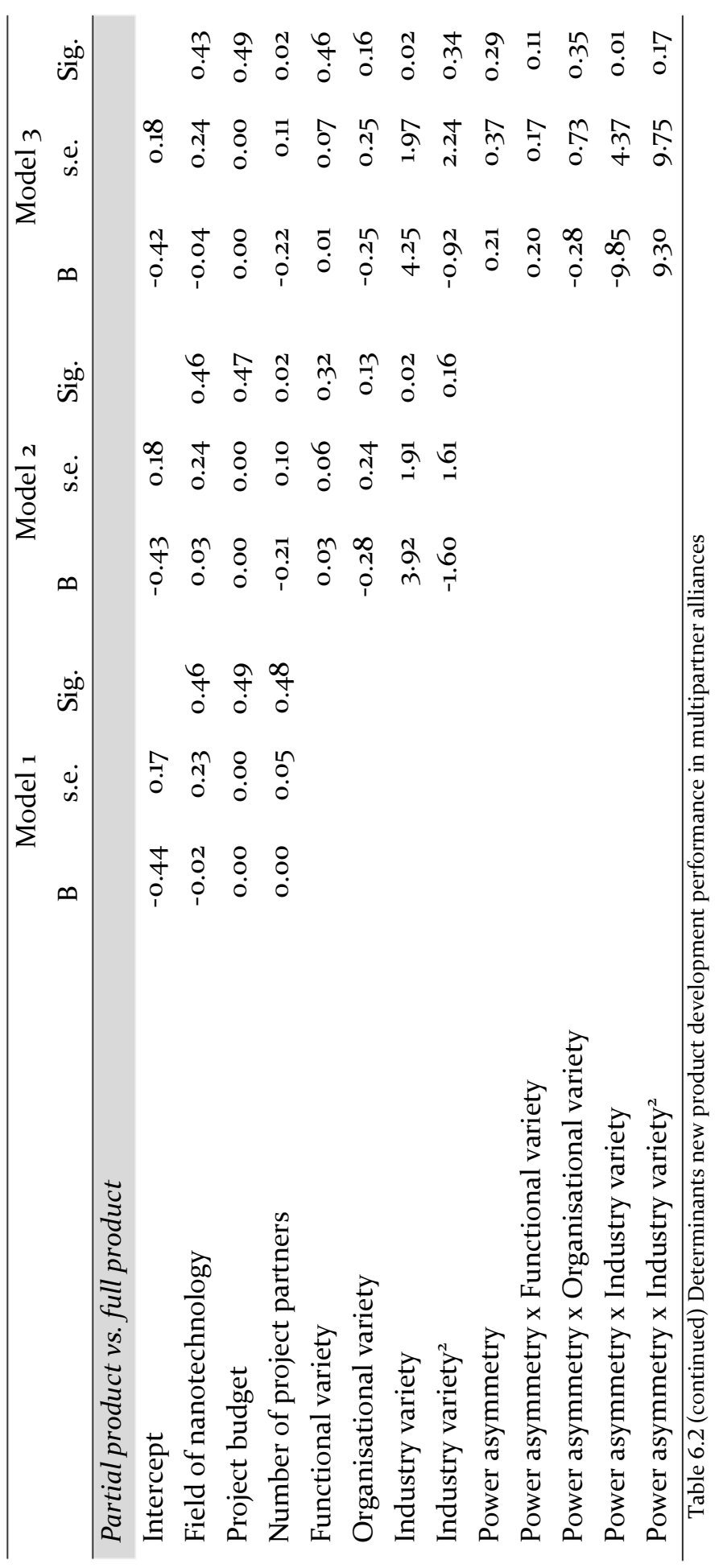


a. Functional variety

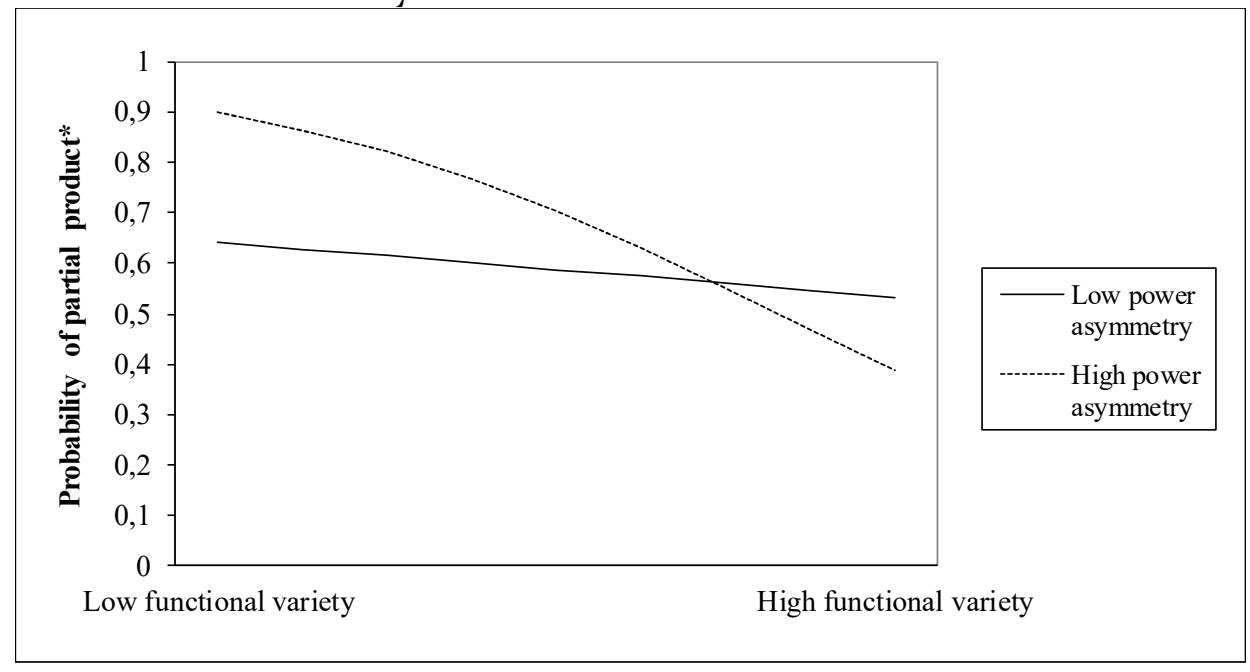

b. Industry variety

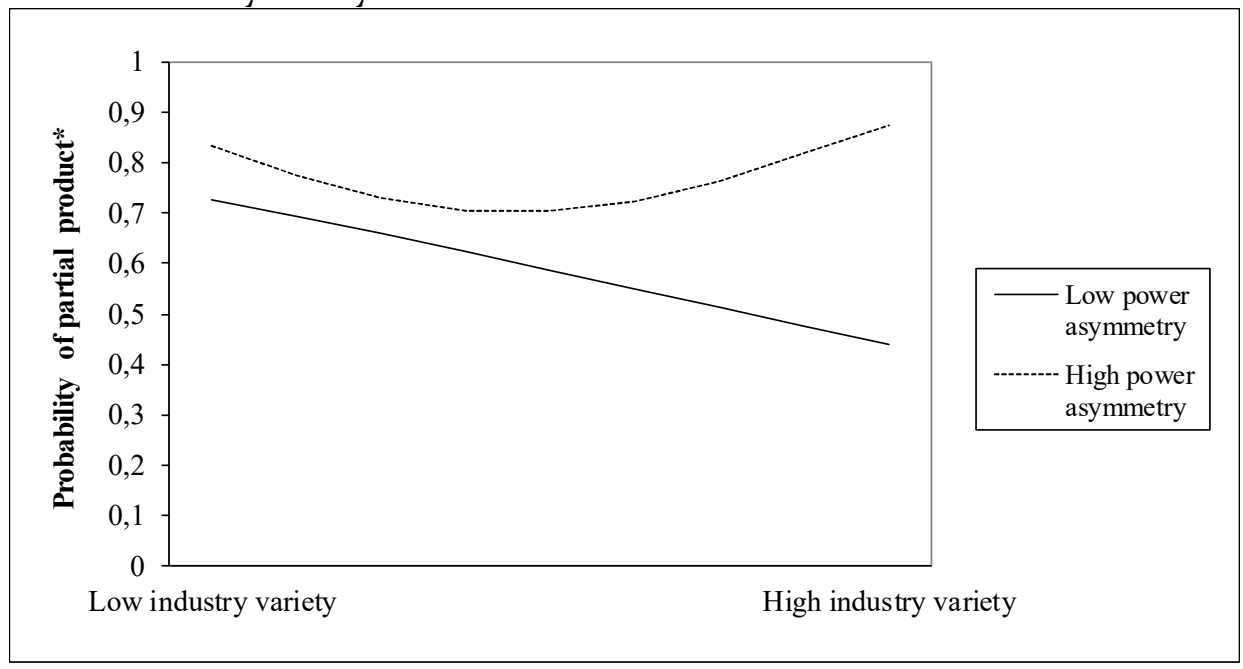

Figure 6.2 The interaction effects between variety and power asymmetry on new product development performance. Note: *Compared to no product; ${ }^{* *}$ Compared to partial product. 
a. Organisational variety

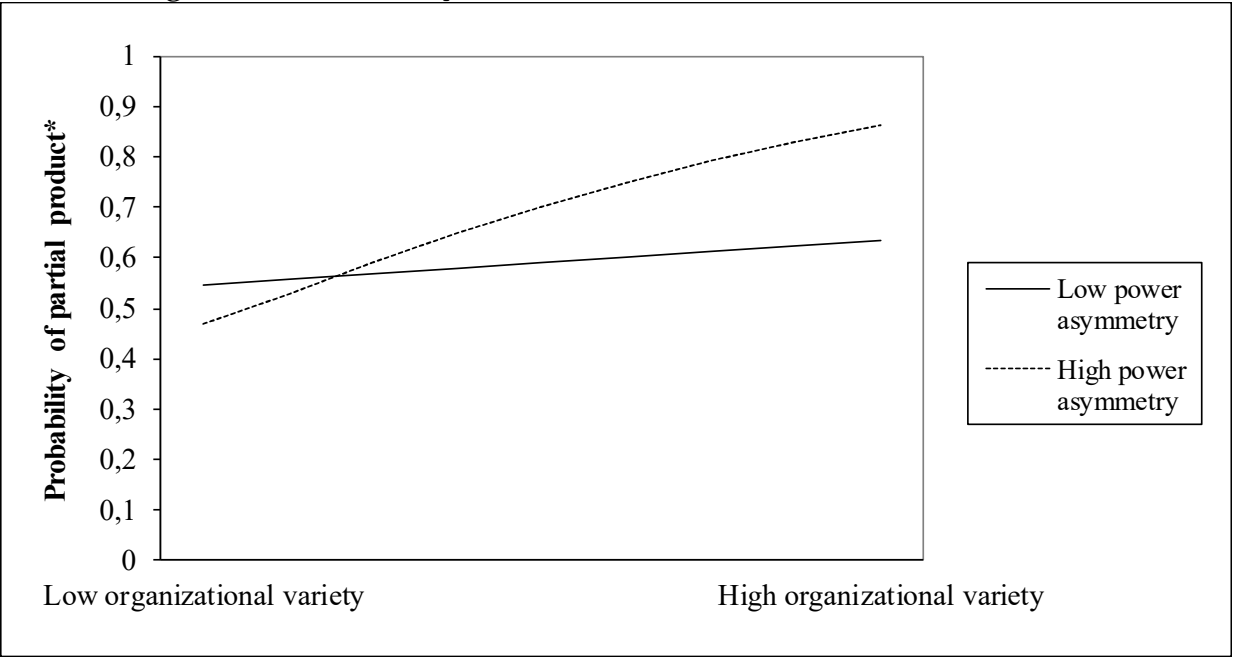

b. Industry variety

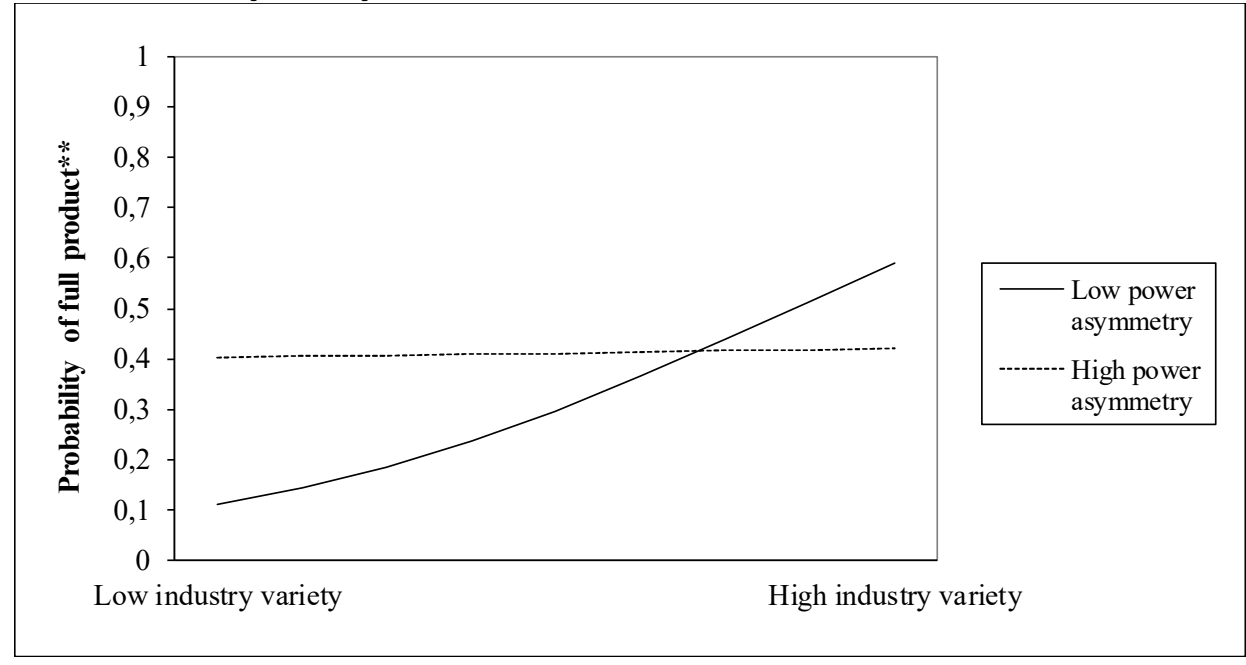

Figure 6.2 (continued) The interaction effects between variety and power asymmetry on new product development performance 
compared to no product, was substaintially strenghtened under high power assymmetry. Additionally, the results show a positive, yet insignificant interaction effect between organisational variety and power asymmetry on the odds of whether no product or a full product was developed. Thus, H4 was partially supported.

Sixth, Table 6.2 shows a significant negative interaction effect between power asymmetry and industry variety on the odds of whether a partial or no product was developed. Figure 6.2c shows that the U-shaped relationship between industry variety and the odds of developing a partial product, compared to no product, was flattened under high power asymmetry, while it became negative and linear (i.e. shape flipped) under low power asymmetry. Further, Figure 6.2d shows that industry variety's positive effect on the odds of developing a full product, compared to a partial product, was subtaintially weakened when power asymmetry was high. Thus, H4c was partially supported.

\subsection{Discussion}

The results show that the relationship between organisational variety and the likelihood of developing a partial product - compared to no product - is strengthened under increased power asymmetry. This supports previous research (e.g. Bunderson \& Reagans, 2011; Dhanaraj \& Parkhe, 2006; Gibb, Sune \& Albers, 2016; Heidl, Steensma \& Phelps, 2014; O'Sullivan, 2005; Pitcher \& Smith, 2001) that argues that powerful partners can contribute to multipartner alliances' new product development success by leveraging knowledge mobility, mitigating appropriation concerns and maintaining alliance stability. However, in contrast to our expectations, the relationship between functional variety and the likelihood of developing a partial product - compared to no product - is also strengthened if power asymmetry increases. Thus, our study also supports previous research (e.g. Bunderson, 2003; Bunderson \& Reagans, 2011; Corsaro, Cantù \& Tunisini, 2012; Harrison \& Klein, 2007; Hoehn-Weiss, Karim \& Lee, 2017) that suggests that powerful partners can hinder alliances' new product development success by decreasing resource exchange. These contradictory results suggest that power 
asymmetry amplifies variety's effects on new product development in multipartner alliances, instead of leveraging its positive and mitigating its negative effects. We will now speculate on the reasons underlying this amplifying effect.

The findings may imply that the new product development-related benefits of variety encourage the 'socialised' use of power in highly asymmetrical multipartner alliances (Bunderson, 2003; Gulati, Wohlgezogen \& Zhelyazkov, 2012). When powerful partners expect benefits from the combination of diverse resources, they may perceive it as worth to helping the alliance to reach its collective new product development goals. In contrast, a powerful partner may incur additional coordination costs while gaining no any additional new product development-related benefits if the partners in the alliance portfolio are similar (Hoehn-Weiss, Karim \& Lee, 2017). Thus, there is a higher likelihood that a powerful partner will use its power to coordinate resource exchange in a multipartner alliance as organisational variety increases.

Further, the coordination costs associated with functional variety seem to encourage the 'personalised' use of power in highly asymmetrical multipartner alliances (Bunderson \& Reagans, 2011; Gulati, Wohlgezogen \& Zhelyazkov, 2012). When coordination challenges fuel worry about a multipartner alliance's benefits, a powerful partner may doubt whether effortful forms of coordination are worthwhile. It may try to minimise individual efforts and risks and to maximise individual benefits (Ariño \& de la Torre, 1998; Gulati, Wohlgezogen \& Zhelyazkov, 2012). Another explanation may be that the coordination issues associated with functional variety are too demanding, even for a powerful partner: its ability to distinguish between truly critical issues and those that there are merely proximate or recent may be limited (Gulati, Wohlgezogen \& Zhelyazkov, 2012; Park \& Ungson, 2001). Thus, a powerful partner has lower motivation or is less able to use its power to solve the coordination issues in multipartner alliances as functional variety increases. 
In contrast to our expectation, we found no significant interaction effects between power asymmetry and functional and organisational variety on the likelihood that a complete product was developed, compared to a partial product. Our results suggest that this could be because it is generally harder to make a conceptual product than a complete one. Indeed, Markham and Lee (2013) show that the number of ideas that survives the new product development process steeply declines. Also, variety "should enhance innovation due to the amount and variety of knowledge to be shared, thereby enable the alliance partners to fill out their initial resource and skill endowments" (Nieto \& Santamaria, 2007, p. 371). Yet it may be less important in the latter stages of product development, such as during testing, validation and commercialisation.

Another result is that there is a higher likelihood of developing both no product and a complete product (compared to a partial product) in multipartner alliances characterised by high industry variety and low power asymmetry. Although this result seems contradictory, it underscores the varied results in research into the effects of inter-organisational differences assuming equal power relations - on alliance performance (see Cobeña, Gallego \& Casanueva, 2017; Lee, Kirkpatrick-Husk \& Madhavan, 2014). The opposing effects may stem from variety's dual effect on new product development performance; although it increases failures, it also increases the number of innovative solutions (Phelps, 2010). Thus, multipartner alliances characterised by low industry variety may typically achieve at least some result, but less often create fully developed innovative solutions. In contrast, high industry variety may open opportunities for successful re-combinatory new product development, but if the partners are unable to successfully coordinate their differences, the effects may be detrimental.

This contradictory effect of industry variety disappears if a multipartner alliance has high power asymmetry. The results show that powerasymmetrical multipartner alliances are generally more likely to lead to a partial or full product. An exception is when there is high industry variety, in which low power asymmetry is more beneficial to achieve a fully developed 
product. Since the partners are from different industries, there are less competitive concerns that would lead them to withhold valuable resources and many opportunities to stimulate new product development (Jiang, Tao \& Santoro, 2010; Phelps, 2010). Based on this discussion, it could therefore be expected that industry variety's positive effect is amplified, yet this is not the case. A possible explanation may be that partners from unrelated industries face many different routines, structures and processes, political and economic systems, and governmental policies, limiting the overlap in backgrounds, experiences and technological bases (Cui \& O'Connor, 2012). In turn, it becomes extremely difficult for a powerful partner to accurately assess the value of others' resources to the new product development process. Thus, it may, despite its best intentions, advance the resources of partners in similar industries, while it may overlook resources of others in dissimilar industries, even when those could be important to new product development success. This is in line with the findings of Tarakci et al. (2016) who show that power asymmetry benefits group performance only when aligned with the power holder's competence.

\subsection{Conclusion}

\subsubsection{Implications}

Our study's main theoretical implication is that research into variety's effects on new product development in multipartner alliances is always underspecified if power asymmetries are not considered. It is hard to imagine any multipartner alliance in which power differences do not exists. Nonetheless, power asymmetries are generally neglected in studies on multipartner alliances (Albers, Schweiger \& Gibb, 2015; Hingley, Angell \& Lindgreen, 2015). Also, few studies have systematically examined how power asymmetry influences variety's effect on new product development success. Our study confirmed previous research that found that different variety types affect new product development in different ways. We also showed that power asymmetry is pervasive in multipartner alliances and has key implications for the relationship between variety and new product development. We expected a powerful actor to always use its power to achieve mutual new product development objectives, but found that the relationship between power asymmetry, variety and new product development is much 
more complicated. We speculated that this is because a powerful actor may either be unwilling or unable to use its power for the multipartner alliance's benefit depending on the variety type it is supposed to coordinate. To determine a multipartner alliance's de facto variety and the resulting likelihood that it will result in new innovative products, we therefore stress that researchers should focus on the question when is a powerful partner willing and able to use its position to solve coordination challenges and when to maximise its individual benefits?

For practicing managers, our study's results highlight the difficulty of developing a fully functional new product, compared to a conceptual one, in a multipartner alliance. To increase their likelihood of success, we suggest that managers form alliances with partners from many different industries and of equal power relations. However, at the same time, we caution managers for such an alliance because the combination of high industry variety and low power asymmetry also dramatically increase the odds of failure. If practicing managers aim for more certain but less developed results, we encourage them to form a multipartner alliance characterised by unequal power relationships and consisting of partners: a) with a single functional purpose, b) with many different organisational types, and c) from either few or many different industries. Also, we emphasise that unequal power relations generally enhance the likelihood that an alliance creates a conceptual product - except when functional variety is very high and/or organisational variety is very low, then partners are better off with equal power relations.

\subsubsection{Limitations and future research}

Our study has some limitations, which open avenues for further research. One limitation is that this study cannot provide direct evidence of the causal mechanisms we hypothesised. Although the hypotheses concerning power asymmetry's moderating effects relied on the argument that a powerful partner is motivated to use its power to coordinate variety in multipartner alliances, our data did not allow use to observe motivation. Although our results are partly consistent with our theoretical expectations, they also indicate that a powerful partner may not be able to coordinate a 
multipartner alliance if the coordination issues become too large. Thus, we need to better understand the mechanisms that underlie the observed power asymmetry and variety's effects on new product development in multipartner alliances.

Another limitation results from our measurement of new product development as a subjective evaluation by an external party. We considered a subjective measure appropriate because the new product development objectives are usually fairly specific for each alliance (Schwartz, Peglow, Fritsch \& Günther, 2012). In addition, same-source variance did not affect our findings because the same individuals did not assess both antecedents and outcomes. However, there are several to other performance measures types (see Christoffersen, 2013). In line with Schwartz, Peglow, Fritsch and Günther (2012), we encourage researchers to use multiple indicators of new product development success.

Also, we have limited our focus to three variety types: functional, organisational and industry variety. However, an overview of Lee, Kirkpatrick-Husk and Madhavan (2014) shows that there are more partner characteristics types ommonly studied in diversity research. Further, Jiang, Tao and Santoro (2010) suggests that variety research should also consider variety in governance structure of alliances. Thus, more research is needed into power asymmetry's effects on the relationship between other variety types and new product development.

Another limitation arises from the selection of publicly funded multipartner R\&D alliances as sample. Although we did not select only successful projects, Schwartz, Peglow, Fritsch and Günther (2012) suggests that $R \& D$ projects with a considerable risk of failure may be excluded in our sample because they are screened on several criteria before the allocation of funding. Thus, researchers may compare power asymmetry's effects in subsidised multipartner R\&D projects to its effects in projects that did not receive public funding. 


\section{CHAPTER 7}

Conclusion

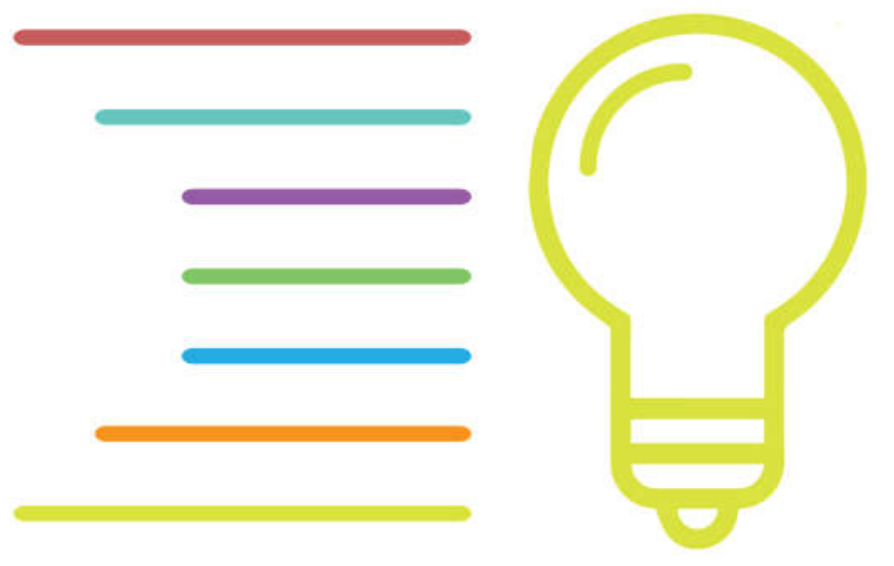


This dissertation started with Mr. Ronsman's ${ }^{3}$ question: how should I initiate and manage my business relationships? As noted in Chapter 1, he found it was difficult to initiate and manage its business relationships, because his startup had a fragile network position compared to his wellestablished business partners. Mr. Ronsman's experiences are no exception; other businesses also struggle to effectively manage their business relationships, especially when network positions and power are unequal. Given this matter's practical relevance, there is surprisingly little research into how network position and related power affect how businesses manage their relationships and the subsequent effects related to the relationship. Thus, in this dissertation, I presented five studies (Chapters 2 to 6), which each examined different aspects of the relationships between network position, network management and network outcomes. Although these studies can be read as separate contributions, they share a common theme in the sense that they all describe how network position and related power affect how businesses behave in business relationships, and - in turn - how this behaviour affects relational outcomes. Accordingly, my main research question was: How do network position and related power affect and are they affected by business relationships management and outcomes in networks? To answer this question, we did an intensive longitudinal embedded case study of a startup in the medical device industry (Chapters 2 to 4 ) and an extensive statistical analysis of 409 multipartner relationships (Chapters 5 and 6). The studies' findings expand our knowledge on how startups in a fragile network position can successfully manage business relationships in interaction. They also contribute to our understanding of how power derived from network position affects collaborative outcomes in business relationships, especially those with multiple partners. In the last chapter of this dissertation, I will address my main research question. Starting by answering the five research questions based on each study's findings, discussions and conclusions. I will then discuss the general theoretical and practical implications of the research I have presented in this dissertation. I end with some suggestions for further research based on a reflection on limitations of my dissertation.

${ }^{3}$ For anonymity reasons, Mr. Ronsman is a fictitious name. 


\subsection{Research findings}

\subsubsection{Chapter 2 - Research question 1}

In Chapter 2, I explored how third actors affect a startup's relationship initiation process and subsequently its network embedding and its business development. Accordingly, my first research question was: How do third actors influence a startup's relationship initiation and subsequent network embedding, as well as its business development? We addressed this research question via a longitudinal case study of a startup's eight relationship initiations and their consequences. Our first finding was that third actors acted as a facilitator that fostered this startup's business relationships rather than as an intermediary that controlled them. The startup exclusively depended on two well-embedded third actors to initiate its business relationships. The startup's relationships advanced from unrecognised to recognised and considered statuses with the third actors' support. However, they played no active role in the consideration status because they did not have the skills to do so. Also, the startup's relationship with well-embedded and skilled third actors did not necessarily result in new relationships; the third actors also had to be motivated to support the startup's development by connecting them to potential valuable partners. Further, we showed that the startup's embedding was facilitated by third actors who initiated new relationships. Especially, the startup's network embedding was strengthened if the third actor remained actively involved in the relationship after its initiation and built a strong relationship with both parties. Our last finding was that the startup would have been unable to develop its technology, business or network without the relationships initiated by the third actors. At the same time, the third actors performed a different role and function, depending on the phase of the startup's venture creation process. Thus, it appeared that third actors affected and were affected by the startup's business development. Based on these findings, we concluded that third actors are crucial to a startup's relationship initiation process, network embedding and business development. Third actors stimulate a startup's relationship initiation process by connecting it to potential valuable partners. In turn, the newly initiated business relationships advance a startup's network embedding and business development. The third actors also facilitate a startup's network 
embedding if they form a strong triadic relationship with it and its new partner.

\subsubsection{Chapter 3 - Research question 2}

In Chapter 3, I sought to learn how a startup in a fragile network position interacts with its partners over time to reach its business relationships' aims. Thus, my second research question was: How does a startup interact with its partners over time to embed itself in the pre-existing network? To address this research question, we conducted a longitudinal case study of 18 interaction episodes between a startup and its partners. Our first finding is that the interaction between the startup and its partners over time could be characterised as a sequence of interaction episodes that were interlinked because the outcomes of a previous episode affected a subsequent one. Further, we discovered that an interaction episode was promoted by an internal or external trigger that could expand or constrain the opportunities for future interactions. In response, the startup and a specific partner used a certain interaction mode: acquiesce, compromise, create, avoid, defy or manipulate. It emerged that acquiescence was used more often by the startup than its partners; the other interaction modes were used by them to a similar extent. In turn, an interaction process was set in motion in which actions and reactions went back and forth between the startup and its partner. It appeared that conceding interaction modes were often answered with conceding ones, while coercive modes of interaction where answered with coercive ones. Eventually, the interaction process resulted in a converting, inhibiting or mixed outcome for the startup, its partner and their relationship. These findings led us to conclude that a startup's interactions with its partners are interactive and dynamic. They are interactive because a startup and its partner react to one another in the interaction process by reciprocating one another's interaction modes. Startups' interactions are dynamic because: 1) previous interaction episodes affect subsequent ones; and 2) a 'trigger' prompts a startup and its partner to act, causing an interaction process that determines the eventual outcomes for the startup, its partner and their relationship. 


\subsubsection{Chapter 4 - Research question 3}

In Chapter 4, I sought to discover the role of structural and behavioural power in business relationship between a startup and its well-established partners. Thus, my third research question was: How do structural and behavioural power interact in a startup's business relationships? The research question was addressed in a longitudinal case study of nine power episodes between a startup and its well-established partners. Our first finding was that, taken together, resource control, network position and formal position determined the startup's and its well-established partners' structural power. Although they did not fully correspond, the startup and its partners formed a perception of their own and the other's power based on this structural power. In turn, the perceived power determined whether a startup will choose to apply power change or power use tactics (i.e. power behaviour). However, the choice for a specific power tactic was influenced by other aspects of the relationship atmosphere, i.e. the closeness between partners, the conflict level in the relationship and the partners' future expectations. Subsequently, the startup's power behaviour influenced whether it could extract the intended benefits from its relationships: power change tactics resulted in realised power if it successfully changed the power perception of its well-established partner; and the usage of conciliatory rather than hostile power use tactics resulted in realised power, but only coalition-building changed structural and/or perceived power. Also, we discovered that the startup often had a disadvantageous power position comparted to its well-established partners. As the startup generally did not recognise its subordinate position, it used more hostile power use tactics than could be expected based on its de facto structural power. In contrast, the startup's partners often had a fairly accurate power perception, and therefore strongly resisted such hostile behaviour. Thus, the startup was often unable to realise its power. Based on these findings, we concluded that a startup's and its well-established partner's structural and behavioural power interact via their perceived power. On the one hand, they decide to apply power tactics based on their perception of each other's power rather than their de facto structural power; on the other hand, they can change their structural power or their partner's perception thereof via power change tactics and coalition-building. 


\subsubsection{Chapter 5 - Research question 4}

In Chapter 5, I sought to understand power asymmetry's impacts on the value creation and appropriation effectiveness of multipartner relationships. Thus, my fourth research question was: What are power asymmetry's effects on value creation and appropriation in multipartner relationships? To address this question, we argued that governance by a lead organisation in powerassymetrical relationships is beneficial to value appropriation, while shared governance in power-symmetrical relationships stimulates value creation. Thus, we expected that power asymmetry derived from structural power sources (i.e. size and age) would negatively affect value creation and would positively affect value appropriation. Yet we proposed that power asymmetry derived from relational power sources (i.e. network centrality) positively affects both outcomes. We also hypothesised that size and age asymmetry moderate the relationship between centrality asymmetry and value creation as well as value appropriation. We tested these hypotheses in a data set of 409 alliances with multiple partners who received funding from the Netherlands Technology Foundation STW between 2000 and 2004. Our first finding is that lead organisation governance in a centrality-asymmetrical relationship stimulates value creation. Size asymmetry moderates this relationship: the higher the size asymmetry, the weaker the positive relationship between centrality asymmetry and value creation. This may be because a central lead organisation has an incentive to govern the collective value creation process. However, a central lead organisation's resources are given disproportionate weight in developing new products when it is also large. Our second finding is that shared governance in a centrality-symmetrical relationship enhances value appropriation. Age asymmetry moderates this relationship: the higher the age asymmetry, the weaker the negative relationship between centrality asymmetry and value appropriation. We suggest that this is because a central lead organisation is motivated to maximise its own benefits at the expense of the collective in the value appropriation process. Yet the potential damage to the central lead organisation's reputation and legitimacy prevents it from acting opportunistically when it is also old. These findings led us to conclude that power asymmetry derived from the same source can have a different effect on value creation vs. value appropriation. Further, power asymmetry 
derived from different sources can have a different effect on the same outcome.

\subsubsection{Chapter 6 - Research question 5}

In Chapter 6, I examined power asymmetry and partner variety's influences on new product development in multipartner relationships. Accordingly, my fifth research question was: What is power asymmetry's effect on the relationship between partner variety and new product development in multipartner relationships? To address this research question, we first argued that the powerful actor - in a multipartner relationship characterised by high power asymmetry - would use its power to coordinate the complexities associated with partner variety and achieve joint new product development goals. Thus, we hypothesised that power asymmetry positively moderates the relationship between functional (a), organisational (b) and industry (c) variety and new product development success in multipartner relationships. We tested these hypotheses in a data set of 409 alliances with multiple partners granted funding from the Netherlands Technology Foundation STW between 2000 and 2004. Our first finding was that the negative and positive effects of functional and organisation variety on new product development in multipartner relationships are amplified if power is high rather than low. Further, we showed that high industry variety increases the likelihood that a multipartner relationship will result in new product development success as well as failure. A subsequent finding was that new product development success is usually higher if power asymmetry is high, regardless of the industry variety level. Low power asymmetry is only more beneficial to new product development success if industry variety is very high. These findings led us to conclude that the relationship between power asymmetry, partner variety and new product development in multipartner relationships is not straightforward. Our findings suggest that this is because a powerful actor may be unwilling or unable to use its power for the benefit of the multipartner relationship, depending on the variety type it is supposed to coordinate. A powerful partner may believe that effortful forms of coordination are not worthwhile if it does not expect benefit from the combination of diverse 
resources, or the issues associated with coordinating variety may be too demanding, even for a powerful partner.

\subsubsection{Synthesis}

Taken together, the five empirical studies allow me to answer this dissertation's main research question: How do network position and related power affect and are they affected by business relationships management and outcomes in networks? Our findings suggest that network position and related power affect business relationship management in three ways: first, startups in a fragile network position strongly depend on third actors to initiate new business relationships; second, they are more likely to comply with the other's interest than their partners, even though they use other interaction modes to a similar extent; third, they employ power change tactics rather than power use tactics if they are aware of their unfavourable power position. However, our findings indicate that how a relationship is managed also affects its network positions. Startups become more embedded into an existing network if third actors build strong business relationships with both parties. Further, they can improve their power position compared to their established partners via: a) building coalitions with other organisations and b) changing their partners' power perception. Network position can be considered an antecedent and a result of network management at the same time. Nonetheless, our findings imply that the ways in which businesses manage their networks also affect other outcomes related to their relationships. Third actors that initiate new business relationships for startups stimulate the startups' business development. Also, conceding interaction modes are likely to advance the relationship, while coercive interaction modes tend to have an inhibiting effect on the relationship. Further, startups can extract - even though not always the intended - benefits from a relationship when they employ power change tactics or conciliatory power use tactics rather than hostile power tactics. In turn, our findings indicate that network outcomes influence how businesses manage their relationships. A startup's business development stage determines a third actor's role in initiating relationships for it. Further, converting outcomes in a previous interaction episode evoke more conceding behaviours rather than coercive behaviours in a subsequent episode than inhibiting outcomes. 
Finally, our findings suggest that network position directly impacts network outcomes. Power asymmetry derived from network position affects both value creation and appropriation in multipartner relationships. Yet, notably, this relationship is dependent on the partner variety type and level in a multipartner relationship.

\subsection{Theoretical contributions}

I discussed the theoretical contributions of the individual studies in this dissertation in the discussion sections of Chapters 2 to 6 . In this section, I highlight this dissertation's four primary contributions to theory. My first contribution is that our findings create a better understanding of how startups - businesses in a fragile network position - successfully initiate, maintain and develop business relationships. Extant research has suggested several ways to overcome startups' relationship management challenges. First, scholars have shown that startups can initiate new business relationships via third actors (Hite, 2005; Jack, Dodd \& Anderson, 2008; Styhre \& Remneland-Wikhamn, 2015). We also revealed that third actors not only facilitated a startup's initiation of business relationships, but also advanced its network embedding and business development. This implies that it is crucial that scholars beyond investigating third actors' roles in initiating business relationships towards exploring their implications for 'connected' businesses. Second, scholars have found that startups can develop their business relationships by complying with their partners' demands (Ariño, Ragozzino \& Reuer, 2008; Thorgren, Wincent \& Boter, 2012). Yet we have shown that a startup can use a range of other interaction modes besides acquiescence: compromise and creation, which usually have a positive outcome; and avoidance, defiance and manipulation, which typically have a negative effect. This suggests that scholars should consider all interaction modes simultaneously rather than one at a time so as to create a more complete understanding of how startups can successfully interact in their business relationships. Third, scholars have demonstrated that startups can successfully mediate against their partners' power (Habib, Bastl \& Pilbeam, 2015; Katila, Rosenberger \& Eisenhardt, 2008; Sawers, Pretorius \& Oerlemans, 2008; Yang, Zheng \& Zhao, 2014). However, we have shown that 
a startup should be aware of its power-disadvantaged position vis-à-vis a specific partner if it is to do so. Though, a subordinate power position often remains unrecognised by a startup and the most suitable power tactics are consequently not applied. This indicates that scholars should include startups' power perception besides their de facto structural potential to research how they deal with power struggles in their business relationships.

Another contribution is based on our finding that business relationship management is an interactive process. As explained in Section 1.2.1, the current management literature assumes that businesses can autonomously manage their business relationships (Aaboen, Holmen \& Pedersen, 2017; Slotte-Kock \& Coviello, 2010). However, in line with IMP's legacy, our findings challenge this assumption by showing that startups' business relationship management takes place in interaction. Specifically, study 2 showed that a startup's decision to use a specific interaction mode is strongly influenced by its partner's and vice versa. Taken together, a startup's and its partner's interaction modes form an interaction process, which results in a certain outcome for both parties and their relationship. In addition, study 3 revealed that a startup's power behaviour is partly derived from its perception of its partner's structural power and power behaviour. In turn, its power behaviour may influence how powerful its partner perceives it to be. In other words, our findings confirm that a startup does not manage its business relationships and its power struggles in isolation; it is affected by its partners and it affects its partners. However, they also indicate that interaction is not necessarily a dyadic process. For instance, we found that third actors played an indispensable role in initiating the case of a startup's business relationships. Also, we uncovered that a startup could create solutions to relational conflicts and could build coalitions to rebalance power differences by involving other organisations in an existing relationship. We also revealed that the mutual power relations - based on network position - between multiple partners in a relationship determines the performance of such relationships. This suggests that not only the two organisations directly involved in a relationship are key to the relationship management process, but also their indirect counterparts. Thus, I argue that scholars must take a 
multi-sided, interactive perspective when investigating how businesses manage their relationships.

Further, our findings extend the current knowledge of power in dyadic relationships towards multipartner relationships. Scholars have argued that power in relationships with multiple partners requires distinct theoretical development and empirical testing from dyadic relationships (Albers, Schweiger \& Gibb, 2015; Hingley, Angell \& Lindgreen, 2015) (see Section 1.2.2). In study 2 , we did not explicitly consider power when investigating how a startup interacts with its business partners. However, we found some evidence that power influenced how the case startup interacted with its partners in a project with multiple partners, i.e. it was more likely to comply with powerful partners' advice. Although in study 3 we focused on power episodes in dyadic relationships, some of these relationships were part of a larger project with multiple partners. The power episodes in these relationships showed that power is not only important in dyadic relationships, but also in multipartner relationships. Given these findings, I decided to study power asymmetry's roles in multipartner business relationships in study 4 and 5 . In study 4 , I revealed that power asymmetry derived from different power sources had different impacts on different types of multipartner relationship effectiveness. In study 5, we showed that the effect of power asymmetry derived from network position on new product development differs depending on the variety type that characterises the multipartner relationship. These findings indicate that power in multipartner relationships is pervasive and complex: it affects network management and outcomes in a various ways, depending on the specific context. Thus, I claim that there are substantial opportunities for scholars to further expand our understanding of network position and related power in multipartner relationships.

My final contribution relates to our conceptualisation and analysis of power as a multidimensional concept. As discussed in Section 1.2.2, little empirical research has combined the three dimensions of power: structural, relational and behavioural (Belaya, Gagalyuk \& Hanf, 2009; Brass \& 
Burkhardt, 1993; Olsen, Prenkert, Hoholm \& Harrison, 2014). Thus, in study 1 , we distinguished between structural and behavioural power. Then we divided them into resource control, network position and formal position (i.e. structural power) as well as power change tactics and power use tactics (i.e. behavioural power). In turn, we showed that these (sub)dimensions of power are interconnected via a startup's and its partners power perceptions. In study 4 , we conceptualised power asymmetry based on the structural (i.e. size and age) and relational (i.e. network position) dimensions. We then revealed that power asymmetry derived from network position directly influences multipartner relationship effectiveness. Power asymmetry derived from structural power sources only affects effectiveness in combination with power asymmetry derived from relational sources. These findings confirm previous research that has suggested that scholars should simultaneously apply different perspectives on power so as to understand power in its entirety (e.g. Belaya et al., 2009; Olsen et al., 2014). Besides power's multidimensionality, every study of power in this dissertation also showed that it cannot be separated from other aspects of the relationship. Specifically, we found that a startup's closeness to its partners, the conflict level between them, and their expectations of their relationship's future influence what type of power tactics they will apply in a power episode. We also showed that power asymmetry affects value creation and appropriation differently in multipartner relationships. Further, we revealed that partner variety type and amount affects whether high power asymmetry positively or negatively influences new product development in multipartner relationships. This implies that scholars who want to provide an accurate picture when analysing power should not only consider power's multidimensionality, but should also incorporate other relational aspects.

\subsection{Managerial implications}

In addition to the specific managerial implications of the individual studies discussed in Chapters 2 to 6 , this dissertation has some general managerial implications for startups, startups' partners, organisations engaged in multipartner relationships and policy-makers. 


\subsubsection{Startups}

The dissertation findings inform startups that their fragile network position has key implications for how they can successfully manage their business relationships. This is crucial, because startups are often excellent inventors, but lack many of the resources to turn these into innovations. Successful business relationships can provide startups with needed resources, such as financial, human and marketing capital to develop and commercialise their inventions. Further, business relationships allow a startup to position itself in an existing network and can connect it to its resource constellations, activity patterns and web of actors, increasing its inventions' value. A first implication of our findings is that startups must realise they can and need to rely on their network to initiate new business relationships, resolve conflicts with and mediate hostile power behaviour of existing partners. First, they should connect to third actors with the willingness and ability to connect them to potential valuable partners. Although these third actors may be 'traditional' third actors (e.g. incubators or accelerators), they may also be other partners with a central position in the network. Second, startups should be aware that the only way to resolve a conflict with an existing partner may involve another one in the relationship. These third partners can find useful novel solutions that they cannot create themselves once a conflict has ended in an impasse. Third, a startup can build coalitions with other organisations to improve a specific partner's perception of its power. This changes the power balance in its favour, since it may persuade the partner to behave in accordance with its interests. Another implication is that startups need to carefully consider how they will behave towards their partners because this will affect whether they will reach their aims in a business relationship. Startups are encouraged to use conceding rather than coercive interaction modes and to employ conciliatory rather than hostile power behaviour. Since startups, unlike their partners, lack a strong network position, behaviour with a negative connotation is usually not accepted by their partner; thus, startups often accomplish the opposite of what they intended to achieve. Further, since businesses tend to reciprocate each other's behaviour, it is more likely that the businesses and/or their relationship benefit if they interact positively. Thus, startups can expect more favourable reactions and therefore outcomes 
if they concede (i.e. acquiesce, compromise or create) to their partners than if they coerce (i.e. avoid, defy or manipulate). Also, they are more likely to evoke conciliatory power behaviour and extract the intended benefits from a relationship if they apply power change tactics (i.e. increasing one's own or decreasing one's partner's contribution) or conciliatory power use tactics (i.e. collaborate, persuade, build coalition, integrate, exchange, or apprise) than if they apply hostile power use tactics (i.e. reject, pressure or legitimate).

\subsubsection{Startups' partners}

Our findings provide two noteworthy suggestions to startups' partners on how they can help startups to successfully manage their business relationships. A startup is often seen as dispensable by its partners because they consider it to be one of the many available options in their wide relationship portfolio. Thus, their commitment to turn startups' inventions into a success may be limited, especially if they see them a potential threat rather than as a future opportunity. Nonetheless, a relationship with a startup should at least entail something of value, otherwise its partner would not have engaged in the relationship. This is why it is also important for startups' partners to make the startup and their relationship a success, whatever this means to them. The first suggestion is that start-ups' partners can enhance a startup's network embedding and business development by initiating relationships with relevant partners. Especially, they can support a startup if they actively remain involved in the initiated relationship and build strong relationships with both parties. A further suggestion is that a startup's partners can help it by choosing more consciously how they respond to its behaviour. Since startups often lack the experience to accurately assess the relationship atmosphere, they may make choices for certain behaviours that do not benefit the relationship. Owing to their experience, startups' partners can usually more accurately assess the closeness, the relative balance of power and the conflict level between them, as well as a relationship's future benefits. Nonetheless, they tend to respond with similar behaviour as a startup, regardless of whether this behaviour is most suitable, given the situation. If they both behave conciliatory, this typically does not harm the relationship; however, it tends to swiftly result in a conflict if they both act aggressively. A startup's partner can prevent this by choosing to positively interact despite a 
startup's aggression; given the high likelihood of reciprocation, it can then expect that a startup will behave more conciliatory. In turn, this may advance the startup, the partner and/or their relationship.

\subsubsection{Organisations in multipartner relationships}

Our findings provide meaningful support to organisations in selecting an optimal partner composition based on partner characteristics that are visible before initiating a relationship with multiple partners. Potential partners in such a relationship face the question whom to allow to join the collaboration and whom to invite into the relationship. This question is crucial, because the relationship's innovation potential will be limited if the initial conditions are not optimal owing to inadequate partner selection. First, our findings suggest that an organisation should carefully design a multipartner relationship in terms of its partners' network position, industry, organisational type and functional purpose, depending on its primary objectives. The potential to develop a complete, new product is the greatest in multipartner relationships with partners from many different industries and equal network positions. However, this partner composition also has the greatest likelihood of failure. If organisations want to decrease this risk, they should involve partners with unequal network positions, a single functional purpose, many different organisational types and either few or many different industries. Our findings indicate that in such a composition of partners, the partner with a central position in the network is likely to coordinate the complexities that arise from high organisational and industry variety. Yet the products will be less developed than in successful multipartner relationships characterised by high industry variety and low centrality asymmetry. Another suggestion is that partners in a multipartner relationship must change their partner composition over time to account for successful value creation and appropriation. Our results indicate that a partner composition consisting of partners with unequal network positions and equal sizes stimulates the development of new products and/or services in a relationship's beginning. In this situation, a central lead organisation can identify, assess and transfer resource contributions from different partners to enhance value creation. It is important that the organisations are relatively similar in size, so that every 
organisation can contribute its unique and superior resources to develop new resource combinations rather than a single large partner mainly imposing its own resources. In contrast, a partner composition consisting of partners with equal network positions enhances new product/service commercialisation in a relationship's end. In this situation, the collective value creation potential is enlarged, because every partner has an equal contribution to the commercialisation process rather than it depending on a single central organisation's network capabilities. When the partners' network positions happen to be unequal, the negative effect can be mitigated by ensuring that the central lead organisation is old. An older organisation is less inclined to behave solely in its own interest at the expense of the collective aims.

\subsubsection{Policy-makers}

The findings in this dissertation have two valuable implications for policy-makers who seek to stimulate startups to initiate business relationships and the formation of multipartner research projects. Currently, policy-makers seek to encourage startups to form business relationships in programmes specifically aimed to boost innovation in startups. Such governmental support is indispensable, because the inventions created by startups can act as an initiator and catalyst for economic progress. However, startups need to initiate, maintain and develop business relationships to turn these inventions into successful innovations; yet they are often sceptical about collaboration and tend to collaborate less than established organisations. Our findings imply that it is not enough if policy-makers merely stimulate startups to have more business relationships. Startups do not have the necessary qualifications, such as knowledge, resources and relationships, to effectively manage business relationships. Thus, business relationships can still fail if policy-makers do not teach them how they can use their network, interact with their partners and deal with power struggles. Thus, governmental programs should support innovation in startups by actively training and coaching them in managing their business relationships rather than merely stimulating their initiation. Further, policy-makers increasingly fund research projects on the condition that more than two organisations are involved. Such governmental investment is necessary because multipartner projects can reduce market, capabilities and interaction 
failures that hinder the innovation process and benefit social welfare. Yet they also bring along numerous challenges that are not present in relationships between two businesses. Thus, multipartner relationships are less likely to be formed than dyadic relationships without governmental support. Our findings show that policy-makers should stimulate the formation of projects with partners from many different industries and similar network positions if they want project to develop complete, new products. However, they need to be aware that such partner composition also increases the risk of failure. If they aim for more certain but less developed new products, they must encourage the formation of projects characterised by unequal power relationships and consisting of partners with a) a single function purpose, b) with many different organisational types, and c) from either few or many different industries. Further, they should allow partners to enter and exit a multipartner relationship over time so that: in the beginning, its value creation potential can be increased by involving partners with unequal network positions and of equal size; in the end, its value appropriation potential can be enlarged by including partners with equal network positions.

\subsection{Limitations and further research}

Despite the theoretical contributions and managerial implications of this dissertation, it has some limitations, which open avenues for further research. I have discussed the limitations and further research avenues of the individual studies in the discussion sections of Chapters 2 to 6. I will now highlight this dissertation's two key conceptual limitations derived from the theories I used and two main methodological weaknesses from a critical realist perspective, as well as four associated suggestions for further research.

\subsubsection{Conceptual limitations and further research}

One conceptual limitation results from the boundaries of the central thesis in which I positioned the empirical studies in this dissertation (see Section 1.2). I chose to focus on network position and related power, because of its potential strong yet underexamined impacts on network management and outcomes. Owing to this focus on network position, I paid little attention to other business attributes and relationship elements that have been shown 
to influence businesses' behaviours and its consequences in networks. For instance, businesses' goals, knowledge bases, capabilities and competences, perceptions and culture can also affect the extent of network collaborations' success. Further, the overall closeness and conflict level in a relationship between two or multiple businesses as well as their expectations of the future are also shown to influence the ways in which businesses will behave. Scholars, myself included, tend to focus on how a single business attribute or relationship element affects network management and outcomes. However, it may be expected that they do not exist in isolation from one another. Study 3 provides some evidence in this direction, showing that the choice for power use or power change tactics is influenced by partners' power perceptions, but that the choice of a specific tactic is derived from other elements of the relationship atmosphere. Also, study 5 demonstrated that, taken together, power asymmetry and partner variety influence new product development in multipartner relationships. Thus, it may be interesting to further explore the effects of the interplay among business attributes and relationship elements on network management and outcomes.

Another conceptual limitation arises from our conceptualisation of power in the various studies. We focused on structural (i.e. size, age and network position) and behavioural (i.e. power change and use tactics) power in study 3; on structural (i.e. size and age) and relational power (i.e. network position) in study 4; and relational power (i.e. network position) in study 5 . Although we studied power based on all three dimensions, many more power conceptualisations exist. For instance, French and Raven's (1959) seminal taxominy categorises five structural power types based on the source of power: coercive, reward, expert, legitimate and referent power. Further, Hardy (1996) distinguishes four behavioural power types: the power of resource, processes, meaning and the system. Thus, power is an ambiguous concept, which has been given various distinct and partly contradictory definitions in both research and practice. Generally, a concept with so many possible definitions is scientifically meaningless, because it is almost impossible to establish convincing generalisations and meaningful relationships with other concepts. Then, why should it (in this instance, power) be researched at all? The concept of power is important because, 
whatever its limitations as a research concept, it is a reality, and one that needs to be analysed and understood. Thus, I argue that scholars should clearly conceptualise power in further research so as to meaningfully examine it empirically and convincingly communicate their findings with practice. Particularly, the interactions between different aspects of power deserve our attention. Although power conceptualisations may often be not strictly comparable to one other, my findings indicate they are interconnected and overlap.

\subsubsection{Methodological limitations and further research}

One methodological limitation arises from the case study approach we used to investigate how a startup's fragile network position affects its business relationship management and associated outcomes (Chapters 2 to 4). Case studies are commonly criticised on the grounds of a lack of methodological rigour and researcher subjectivity. To ensure methodological rigour, we based the conceptual research model on existing theory, structured in terms of a critical realist causal explanation. To minimise the risks associated with researcher subjectivity, we carefully integrated data from three sources: observations, interviews and archival documents. However, the most prominent criticism of case studies is their limited possibilities for generalisation. Here, a distinction should be made between statistical (i.e. enumerate frequencies) and analytical (i.e. expand and generalise theories) generalisability. From a critical realist perspective, case studies are well-suited to expand and generalise theories, because they can identify "the deep processes at work under contingent conditions via particular mechanisms" (Easton, 2010, p. 126). Nonetheless, the possibilities for statistical generalisability are unavoidably limited based on a case study. Yet, critical realists argue that mere regularities among sequences of events cannot provide causal explanations. Thus, we did not intend to statistically generalise, but to elucidate certain aspects of existing theories in a startup's business relationship initiations, interaction episodes and power struggles. Still, future research should investigate the relationships identified in the case in larger more diverse samples of startups so as to validate our findings' statistical generalisability. 
A further methodological limitation of my dissertation results from our statistical analysis of the relationship between power asymmetry and innovation performance (Chapter 4) as well as partner variety's influence on this relationship (Chapter 5) in multipartner relationships. From a critical realist perspective, the use of statistics limits our ability to provide meaningful causal explanations for the hypothesised relationships. To illustrate, in study 4 , we argue that power asymmetry leads to lead organisation governance, while power symmetry leads to shared governance in a multipartner relationship. We hypothesised that power asymmetry is more beneficial to value appropriation than value creation, because lead organisation governance is not well-suited to stimulate new product/service development. Yet we could not directly observe the governance type used in a multipartner relationship. In study 5, we explained the power asymmetry's moderating effect on the relationship between partner variety and new product development based on the argument that a powerful partner is motivated and legitimised to use its power to coordinate the complexities associated with variety in multipartner relationships. However, the gathered data did not allow us to directly observe a powerful partner's motivation and its power's legitimatisation by less powerful partners. Although the results are partly consistent with theoretical expectation in both studies, they indicate that a powerful partner may not be motivated or able to successfully govern and coordinate a multipartner relationship characterised by power asymmetry. Thus, we need a better understanding of the causal mechanisms that explain the relationships between partner variety, power asymmetry and innovation performance in relationships with multiple partners. 


\section{Bibliography}

Aaboen, L., Dubois, A. \& Lind, F. (2011). Start-ups starting up: Firms looking for a network. The IMP Journal, 5(1), 42-58.

Aaboen, L., Dubois, A. \& Lind, F. (2013). Strategizing as networking for new ventures. Industrial Marketing Management, 42(7), 1033-1041.

Aaboen, L., Holmen, E. \& Pedersen, A-C. (2017). Initiation of business relationships in start ups. In L. Aaboen, A. La Rocca, F. Lind, A. Perna \& T. Shih (Eds.), Starting up in business networks: Why Relationships matter in Entrepreneurship. Londen, United Kingdom: Palgrave Macmillian.

Aaboen, L., Laage-Hellman, J., Lind, F., Öberg, C. \& Shih, T. (2016). Exploring the roles of university spin-offs in business networks. Industrial Marketing Management, 59, 157-166.

Aarikka-Stenroos, L. (2009). What stimulates business actors to promote others' business without monetary rewards? Exploratory narrative research on motivation factors. Paper presented at the 25th IMP Conference, Marseilles, France.

Aarikka-Stenroos, L. (2011). Reference Communication and Third Actors in the Initiation of Business Relationships. Dissertation, Turku School of Economics, Turku, Finland.

Aarikka-Stenroos, L. \& Halinen, A. (2007). The promoting role of third actors in initiating business relationships. Paper presented at the 23rd IMP Conference, Manchester, Great Britain.

Abrahamsen, M. H., Henneberg, S. C., Huemer, L. \& Naudé, P. (2016). Network picturing: An action research study of strategizing in business networks. Industrial Marketing Management, 59, 107-119.

Achrol, R. S. (1997). Changes in the theory of interorganizational relations in marketing: Toward a network paradigm. Journal of the academy of marketing science, 25(1), 56.

Ahuja, G., Polidoro, F. Jr. \& Mitchell, W. (2009). Structural homophily or social asymmetry? The formation of alliances by poorly embedded firms. Strategic Management Journal, 30(9), 941-958. 
Albers, S., Schweiger, B. \& Gibb, J. (2015). Complexity, power and timing in multipartner alliances. In T. K. Das (Ed.), Managing multipartner strategic alliances. Charlotte, United States: Information Age Publishing, Inc.

Alvarez, S. A. \& Barney, J. B. (2001). How entrepreneurial firms can benefit from alliances with large partners. Academy of Management Executive, 15(1), 139-148.

Anderson, A. R., Dodd, S. D. \& Jack, S. (2010). Network practices and entrepreneurial growth. Scandinavian Journal of Management, 26(2), 121-133.

Ariño, A. \& de la Torre, J. (1998). Learning from Model Failure: Towards an Evolutionary Model of Collaborative Ventures. Organization Science, 9(3), 306-325.

Ariño, A., Ragozzino, R. \& Reuer, J. J. (2008). Alliance dynamics for entrepreneurial firms. Journal of Management Studies, 45(1), 147-168.

Arranz, N. \& de Arroyabe J. C. F. (2012). Can innovation network projects result in efficient performance? Technological Forecasting and Social Change, 79(3), 485-497.

Arroyabe, M. F., Arranz, N. \& Fdez. de Arroyabe, J. C. (2015). R\&D partnerships: An exploratory approach to the role of structural variables in joint project performance. Technological Forecasting and Social Change, 90(B), 623-634.

Astley, W. G. \& Sachdeva, P. S. (1984). Structural sources of intraorganizational power: A theoretical synthesis. Academy of Management Review, 9(1), 104-113.

Bach, L., Matt, M. \& Wolff, S. (2014). How do firms perceive policy rationales behind the variety of instruments supporting collaborative R\&D? Lessons from the European Framework Programs. Technovation, 34(56), 327-337.

Badir, Y. F., Buchel, B. \& Tucci, C. L. (2005). The role of the network lead company in integrating the NPD process across strategic partners. International Journal of Entrepreneurship and Innovation Management, 5(1-2), 117-137. 
Bae, J. H. \& Gargiulo, M. (2004). Partner substitutability, alliance network structure, and firm profitability in the telecommunications industry. Academy of Management Journal, 47(6), 843-859.

Barbuto, J. E. J. \& Gifford, G. T. (2009). Influence triggers and compliance: A discussion of the effects of power, motivation, resistance and antecedents. In D. Tjosvold \& B. Wisse (Eds.), Power and interdependence in organizations. Cambridge, United Kingdom: Cambridge University Press.

Baum, J. A. C., Calabrese, T. \& Silverman, B. S. (2000). Don't go it alone: Alliance network composition and startups' performance in Canadian biotechnology. Strategic Management Journal, 21(3), 267-294.

Bazyar, A., Teimoury, E., Fesharaki, M., Moini, A. \& Mohammadi, S. (2013). Linking power, risk, and governance: A survey research in new product development relationships. Journal of Business $\mathcal{E}$ Industrial Marketing, 28(5), 371-382.

Belaya, R., Gagalyuk, T. \& Hanf, J. (2009). Measuring asymmetrical power distribution in supply chain networks: What is the appropriate method? Journal of Relationship Marketing, 8(2), 165-193.

Belso-Martínez, J. A. (2015). Resources, governance, and knowledge transfer in Spanish footwear clusters: Can local firms be locked out by their crucial partner? International Regional Science Review, 38(2), 202-231.

Bengtsson, M. \& Johansson, M. (2012). Managing coopetition to create opportunities for small firms. International Small Business Journal, 32(4), 401-427.

Beverland, M. \& Lindgreen, A. (2010). What makes a good case study? A positivist review of qualitative case research published in Industrial Marketing Management, 1971-2006. Industrial Marketing Management, 39(1), 56-63.

Bizzi, L. \& Langley, A. (2012). Studying processes in and around networks. Industrial Marketing Management, 41(2), 224-234.

Bliemel, M. J. \& Maine, E. M. (2008). Network embeddedness as a predictor of performance for new technology-based firms. International Journal of Technoentrepreneurship, 1(3), 313-341. 
Bonacich, P. (1987). Power and centrality: A family of measures. American journal of sociology, 92(5), 1170-1182.

Borgatti, S. P. \& Halgin, D. S. (2011). On network theory. Organization Science, 22(5), 1168-1181.

Branstetter, L.G. \& Sakakibara, M. (2002). When do research consortia work well and why? Evidence from Japanese panel data. American Economic Review, 92(1), 143-159.

Brass, D. J. \& Burkhardt, M. E. (1993). Potential power and power use: An investigation of structure and behavior. Academy of management journal, 36(3), 441-470.

Brennan, R., Canning, L. \& McDowell, R. (2014). Inter-firm relationship and networks. In R. Brennan, L. Canning \& R. McDowell (Eds.), Business-toBusiness Marketing. London, United Kingdom: Springer.

Bruderl, J. \& Schussler, R. (1990). Organizational mortality: The liabilities of newness and adolescence. Administrative Science Quarterly, 35(3) 530547.

Buch-Hansen, H. (2014). Social network analysis and critical realism. Journal for the Theory of Social Behaviour, 44(3), 306-325.

Bunderson, J. S. \& Reagans, R. E. (2011). Power, status, and learning in organizations. Organization Science, 22(5), 1182-1194.

Bunderson, J. S. (2003). Team member functional background and involvement in management teams: Direct effects and the moderating role of power centralization. Academy of Management Journal, 46(4), 458-474.

Burt, R. S. (1992). Structural holes: The social structure of competition. Cambridge, United Kingdom: Harvard University Press.

Burt, R. S. (2000). The network structure of social capital. Research in Organizational Behavior, 22, 345-423.

Camison-Zornoza, C., Lapiedra-Alcami, R., Segarra-Cipres, M. \& BoronatNavarro, M. (2004). A meta-analysis of innovation and organizational size. Organization studies, 25(3), 331-361.

Castiglioni, M., Castro, I. \& Galán, J. L. (2015). The choice and formation of multipartner alliances: Underpinning factors. In T. K. Das (Ed.), Managing multipartner strategic alliances. Charlotte, United States: Information Age Publishing, Inc. . 
Chen, X., Zou, H. \& Wang, D. T. (2009). How do new ventures grow? Firm capabilities, growth strategies and performance. International Journal of Research in Marketing, 26(4), 294-303.

Chesbrough, H., Vanhaverbeke, W. \& West, J. (2006). New Frontiers in Open Innovation. London, United Kingdom: Oxford University Press.

Chicksand, D. (2015). Partnerships: The role that power plays in shaping collaborative buyer-supplier exchanges. Industrial Marketing Management, 48, 121-139.

Christoffersen, J. (2013). A review of antecedents of international strategic alliance performance: Synthesized evidence and new directions for core constructs. International Journal of Management Reviews, 15(1), 66-85.

Cobeña, M., Gallego, A. \& Casanueva, C. (2017). Heterogeneity, diversity and complementarity in alliance portfolios. European Management Journal, 35(4), 464-476.

Colombo, M. G., Laursen, K., Magnusson, M. \& Rossi-Lamastra, C. (2012). Small business and networked innovation: Organizational and managerial challenges. Journal of Small Business Management, 50(2), 181-190.

Colurcio, M., Wolf, P., Kocher, P. Y. \& Spena, T. R. (2012). Asymmetric relationships in networked food innovation processes. British Food Journal, 114(5), 702-727.

Corsaro, D., Cantù, C. \& Tunisini, A. (2012). Actors' heterogeneity in innovation networks. Industrial Marketing Management, 41(5), 780789.

Corsaro, D., Ramos, C., Henneberg, S. C. \& Naudé, P. (2011). Actor network pictures and networking activities in business networks: An experimental study. Industrial Marketing Management, 40(6), 919-932.

Cowan, K., Paswan, A. K. \& Van Steenburg, E. (2015). When inter-firm relationship benefits mitigate power asymmetry. Industrial Marketing Management, 48, 140-148.

Cui, A. S. \& O'Connor, G. (2012). Alliance portfolio resource diversity and firm innovation. Journal of Marketing, 76(4), 24-43. 
Das, T. K. \& He, I. Y. (2006). Entrepreneurial firms in search of established partners: Review and recommendations. International Journal of Entrepreneurial Behaviour and Research, 12(3), 114-143.

Das, T. K. \& Teng, B. S. (2002). The dynamics of alliance conditions in the alliance development process. Journal of Management Studies, 39(5), 725-746.

Das, T.K. \& Teng, B. S. (2000). A resource-based theory of strategic alliances. Journal of Management, 26(1), 31-61.

Davenport, S. \& Leitch, S. (2005). Circuits of power in practice: Strategic ambiguity as delegation of authority. Organization Studies, 26(11), 16031623.

Deeds, D. L. \& Hill, C. W. L. (1996). Strategic alliances and the rate of new product development: An empirical study of entrepreneurial biotechnology firms. Journal of Business Venturing, 11(1), 41-55.

Dhanaraj, C. \& Parkhe, A. (2006). Orchestrating innovation networks. Academy of Management Review, 31(3), 659-669.

Diestre, L. \& Rajagopalan, N. (2012). Are all 'sharks' dangerous? New biotechnology ventures and partner selection in R\&D alliances. Strategic Management Journal, 33(10), 1115-1134.

Doorewaard, H. \& Verschuren, P. (2010). Designing a research project. The Hague, The Netherlands: Boom Lemma Uitgevers.

Dyer, J. H. (1997). Effective interfirm collaboration: How firms minimize transaction costs and maximize transaction value. Strategic Management Journal, 18(7), 535-556.

Easton, G. (2010). Critical realism in case study research. Industrial Marketing Management, 39(1), 118-128.

Edvardsson, B., Holmlund, M. \& Strandvik, T. (2008). Initiation of business relationships in service-dominant settings. Industrial Marketing Management, 37(3), 339-350.

Eisenhardt, K. M. (1989). Building theories from case study research. The Academy of Management Review, 14(4), 532-532.

Ellegaard, C., Medlin, C. J. \& Geersbro, J. (2014). Value appropriation in business exchange: Literature review and future research opportunities. Journal of Business E Industrial Marketing, 29(3), 185-198. 
Elo, M. \& Törnroos, J. (2005). Relationships and networks-events enabling and inhibiting corporate internationalisation. Paper presented at the 21st IMP conference, Rotterdam, The Netherlands.

Farrell, D. (1983). Exit, voice, loyalty, and neglect as responses to job dissatisfaction: A multidimensional scaling study. Academy of Management Journal, 26(4), 596-607.

Ford, D. \& Mouzas, S. (2008). Is there any hope? The idea of strategy in business networks. Australasian Marketing Journal, 16(1), 64-78.

Ford, D. \& Mouzas, S. (2013). The theory and practice of business networking. Industrial Marketing Management, 42(3), 433-442.

Ford, D., Gadde, L-E., Håkansson, H., Snehota, I. \& Waluszewski, A. (2008). Analysing business interaction. Paper presented at the 24st IMP Conference, Uppsala, Sweden.

Ford, R. C., Wang, Y. \& Vestal, A. (2012). Power asymmetries in tourism distribution networks. Annals of Tourism Research, 39(2), 755-779.

Forshey, P. (2014). Resource value as a source of negotiating power: Determinants of alliance funding amounts in the US biotech industry. Academy of Strategic Management Journal, 13(1), 75.

Freeman, L. C. (1978). Centrality in social networks conceptual clarification. Social networks, 1(3), 215-239.

French, J. R. \& Raven, B. (1959). The bases of social power. In J. M. Shafritz, J. S. Ott \& Y. S. Jang (Eds.), Classics of organization theory. Boston, United States: Cengage Learning.

Gadde, L-E. (2010). Activity coordination and resource combining in distribution networks: Implications for relationship involvement and the relationship atmosphere. Journal of Marketing Management, 20(12), 157-184.

Gardet, E. \& Fraiha, S. (2012). Coordination modes established by the hub firm of an innovation network: The case of an SME bearer. Journal of Small Business Management, 50(2), 216-238.

Geyskens, I. \& Steenkamp, J. B. E. M. (2000). Economic and social satisfaction: Measurement and relevance to marketing channel relationships. Journal of Retailing, 76(1), 11-32. 
Gibb, J., Sune, A. \& Albers, S. (2016). Network learning: Episodes of interorganizational learning towards a collective performance goal. European Management Journal, 35(1), 15-25.

Gibbert, M., Ruigrok, W. \& Wicki, B. (2008). Research notes and commentaries: What passes as a rigorous case study? Strategic Management Journal, 29(13), 1465-1474.

Gil, N. \& Beckman, S. (2007). Design reuse and buffers in high-tech infrastructure development: A stakeholder perspective. IEEE Transactions on Engineering Management, 54(3), 484-497.

Gnizy, I. (2016). Power dynamics of the international marketing within firms and how they shape international performance. Industrial Marketing Management, 57, 148-158.

Goerzen, A. \& Beamish, P. W. (2005). The effect of alliance network diversity on multinational enterprise performance. Strategic Management Journal, 26(4), 333-354.

Granovetter, M. (1985). Economic action and social structure: The problem of embeddedness. American Journal of Sociology, 91(3), 481-510.

Gulati, R. (1998). Alliances and networks. Strategic Management Journal, 19(4), 293-317.

Gulati, R., Wohlgezogen, F. \& Zhelyazkov, P. (2012). The two facets of collaboration: Cooperation and coordination in strategic alliances. Academy of Management Annals, 6(1), 531-583.

Habib, F., Bastl, M. \& Pilbeam, C. (2015). Strategic responses to power dominance in buyer-supplier relationships: A weaker actor's perspective. International Journal of Physical Distribution $\mathcal{E}$ Logistics Management, 45(1/2), 182-203.

Hagedoorn, J., Link, A. N. \& Vonortas, N. S. (2000). Research partnerships. Research Policy, 29(4-5), 567-586.

Håkansson, H. (1982). An interaction approach. In H. Håkansson (Ed.), International marketing and purchasing of industrial goods: An interaction approach. Chichester, United Kingdom: John Wiley \& Sons.

Håkansson, H. \& Ford, D. (2002). How should companies interact in business networks? Journal of Business Research, 55(2), 133-139. 
Håkansson, H. \& Waluszewski, A. (2007). Knowledge and innovation in business and industry: The importance of using others. London; United Kingdom: Routledge.

Håkansson, H. \& Waluszewski, A. (2013). A never ending story: Interaction patterns and economic development. Industrial Marketing Management, 42(3), 443-454.

Håkansson, H., Ford, D. I., Gadde, L-E., Snehota, I. \& Waluszewski, A. (2009). Business in networks. Chichester, United Kingdom: John Wiley \& Sons. Håkansson, H., Olsen, P. I. \& Bakken, T. (2013). Agency and economizing in interacted economies. The IMP Journal, 7(2), 106-111.

Halinen, A., Medlin, C. J. \& Törnroos, J. (2012). Time and process in business network research. Industrial Marketing Management, 41(2), 215-223.

Hallen, B. L., Katila, R. \& Rosenberger, J. D. (2014). How do social defences work? A resource-dependence lens on technology ventures, venture capital investors, and corporate relationships. Academy of Management Journal, 57(4), 1078-1101.

Hamel, G. (1991). Competition for competence and interpartner learning within international strategic alliances. Strategic Management Journal, 12(1), 83-103.

Hardy, C. \& Phillips, N. (1998). Strategies of engagement: Lessons from the critical examination of collaboration and conflict in an interorganizational domain. Organization Science, 9(2), 217-230.

Hardy, C. (1996). Understanding power: Bringing about strategic change. British Journal of Management, 7(s1), S3-S16.

Harrison, D. A. \& Klein, K. J. (2007). What's the difference? Diversity constructs as separation, variety, or disparity in organizations. Academy of Management Review, 32(4), 1199-1228.

Harrison, D., Holmen, E. \& Pedersen, A. (2010). How companies strategise deliberately in networks using strategic initiatives. Industrial Marketing Management, 39(6), 947-955.

He, Q., Ghobadian, A. \& Gallear, D. (2013). Knowledge acquisition in supply chain partnerships: The role of power. International Journal of Production Economics, 141(2), 605-618. 
Heidl, R. A., Steensma, H. K. \& Phelps, C. (2014). Divisive faultlines and the unplanned dissolutions of multipartner alliances. Organization Science, 25(5), 1351-1371.

Herbst, U., Schwartz, S. \& Voeth, M. (2008). The management of intra-versus inter-organizational negotiations: An empirical comparison. Paper presented at the 1st French - German - Swiss Workshop on B2B Marketing, Lausanne, Switzerland.

Herlin, H. \& Pazirandeh, A. (2012). Nonprofit organizations shaping the market of supplies. International Journal of Production Economics, 139(2), 411-421.

Heuven, J. \& Groen, A. (2012). The role of social networks in financing technology-based ventures: An empirical exploration. Venture capital, 14(2-3), 131-149.

Hingley, M. K. (2005). Power to all our friends? Living with imbalance in supplier-retailer relationships. Industrial Marketing Management, 34(8), 848-858.

Hingley, M. K., Angell, R. \& Lindgreen, A. (2015). The current situation and future conceptualization of power in industrial markets. Industrial Marketing Management, 48, 226-230.

Hirschman, A. O. (1970). Exit, voice and loyalty: Responses to decline in firms, organizations and states. Cambridge, United Kingdom: Harvard University Press.

Hite, J. M. (2005). Evolutionary processes and paths of relationally embedded network ties in emerging entrepreneurial firms. Entrepreneurship Theory and Practice, 29(1), 113-144.

Hoang, H. \& Yi, A. (2015). Network-based research in entrepreneurship: A decade in review. Foundations and Trends in Entrepreneurship, 11(1), 154.

Hoehn-Weiss, M. N. \& Karim, S. (2014). Unpacking functional alliance portfolios: How signals of viability affect young firms' outcomes. Strategic Management Journal, 35(9), 1364-1385.

Hoehn-Weiss, M. N., Karim, S. \& Lee, C-H. (2017). Examining alliance portfolios beyond the dyads: The relevance of redundancy and nonuniformity across and between partners. Organization Science, 28(1), 56-73. 
Hoffmann, W. H. \& Schlosser, R. (2001). Success factors of strategic alliances in small and medium-sized enterprises: An empirical survey. Long Range Planning, 34(3), 357-381.

Holmen, E. \& Pedersen, A. (2003). Strategizing through analyzing and influencing the network horizon. Industrial Marketing Management, 32(5), 409-418.

Holmen, E., Roos, K., Kallevag, M., Raesfeld, A. v., Boer, L. de \& Pedersen, A. (2005). How do relationships begin? Paper presented at the 21st IMP Conference, Rotterdam, The Netherlands.

Homburg, C., Wilczek, H. \& Hahn, A. (2014). Looking beyond the horizon:

How to approach the customers' customers in business-to-business markets. Journal of Marketing, 78(5), 58-77.

Howells, J. (2006). Intermediation and the role of intermediaries in innovation. Research Policy, 35(5), 715-728.

Huberman, A. M. \& Miles, M. B. (1994). Data management and analysis methods. Thousand Oaks, United States: Sage Publications.

Huggins, R., Izushi, H., Prokop, D. \& Thompson, P. (2015). Network evolution and the spatiotemporal dynamics of knowledge sourcing. Entrepreneurship and Regional Development, 27(7-8), 474-499.

Hughes-Morgan, M. \& Yao, B. E. (2016). Rent appropriation in strategic alliances: A study of technical alliances in pharmaceutical industry. Long Range Planning, 49(2), 186-195.

Human, S. E. \& Provan, K. G. (2000). Legitimacy building in the evolution of small-firm multilateral networks: A comparative study of success and demise. Administrative Science Quarterly, 45(2), 327-365.

Huxham, C. \& Beech, N. (2009). Inter-organizational power. In S. Cropper, C. Huxham, M. Ebers \& P. S. Ring (Eds.), The Oxford handbook of interorganizational relations. New York, United States: Oxford University Press.

Huxham, C. \& Vangen, S. (2013). Managing to collaborate: The theory and practice of collaborative advantage. New York, United States: Routledge. Ibarra, H. (1993). Network centrality, power, and innovation involvement: Determinants of technical and administrative roles. Academy of Management Journal, 36(3), 471-501. 
Jack, S., Dodd, S. \& Anderson, A. R. (2008). Change and the development of entrepreneurial networks over time: A processual perspective. Entrepreneurship \& Regional Development, 20(2), 125-159.

Jiang, R. J., Tao, Q. T. \& Santoro, M. D. (2010). Alliance portfolio diversity and firm performance. Strategic Management Journal, 31(10), 1136-1144.

Johnsen, R. E. \& Lacoste, S. (2016). An exploration of the 'dark side' associations of conflict, power and dependence in customer-supplier relationships. Industrial Marketing Management, 59, 76-95.

Kähkönen, A. K. (2014). The influence of power position on the depth of collaboration. Supply Chain Management, 19(1), 17-30.

Kähkönen, A. K. (2015). The context-dependency of buyer-supplier power. International Journal of Procurement Management, 8(4), 396-415.

Kähkönen, A. K. \& Lintukangas, K. (2010). Dyadic relationships and power within a supply network context. Operations and supply chain management, 3(2), 59-69.

Kalaignanam, K., Shankar, V. \& Varadarajan, R. (2007). Asymmetric new product development alliances: Win-win or win-lose partnerships? Management Science, 53(3), 357-374.

Kanter, R. M. (2000). When a thousand flowers bloom: Structural, collective, and social conditions for innovation in organization. In R. Swedberg (Ed.), Entrepreneurship: The social science view. Oxford, United States: Oxford University Press.

Kassler, W. J. \& Goldsberry, Y. P. (2005). The New Hampshire public health network: Creating local public health infrastructure creating through community-driven partnerships. Journal of Public Health Management and Practice, 11(2), 150-157.

Katila, R., Rosenberger, J. D. \& Eisenhardt, K. M. (2008). Swimming with sharks: Technology ventures, defense mechanisms and corporate relationships. Administrative Science Quarterly, 53(2), 295-332.

Kilduff, M. \& Brass, D. J. (2010). Organizational social network research: Core ideas and key debates. Academy of Management Annals, 4(1), 317-357.

Kim, B. K. \& Park, S. K. (2015). The role of partner communication on cooperative R\&D between SMEs and public research institutes in Korea. Asian Journal of Technology Innovation, 23(3), 366-382. 
Kim, P. H., Pinkley, R. L. \& Fragale, A. R. (2005). Power dynamics in negotiation. Academy of Management Review, 30(4), 799-822.

Kipnis, D., Schmidt, S. M. \& Wilkinson, I. (1980). Intraorganizational influence tactics: Explorations in getting one's way. Journal of applied psychology, 65(4), 440.

Kirkels, Y. \& Duysters, G. (2010). Brokerage in SME networks. Research Policy, 39(3), 375-385.

Kiyak, T., Roath, A. S. \& Schatzel, K. E. (2001). An examination of the coercive power-satisfaction relationship within a relational exchange: The moderating role of dealer resistance. Journal of Marketing Channels, 8(Part 3/4), 3-28.

Koka, B. R. \& Prescott, J. E. (2002). Strategic alliances as social capital: A multidimensional view. Strategic Management Journal, 23(9), 795-816.

La Rocca, A., Ford, D. \& Snehota, I. (2013). Initial relationship development in new business ventures. Industrial Marketing Management, 42(7), 1025-1032.

Laage-Hellman, J., Landqvist, M. \& Lind, F. (2017). R\&D Collaboration and Start Ups. In L. Aaboen, A. La Rocca, F. Lind, A. Perna \& T. Shih (Eds.), Starting up in business networks: Why Relationships matter in Entrepreneurship. London, United Kingdom: Palgrave Macmillian.

Lacoste, S. \& Johnsen, R. E. (2015). Supplier-customer relationships: A case study of power dynamics. Journal of Purchasing and Supply Management, 21(4), 229-240.

Lai, C-S. (2009). The use of influence strategies in interdependent relationship: The moderating role of shared norms and values. Industrial Marketing Management, 38(4), 426-432.

Lamine, W., Jack, S., Fayolle, A. \& Chabaud, D. (2015). One step beyond? Towards a process view of social networks in entrepreneurship. Entrepreneurship and Regional Development, 27(7-8), 413-429.

Langley, A. (1999). Strategies for theorizing from process data. Academy of Management Review, 24(4), 691-710. 
Langley, A., Smallman, C., Tsoukas, H. \& Van de Ven, A. H. (2013). Process studies of change in organization and management: Unveiling temporality, activity, and flow. Academy of Management Journal, 56(1), $1-13$.

Larson, A. \& Starr, J. (1993). A network model of organization formation. Entrepreneurship \& Regional Development, Winter, 5-15.

Larson, A. (1992). Network dyads in entrepreneurial settings: A study of the governance of exchange relationships. Administrative Science Quarterly, 37(1), 76-104.

Lavie, D. (2007). Alliance portfolios and firm performance: A study of value creation and appropriation in the US software industry. Strategic Management Journal, 28(12), 1187-1212.

Lavie, D., Lechner, C. \& Singh, H. (2007). The performance implications of timing of entry and involvement in multipartner alliances. Academy of Management Journal, 50(3), 578-604.

Lawler, E. J. (1992). Power processes in bargaining. The Sociological Quarterly, 33(1), 17-34.

Lee, C. J. \& Johnsen, R. E. (2012). Asymmetric customer-supplier relationship development in Taiwanese electronics firms. Industrial Marketing Management, 41(4), 692-705.

Lee, D. D., Kirkpatrick-Husk, K. \& Madhavan, R. (2014). Diversity in alliance portfolios and performance outcomes a meta-analysis. Journal of Management, 43(5), 1472-1497.

Leonard-Barton, D. (1990). A dual methodology for case studies: Synergistic use of a longitudinal single site with replicated multiple sites. Organization Science, 1(3), 248-266.

Li, D., Eden, L., Hitt, M. A., Ireland, R. D. \& Garrett, R. P. (2012). Governance in multilateral R\&D alliances. Organization Science, 23(4), 1191-1210.

Low, B. K. H. (1997). Managing business relationships and positions in industrial networks. Industrial Marketing Management, 26(2), 189-202.

Low, B. K. H. \& Johnston, W. J. (2009). The evolution of network positions in emerging and converging technologies. Journal of Business $\mathcal{E}$ Industrial Marketing, 24(5/6), 431-438.

Lui, S. S. \& Ngo, H. (2005). An action pattern model of inter-firm cooperation*. Journal of Management Studies, 42(6), 1123-1153. 
Mack, N., Woodsong, C., MacQueen, K. M., Guest, G. \& Namey, E. (2005). Qualitative research methods: a data collectors field guide. North Carolina, United States: Family Health International.

Maglaras, G., Bourlakis, M. \& Fotopoulos, C. (2015). Power-imbalanced relationships in the dyadic food chain: An empirical investigation of retailers' commercial practices with suppliers. Industrial Marketing Management, 48, 187-201.

Mainela, T., Pernu, E. \& Puhakka, V. (2011). The development of a high-tech international new venture as a process of acting: A study of the lifespan of a venture in software business. Journal of Small Business and Enterprise Development, 18(3), 430-456.

Marhold, K., Jinhwan Kim, M. \& Kang, J. (2017). The effects of alliance portfolio diversity on innovation performance: A study of partner and alliance characteristics in the bio-pharmaceutical industry. International Journal of Innovation Management, 21(1), 1750001.

Markham, S. K. \& Lee, H. (2013). Product development and management association's 2012 comparative performance assessment study. Journal of product innovation management, 30(3), 408-429.

Matt, M., Robin, S. \& Wolff, S. (2012). The influence of public programs on inter-firm R\&D collaboration strategies: Project-level evidence from EU FP5 and FP6. Journal of Technology Transfer, 37(6), 885-916.

McClelland, D. C. (1975). Power: The inner experience. New York, United States, Irvington.

McEvoy, P. \& Richards, D. (2006). A critical realist rationale for using a combination of quantitative and qualitative methods. Journal of Research in Nursing, 11(1), 66-78.

McFarland, R. G., Challagalla, G. N. \& Shervani, T. A. (2006). Influence tactics for effective adaptive selling. Journal of Marketing, 70(October), 103-117.

Medlin, C. J. (2004). Interaction in business relationships: A time perspective. Industrial Marketing Management, 33(3), 185-193.

Meehan, J. \& Wright, G. H. (2012). The origins of power in buyer-seller relationships. Industrial Marketing Management, 41(4), 669-679. 
Meqdadi, O., Johnsen, T. E. \& Johnsen, R. E. (2017). The role of power and trust in spreading sustainability initiatives across supply networks: A case study in the bio-chemical industry. Industrial Marketing Management, 62, 61-76.

Molm, L. D. (2009). Power and social exchange. In D. Tjosvold \& B. Wisse (Eds.), Power and interdependence in organizations. Cambridge, United Kingdom: Cambridge University Press.

Moran, P. (2005). Structural vs. relational embeddedness: Social capital and managerial performance. Strategic management journal, 26(12), 11291151.

Mouzas, S. \& Ford, D. (2007). Contracting in asymmetrical relationships: The role of framework contracts. The IMP Journal, 1(3), 42-63.

Muthusamy, S. K. \& White, M. A. (2006). Does power sharing matter? The role of power and influence in alliance performance. Journal of Business Research, 59(7), 811-819.

Nepelski, D. \& Piroli, G. (2016). Organizational diversity and innovation potential of EU-funded research projects. The Journal of Technology Transfer, 1-25.

Nieto, M.J. \& Santamaria, L. (2007). The importance of diverse collaborative networks for the novelty of product innovation. Technovation, 27(6-7), 367-377.

Nishimura, J. \& Okamuro, H. (2016). Knowledge and rent spillovers through government-sponsored R\&D consortia. Science and Public Policy, 43(2), 207-225.

Nyaga, G. N., Lynch, D. F., Marshall, D. \& Ambrose, E. (2013). Power asymmetry, adaptation and collaboration in dyadic relationships involving a powerful partner. Journal of Supply Chain Management, 49(3), 42-65.

Obstfeld, D. (2005). Social networks, the tertius iungens orientation, and involvement in innovation. Administrative Science Quarterly, 50(1), 100-130.

Okamuro, H. \& Nishimura, J. (2015). Not just financial support? Another role of public subsidy in university-industry research collaborations. Economics of Innovation and New Technology, 24(7), 633-659. 
Oliver, C. (1991). Strategic responses to institutional processes. Academy of Management Review, 16(1), 145-179.

Olsen, P. I., Prenkert, F., Hoholm, T. \& Harrison, D. (2014). The dynamics of networked power in a concentrated business network. Journal of Business Research, 67(12), 2579-2589.

O'Sullivan, A. (2005). Network-based organizing for product innovation: How power imbalances matter. Management, 8(4), 123-143.

Oukes, T. \& Raesfeld, A. v. (2016). A start-up in interaction with its partners. The IMP Journal, 10(1), 50-80.

Oukes, T. \& Raesfeld, A. v. (2017). Third actors initiating business relationships for a medical device start-up: the effect on its network embedding and venture creation process. In L. Aaboen, A. La Rocca, F. Lind, A. Perna \& T. Shih (Eds.), Starting up in business networks: Why Relationships matter in Entrepreneurship. London: Palgrave Macmillian.

Oukes, T. \& Raesfeld, A. v. (2014). Resource interaction in relation to power: how startups strategize to cope with the challenges of mobilizing and leveraging resources in asymmetrical power relationships. Paper presented at the $30^{\text {th }}$ IMP Conference, Bordeaux, France.

Park, S. H. \& Ungson, G. R. (2001). Interfirm rivalry and managerial complexity: A conceptual framework of alliance failure. Organization Science, 12(1), 37-53.

Parkhe, A. (1998). Understanding trust in international alliances. Journal of world business, 33(3), 219-240.

Parkhe, A. (1991). Interfirm diversity, organizational learning, and longevity in global strategic alliances. Journal of International Business Studies, 22(4), 579-601.

Pfajfar, G., Shoham, A., Makovec Brenčič, M., Koufopoulos, D., Katsikeas, C. S. \& Mitrega, M. (2017). Power source drivers and performance outcomes of functional and dysfunctional conflict in exporter-importer relationships. Industrial Marketing Management, article in press.

Pfeffer, J. \& Salancik, G. R. (1978). The External Control of Organizations: A Resource Dependence Perspective. New York, United States: Stanford Business Books. 
Pfeffer, J. (2009). Understanding power in organizations. In D. Tjosvold \& B. Wisse (Eds.), Power and interdependence in organizations. Cambridge, United Kingdom: Cambridge University Press.

Phelps, C. C. (2010). A longitudinal study of the influence of alliance network structure and composition on firm exploratory innovation. Academy of Management Journal, 53(4), 890-913.

Ping, R. A. (1993). The effects of satisfaction and structural constraints on retailer exiting, voice, loyalty, opportunism, and neglect. Journal of Retailing, 69(3), 320-352.

Ping, R. A. (1999). Unexplored antecedents of exiting in a marketing channel. Journal of Retailing, 75(2), 218-241.

Pinkley, R. L. (1995). Impact of knowledge regarding alternatives to settlement in dyadic negotiations: Whose knowledge counts? Journal of Applied Psychology, 80(3), 403-417.

Pitcher, P. \& Smith, A. D. (2001). Top management team heterogeneity: Personality, power, and proxies. Organization Science, 12(1), 1-18.

Plouffe, C. R., Bolander, W., Cote, J. A. \& Hochstein, B. (2016). Does the customer matter most? Exploring strategic frontline employees' influence of customers, the internal business team, and external business partners. Journal of Marketing, 80(1), 106-123.

Prashantham, S. \& Birkinshaw, J. (2008). Dancing with gorillas: How small companies can partner effectively with MNCS. California Management Review, 51(1), 6-23.

Pressey, A. D. \& Qiu, X. X. (2007). Buyer-supplier relationship dissolution: The Chinese context. Journal of Business and Industrial Marketing, 22(2), 107-117.

Provan, K. G. (1980). Recognizing, measuring, and interpreting the potential/enacted power distinction in organizational research. Academy of Management Review, 5(4), 549-559.

Provan, K. G. \& Kenis, P. (2008). Modes of network governance: Structure, management, and effectiveness. Journal of Public Administration Research and Theory, 18(2), 229-252.

Provan, K. G., Fish, A. \& Sydow, J. (2007). Interorganizational networks at the network level: A review of the empirical literature on whole networks. Journal of Management, 33(3), 479-516. 
Raesfeld, A. v., Geurts, P. \& Jansen, M. (2012). When is a network a nexus for innovation? A study of public nanotechnology R\&D projects in the Netherlands. Industrial Marketing Management, 41(5), 752-758.

Raesfeld, A. v., Geurts, P., Jansen, M., Boshuizen, J. \& Luttge, R. (2012). Influence of partner diversity on collaborative public R\&D project outcomes: A study of application and commercialization of nanotechnologies in the Netherlands. Technovation, 32(3-4), 227-233.

Raesfeld, A. v. \& Roos, K. (2008). How should a small company interact in its business network to sustain its exchange effectiveness? Creativity and innovation management, 17(4), 271-280.

Rehme, J., Nordigården, D., Ellström, D. \& Chicksand, D. (2016). Power in distribution channels: Supplier assortment strategy for balancing power. Industrial Marketing Management, 54, 176-187.

Rindt, J. \& Mouzas, S. (2015). Exercising power in asymmetric relationships: The use of private rules. Industrial Marketing Management, 48, 202-213. Ring, P. S., Doz, Y. L. \& Olk, P. M. (2005). Managing formation processes in R\&D consortia. California Management Review, 47(4), 137-156.

Ring, Peter S. \& Van de Ven, A. H. (1994). Developmental processes of cooperative interorganizational relationships. The Academy of Management Review, 19(1), 90-118.

Ritter, T. \& Gemunden, H. G. (2003). Network competence: Its impact on innovation success and its antecedents. Journal of Business Research, 56(9), 745-755.

Rokkan, A. I. \& Haugland, S. A. (2002). Developing relational exchange: Effectiveness and power. European Journal of Marketing, 36(1/2), 211230.

Rose, F. (2012). The economics, concept, and design of information intermediaries: A theoretic approach. Heidelberg, Germany: PhysicaVerlag.

Rosenbusch, N., Brinckmann, J. \& Bausch, A. (2011). Is innovation always beneficial? A meta-analysis of the relationship between innovation and performance in SMEs. Journal of Business Venturing, 26(4), 441-457. 
Rothaermel, F. T. \& Boeker, W. (2008). Old technology meets new technology: Complementarities, similarities, and alliance formation. Strategic Management Journal, 29(1), 47-77.

Rutherford, T. \& Holmes, J. (2008). 'The flea on the tail of the dog': Power in global production networks and the restructuring of Canadian automotive clusters. Journal of Economic Geography, 8(4), 519-544.

Ryan, A., Tähtinen, J., Vanharanta, M. \& Mainela, T. (2012). Putting critical realism to work in the study of business relationship processes. Industrial Marketing Management, 41(2), 300-311.

Sakakibara, M. (1997a). Evaluating government-sponsored R\&D consortia in Japan: Who benefits and how? Research Policy, 26(4), 447-473.

Sakakibara, M. (1997b). Heterogeneity of firm capabilities and cooperative research and development: an empirical examination of motives. Strategic Management Journal, 18, 143-164.

Sakakibara, M. (2002). Formation of R\&D consortia: Industry and company effects. Strategic Management Journal, 23(11), 1033-1050.

Sawers, J. L., Pretorius, M. W. \& Oerlemans, L. A. G. (2008). Safeguarding SMEs dynamic capabilities in technology innovative SME-large company partnerships in South Africa. Technovation, 28(4), 171-182.

Sayer, A. (2000). Realism and Social Science. London, United Kingdom: SAGE Publications Ltd.

Sayer, A. (2010). Method in social science. Abingdon, United Kingdom: Routledge.

Schwartz, M., Peglow, F., Fritsch, M. \& Günther, J. (2012). What drives innovation output from subsidized R\&D cooperation? Project-level evidence from Germany. Technovation, 32(6), 358-369.

Shane, S. \& Venkataraman, S. (2000). The promise of entrepreneurship as a field of research. Academy of management review, 25(1), 217-226.

Sheu, J. B. (2015). Power shifts and relationship quality improvement of producer-retailer green channel dyads under government intervention. Industrial Marketing Management, 50, 97-116.

Shipilov, A. V., Li, S. X. \& Greve, H. R. (2011). The prince and the pauper: Search and brokerage in the initiation of status-heterophilous ties. Organization Science, 22(6), 1418-1434. 
Simmel, G. \& Wolff, K. H. (1950). The sociology of Georg Simmel. Glencoe, United States: The Free Press.

Slotte-Kock, S. \& Coviello, N. (2010). Entrepreneurship research on network processes: A review and ways forward. Entrepreneurship Theory and Practice, 34(1), 31-57.

Snehota, I. (2011). New business formation in business networks. The IMP Journal, 5(1), 1-9.

Spanos, Y. E. \& Vonortas, N. S. (2012). Scale and performance in publicly funded collaborative research and development. RED Management, 42(5), 494-513.

Sridharan, R. \& Simatupang, T. M. (2013). Power and trust in supply chain collaboration. International journal of value chain management, 7(1), 7696.

Stuart, T. E. (2000). Interorganizational alliances and the performance of firms: A study of growth and innovation rates in a high-technology industry. Strategic Management Journal, 21(8), 791-811.

Stuart, T. E. \& Sorenson, O. (2007). Strategic networks and entrepreneurial ventures. Strategic Entrepreneurship Journal, 1(3-4), 211-227.

Styhre, A. \& Remneland-Wikhamn, B. (2015). Connecting life science entrepreneurs with resources and expertise: The role of iungens brokerage in life science innovation. Technology Analysis $\mathcal{E}$ Strategic Management, 28(6), 627-638.

Sutton-Brady, C., Kamvounias, P. \& Taylor, T. (2015). A model of supplierretailer power asymmetry in the Australian retail industry. Industrial Marketing Management, 51, 122-130.

Swanborn, P. G. (2013). Case studies: wat, wanneer en hoe? Den Haag, The Netherlands: Boom Lemma uitgevers.

Tang, J., Tang, Z. \& Katz, J. A. (2014). Proactiveness, stakeholder-firm power difference, and product safety and quality of Chinese SMEs. Entrepreneurship Theory and Practice, 38(5), 1129-1157.

Tarakci, M., Greer, L. L. \& Groenen, P. J. (2016). When does power disparity help or hurt group performance? Journal of applied psychology, 101(3), 415 . 
Thorgren, S., Wincent, J. \& Boter, H. (2012). Small firms in multipartner R\&D alliances: Gaining benefits by acquiescing. Journal of Engineering and Technology Management, 29(4), 453-467.

Thorgren, S., Wincent, J. \& Eriksson, J. (2011). Too small or too large to trust your partners in multipartner alliances? The role of effort in initiating generalized exchanges. Scandinavian Journal of Management, 27(1), 99112.

Tichy, N. \& Fombrun, C. (1979). Network analysis in organizational settings. Human Relations, 32(11), 923-965.

Tjemkes, B. \& Furrer, O. (2010). The antecedents of response strategies in strategic alliances. Management Decision, 48(7), 1103-1133.

Touboulic, A., Chicksand, D. \& Walker, H. (2014). Managing imbalanced supply chain relationships for sustainability: A power perspective. Decision Sciences, 45(4), 577-619.

Tripsas, M., Schrader, S. \& Sobrero, M. (1995). Discouraging opportunistic behavior in collaborative R\&D: A new role for government. Research Policy, 24(3), 367-389.

Valente, T. W., Coronges, K., Lakon, C. \& Costenbader, E. (2008). How correlated are network centrality measures? Connections, 28(1), 16.

Van Bockhaven, W., Matthyssens, P. \& Vandenbempt, K. (2015). Empowering the underdog: Soft power in the development of collective institutional entrepreneurship in business markets. Industrial Marketing Management, 48, 174-186.

Van de Ven, A. H. (1992). Suggestion for studying strategy process: A research note. Strategic Management Journal, 13(Summer), 169-191.

Vandaie, R. \& Zaheer, A. (2014). Surviving bear hugs: Firm capability, large partner alliances, and growth. Strategic Management Journal, 35(4), 566-577.

Vanhaverbeke, W., Duysters, G. \& Noorderhaven, N. (2002). External technology sourcing through alliances or acquisitions: An analysis of the application-specific integrated circuits industry. Organization Science, 13(6), 714-733.

Vedel, M., Holma, A-M. \& Havila, V. (2016). Conceptualizing interorganizational triads. Industrial Marketing Management, 57, 139-147. 
Wang, C. H. (2011). The moderating role of power asymmetry on the relationships between alliance and innovative performance in the hightech industry. Technological Forecasting and Social Change, 78(7), 12681279.

Wang, H., Zhao, J., Li, Y. \& Li, C. (2015). Network centrality, organizational innovation, and performance: A meta-analysis. Canadian Journal of Administrative Sciences, 32(3), 146-159.

Wedin, T. (2001). Networks and demand. The use of electricity in an industrial process. Dissertation, Uppsala University, Uppsala, Sweden.

Whetten, D. A. (1981). Interorganizational relations: A review of the field. The Journal of Higher Education, 52(1), 1-28.

Wilkinson, I. (1996). Distribution channel management: Power considerations. International Journal of Physical Distribution $\mathcal{E}$ Logistics Management, 26(5), 31-41.

Wincent, J., Thorgren, S. \& Anokhin, S. (2013). Managing maturing government-supported networks: The shift from monitoring to embeddedness controls. British Journal of Management, 24(4), 480497.

Wolfe, R. J. \& McGinn, K. L. (2005). Perceived relative power and its influence on negotiations. Group Decision and Negotiation, 14(1), 3-20.

Wrong, D. H. (1979). Power: Its forms, bases and uses. Oxford, United States: Blackwell.

Wu, J. \& Pangarkar, N. (2015). Structural strategies for mitigating transaction costs in multipartner alliances: An empirical examination. In T. K. Das (Ed.), Managing multipartner alliances. Charlotte, United States: Information Age Publishing, Inc.

Wynarczyk, P., Piperopoulos, P. \& McAdam, M. (2013). Open innovation in small and medium-sized enterprises: An overview. International Small Business Journal, 31(3), 240-255.

Yan, T. \& Wagner, S. M. (2017). Do what and with whom? Value creation and appropriation in inter-organizational new product development projects. International Journal of Production Economics, 191, 1-14. 
Yang, H., Zheng, Y. \& Zhao, X. (2014). Exploration or exploitation? Small firms' alliance strategies with large firms. Strategic Management Journal, 35(1), 146-157.

Yeniyurt, S. \& Carnovale, S. (2017). Global supply network embeddedness and power: An analysis of international joint venture formations. International Business Review, 26(2), 203-213.

Yin, X., Wu, J. \& Tsai, W. (2012). When unconnected others connect: Does degree of brokerage persist after the formation of a multipartner alliance? Organization Science, 23(6), 1682-1699.

Yli-Renko, H. \& Autio, E. (1998). The network embeddedness of new, technology-based firms: Developing a systemic evolution model. Small Business Economics, 11(3), 253-267.

Yukl, G. \& Falbe, C. M. (1990). Influence tactics and objectives in upward, downward, and lateral influence attempts. Journal of applied psychology, 75(2), 132.

Zeng, S. X., Xie, X. \& Tam, C. M. (2010). Relationship between cooperation networks and innovation performance of SMEs. Technovation, 30(3), 181-194.

Zimmerling, R. (2005). The concept of influence. In F. J. Laporta, A. Peczenik \& F. Schauer (Eds.), Influence and power: Variations on a messy theme. Dordrecht, The Netherlands: Springer. 


\section{Summary}

In this dissertation, I researched how network position, network management and network outcomes interrelate. My focus was on two aspects that, in my view, deserved more scholarly attention: 1) how startups in a fragile network position initiate, maintain and develop business relationships in interaction; and 2) how network position and related power influence network outcomes in multipartner relationships compared to other power sources. Thus, this dissertation's main research question was: How do network position and related power affect and are they affected by business relationships management and outcomes in networks? To address this question, I presented the five studies in this dissertation.

In study 1, we explored how third actors influence a startup's relationship initiation process and subsequently its network embedding and its business development. We analysed the relationship initiations of a startup and its eight partners in a longitudinal case study. Our analysis was based on four models grounded in the industrial marketing and purchasing as well as entrepreneurship literatures. We found that third actors stimulated the startup's relationship initiation process by connecting it to potential valuable partners. In turn, the new business relationships advanced the startup's network embedding and business development. Further, we showed that third actors strengthened the startup's network embedding if they built strong relationships with both parties. These findings led us to conclude that third actors are crucial in a startup's relationship initiation process, network embedding and business development.

In study 2, we investigated how a startup interacts with its partners over time. We created an interaction model based on two action typologies developed in the strategic management literature. We used this model to analyse 18 interaction episodes between a startup and its partners in a case study. We showed that the relationships between the startup and its partners were interactive because the startup and its partners reacted to one another in an interaction episode by reciprocating one another's interaction modes. 
Further, they were dynamic because: 1) previous interaction episodes affected subsequent ones; and 2) a trigger prompted the startup and its partner to act, causing an interaction process that determined the eventual outcomes for the startup, its partner and their relationship. Based on these findings, we concluded that a startup's relationships with its partners are interactive and dynamic.

In study 3, we researched how structural and behavioural power interact in business relationships between a startup and its well-established partners. We applied a dynamic two-sided model of power in interpersonal negotiations to nine power episodes between a startup and its established partners in a longitudinal case study. We found that: on the one hand, the startup and its partners decided to apply power tactics based on their perception of one another's power rather than their de facto structural power; on the other hand, they changed their structural power or their partner's perception via power change tactics and coalition-building. Thus, we concluded that a startup's and its well-established partner's structural and behavioural power interact via their perceived power.

In study 4, we examined how power asymmetry affects multipartner relationship effectiveness. Based on decision-making theory, we proposed that power asymmetry influences effectiveness differently, depending on the power source (i.e. size, age or network centrality) and effectiveness type (value creation or appropriation) considered. We tested our hypotheses in a database of 409 multipartner alliances granted governmental funding between 2000 and 2004. We showed that the positive direct effect of centrality asymmetry on value creation was weakened when size asymmetry was high. Further, centrality asymmetry's negative direct effect on value appropriation was weakened when age asymmetry was high. These findings led us to conclude that power asymmetry derived from the same source can have a different effect on value creation vs. appropriation; the reverse also applies.

In study 5, we studied how power asymmetry influences the relationship between variety and new product development in multipartner 
relationships. We hypothesised that power asymmetry positively moderates the relationship between variety (i.e. functional, organisational and industry variety) and new product development based on theories from the interpersonal power literature. We tested the hypotheses in a database of 409 multipartner alliances subsidised between 2000 and 2004. We found that functional and organisational variety's effects on new product development success were amplified if power asymmetry is high. Also, we showed that the odds of new product development success were usually higher when power asymmetry was high, regardless of the industry variety level. Based on these findings, we concluded that how power asymmetry affects the relationship between variety and new product development depends on the variety type under consideration.

Taken together, the studies' findings expand our present understanding of how startups in a fragile network position initiate, maintain and develop business relationships by taking an interactive perspective rather than an organisational one. Further, they extend our current knowledge of power as a single dimensional concept in dyadic relationships towards a multidimensional concept in multipartner relationships. The studies' findings also inform startups, startups' partners, businesses involved in multipartner relationships and policy-makers about how they can improve network management and therefore network outcomes. Finally, the studies' conceptual and methodological limitations open avenues for further intensive and extensive research into the interplay among additional business attributes and alternative relational elements, and its impacts on network management and outcomes 



\section{Samenvatting}

In dit proefschrift heb ik onderzocht hoe netwerkpositie, netwerkmanagement en netwerkuitkomsten met elkaar samenhangen. Mijn focus lag op twee aspecten die, naar mijn mening, meer wetenschappelijke aandacht verdienden: 1) hoe startups in een kwetsbare netwerkpositie bedrijfsrelaties initiëren, onderhouden en ontwikkelen in interactie; en 2) hoe netwerkpositie en gerelateerde macht netwerkuitkomsten beïnvloeden in bedrijfsrelaties tussen meerdere partners in vergelijking met andere machtsbronnen. De centrale onderzoeksvraag van dit proefschrift was: Hoe beïnvloeden netwerkpositie en gerelateerde macht (en worden zij beïnvloed door) bedrijfsrelatiemanagement en netwerkuitkomsten? Om deze vraag te beantwoorden, legde ik vijf studies voor in dit proefschrift.

In studie 1 onderzochten wij hoe derden het bedrijfsrelatieinitiatieproces van een startup beïnvloeden en vervolgens de netwerkinbedding en ontwikkeling van het bedrijf. Wij analyseerden de bedrijfsrelatie-initiatieprocessen van een startup en acht partners in een longitudinale Casestudy. Onze analyse was gebaseerd op vier modellen uit de industrial marketing and purchasing en ondernemerschapsliteratuur. Het bleek dat derde partijen het bedrijfsrelatie-initiatieproces stimuleerde door de startup te koppelen aan potentieel waardevolle partners. Vervolgens droegen de nieuwe bedrijfsrelaties bij aan de netwerkinbedding en bedrijfsontwikkeling van de startup. Daarnaast vonden wij dat derde partijen de netwerkinbedding van de startup versterkten als zij een sterke relatie opbouwden met beide partijen. Deze bevindingen leidden tot de conclusie dat derde partijen cruciaal zijn in het bedrijfsrelatie-initiatieproces, de netwerkinbedding en de bedrijfsontwikkeling van een startup.

In studie 2 bestudeerden wij hoe, na verloop van tijd, een startup met zijn partners interacteert. Wij ontwikkelden een interactiemodel op basis van twee actietypologieën uit de strategisch managementliteratuur. Wij gebruikte dit model om 18 interactie-episodes tussen een startup en zijn partners te analyseren in een Casestudy. Wij ontdekten dat de bedrijfsrelaties tussen de 
startup en zijn partners interactief waren, omdat zij elkaars gedrag spiegelden in een interactie-episode. Daarnaast waren de bedrijfsrelaties dynamisch, omdat: 1) eerdere interactie-episodes volgende episodes beïnvloedden; en 2) een trigger de startup en zijn partners ertoe aanzette om actie te ondernemen, waardoor een interactieproces ontstond die de uiteindelijke uitkomsten voor de startup, zijn partner en de bedrijfsrelatie bepaalde. Op basis van deze bevindingen concludeerden wij dat de bedrijfsrelaties tussen een startup en zijn partners interactief en dynamisch zijn.

In studie 3 onderzochten wij hoe structurele macht en machtsgedrag met elkaar samenhangen in de bedrijfsrelaties tussen een startup en zijn reeds gevestigde partners. Wij pasten een dynamisch, tweezijdig machtsmodel voor interpersoonlijke onderhandelingen toe op negen machtsepisodes tussen een startup en zijn gevestigde partners in een longitudinale casestudie. Het bleek dat: aan de ene kant, de startup en zijn partners hun machtsgedrag bepaalde op basis van de percepties van elkaars macht in plaats van hun daadwerkelijke structurele macht; aan de andere kant, veranderden zij hun structurele macht of de perceptie van hun partners door veranderingsgerichte machtstactieken en coalitievorming. Wij concludeerden daarom dat de structurele macht en het machtsgedrag van een startup en zijn partners elkaar beïnvloeden via hun machtspercepties.

In studie 4 bestudeerden wij hoe machtsasymmetrie de effectiviteit van bedrijfsrelaties met meerdere partners beïnvloedt. Op basis van besluitvormingstheorie veronderstelden wij dat machtsasymmetrie een ander effect heeft op effectiviteit afhankelijk van de machtsbron (grootte, leeftijd of netwerkcentraliteit) en het type effectiviteit (waardecreatie of -toe-eigening) dat wordt onderzocht. Wij testten onze hypothesen in een database met 409 allianties tussen meerdere partners die financiering van de overheid waren toegekend tussen 2000 en 2004 . Wij vonden dat het positieve, directe effect van asymmetrie in centraliteit op waardecreatie afzwakte als de asymmetrie in grootte hoog was. Daarnaast werd het negatieve, directe effect van asymmetrie in centraliteit op waardetoe-eigening afgezwakt door hoge asymmetrie in leeftijd. Deze bevindingen leidden tot de conclusie dat 
machtsasymmetrie afgeleid van dezelfde machtsbron een ander effect kan hebben op waardecreatie versus -toe-eigening: het omgekeerde geldt ook.

In studie 5 onderzochten wij hoe machtsasymmetrie de relatie tussen variëteit en de ontwikkeling van nieuwe producten in bedrijfsrelaties met meerdere partners beïnvloedt. Op basis van theorieën uit de literatuur over interpersoonlijke macht veronderstelden wij dat machtsasymmetrie de relatie tussen variëteit (functionele, organisatorische en industrievariëteit) en de ontwikkeling van nieuwe producten positief beïnvloedt. Wij testten onze hypothesen in een database van 409 allianties tussen meerdere partners die subsidie waren toegekend tussen 2000 en 2004. Het bleek dat de effecten van functionele en organisatorische variëteit op succesvolle productontwikkeling werden versterkt als de machtsasymmetrie hoog was. Wij ontdekten ook dat de kans op succes in productontwikkeling meestal groter was als de machtsasymmetrie hoog was, onafhankelijk van de industrievariëteit. Op basis van deze bevindingen concludeerden wij dat hoe machtsasymmetrie de relatie tussen variëteit en de ontwikkeling van nieuwe producten beïnvloedt afhangt van het type variëteit dat wordt onderzocht.

Tezamen vergroten de bevindingen van deze studies ons huidige inzicht in hoe startups met een kwetsbare netwerkpositie bedrijfsrelaties initiëren, ontwikkelen en onderhouden door een interactief in plaats van een bedrijfsperspectief te nemen. Daarnaast breiden ze onze huidige kennis over macht uit van een eendimensionaal concept in dyadische relaties naar een multidimensionaal concept in bedrijfsrelaties met meerdere partners. De bevindingen van de studies informeren ook startups, de partners van startups, organisaties die betrokken zijn bij bedrijfsrelaties tussen meerdere partners en beleidsmarkers over hoe ze netwerkmanagement en -uitkomsten kunnen verbeteren. Ten slotte, de conceptuele en methodologische beperkingen van de studies geven aanleiding tot intensiever en uitgebreider onderzoek naar de samenhang tussen aanvullende bedrijfseigenschappen en alternatieve relationele aspecten, en de impact hiervan op netwerkmanagement en uitkomsten. 



\section{About the author}

Tamara Oukes was born (1991) and raised in Velp, The Netherlands. In 2008, she began to study Business Administration at the University of Twente. She was active in the Study Association Stress and served as a student assistant.

In 2011, she obtained her Bachelor of Science (cum laude) with a thesis on innovative work behaviours among production workers at Apollo Vredestein (Enschede, The Netherlands). She then followed a two-year double degree programme that resulted in two Master of Science degrees: Business Administration (cum laude) (University of Twente) and Innovation Management \& Entrepreneurship (Technical University Berlin).

In 2013, she was intern at Inreda Dabietic B.V. (Goor, The Netherlands), a startup developing an artificial pancreas for the treatment of diabetes. She completed her double degree with a thesis on the management of interorganisational relationships over time.

After her studies, Tamara enrolled as a PhD student at the University of Twente. Her PhD was financed by PCDIAB, a research project funded by the European Commission under the Seventh Framework Programme (grant number: 305654). The consortium focussed on the development of a portable bihormonal artificial pancreas. She researched how Inreda Diabetic B.V. - one van the consortium members - initiated, maintained and developed business relationships in interaction.

From 2013 to 2016, Tamara served at the company two to three days per week, to do research and to assist the commercial director. She also studied how network position and related power influence the performance of multipartner alliances funded by the Dutch Technology Foundation STW.

She published her research in the book Starting up in business networks: Why relationships matter in entrepreneurship and in scientific journals (IMP 
Journal and Industrial Marketing Management). She has also presented her research at conferences, such as the IMP conference and the PDMA's annual Research Forum.

Besides her $\mathrm{PhD}$, in 2016, Tamara started teaching at the University of Twente. She has taught courses such as Organization and Strategy, Global Entrepreneurship, and Business Development in a Network Perspective. In 2017, she became involved in the Bachelor programme Creative Technology, coordinating the Literature Research Project and teaching the course Innovation and Entrepreneurship. In 2018, she became the coordinator of the Entrepreneurship, Innovation and Strategy specialisation in the Master's programme Business Administration. Between 2013 and 2018, she supervised multiple student theses in the Bachelor programme International Business Administration and the Master's programme Business Administration.

Tamara also trains nascent entrepreneurs in identifying, evaluating and managing their networks at the University of Twente and VentureLab North. 
